\title{
JOB DESIGN FOR IT-SHARED SERVICES ORGANIZATIONS
}

\author{
BY \\ AARENI URUTHIRAPATHY, M.B.A \\ A Thesis submitted to the Faculty of Graduate Studies and Research \\ In partial fulfillment of the \\ Degree of Doctor of Philosophy, Management \\ Sprott School of Business \\ Carleton University \\ Ottawa, Ontario
}

(C) Copyright 2011, Aareni Uruthirapathy 
Library and Archives

Canada

Published Heritage Branch

395 Wellington Street

Ottawa ON K1A ON4

Canada
Bibliothèque et

Archives Canada

Direction du

Patrimoine de l'édition

395 , rue Wellington

Ottawa ON K1A ON4

Canada
Your file Votre référence
ISBN: $978-0-494-81553-3$
Our file Notre référence
ISBN: $978-0-494-81553-3$

\section{NOTICE:}

The author has granted a nonexclusive license allowing Library and Archives Canada to reproduce, publish, archive, preserve, conserve, communicate to the public by telecommunication or on the Internet, loan, distribute and sell theses worldwide, for commercial or noncommercial purposes, in microform, paper, electronic and/or any other formats.

The author retains copyright ownership and moral rights in this thesis. Neither the thesis nor substantial extracts from it may be printed or otherwise reproduced without the author's permission.
AVIS:

L'auteur a accordé une licence non exclusive permettant à la Bibliothèque et Archives Canada de reproduire, publier, archiver, sauvegarder, conserver, transmettre au public par télécommunication ou par l'Internet, prêter, distribuer et vendre des thèses partout dans le monde, à des fins commerciales ou autres, sur support microforme, papier, électronique et/ou autres formats.

L'auteur conserve la propriété du droit d'auteur et des droits moraux qui protège cette thèse. Ni la thèse ni des extraits substantiels de celle-ci ne doivent être imprimés ou autrement reproduits sans son autorisation.
In compliance with the Canadian Privacy Act some supporting forms may have been removed from this thesis.

While these forms may be included in the document page count, their removal does not represent any loss of content from the thesis.
Conformément à la loi canadienne sur la protection de la vie privée, quelques formulaires secondaires ont été enlevés de cette thèse.

Bien que ces formulaires aient inclus dans la pagination, il n'y aura aucun contenu manquant.

\section{Canadä}




\begin{abstract}
Shared services organizations have emerged to provide organizations with high quality service at reduced cost. A shared services organization (SSO) is an organizational arrangement whereby a principal service provider delivers standardized services for many client organizations through shared governance processes. When an SSO provides information technology services to its clients, it is referred to as an IT-SSO. Transitioning to an IT-SSO work setting is often extremely difficult for employees. Proper job design can provide IT-SSO employees with enriched and more satisfying work experiences. To date no study in organizational theory has focused on job design for IT-SSO employees. Therefore, the main research question addressed in this study is, "What job characteristics lead to better job outcomes for individuals working in an IT-SSO?" Following a thorough review of the literature on work design and service orientation, a job design model for IT-SSO employees incorporating motivational characteristics (autonomy, skill variety, task identity, task variety, task significance, feedback from others, information processing), social characteristics (interdependence, feedback from others, social support, interaction outside the organization) and service orientation characteristics (service technology, service failure prevention, service failure recovery) has been proposed. In order to validate this IT-SSO job design model, data was collected from a Canadian Federal Government IT-SSO using mixed methods.

The research indicates that among the motivational characteristics, autonomy consistently predicted job satisfaction, job performance and turnover intentions; social characteristics influenced job outcomes equally as motivation characteristics and, except for initiated task interdependence, all the other social job characteristics were related to job outcomes. Service orientation characteristics have been introduced as work context characteristics into the ITSSO job design model. These newly introduced service orientation characteristics (service failure prevention, service failure recovery) also significantly predicted job outcomes. In addition to the influence of motivational, social, and service characteristics on job outcomes, that of transactional work, transformational work and professional work was also studied. The study found that individuals performing transactional work and transformational work reported significantly higher levels of job satisfaction than those performing professional work. Further, individuals with non-IT skills had greater intentions to leave the IT-SSO.
\end{abstract}




\section{Acknowledgments}

This research is dedicated to the worship of Lord Siva for His gracious assistance showered on me in the pursuit of my studies and to my loving Appa whom I lost during the final stages of my doctoral program.

I want to thank my husband Uruthi for his unconditional love and for always being there for me. Without his help and support I would never have been able to attain this level of accomplishment. Special thanks goes to my son Aathavan whose sweet smile gave me the strength to keep going in the program. I also want to thank my ever loving mother, Nagapooshani Thiyagarajah, for being a role model of academic achievement, and for showering me with affection and gifts during difficult times in my life. My little niece Abirami also deserves a thank you for her doting chats.

I am ever grateful to my thesis supervisor, Dr. Gerald Grant, for his patience and invaluable guidance during my Ph.D at Sprott School of Business. His office door was always open to me in times of trouble and joy. Through his optimistic focus and encouraging comments, he would lift my spirits whenever I faced challenges and disappointments. Thank you !

Thanks go to my committee, Dr. Lorraine Dyke and Dr. Irene $\mathrm{Lu}$, for their insightful contributions to my thesis and for their unwavering support during the final weeks of the program. I also acknowledge the help given to me by Dr. Nsakanda in translating my questionnaire into French, and by Dr. Diane Huberman-Arnold and Elizabeth Dwivedi for editing my dissertation.

Thanks also goes to my wonderful friends and fellow Ph.D candidates Anahit Armenakyan, Ajit Thomas, Dong Young Kim, Harry Chhina, Maggie Stevenson, Vedmani Sharon and Vinita Ambawani for listening to me and motivating me.

Last but not least I must thank the senior management of ITSB for accommodating the request to study their organization, and all those individuals who took the time to participate in my study. Without their help I would not have finished my Ph.D program. 


\section{Table of Contents}

Chapter 1 - 01

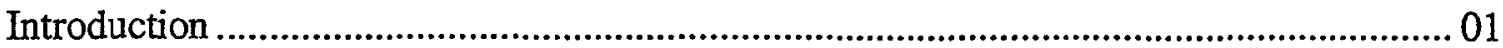

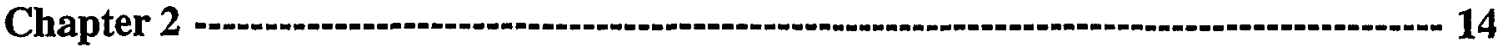

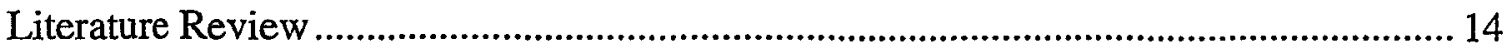

2.1 Shared Services Organizations -

2.2 Trends in Shared-Services Organizations and the Change Management Process --- 21

2.3 Job Characteristics in Shared Services Organizations --

2.3.1 Skills required in an SSO - 30

2.3.2 Relationships in an SSO 33

2.3.3 Service Orientation -- 36

2.4 Discussion on the Existing Literature on SSOs-a 37

2.5 Work Design Literature --_-_. 42

2.6 Discussion of Work Design Literature-- 55

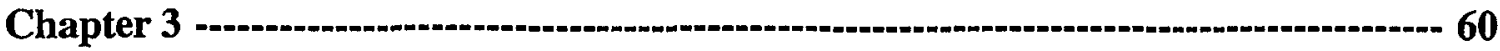

Conceptual Framework for Job Design for IT Shared Services Organizations .................. 60

3.1 Research Objective --..- 60

3.2 Research Questions --_- 60

3.3 Motivational Characteristics- 62

3.3.1 Autonomy - 62

3.3.2 Skill Variety -..- 65

3.3.3 Task Identity-_-_- 67

3.3.4 Task Significance --_- 68

3.3.5 Task Variety --o 69

3.3.6 Feedback from the job --_ 71

3.3.7 Information Processing -

3.4 Social Characteristics--- 77

3.4.1 Task Interdependence -_- 80

3.4.2 Feedback from others - 80

3.4.3 Social Support--- 81

3.4.4 Interaction Outside the Organization --_.-_ 83

3.5 Service Orientation Characteristics-- 84

3.5.1 Service Technology -_- 85

3.5.2 Service Failure Prevention--_- 86 


\section{Table of Contents}

3.5.3 Service Failure Recovery--

3.5.4 Service Standard Communications -._-

3.6 Occupation Variables - -

3.7 Outcome Variables - -

Chapter 4 - 92

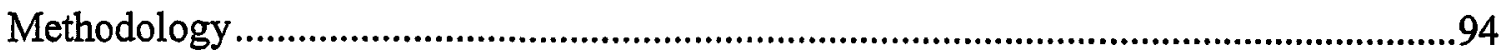

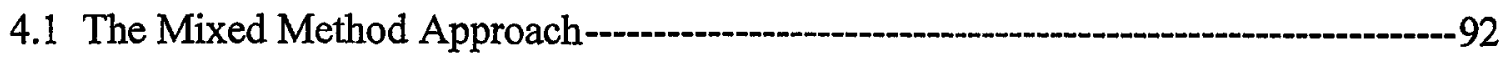

4.2 Integrating the Quantitative and Qualitative Data Sets---_-

4.3 Measurement Scales for Motivational and Social Characteristics -_-_____-_._-98

4.4 Measurement Scales for Service Orientation Characteristics-_-_-_-_ 104

4.5 Measurements for Occupation Variables -.... 105

4.6 Measurements for Outcome Variables -

4.6.1 Job Satisfaction - 107

4.6.2 Job Performance --_-_- 107

4.6.3 Turnover Intentions -

4.7 Questions on the Interview Schedule -

\section{Chapter 5}

Quantitative Analysis.

5.1 Sample

5.2 Descriptive Analysis --_- 114

5.2.1 Data Preparation - - 117

5.2.2 Respondent Characteristics --_-_- 118

5.2.3 Sequence of Analysis Procedure - - 120

5.3 Factor Analysis-- 121

5.3.1 Factor Analysis on Motivational Characteristics - - 122

5.3.2 Factor Analysis on Social Characteristics --_.-- 127

5.3.3 Factor Analysis on Service Orientation Characteristics---_- 130

5.3.4 Factor Analysis on Outcome Variables --- 133

5.4 Examining the Reliability and Validity of the scales through Confirmatory Factor

Analysis (CFA) -

5.4.1 Reliability-a-o- 138

5.4.2 Construct Validity - - 138

5.4.3 Discriminant Validity -..._- 139

5.4.4 Calculating AVE, Composite Reliability, Convergence validity and Discriminate

validity ---_--o 139

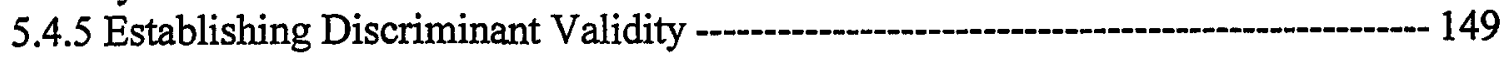




\section{Table of Contents}

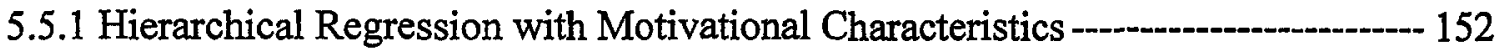

5.5.1.2 Motivational Characteristics and Job Performance -._- 154

5.5.1.3 Motivational Characteristics and Turnover-_- 156

5.5.2 Hierarchical Regression with Social Characteristics and Outcome Variables---- 158

5.5.2.1 Social Characteristics and Job Satisfaction-_- 160

5.5.2.2 Social Characteristics and Job Performance--_o 160

5.5.2.3 Social Characteristics and Turnover-_. 162

5.5.3 Hierarchical Regression with Service Orientation Characteristics and Outcome

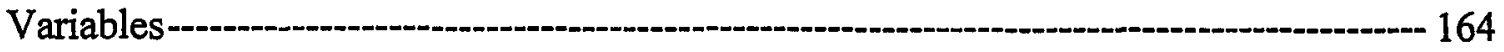

5.5.3.1 Service Orientation Characteristics and Job Satisfaction-_-_-_- 164

5.5.3.2 Service Orientation Characteristics and Job Performance -._-_._- 166

5.5.3.3 Service Orientation Characteristics and Turn Over--_-

\section{Chapter 6}

Qualitative Data Analysis-

6.1 The Sample -

6.1.1 Data collection - - 173

6.1.2 Analyzing qualitative data --_ 174

6.1.3 Establishing Reliability and Validity of the Qualitative Data Analysis -_-_-_-_.-175

6.2 Respondent characteristics --a 177

6.3 Motivational Characteristics --_- 178

6.3.1 Autonomy -...- 178

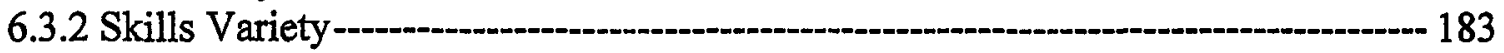

6.3.3 Task Significance --_- 185

6.3.4 Task Identity---o- 187

6.3.5 Feedback from Job -._- 189

6.3.6 Task Variety - 191

6.3.7 Information Amount- 193

6.3.8 Information Equivocality -ב- 195

6.4 Social Characteristics ---ore 197

6.4.1 Initiated and Received interdependence-(- 197

6.4.2 Feedback from Others- 198

6.4.3 Social Support-1- 200

6.4.4 Interaction outside the Organization -..- 202

6.5 Service Orienation Job Characteristics -.._- 204

6.5.1 Service Technology -- 204

6.5.2 Service Failure Prevention - -

6.5.3 Service Failure Recovery -._- 208

6.5.4 Service Standards Communication -.-- 210

6.6 Job Outcomes - - 211 


\section{Table of Contents}

6.6. 1.Job Satisfaction -...-214

6.6.2 Quality, Quantity and Accuracy-_-_- 214

6.6.3 Progress in Career --o 218

6.6.4 Innovative Ideas -- 220

6.6.5 Team Work----o- 221

6.6.6 Overall Good of the Company- 223

6.6.7 Turnover - 224

6.7 Analyzing Data from the Short Question -..... 225

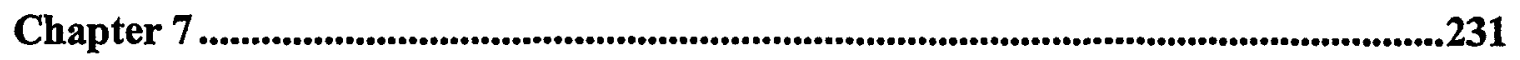

Discussion: Integrating Qualitative and Quantitative Analysis................................. 231

7.1 Motivational Job Characteristics and Job Outcomes -...- 241

7.2 Social Characteristics and Job outcomes -.-241

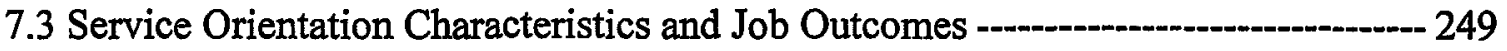

7.4 Occupation Variables and Job Outcomes --- 255

7.4.1 Type of Work and Outcomes -

7.4.2 Types of Skills and Job Outcomes - 259

7.5 Revising the ITS Job Design Model -_- 260

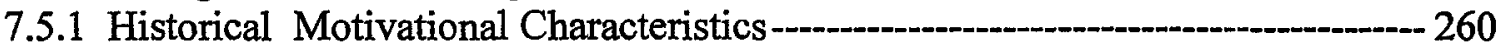

7.5.2 The Importance of Social Orientation Characteristics in ITS ---_-_- 264

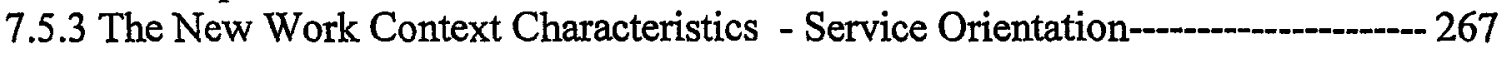

Chapter 8 - -

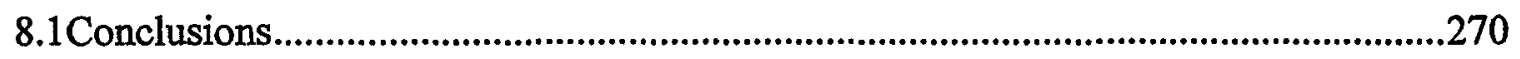

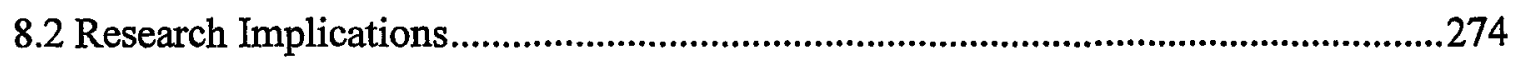

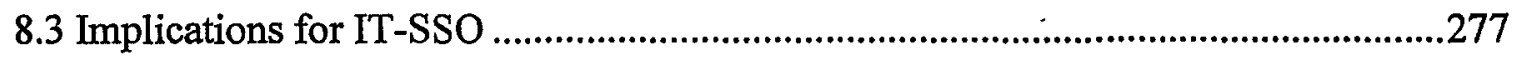

8.4 Contributions --- 285

8.5 Limitations and Future Research Directions--.-- 287

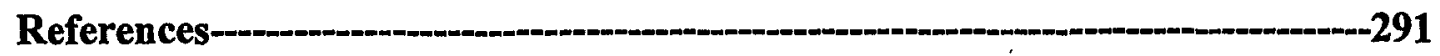

Appendix-31 


\section{List of Tables}

Table 1 Characteristics of Shared Services 16

Table 2 Barriers of Mixed Methods 94

Table 3 Scales for the Motivational Characteristics 101

Table $4 \quad$ Scales for the Social Characteristics 105

Table $5 \quad$ Scales for the Service Orientation Characteristics 110

Table 6 Measures for Outcome Variables 111

Table 7 Motivation Characteristics Question for the Interview 112

Table $8 \quad$ Social Characteristics Questions for the Interviews 112

Table 9 Services Orientation Characteristics Questions for the Interview 112

Table 10 Job Outcomes Questions for the Interview 112

Table $11 \quad$ Stratified Sampling of ITS employees 116

Table 12 Correlations between the Motivational, Social and 118

Table 13 Type of Work Performed by the ITS employees 119

Table 14 Work Experience of ITS employee 119

$\begin{array}{lll}\text { Table } 15 & \text { Type of Skills } & 120\end{array}$

Table 16 Factor loadings for Autonomy 123

$\begin{array}{lll}\text { Table } 17 & \text { Factor loadings for Skill Variety } & 124\end{array}$

$\begin{array}{lll}\text { Table } 18 & \text { Factor loadings for Task Identity } & 124\end{array}$

$\begin{array}{lll}\text { Table } 19 & \text { Factor loading for Task significance } & 125\end{array}$

$\begin{array}{lll}\text { Table } 20 & \text { Factor loading for Task Variety } & 125\end{array}$

Table 21 Factor loadings for Feedback from Job 126

Table 22 Factor loadings for Information Amount 126

$\begin{array}{lll}\text { Table } 23 & \text { Factor loadings for Equivocality } & 127\end{array}$

Table $24 \quad$ Factor loadings for Initiated Task Interdependence 128

Table 25 Factor loadings for Received Task Interdependence 128

Table 26 Factor loadings for Feedback from Others 129

Table 27 Factors loading for Interaction outside the Organization 129

$\begin{array}{lll}\text { Table } 28 & \text { Factor loadings for Social Support } & 130\end{array}$

Table 29 Factor loadings on Service Technology 131

Table $30 \quad$ Factor loadings on Service Failure Prevention 131

Table 31 Factor loadings on Service Failure Recovery 132

Table 32 Factor loadings on Service Standard Communication 132

Table 33 Factor Loadings on Job Satisfaction . 133

Table $34 \quad$ Factor loadings on Job performance (Job) 134

Table 35 . Factor loadings on Job performance (Career) 134

Table $36 \quad$ Factor loadings on Job performance (Innovator) 135

Table $37 \quad$ Factor loadings on Job performance (Team) 135

Table $38 \quad$ Factor loadings on Job performance (Org) 135 


\section{List of Tables}

$\begin{array}{lll}\text { Table } 39 & \text { Factor Loadings on Turnover } & 136\end{array}$

Table $40 \quad$ Reliability and Validity of Motivational Characteristics 141

Table 41 Reliability and Validity of Motivational Characteristics (Cont) 142

$\begin{array}{lll}\text { Table } 42 & \text { Reliability and Validity of Social Characteristics } & 143\end{array}$

Table 43 Reliability and Validity of Service Orientation Characteristics. 145

$\begin{array}{lll}\text { Table } 44 & \text { Reliability and Validity of Outcome Variables } & 147\end{array}$

$\begin{array}{lll}\text { Table } 45 & \text { Reliability and Validity of Outcome Variables } & 148\end{array}$

Table $46 \quad$ CFA results for Discriminant Validity - Service Variables 151

Table 47 Model Summary of Occupation Variables, Motivational 152

Table 48 Coefficient Table for Occupation Variables, Motivational 153

Table 49 Hierarchical Regressions when Job Performance is the Dependent 155 Variable with Motivational Variables

Table 50 Model Summary of Occupation Variables, Motivational Variables 156

Table $51 \quad$ Coefficient Table for Occupation Variables, Motivational 157

Table $52 \quad$ Model Summary of Occupation Variables, Social Variables 158

Table 53 Coefficient Table for Occupation Variables, Social Variables and 159

Table 54 Hierarchical Regressions when Job Performance is 161

Table 55 Model Summary of Occupation Variables, Social Variables 162

Table 56 Coefficient Table for Occupation Variables, Social Variables 163

Table $57 \quad$ Model Summary of Occupation Variables, Service Orientation 164

Table $58 \quad$ Coefficient Table for Occupation Variables, Service Orientation 165

Table 59 Hierarchical Regressions when Job Performance is the 166

Table $60 \quad$ Model summary of Occupation Variables, Service 168

Table 61 Coefficient Table for Occupation Variables, Service Orientation 169

Table 62 Incremental Regression Results for Outcomes 170

Table 63 Stratified Sampling of ITS Interview Participants 172 


\section{List of Tables}

Table 64 Demographic Information 177

Table 65

Decision Making Autonomy

Table 66

Results for Autonomy in Methods

Table 67

Results for Autonomy in Scheduling

Table 68

Results for Skills Variety

Table 69

Results for Task Significance

Table 70

Results for Task Identity

188

Table 71

Results for Feedback from Job

Table 72

Results for Task Variety

Results for Information Amount

Table 74

Results for Information Equivocality

Table 75

Results for Initiated and Received interdependence

197

Table 76

Results for Feedback from Others

Table 77

Results for Social Support

Table 78

Results for Interaction outside the Organization

205

Table 79

Results for Service Technology

207

Table 80

Results for Service Failure Prevention

Table 81

Results for Service Failure Recovery

Table 82

Table 83

Results for Service Standards Communication

212

Results for Ideal Job

214

Results for Job Satisfaction $\quad 215$

Table 84

Results for Quality

217

Table 86

Results for Quantity

217

Table 87

Results for Accuracy

Table 88

Results for Progress in Career

Table 89

Results for Innovative Ideas

220

Table 90

Results for Team Work

223

Table 91

Results for the Overall Good of the Company

Table 92

Results for Turnover

Table 93

Individual Characteristics Identified by ITS Members

Table 94

Individual Skill Sets Identified by ITS Member

227

Table 95

Organizational Level Characteristics Identified by ITS Members

Table 96

Job Characteristics Identified by Interview Participants 


\section{$\underline{\text { List of Figures }}$}

Figure $1 \quad$ Extended Work Design model: Humphrey, Nahrgang and 49

Morgeson (2007)

Figure 2 Conceptual Framework for Job Design for IT Shared Services 61

Figure 3 Motivational Characteristics at ITS 261

Figure 4 Social Characteristics, Control variables and Outcome Variables 265 at ITS

$\begin{array}{lll}\text { Figure 5 Service Orientation Characteristics at ITS } & 267\end{array}$ 


\section{Chapter 1}

\section{Introduction}

At present, organizations are under severe pressure to finds ways to reduce operating costs while maintaining optimal efficiency. Government agencies are also seeking ways to improve work settings by consolidating agencies and using standardized services to reduce service costs. Over the past 15 years, shared services organizations (SSO) have emerged to provide organizations with top quality services at reduced cost (A.T. Kearney, 2004). In order to formulate a clear definition of an IT sharedservices center, Schulz et al. (2009) performed a review of the literature on shared services. Their study found that the shared-services centre offers a "consolidation of processes within the group in order to reduce redundancies, delivers support processes as its core competency, is a separate organizational unit within the group, is aligned with external customers, has a clear focus on internal customers and is operated like a business" (pg. 4). A significant feature, the study noted, was "cost cutting [as] a major driver for implementation" (pg. 4). Large private enterprises and government agencies often have support functions within different organizational units where services are duplicated by each unit. For example, different units within a large enterprise or government agency may have their own IT systems support staff providing services. These organizations could greatly benefit from consolidating these services into one central, shared entity and requesting service delivery as needed. In general, activities that are strategic to organizations are not moved over to shared services; however, as A.T. Kearney (2004) states, homogenous functions that 
are widely used across an enterprise and transaction-based activities are best suited to be moved to a shared-services centre.

The shared-services unit has become popular in both the private and public sectors as a way of delivering many different types of services-for instance, HR, finance, healthcare, inventory management and information technology. For example, in the private sector, Siemens Shared Services delivers services such as payroll administration and tax reports through their new HR system to 70,000 Siemens Employees (Tech Republic, 2009). HP Enterprise Services has created an IT sharedservices centre that consolidates and distributes IT functions through a shared infrastructure. Similarly, in the public sector, according to Dexter's 2007 report on shared services in Canada, Shared Services BC handles processes such as procurement and supply, strategic acquisitions and intellectual property, payroll and corporate accounting, and workplace technical support for the province of British Columbia. The Government of Alberta's service centre, Service Alberta, established in 1999, provides a range of services in administration, finance, human resources, and information technology for Alberta's 24 government ministries. The Government of Canada has joined a number of the provincial governments in moving some of its IT functions into an IT shared-services unit. The Information Technology Service Branch (ITSB) of Public Works and Government Services Canada (PWGSC) established an IT shared-services organization (IT-SSO) in late 2005 to consolidate government networks, data centers, desktops and common applications across many 
partner government agencies. The IT-SSO was expected to save taxpayers up to $\$ 600$ million annually (Kovessy, 2009).

Many organizations have seen success in cutting costs by implementing an SSO. For example, in the mid-1980's, Digital Equipment Corporation (DEC) reported annual savings of $\$ 45$ to $\$ 50$ million after the move to a shared-services model (Davis, 2005). After establishing its shared services organization in 1993, Xerox was able to save more the $\$ 600$ million within a period of six years (Frost, 2001).

Apart from economies of scale and cost control, shared services provide a number of other benefits to their client organizations. By moving into an IT shared-services arrangement, governments can retire legacy systems that devour IT budgets, provide citizens with better, streamlined services through an integrated system rather than through a number of isolated systems, and better handle information about and provided by citizens (Ruge, 2007). IT shared-services organizations are highly specialized in the IT services they provide, leading to fewer errors and significant time savings. According to the recent Sarbanes-Oxley Act, simplifying the process of IT service delivery allows organizations to maintain organizational process control, (SAP white paper, 2004); further, IT shared services can provide IT systems support to consolidate a company's contracts and operational data and analyze them in detail (SAP white paper, 2004). By freeing up partner organizations from IT support activities, the SSO allows these clients to concentrate on their core business activities (Herbert \& Seal, 2009). 
No matter which functions are moved into an SSO, such an arrangement has its own challenges. When partner organizations move certain functions to an SSO, they have to depend on another party to deliver these services, which then have to be integrated with the functions that are managed by the organization's in-house services. Loss of face-to-face contact with a service provider, lack of employee representation, questions about ownership of problems, inability to handle IT problems posed by state-of-the-art technologies, and unbalanced power distribution have been identified as major issues with shared-services arrangements (Cooke, 2006; Redman et al., 2007). To be effective, SSOs need to manage these people- and technology-related issues carefully. How these issues are to be handled is generally outlined in the service-level agreements. Detailed service-level agreements between SSOs and their client organizations describe the services to be provided by the SSO; however, it is not possible to anticipate every detail of the service relationship between the two parties in such agreements.

In organizations that have moved to an SSO model, instances arise where managers and employees complain about loss of control at work and criticize the SSOs for lack of communication and poor decision making (Strikwerda, 2006). High levels of interdependence across organizational boundaries coupled with the maintenance of strong inter-organizational connections are critical in SSOs (Janssen, Joha and Zuurmond, 2009). However, overlapping roles and responsibilities have resulted in some groups of employees experiencing job dissatisfaction after the implementation 
of an SSO (Redman, Snape, Wass and Hamilton, 2007). Occasionally problems have proved to be unsurmountable, as Strikwerda (2006) notes: "Cases are known of shared services centers which had to be closed down due to unmanageable or unmanaged conflicts" (pg. 5).

A shared-services worker can be defined as one who performs work across two or more organizations on a day-to-day basis (Redman et al., 2007). Shared-services employees at different levels work towards fulfilling the terms of shared-services agreements. They have to maintain high levels of coordination within the SSO organizations and with employees of the partner organizations for smooth service delivery. Many studies focused on shared services have pointed out that the individuals who work in an SSO make a huge difference to the success of that organization. For example, Farndale, Paauwe and Hoeksema (2009) found that competent staff was one of the most critical factors for the success of an SSO. Reilly and Williams (2003) recognized that detailed role design is an important part of introducing shared services into an organization; indeed they highlighted this need for detailed role design and also the need for a good balance between the two groups of shared-services employees-the strategists and the specialists. According to Bergeron (2003), a special breed of employees, focused training for transitioned employees, and the specific skills required by transition managers are key to the success of the SSO. Literature on shared services (Reilly and Williams, 2003; Bergeron, 2003; Redman et al., 2007) confirms that individuals working in an SSO are critical to the success of the organization, but these studies concentrate more on 
how an SSO can be implemented and tend to deal with issues surrounding implementation. Although these authors point out that talented individuals with relevant work experience make a difference to an SSO, they do not adequately illustrate how the work required in an SSO needs to be designed so as to enhance accountability and organizational outcomes in these service organizations. These issues, which are related to people management, indicate strongly that job design is critical in shared service organizations.

Work design can be defined as "systematic organization, design and articulation of work activities at one or more levels of the organization: system wide, process, group, job and task" (Torraco, 2005, pg. 87). When work in its broader aspects is discussed, it is denoted as work design; the narrower focus of work is denoted by the term "job design" (Parker \& Wall, 1998). Good job design has been proven to enhance individual and organizational effectiveness (Hackman and Oldham, 1975; Fried and Ferris, 1987; Humphrey and Morgeson, 2007). It can be argued that through effective job design, SSO's can create a well-trained workforce equipped with the special skills required by the different types of employees in the organization. Redman et al. (2007) point out that SSO employees must contend with power imbalances, and they argue that better job design is key to eliminating such imbalances. Through proper work and job design, SSOs can create a skilled workforce, balance power equitably among individuals working at all levels, and develop a first-rate infrastructure. 
The dearth of studies focused solely on job design in the shared services literature is notable. Empirical studies looking at how jobs can be designed with a view to enriching individual work within new forms of organizational arrangement would significantly enhance the operations and outcomes of IT shared services organizations as well as the organizational behavior literature.

The overall objective of this research is to identify the job characteristics that enhance job satisfaction and job performance and diminish turnover intentions for individuals working in shared-services organizations. The specific shared-services context for this research is an IT shared-services organization (IT-SSO) within the Canadian Federal Government. Therefore, we address four research questions in this study. (1) What is the nature of the work required in an IT-SSO organization? (2) What characteristics lead to better job outcomes for individuals working in an IT-SSO? (3) Do the type of skills used by individuals, and type of work in an IT-SSO have any effect on job outcomes? This thesis seeks to answer these research questions, and in doing so, to contribute to an understanding of effective job design in the IT-SSO.

Within a government setting, shared services can be viewed as an arrangement designed to bring about reform in the delivery of government services (Dollery and Grant, 2010). Shared services arrangements have been studied across many different countries (Ulbrich, 2006 ; Cooke, 2006; Janssen and Joha , 2006). In the Canadian context, Whitfield (2007) reports on provincial level shared services in the provinces 
of British Columbia and Alberta. But to date no study has been published on shared services performance at the federal level. The Information Branch of Public Works and Government Services Canada (PWGSC), with the guidance of the Treasury Board of Canada, was transformed into one of the largest federal shared services organizations in 2003 (ITS Fact sheet, 2009) with the aim of cutting government costs by $15-20 \%$ (ITS Factsheet , 2009). Moving into a shared services setting can be challenging for those who have not previously worked in this environment. Studying the important job characteristics of this shared services arrangement in the Canadian federal context will provide valuable insight as to how government agencies can enrich work in the public service. In their the article "Bridging Research and Policy," Stone et al ( 2001, pg. 3) state that -lack of access to research, data and analysis is challenging for both researchers and policy makers. Given this frequent lack of access, when access is achieved and an empirical study is undertaken to explore the nature of work in a federal shared services organization, the findings are that much more valuable and unique.

Secondly, Humphrey, Nahrgang and Morgeson (2007) presented an extended job design model though a meta-analysis of 259 studies on job design to date. Their model included three job characteristics with job outcomes. Motivational characteristics are commonly used in job design studies (Campion and Thayer 1987). Social characteristics were brought into job design models to understand how advice and assistance at work can influence job outcomes (Morgeson and Humphrey, 2006). Studies using a wide range of motivational characteristics and social characteristics 
together are not common in the job design literature; rather, these factors are more often analyzed separately or as moderating variables between job characteristics and job outcomes. Empirically studying the motivational and social characteristics put forward by Humphrey, Nahrgang and Morgeson (2007) study will help to validate the predications made in their study.

Thirdly, the need to focus on contextual characteristics in job design has been raised by organizational behaviour researchers (Jones, 2006; Morgeson, Dierdorff and Hmurovic, 2010). Jones (2006) defines context as "situational opportunities and constraints that affect the occurrence and meaning of organizational behaviour as well as functional relationships between variables" (2006, pg.386). Others consider work context characteristics as broad performance contexts (Humphrey, Nahrgang and Morgeson (2007). Jones (2006) stresses that the context of the study itself-where the study has taken place-is important, and that only when this description of the context is provided can an understanding of personal interactions in the situation and applications of the research have more "subtlety" and "power." Further, Morgeson, Dierdorff and Hmurovic (2010) suggest that work roles can be influenced by situations in the work place, and that the relationships between work roles and job outcomes can be influenced by work context characteristics. These researchers believe that studies bringing out the work context and its role in work design can significantly contribute to the literature on organizational behaviour. Traditionally in job design, physical demands, work conditions and ergonomics are studied as work context characteristics (Humphrey, Nahrgang and Morgeson, 2007). 
Service is key in the SSO. The organization must deliver error-free, top-quality service to its current customers in order to establish an excellent reputation for service delivery and attract new customers. Frost (2001) says that along with being costreduced service providers, SSOs need to work towards being a "supplier of choice." To achieve an outstanding reputation, shared services need to be focused on customer satisfaction through service delivery. This has to be the norm, not only at the top level, but at all levels of an SSO. Service orientation has been a popular notion in the private sector (Crane, 1994; Hogan, Hogan and Busch, 1984; Lytle et al. 1998), and the need for service orientation has been studied in the public sector as well (McNulty and Ferkie, 2001). Lytle et al. (1998) related service orientation to job outcomes, and other researchers (Saura et al 2005; Gonzalez and Garazo 2006; Yoon, Choi and Park 2007) have also found that service orientation at the individual level can enhance job outcomes. However, service orientation characteristics and their relationship with work outcomes have not previously been studied within the IT service delivery sector where job design issues have been the focus. Lytle et al.(1998) looked at how service delivery, service failure prevention methods, recovery methods, and service standards communication relate to service orientation. In their study the authors link these four components to individual job outcomes. But the influence of service orientation as a work context characteristic has never been studied along with other motivational and social characteristics. Therefore, studying how service orientation functions along with other job characteristics in a public service setting will contribute to a larger understanding of service orientation and its potential function as a work context characteristic. 
Fourthly, transitional work, transformational work, and professional work (though there is not a lot of research available about these classifications) are commonly described as the types of work performed in shared services organizations (Bergerson, 2003; Redman, 2007). There is some indication that those who perform transactional work are not satisfied with their work, and there are also questions as to whether new kinds of skills sets are necessary to work in shared services (Redman et al., 2007), but there are very few studies that focus on job design related specifically to IT employees. Most of the existing IT-SSO research is conceptual or based on case studies; moreover, the surveys that have been carried out are from private research firms (Accenture 2005; Government Technology, 2007) and there are no large-scale surveys on shared services published in academic journals. As well, empirical studies examining IT-SSO settings are rare in the shared services literature. The shared services organization represents a major innovation in service delivery and is slated to become a dominant form of organization in both the public and private sectors. SSOs typically involve thousands of employees; thus, job design in these settings is not only critical but strategically vital if organizations are to be successful in meeting their objectives. For the most part, the shared services literature is concerned with how to implement shared services and how to avoid pitfalls (Ulrich, 1996; Reilly and Williams, 2003; Bergerson, 2003). The research (Legare and Bechtel, 2001; Strikwerda, 2006) that deals with organizational change in SSOs addresses change only at the organizational level and does not focus on individual level changes, how roles and responsibilities are delegated, or how individual work outcomes can contribute to the overall function of an SSO. When a single organization is preparing 
to provide services across many other organizations, there are going to be changes at both the organizational and individual levels. So far the shared services literature has not addressed the issue of individual work in the shared services work setting. The closest the literature has come to defining the actual work of employees is identifying the areas of transformational and transactional work and the considerable overlaps between them (Reilly and Williams, 2003; Farndale, Paauwe and Hoeksema, 2009). How these categories of work affect individual work behavior and SSO outcomes has not been studied. No empirical research has been done concerning the nature of individual roles in an SSO work setting. This gap in the literature needs to be filled and this thesis will contribute towards this endeavor.

Clearly, knowledge of how to design work in a federal SSO has to be strengthened through research. Understanding the nature of work in an SSO, identifying the dominant job characteristics that enhance individual outcomes, and including service orientation characteristics in a job design model can contribute significantly to both the shared-services and job design literature. Moreover, empirically studying how different types of work and different types of skill sets influence job outcomes in a shared services setting will help managers to design training and recruitment programs.

The thesis will proceed as follows. In chapter two, the literature review on shared services organizations, job design and service orientation is presented. Chapter three describes the IT-SSO job design model and outlines the main research objectives and 
research questions of this study. Chapter four discusses the mixed methodology used in this study to collect quantitative and qualitative data. The quantitative data analysis is presented in chapter five, followed by the qualitative data analysis in chapter six. Chapter seven consists of a discussion of the key findings of both the quantitative and qualitative analyses. The chapter also revisits the IT-SSO job design model, highlighting the job characteristics that have emerged as important to job satisfaction for IT-SSO members. Chapter eight concludes the study, proposes job design recommendations for the IT-SSO, and discusses implications of the study for future research. 


\section{Chapter 2}

\section{Literature Review}

This chapter will first discuss the notion of shared services and the recent shared services organization trends in Canada and across the globe. Secondly, literature that specifically focuses on the organizational changes that take place during the move to an SSO is outlined. Throughout this literature review, job characteristics that are necessary in a shared services work setting are identified. Finally, the chapter discusses the work design literature in organization theory to propose a job characteristics model for shared services organizations that will enhance individual job outcomes.

\subsection{Shared Services Organizations}

Accenture (2005) defines the shared-services organization simply as a stand-alone entity whose only mission is to provide services as effectively and efficiently as possible. Other researchers expand this definition to provide a broader understanding of the nature of this stand-alone entity. Shah (1998) identifies the SSO as a service provider with a diverse set of business units, a center of excellence that is accountable for quality and responsive to the needs of the customers for whom it provides services, and a place to deploy new technology while aiming to leverage intellectual and capital assets. Janssen and Joha (2006) explain the SSO as "a separate and accountable semi-autonomous unit within an (inter)organizational entity, used to bundle activities and provide specific pre-defined services to the operational units within that (inter)organizational entity, on the basis of agreed 
conditions" (p.103). Further, SSOs can include shared services centers and centers of excellence. Shared services centers provide shared transactional services, and centers of excellence are organizational units that provide shared transformation services (Ulrich, 1995). Shared services centers are also called centers of scale (Quinn, Cooke, and Kris 2000). Reilly and Williams (2003) differentiate SSOs from other services according to three dimensions: firstly, the nature of the shared services is determined by the customer; secondly, customers select from a variety of standardized services; and thirdly, SSOs can have a number of users at the same time.

At first glance, the notion of an SSO overlaps with the idea of centralization and outsourcing. But there are significant differences between an SSO and centralization, outsourcing, and a service consolidation arrangement. In the following table we highlight these differences. 
Table 1: Characteristics of Shared Services

\begin{tabular}{|c|c|c|}
\hline & Traditional Head Office & SSO \\
\hline Output focus & Self-serving (top management) & $\begin{array}{l}\text { Customer centered (for } \\
\text { business divisions) }\end{array}$ \\
\hline Input focus & $\begin{array}{l}\text { Functional learning, } \\
\text { specialization, role focused }\end{array}$ & $\begin{array}{l}\text { Process centered, specialist } \\
\text { centres of excellence and multi- } \\
\text { skilled tasking focus }\end{array}$ \\
\hline Location & Within HO campus & Separate site, physically remote \\
\hline $\begin{array}{l}\text { Governance } \\
\text { Relationship with division } \\
\text { Relationship with Head Office }\end{array}$ & $\begin{array}{l}\text { Hierarchical } \\
\text { Formal roles, impersonal roles, } \\
\text { impersonal relations, no choice } \\
\text { of division } \\
\text { Report to multiple HO directors } \\
\text { Staff responsible to specific } \\
\text { division heads (role) in HO }\end{array}$ & $\begin{array}{l}\text { Arm's length - quasi market } \\
\text { Contractual (service levels } \\
\text { agreement) underpinned by } \\
\text { personal relationships } \\
\text { Divisions have choice of } \\
\text { providers or influence over } \\
\text { SSO } \\
\text { Semi-autonomous reporting to } \\
\text { multiple divisional contacts } \\
\text { Report to one person, board } \\
\text { directors } \\
\text { Call centre is "one stop shop," } \\
\text { not person specific }\end{array}$ \\
\hline Objectives & Coordination and control & $\begin{array}{l}\text { Process efficiency through BPR } \\
\text { \& elimination of duplicate tasks } \\
\text { Divisional focus on core } \\
\text { activities }\end{array}$ \\
\hline Outlook/Culture & $\begin{array}{l}\text { Back-office, passive, reactive, } \\
\text { skills and infrastructure good } \\
\text { enough }\end{array}$ & $\begin{array}{l}\text { Back-office, reactive } \\
\text { But also front-office proactive } \\
\text { Continual improvement }\end{array}$ \\
\hline Cost Recovery & $\begin{array}{l}\text { Carried as central cost or } \\
\text { apportioned on an arbitrary or } \\
\text { equitable basis, objective being } \\
\text { minimization of transaction } \\
\text { costs and leverage of divisions }\end{array}$ & $\begin{array}{l}\text { Unit charges per activity or } \\
\text { output. } \\
\text { Allocated per division on the } \\
\text { basis of traceable captive } \\
\text { resource or apportioned on } \\
\text { equitable basis }\end{array}$ \\
\hline IT/IS & $\begin{array}{l}\text { Consolidation is main focus } \\
\text { Spreadsheet interfaces with } \\
\text { divisional best-of-breed systems }\end{array}$ & $\begin{array}{l}\text { Enterprise (ERP) } \\
\text { Standardization of } \\
\text { inputs/outputs, processes and } \\
\text { communication protocols }\end{array}$ \\
\hline
\end{tabular}

Adapted from Herbert and Seal (2009)

Herbert \& Seal (2009) differentiate an SSO from a traditional head-office service in terms of aspects such as output focus, input focus, location, governance, objectives, culture, cost recharge and the use of information technology. The traditional head- 
office organization serves itself through a hierarchical structure using a top-down approach. Divisions within the organization perform various functions, and each division has its own divisional head whose main duty is to coordinate and control activities within the rest of the organization. These divisions have their own divisional best-of-breed information system to fulfill their IT requirements. Services provided by the different functions are recharged on an equitable basis. The organizational culture of such traditional head office services are not typically customer focused and individuals work according to a pre-determined set of work routines. Employees need not be proactive in performing their duties.

The SSO, on the other hand, needs to be highly customer focused and service oriented. Within the SSO, there is no divisional separation of functions; rather work is viewed as a whole multitasked process. SSOs are located mostly away from their customer locations, function as semi-autonomous units and are generally governed by a board of directors. Their main objective is to eliminate the duplication of tasks and provide excellent services through service agreements to many clients. All costs are traceable and the clients are charged according to the level of output. SSOs often use enterprise resource systems (ERP) to integrate their client base. In addition to these differences, as Quinn, Cooke, and Kris (2000) state, the SSO does not typically enforce policy-related issues; centralized units, on the other hand, do enforce policy conformity. 
SSOs should also be distinguished from outsourcing. Kern and Willcocks (1998) define IT outsourcing as "a decision taken by an organization to contract out or sell the organization's IT assets, people/or activities to a third-party supplier, who in exchange provides and manages assets and services for monetary returns over an agreed time period" (pg. 322). A survey on outsourcing conducted by Kakabadse and Kakabadse (2002) shows that controlling cost, obtaining best practices, improving services, focusing on core competencies, improving the ability to develop new products and services, accessing new technology and reducing staff were the top reasons for outsourcing IT services. Kern and Willcocks' (1998) definition of outsourcing indicates that IT outsourcing is a much more advanced move whereby organizations move their IT services partly or entirely to a third-party vendor. In an SSO, services are consolidated by an internal service provider and standard IT services are provided to many business units. In other words, there is one internal service provider and many client organizations. Also, Kakabadse and Kakabadse's (2002) survey shows that when organizations choose the option of outsourcing it is to achieve a wider objective such as enhanced capability to develop new products, capacity to change and position in the value chain ; whereas the primary move to an SSO is made to reduce cost and attain good service delivery. Janssen and Joha (2006), who studied the motives of shared-services centers in public administration, explain that an SSO's resources are the people inside the organizational entity, whereas for the business that sets up an outsourcing arrangement, the services are provided largely by outside experts. Because SSOs are constituted by their internal people and resources, there needs to be much greater coordination between the SSO and its 
business units. However, the degree of attention required will be less when the best possible outsourcing arrangement is made and the services needed are agreed upon. Although outsourcing and SSOs can be differentiated based on how they are defined, their operational objectives, and the use of resources; the most fundamental difference between outsourcing and shared services organizations is that an SSO is an internal service provider and therefore is part of the corporate structure of an organization (Ulbrich, 2006), while outsourcing arrangements are performed entirely by external service providers.

A shared-services organization can be established according to one of four models. Quinn, Cooke, and Kris (2000) explain the different shared-services models as the basic model, the market place model, the advanced market place model and the independent business model. These different models represent a continuum of shared services, which does not mean that every SSO goes through these stages, but rather that an SSO has the choice of growing from a basic model to an independent business unit. The most basic model of shared services is one where the SSO presents itself as purely a cost-reduction centre providing standardized services. This basic shared-services model works towards the consolidation of administrative work for its clients. The SSC provides its services solely to the clients' internal departments and business units and the costs are fully attributed to them. The basic model does not have separate governance and its services remain strictly those mandatory to its clients. The market place model of shared services is an extension of the basic model. Along with consolidating transactional and administrative work, 
this model offers provisional advisory services. The main objective is to reduce costs while at the same time providing superior quality service delivery. The clients have the option to choose what services they require and are fully charged for them. In this model, the SSO has its own governance system to oversee adherence to standard and corporate policies, while the shared-services unit concentrates on service delivery.

In the advanced market place model, the SSO has to directly compete with outside service providers delivering the same services. This is because the services are provided at market price and the clients have the option to choose the best service provider. For this reason, the advanced market place SSO must eliminate those services in areas where it is less competitive and concentrate on the services in which it is most skilled in order to establish an excellent reputation. In addition, the advanced market place SSO can sell its surplus services to customers outside of its organization. When an SSO deliver services to both internal and outside clients, it becomes an independent business unit and has to compete with similar service providers in marketing its services to many different organizations. For an independent business unit, the main objective is to earn high profits by delivering superior services under competitive conditions. In the advanced market place model, the services are offered at market price, and therefore the clients or partner organizations have the opportunity to buy services from other outside service providers if they are not satisfied with those offered by the SSO. Thus the advanced market place SSO has to compete vigorously with external vendors who provide the 
same services. Hence, at this stage the objective of the SSO is to provide its partner organizations with a wide choice of services. The most advanced model of the SSO functions as an independent business unit. At this mature level the SSO will be competing directly with major companies in a common business environment, delivering services to multiple client organizations. The main objective at this level is to provide highly competitive services while generating revenues and profits for the SSO. The IT-SSO where data was collected for this study, is currently moving from the basic model stage to the market place model.

\subsection{Trends in Shared-Services Organizations and the Change Management Process}

Shared services has been a popular notion in the private sector for the past 15 years and its implementation has delivered good results (A.T. Kearney, 2004). Many medium and large private enterprises have been successful in establishing sharedservices units. In the U.S., General Electric (GE) is reported to be the first organization to implement a shared services centre to control their accounts in their North American operations (Davis, 2005). Following GE's success, Digital Equipment Corporation (DEC) established a shared-services unit for its financial services, eliminating 150 duplicated systems and contributing to the saving of $\$ 40$ to $\$ 50$ million a year (Davis, 2005). Carr (2008) reports that a survey by the English Institute of Chartered Accounts found that more than $30 \%$ of Fortune 500 companies have set up a shared services center for their accounting function, which has allowed them to enjoy a $46 \%$ cost saving. It was further reported that companies 
such as the BBC, Bristol Myers Squibb, Ford, Hewitt Packard, Pfizer and Rolls Royce have successfully implemented shared services centers.

Faced with the challenge of cost reduction, many government agencies across the globe have implemented shared-services units. In Canada, the Information Technology Service Branch (ITSB) of Public Works and Government Services Canada (PWGSC) established an IT shared-services organization (IT-SSO) in late 2005. In this pilot project, the Canada School of Public Service, Health Canada, Parks Canada, the Privy Council Office, Transport Canada, and Veterans' Affairs joined the IT-SSO (Hession, 2008). In Ontario, the provincial government successfully moved their payment, payroll, and strategic procurement functions from 21 different services into a shared services bureau (A.T Kearney, 2004).

In the U.K, to provide better HR facilities for the large number of stakeholders, the National Health Services (NHS) moved its HR functions to an HR-SSO. This allowed the NHS to strategically position its HR services and overcome challenges in the areas of career management, skill improvement, staff morale and people management skills (Redman, Snape, Wass and Hamilton, 2007). In Australia and New Zealand there have been many successful SSO implementations at local and government levels; for instance, the Auckland District Health Board consolidated its back-office functions into an SSO serving major hospitals (A.T. Kearney, 2004). 
Similarly, many governments have also reduced costs and improved the efficiency of their operations. In Canada, Service Ontario centralized its payment, payroll and strategic procurement functions, transferring 1300 employees from 22 different ministries into one shared-services bureau; Shared Services B.C provides four different programs, including Procurement and Supply Services (PSS), Strategic Acquisitions and Intellectual Property (SAIP), Payroll Services and Corporate Accounting Services (CAS), and Workplace Technology Services (WTS) for its ministries; and the Alberta Corporate Service Centre handles processes for administration services, finance services, human resources services and information technology services for 24 government ministries (Whitfield,2007).

The non-profit sector has also begun to benefit from the use of shared services, as Walsh, Lowndes and Newton (2008) report. Referring to Arsenault's (1998) research, Walsh et al. (1998) state that in the non-profit sector, shared-services providers are called Management Service Organizations (MSO). They describe four MSO models - the classical business model, the dedicated shared-services centre, the peak body support model, and the co-location that operate in the non-profit sector. The classical business model brings together functions that otherwise would be carried out separately into one single business unit. Dedicated shared-services centers offer non-profit organizations the opportunity to sub-contract some of their business functions. The peak body support model is a primary organization within the nonprofit sector that provides services for other non-profit organizations for a membership fee. The co-location model permits organizations to use resources 
commonly. Though the implementation of shared-services organizations in the nonprofit sector has not grown as quickly or as extensively as in the private and public sectors, non-profit organizations can look to shared services to reduce costs and increase efficiency.

The decision by businesses or government agencies to move their services into an SSO involves a significant organizational change. This is because services that are provided by separate business units must be consolidated into one entity, and that single entity then has to provide standard services across many business units. The shift to shared services can be a more difficult one for government agencies, which are accustomed to internal bureaucracies. For such rational systems, implementing a shared-services unit is not an easy task. There is some research in the shared services literature that specifically focuses on the organizational changes undergone in the move to shared services. Ulbrich (2006) links SSOs to business process reengineering (BPR) and suggests that there are similarities between the two because they are fundamentally process-oriented and aim at designing better service delivery for better organizational outcomes. Similarly, Lacity and Fox (2008) explain Reuter's implementation of global shared services as combining four types of change, including business process redesign, organizational redesign, sourcing redesign and technology enablement. The study found that adopting a transformation approach, analyzing the costs and attributes, assessing the organization's readiness, and ensuring that internal staff clearly understand the process were all critical for successful change. Legare and Bechtel (2001), whose study focused on a shared- 
services model at an air product company, stressed that the initial move to an SSO or the establishment of an SSO requires step-by-step change management. The change management program needs to have a clear vision of change, proper management alignment, accountability in work-related issues and good communication with employees for successful implementation of the SSO. Lack of these elements would represent a significant barrier to successful change.

Managing change in organizations largely depends on the individuals who must work through the changes. This is the same with the organizational change that is involved in the creation of an SSO. Bergerson (2003) identifies several key factors related to the establishment of an SSO, and most of these centre around the individuals working with the SSO. The research asserts that, for the successful establishment of an SSO, there is a need for a special breed of employees with an enterprising spirit. Specifically, the transition managers require special skills, and the quality and experience of the transition team is closely related to the success or failure of the SSO. In addition, training employees for the transition was also found to be key; simply throwing employees into a new management structure and work environment without additional training would not be effective. A Conference Board of Canada report (2005) on shared services point out that a shift to shared services can be an enormous burden on the workforce that must go through the change: "Loss of jobs or the threat of job loss, new reporting relationships, working with unfamiliar people, and brand new shared services entities are all difficult for staff. As front-line staff are moved into new roles in the shared services entity, they may feel detached from their home department, anxious about the skills required, or worse, like 'second-class 
citizens" (pg. 5). In any organizational change, the "people" aspect has to be handled carefully, otherwise this itself will become the biggest barrier to change. This applies no less to the move to shared services.

The SSO is an organization with few boundaries. It is responsible for generating quality services to be shared by many organizations. This makes the nature of the work of SSO employees different from that carried out in organizations where services do not cross functional and organizational boundaries. Failure on the part of an SSO employee can have a greater impact across many client organizations. Ulrich (1996) underlines the fact that the greatest challenges in implementing an SSO are in working and managing work without organizational boundaries. This is because prior to the establishment of an SSO, the organization is used to working within functional boundaries, but with the SSO this thinking will have to change. Ulrich (1996) suggested that the removal of boundaries will come only when individuals with different roles in the organization come together with a shared sense of unity towards achieving a common goal. Strikwerda (2006) stresses that the organizational change brought about by establishing an SSO needs to be viewed by the organization as a corporate change. It should not be mistaken for the kind of change associated with an IT project. The author suggests that when an organization thinks that creating an SSO is similar to an IT project where the IT unit spearheads the change process, the shared services endeavour is bound to fail. Strikwerda (2006) further explains that moving into a shared services arrangement is fundamentally a corporate change, where the change comes from top management and changes need to take place 
according to the chosen shared services business model, its new tasks and accountabilities: The concept of corporate change acknowledges the creation of new roles and identities and acknowledges that a phase is needed in which key players, usually managers of units, are provided with the opportunity to confirm each other's roles through role negotiation, including key management processes of planning, coordination and decision making, in order to develop a level of comfort with the new organization to be implemented.

The corporate change approach called for by Strikwerda (2006) in the shift to shared services indicates that roles and accountability need to change around the shared services business model. Reilly and Williams (2003) classify the work of shared services employees into three tiers. The first tier consists of generalists who are firstlevel problem-solvers and perform transactional processing. The second tier.includes functional specialists who provide high-level expertise and policy interpretation. The third tier is made up of those individuals whose work is related to the policy design capabilities of the SSO. Reilly and Williams (2003) assert that balancing work between generalists (those who perform transactional work) and specialists (those who perform transformational work) is important for the SSO. Moreover, they suggest that SSO employees need to be all-rounders; that is, generalists would focus on their transactional work but also familiarize themselves with some transformational work. 
Reilly and Williams (2003) further note that there are considerable overlaps among the three tiers, and that the SSO needs to strike a balance among these different areas. Other researchers (Redman et al., 2007; Farndale, Paauwe and Hoeksema, 2009) classify SSO members more broadly as performing either transformational or transactional work. Farndale et al. (2009) studied the actual work of employees in 15 SSOs in the Netherlands and found that $42 \%$ performed first-tier work, $28 \%$ carried out second-tier work, and only $7 \%$ percent worked in the third tier. The remainder of the employees did not fit into these tiers but were found to be performing managerial work (13\%) and support services falling within overlaps among the three tiers.

Ulrich (1996) suggests that in order to encourage boundaryless behavior, an SSO needs to provide incentives to its employees. However, this study takes the view that attention needs to be first given to individual job design. The study propose that when jobs are designed in an effective and competent manner, shared-services employees will experience better job outcomes and the SSO outcomes will be enhanced as well. A job design model specifically created for shared services workers will allow us to understand which job characteristics best describe the nature of work in an SSO. This will also enable researchers to identify among these characteristics which job characteristics will enhance individual and organizational outcomes. It will contribute to the shared-service literature which thus far has addressed work related issues only at the organizational level, and not directed its attention towards individual level analysis. Limited studies have shown that transactional workers are unhappy about how their jobs are designed; and further 
research was required to determine how their jobs can be designed in a better way to thwart job dissatisfaction ( Redman et al., 2007). Identifying the job characteristics in an shared services organization which facilitate better job outcomes at all levels of SSO is a valuable contribution to the shared services literature. To propose a job design model for an SSO organization, it is important first to analyze the nature of the work and the job characteristics involved in the SSO work setting. In what follows, we review the existing literature on shared services organizations to understand the nature of individual work in an SSO and the predominant job characteristics.

\subsection{Job Characteristics in Shared Services Organizations}

The literature on SSOs is not voluminous; it consists of some peer-reviewed articles, books, theses, and a number of write-ups by practitioners in professional magazines. In this literature, studies that focus on human resources in shared services (Cooke, 2006; Redman et al., 2007; Farndale et al., 2009) give us some understanding as to the nature of human resources activities in the shared services setting. When we analyze the current SSO literature to understand the work-related issues for SSO employees, three themes emerge: the need to identify employees with a unique set of skills; the importance of relationship management; and the necessity of service orientation among SSO members. In the following section, studies that bring up these issues are outlined and then discussed. 


\subsubsection{Skills required in an SSO}

Reilly and Williams (2003) divide SSO employees into three tiers. The first tier consists of generalists who are first-level problem-solvers and perform transactional processing. In the second tier are the functional specialists who provide high-level expertise and policy interpretation. The third tier is made up of those individuals whose work is related to the policy design capabilities of the SSO. Other researchers (Redman et al., 2007; Farndale, Paauwe and Hoeksema, 2009) classify SSO members more broadly as performing either transformational or transactional work. Transactional and transformational employees are also referred to as generalists and specialists (Reilly and Williams, 2003).Whether for transactional or transformational work, recruiting the right type of person has been shown to be important. Cooke (2006) explains the effect on employees of the creation of an HR shared services centre at Consult-Corp U.K. In this HR- SSO the staff were classified broadly as transactional and transformational employees. The SSO management did not want the transactional employees to be highly qualified; rather they needed individuals with no degree qualification and limited working knowledge. Special attention was given to individuals with good communication skills and personality. Because the transactional HR activities were built into the technical system, the management emphasized that if individuals knew the processes and the organization as a whole very well, this knowledge was good enough to enable them to perform the transactional activities. The second category was transformational staff, who were consultants having good knowledge in human resources, management, negotiation and change management. The main activity of 
these individuals was to work closely with the client organizations and maintain good relationships on behalf of the SSO. Reilly and Williams (2003) looked specifically at the issues of role design, mainly emphasizing that there needs to be a balance between specialists and generalists. They suggested the way to strike a balance between the two groups would be to ask employees to be all-rounders but at the same time to develop expertise in one area. This way a project consultant, while specializing in one area, might be able to tackle any issue, and employees in administrative positions would do all kinds of tasks while developing deeper knowledge of how the SSO really works. Reilly and Williams (2003) also suggested the use of an "escalation procedure" (p. 55) in which administrative staff would handle issues first, but when they lacked the appropriate knowledge and skill they would seek the help of a specialist.

Day and Norris (2006) describe how New Zealand's health sector implemented Information for Health, Working to Add Value to E-information (WAVE), and the shared services initiatives that were part of this program. The study focuses on the changes the IS staff underwent during the move to shared services. The study revealed that individual IS staff had to adapt to varying degrees of change during the move to the shared services. Degrees of uncertainty, workload, communication resources, and expectations of failure were recurrent themes that were identified by shared services workers. Employees experienced uncertainty and a sense of ambiguity because they were not doing the same work they had been doing previously, and they wanted more involvement with the project. They also 
experienced a heavier workload because many things were happening very fast, and they had to maintain their current level of work while transitioning to the shared services arrangement. Leadership issues also come up in times of change, and moving into a shared services arrangement is no exception. Employees wanted visible leaders with a good sense of judgment. They wanted their managers to be good communicators and also preferred written communication so that they could, at any time, get back to what they had been asked to do and what had been carried out. Day and Norris (2006) also point out that having the right people, who had excellent knowledge and expertise in dealing with major change, was critical for the success of this shared services implementation.

Redman, Snape, Wass and Hamilton (2007) evaluated the human resources function in the SSO set up by the NHS in the U.K. This study suggests that employees at an SSO need to possess good communication skills, organizational skills, and an understanding of all of the activities of the organization. Apart from identifying these skill sets, the study noted that semi-detached units such as the shared services unit found it difficult to distinguish transactional from Transformational work. Transactional work deals with administrative work, while transformational work focuses on managing relationships and attending to business affairs. The study found that transactional work was performed better with an SSO than transformational work, mainly because SSO workers were not able to manage the political tensions that arose when dealing with several organizations. Redman et al. (2007), who conducted the only study that primarily focuses on the impact of the 
work on employees in an SSO work setting, found that employees who were colocated were more satisfied and less likely to quit than individuals who worked for more than one client organization on a daily basis. They also found that shared services workers felt the "power shift in favor" of the client organization and were worried about how they would handle multiple priorities from different organizations. One of the most important findings of the Redman et al. (2007) study was that the work in an SSO involved shared roles, which needed more support and development and better job design. This was especially important for transactional employees, who reported high levels of dissatisfaction.

\subsubsection{Relationships in an SSO}

The second people-related issue in an SSO is relationship management. Many researchers believe that relationship management is pivotal for effective IT shared services. Grant, Brown, Uruthirapathy and McKnight (2006) recommend relationship management as an element in the governance structure of public sector shared services to promote communications, staffing of the shared services, and for cultural analysis.

Cooke (2006) identified relationships with clients as having important implications for the SSO. Before the establishment of HR shared services, an organization had face-to-face relationships with employees, but once services were delivered through the HR- SSO there was no more face-to-face contact with employees within the same organization, and this had a negative effect on the work. Ulrich (1996) explains this effect further through the notion of "depersonalization" (pg. 22). 
When shared services employees are not able to see their final product and whom they are serving, they experience less personal contact in their jobs. To avoid this situation, some level of relationship between the SSO and employees of the client organizations is necessary. The Conference Board of Canada (2006) report on shared- services describes building trust through relationship management. Managers need to build personal relationships with employees at the client organizations to understand what they need and how they need services to be delivered, even though this has been set out in the service level agreements. As the conference board report (2006) states, "Executives from shared services organizations emphasized personal relationship building" (pg. 23). The report further outlines how having proper approaches to understanding clients' needs, regular communication with the clients, and service level agreements can be used to build good relationships. First, both formal and informal approaches need to be adopted by the SSO to understand the needs of the clients. The SSO needs to employ formal means such as customer surveys to get feedback from the clients concerning service delivery and to understand their satisfaction level. When the need for improvement in service delivery is indicated, this must be incorporated.

The report outlines how the importance of having informal relationships with employees at the client organizations can also provide important feedback on how service quality can be improved. Secondly, a part of good relationship-building is to have open communication with employees at the client organizations. Through meetings and open communications, both parties are provided with an opportunity 
to discuss the challenges in service delivery and how these can be met. Both parties need to develop an early agreement on performance levels. Thirdly, the service level agreement also outlines the commitments of both parties and how they can be achieved, and determines the level of interaction between the two parties.

Quinn et al. (2000) explain that shared services need not proactively perform marketing or sales activities unless they want to sell their services to outside customers (as the advanced and independent units do). But the authors note that good relationships mean good business and they explain how relationship management in an SSO can take the form of a formal role, or part of a shared services manager's job, or an activity in the SSO. When organizations include relationship management as a formal role, they employ a relationship manager to understand the client organization's priorities, monitor client and employee satisfaction, engage in high-level problem solving, enhance communication and influence service-mindedness among employees. When relationship management is understood to be part of a shared services manager's job, the manager and his or her staff will take the work of building relationships with client organizations very seriously. Relationship building as an activity within the SSO allows employees to build networks in their day-to-day activities. This way the SSO and client organization employees will have good interactions.

\subsubsection{Service Orientation}

The main objective of an SSO is to provide top quality services for it client organizations. Reilly and William (2003) state that in an SSO, the services are 
directed by the clients, and the main focus in service delivery is to provide the services required by the clients and not what the SSO chooses to provide them. Shared services are always under pressure to deliver superior services because they are established with the primary purpose of providing top quality services at a reduced cost. Herbert and Seal (2009) believe that "selling orientation" is important for an SSO for two main reasons: first, an SSO has to convince the client organizations that they would benefit by using an SSO; and secondly, the SSO has to persuade clients to continue using its services. Farndale et al. (2009) found that having the correct service scope was a critical success factor for SSOs. They identified service scope as the ability to deliver services that would meet all demands of the customers. Redman et al. (2009) found that employees working in SSOs need to engage in marketing and self-promotion and be "proactive about image and profile" (pg. 1502). What this shared services research (Reilly and William, 2003; Herbert and Seal 2009; Farndale et al., 2009) suggests is that, fundamentally, the SSO needs to embody service excellence. To provide service excellence, organizations need to be service oriented at both the individual and organizational levels (Homburg, Hoyer \& Fassnacht, 2002). Lytle, Hom, and Mokwa (1998) define service orientation formally as "an organization-wide embracement of a basic set of relatively enduring organizational policies, practices and procedures intended to support and reward service-giving behaviors that create and deliver "service excellence" (pg. 459). According to this definition, to become service oriented, the SSO needs to implement policies, practices and procedures that would encourage service-oriented behavior across the organization and raise their 
business profile as a service provider. Hence, moving into an SSO is not only a process of structural change, but also involves organizational cultural and behavioral changes. This new culture and associated behavioral changes need to include service orientation at the individual and organizational levels in order to achieve better SSO outcomes.

\subsection{Discussion on the Existing Literature on SSOs}

When we examine the literature on the people aspect of shared services, we find that there is a need for a special breed of employee with a special skill set that includes the ability to maintain relationships and be service oriented - which are issues in an SSOs. When we analyze the skill needs of SSO workers, we find that there is clearly a difference between transactional employees and transformational employees. Cooke (2006) indicated that for transactional services, the SSO was not targeting individuals who possessed a degree but wanted employees with good communication skills and friendly, outgoing personalities. Cooke (2006) also found that the transactional work of an SSO was built into the processes and the SSO only wanted the transactional employees to understand the processes very well. This leads to the question as to how this would affect work outcomes such as job satisfaction and career development among transactional employees in an SSO. Redman et al. (2007), in the only study that emphasized better work design, confirmed lower levels of job satisfaction in transactional employees and recommended job rotation for these workers. The study also found that transactional workers were more dissatisfied with their jobs than transformational workers. Further, Reilly and Williams (2003) indicate that an SSO has to maintain balance 
between generalists and specialists. They describe the "escalation procedure" process where the generalists handle an issue at work as far as they can, and then leave the rest to the specialists. But this escalating procedure can become ineffective if the generalists have to constantly seek the help of the specialists to perform their work. If an organization wants to function more effectively, the roles of generalist and specialist need to be defined and balanced more productively. There is a need to provide enriched work for transactional employees in an SSO to avoid high turnover in such jobs. The existing literature merely raises these issues but does not provide enough detail as to how the deficiencies of job design can be rectified or how poor work design affects the work performance of shared services employees. Clearly, there is a need for a focused study to identify specific job characteristics that are critical for transactional and transformational employees in an SSO and to look at how defining these characteristics can affect individual work outcomes. Further, Redman et al. (2007) indicate that SSO employees felt there was a "power shift" to the client organizations. How do these issues affect SSO workers' job satisfaction and other job outcomes? Investigating these issues in a real SSO can help us understand them more clearly.

When working across many client organizations, shared services employees require excellent communication and interpersonal skills. As described by Goh, Satya, and Yeo (2007), "All members of the new shared services unit are expected to interact and be interactive" (pg. 253). Day and Norris (2006) also found that communication resources were essential for IT-SSO work. The current SSO literature describes the 
work at an SSO through broad topics such as change management, communications, relationship and service management qualities. In which work situations these skills are more important has not been sufficiently brought to light, nor has how these skills impact the overall job outcomes of shared services employees been given adequate attention. The main reason for this is that the studies have used the organizational level, not the individual level, as the unit of analysis. The organizational level studies on SSO design deal mostly with issues of how organizations can successfully implement an SSO, what the pitfalls are, and how to avoid them. Designing the actual work and the impact of work design on employees are covered only as side issues and receive little attention.

The second people-related issue in shared services is the need to build good relationships among the different shared services stakeholders. In their daily work, SSO employees are encouraged to build good work relationships with their client organizations. In order for them to do so, the SSO managers have to facilitate such activities and behavior. Managers need to provide enough information about the work and encourage their employees to interact with their touch points at the client organizations. They also need to provide opportunities for shared services employees to meet with one another. How much relationship building at the individual level is permitted or encouraged in an SSO and how this is divided among transactional and transformational employees is not clear in any studies that emphasize relationships in SSOs. Very little information is provided as to how individual employees maintain relationships in their work environment or how the 
need to maintain such relationships affects work outcomes. Whether SSO work allows individual employees to maintain relationships, the nature of these relationships, and how they affect job satisfaction, job performance and employee turnover raise questions that need to be addressed.

Finally, the shared services literature review indicates that shared services employees need to be service oriented to sustain current clients and attract more client organizations into their business model. Service orientation can be exercised at both organizational and individual levels (Homburg, Hoyer and Fassnacht, 2002). Service orientation at the individual level is associated with promoting individual traits such as good judgment, likeability, social skills and willingness to follow rules among employees (Hogan, Hogan and Busch, 1984). At the organizational level, businesses can achieve service orientation in two ways: by implementing organizational arrangements that encourage service orientation, and by articulating business strategies that promote service orientation (Homburg, Hoyer and Fassnacht, 2002). Lytel, Hom and Mokwa (1998) proposed that organizational level service orientation could be achieved through policies, practices and procedures. They demonstrated that service leadership, human resource management, service encounter practices and service system practices can increase organizational level service orientation. To achieve service orientation among employees, SSOs need to adopt practices that enhance service orientation. At the individual level they can begin by recruiting individuals who show good judgment and are likeable, socially skilled and willing to follow rules - all qualities that enhance service orientation in individuals. In addition, 
SSOs can build the practice of service orientation into individual work. For example, Lytel, Hom and Mokwa (1998) outline service failure prevention as a practice that can enhance service orientation in organizations. In an SSO work setting, work is connected through processes, and the failure of one individual process affects the entire system. In the area of service delivery, individual work has to be designed in such a way as to ensure that sufficient measures are in place to prevent service failure in the work unit; only then can an enterprise-wide service failure prevention procedure succeed. Thus far, the notion of service orientation has been briefly discussed in the shared services literature, but no in-depth study as to whether or how individual level service orientation can be implemented is available. Designing SSO jobs in such a way that service orientation is understood as part of the individual's work and how this would affect the work outcomes of SSO employees could be significant for the development of SSOs.

The above discussion on the existing SSO literature highlights the fact that job design in SSOs is an under-studied topic and requires further exploration. Firstly, the discussion establishes that there is a need to identify the job characteristics of transformational and transactional work and how these job characteristics affect shared services employee outcomes. This knowledge would allow SSO managers to understand how work can be balanced between the two groups of employees. An SSO can also find ways to increase job satisfaction among transactional employees, which have been reported to be low. Secondly, the literature review establishes that relationships with client organizations are important and managers need to 
encourage employees to maintain relationships through their actual work activities. Forging relationships needs to be part of individual work as well. Thirdly, service orientation has to be built into jobs in order to facilitate the exercise of service orientation at the individual level. These issues make it necessary to understand which job characteristics would allow SSO employees to perform their roles well while also enjoying a meaningful work experience. In the following section, we examine the work design literature in order to propose a job design model that would explain job design in the SSO.

\subsection{Work Design Literature}

One of the most popular approaches to work design is the motivational approach (Campion and Thayer, 1987). The motivational approach to job design emphasizes meaningful tasks for individuals, taking into consideration the human interaction aspect of the job. This work design approach assumes that when individuals are motivated at work, their personal involvement in the job increases, thereby enhancing their performance and job satisfaction (Campion and Thayer, 1987). In the motivational approach, the most popular job design model, the Job Characteristics Model, was proposed in 1975 by Hackman and Oldham. In the Job Characteristics Model, the job characteristics of skill variety, task identity, and task significance are linked to a psychological state of experiencing meaningfulness at work; autonomy is linked to a psychological state of feeling responsible in one's work; and feedback from the job has been connected to a psychological state of having knowledge of outcomes. The Job Characteristics Model suggests that these five job dimensions and the three associated psychological states lead to high motivation, high job satisfaction 
and low employee turnover. The Job Characteristics Model included one more component, growth need strength (GNS), which moderates employees' reaction to their work. Individuals experience different levels of personal accomplishment. Some are happy with present conditions at work, while others would like to advance themselves beyond their present conditions, and still others would like to advance themselves beyond their present level of attainment. The latter category are said to have strong "growth needs" and are predicted to develop high internal motivation when working on a complex, challenging job (Hackman and Oldham, 1975). On the basis of their model, Hackman and Oldham calculated the Motivational Potential Score $($ MPS $=[$ skill variety + task identity + task significance/3 $] *$ autonomy* feedback). Jobs that scored high on the MPS scale were linked to high motivation in individuals. Hackman and Oldham's model has been widely studied and is the central focus of the work design literature (Humphrey and Morgeson 2007). Despite the job characteristics model's popularity, however, its shortcomings have also been highlighted by many researchers. In their study, Johns, Xie and Fang (1992) found that the relationship between the job dimension and the individual's psychological state was not similar to that predicted by the Job Characteristics Model. Harvey, Billings and Nilan (1995) showed that the constructs predicted by the job characteristics model required confirmatory factor analysis to understand the factor structure of the model. Morgeson and Humphrey (2006) believe that the job characteristics model concentrates on a rather narrow set of characteristics, and also question the psychometric properties of the Job Diagnostic Survey that was used to measure the job characteristics. 
Following the Hackman and Oldham (1975) study, a number of other studies have empirically tested the job characteristics model, the job dimensions, the critical psychological states of the workers, and the work outcomes. In 1987, Fried and Ferris (1987) carried out a meta-analysis to validate the job characteristics model. This meta- analysis included 75 studies that were based on the job characteristics model, and provided some important findings on this model. Fried and Ferris (1987) found that more than one job dimension was important in the model, but there was not enough evidence to support the five-factor solution proposed by the model. Further, they found that the relationships between the job characteristics and psychological states were generally stronger than the relationships between job characteristics and behavioral outcomes, and that a simple index to identify complexity was a better predictor for outcomes than the multiplicative MPS index. Also, only two psychological states were found to be important as opposed to the original three (experienced meaningfulness and experienced responsibility were proposed as a single dimension). They also observed that job feedback was moderated not only by knowledge of results and psychological state, but by other factors as well, and the GNS did not have as much of a moderating role as suggested by Hackman and Oldham (1975).

After Hackman and Oldham (1976) proposed the job characteristics model, other researchers identified variables that can strengthen the predictions of the model. One such job characteristic was task interdependence. Kiggundu $(1981,1983)$ is credited 
with integrating task interdependence into the Hackman and Oldham (1986) model. In Kiggundu's study, task interdependence is viewed as initiated task interdependence and received task interdependence. According to Kiggundu (1983),

Initiated task interdependence can be defined as the extent to which work flows from one particular job to one or more other jobs such that the successful performance of the latter depends on the initiating job. Received interdependence on the other hand is the extent to which a person in a particular job is affected by the workflow from one or more other jobs. (1983, p. 147).

Both types of interdependence were studied through the dimensions of scope, resources, and criticality. Here, scope is related to the extent to which a job is connected with other jobs; resources refers to how much the interdependence is based on resources necessary to accomplish the task; and criticality is the extent to which other jobs are critical for the performance of the focal job. Kiggundu (1983) hypothesized that initiated task interdependence leads to experienced responsibility and can increase positive work outcomes. It was the opposite, however, for received task interdependence: when a job is affected by workflow from other jobs, the situation can lead to negative work outcomes. Data from a sample of 138 employees showed that initiated task interdependence (based on the two dimensions of resources and criticality) was significantly correlated with critical psychological states. Initiated task interdependence also correlated positively with the other three work outcomes: job satisfaction, growth satisfaction and reduced tendency to leave the job. Kiggundu (1983) concluded that when job task interdependence was based on resources critical to the accomplishment of the task, this provided a psychological state conducive to positive work outcomes. Received interdependence did not show the strong results 
that initiated interdependence did (under received interdependence, resources was positively related to psychological state).

In 1985, Campion and Thayer presented a comprehensive interdisciplinary work design framework. To formulate this framework, they first selected 700 job-design rules from the literature relating to organizational psychology, industrial engineering, human factors, and socio-technology. On the basis of their commonality, these rules were divided into 70 categories and a principle was derived from each category. These principles were then organized into four categories: the motivational, mechanistic, biological and perceptual-motor approaches to work design.

In Campion and Thayer's (1987) framework, a motivational approach to job design is required in an organization when it faces issues such as autonomy, intrinsic job feedback, extrinsic job feedback, social interaction, task/goal clarity, task variety, task identity, ability/skill-level requirements, ability/skill variety, task significance, growth/learning, promotion, achievement, participation, communication, pay adequacy, recognition and job security. A mechanistic approach to job design is considered to be ideal when an organization wants to achieve job specialization, specialization of tools and procedures, task simplification, single activity, repetition, spare time and automation (Campion and Thayer, 1987). The biological and perceptual approaches to work design are not mutually exclusive and often overlap. The factors that need to be considered in the biological approach to work design are level of muscular strength, capacity to lift weights, muscular endurance, seating, size 
differences, wrist movement, noise, climate, work breaks and shift work. The perceptual work design approach aims to reduce the mental strain endured by many workers in the hope that this will maintain an equilibrium between employee wellbeing and work load (Campion and Thayer 1985). Campion et al. (1985) emphasize that each of these approaches results in different outcomes, and an interdisciplinary framework is required to understand the work design theories. They hypothesised that the motivational approach would relate positively to satisfaction, the mechanistic approach would relate to efficiency, the biological approach to physical well-being, and the perceptual approach to reliability. To test these hypotheses, Campion et al. (1985) used a Multi-method Job Design Questionnaire (MJDQ) to collect data to validate their framework. The MJDQ had a 70-item scale which had constructs to measure all four approaches and their related outcomes. A field study with a sample of 121 jobs, 215 incumbents and 23 supervisors from five different organizations was performed. The results provided evidence to support all four hypotheses based on the four approaches. Subsequent to their original study, Campion and associates carried out several other studies (Campion, 1988; Campion \& McClelland, 1991, 1993) using the interdisciplinary framework.

In 2006, Morgeson and Humphrey developed and validated a measure for assessing job design and the nature of different kinds of work. They argued that more job characteristics need to be integrated into a job design model to understand the complexity of work-related issues. Their study proposed a work design questionnaire (WDQ) with motivational, social and work context characteristics. The motivational 
characteristics included the task characteristics (autonomy, task variety, task significance, task identity, feedback from jobs) and the knowledge characteristics (job complexity, information processing, problem solving, skill variety, specialization) of the work. In addition to the popular motivational characteristics, the authors categorized social characteristic factors (social support, interdependence, interaction outside the organization, feedback from others) that take into consideration the social circumstances of the work; and contextual characteristics (ergonomics, physical demands, work conditions and equipment use) that depict the context in which the work takes place. The work design questionnaire proposed by Morgeson and Humphrey (2006) was tested with a sample of 540 job incumbents holding 243 jobs, and showed high reliability.

In 2007, Humphrey, Nahrgang and Morgeson performed a meta-analysis on all the work design literature so far and presented a theoretically extended job design model. Their study included 259 other studies based on responses from 219,625 participants. It is one of the most recent and largest meta-analytical studies done on work design. The extended model tested in the meta-analysis included motivational, social and contextual job characteristics. In addition, the meta-analysis also tested the mediating factors in a whole range of job outcomes. 
Figure 1. Extended Work Design model: Humphrey, Nahrgang and Morgeson (2007, pg 1334)

\begin{tabular}{|l|}
\hline \multicolumn{1}{c|}{ Work Design Characteristics } \\
\hline Motivational Characteristics \\
Autonomy \\
- Work Scheduling Autonomy \\
- Work Methods Autonomy \\
- Decision-Making Autonomy \\
Skill Variety \\
Task Variety \\
Significance \\
Task Identity \\
Feedback from the Job \\
Information Processing \\
Job Complexity \\
Specialization \\
Problem Solving
\end{tabular}

\begin{tabular}{|l|}
\multicolumn{1}{|c|}{ Mediators } \\
\hline \multicolumn{1}{|c|}{ Critical Psychological States } \\
Experienced Meaningfulness \\
Experienced Responsibility \\
Knowledge of Results
\end{tabular}

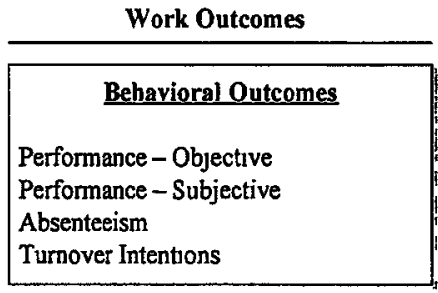

\begin{tabular}{|l|}
\multicolumn{1}{|c|}{ Attitudinal Outcomes } \\
Satisfaction - Job \\
Satisfaction - Supervisor \\
Satisfaction - Coworker \\
Satisfaction - Compensation \\
Satisfaction - Growth \\
Satisfaction - Promotion \\
Organizational Commitment \\
Job Involvement \\
Internal Work Motıvation
\end{tabular}

Interdependence

Social Characteristics

Feedback from Others

Social Support

Interaction Outside the Organization

Work Context Characteristic

Physical Demands

Work Conditions

Ergonomics

\begin{tabular}{l} 
Role Perception Outcomes \\
Role Ambiguity \\
Role Conflict \\
\hline
\end{tabular}

\begin{tabular}{|l|}
\multicolumn{1}{|c|}{ Well-Being Outcomes } \\
Anxiety \\
Stress \\
Burnout/exhaustion \\
Overload \\
\hline
\end{tabular}

The extended job design model includes motivational characteristics, social characteristics and work context characteristics. In the group of motivational characteristics, in addition to Hackman and Oldham's five job characteristics, the extended model includes task variety, information processing, job complexity, specialization and problem solving as factors. The social characteristics in the Humphrey et al (2007) model include factors such as interdependence, feedback from others, social support and interaction outside the organization. These social characteristics were associated with many positive job outcomes, and were found to more strongly influence employee turnover than motivational characteristics. The 
social characteristics also had a greater influence on individual organizational commitment than motivational characteristics. Further, motivational and social characteristics had an equal impact on other job outcomes such as supervisor satisfaction, coworker satisfaction, job involvement, role ambiguity and stress. Work context characteristics showed some impact on job satisfaction and had significant influence on stress levels. The extended job design model proposed by Humphrey et al (2007) studied the mediating role of the motivational characteristics in the outcomes of the three critical psychological factors proposed by Hackman and Oldham's (1980) model. Of the three psychological states, only experienced meaningfulness showed evidence of playing a mediating role between job characteristics and job outcomes.

Over the past 20 years, studies on work design have concentrated on identifying different job characteristics and have been carried out in different work settings. These studies provided the basis for Campion et al's (1985) interdisciplinary frame of job design, which describes four different approaches. When organizations want to enrich work in order to increase employee job satisfaction, the motivational approach is recommended. When the work context requires a standardized process, a motivational approach may not be suitable and a mechanized approach may be required. These different requirements of job design have led to diverse studies based on different employee samples. For example, from data collected from a small wastewater plant, Burr and Cordery (2001) studied how work control and skill utilization can enhance task motivation. Similarly, Nevala-Puranen, Pakarinen, and 
Louhevaara, (2003) performed an experiment to determine how work can be designed to reduce neck, shoulder and arm pain of news paper delivery employees. Hill (2006) focused on job design for employees at a U.S. welfare center.

A few studies have been done on how job design can be carried out for IS professionals. Gambill, Clark and Wilkes (2000) researched the nature of work design for IS professionals. The main objective of the research was to understand whether motivation was important for IS professionals and what task design variables were necessary for work design. Gambill et al. selected fourteen factors from equity theory, job characteristics theory, expectancy theory, and goal theory. The fourteen factors were task identity, goal specificity, participation, employee voice, feedback from job, feedback from goals, skill variety, goal difficulty, task significance, autonomy, procedural justice, distributive justice, physical dressings, and individual differences. A motivational design rating form using these factors was created and was administered to 30 organizations. Five IS professionals in each organization completed the questionnaire. First, the respondents were asked whether work motivation was important to them. The results showed that work motivation was considered important by IS professionals, and that factors such as task identity, employee input, feedback (including feedback from both jobs and goals), goal difficulty, autonomy, justice (both procedural and distributive), physical dressings (floor space, desk space, etc.) and individual differences correlated with motivation for IS professionals. The authors explained that task design factors such as goal specificity, skill variety, participation in goal setting and task significance did not 
correlate with motivation, perhaps because these factors may have been "watered down" in the statistical process or the participants did not know their true meaning.

While Gambill et al. (2000) studied what motivates IS professionals, Ang and Slaughter (2001) studied the differences in behavior, attitude and performance between contract IS workers and permanent IS workers. Ang and Slaughter (2001) believed that job design can play a significant role in improving contract employees' work attitudes, behavior and performance. To understand the differences in work attitudes, the authors hypothesized that IS contract workers experience lower levels of support and distributive justice and greater alienation in the workplace than their permanent counterparts. To test the behavioral differences, the authors hypothesized that the in-role and extra-role behavior of contract professionals would be lower than that of permanent professionals. Similarly, to understand the differences in performance between these two group of employees, the authors hypothesized that contract workers would show lower levels of loyalty, obedience, trustworthiness and performance than permanent employees. These hypotheses were tested using data collected from 15 contract IS professionals and 48 permanent employees working for a transportation company. The results for the attitude variable showed that the contract workers received greater organizational support than the permanent employees, and that distributive justice and alienation were equal for both types of employees. However, in the constructs that measured behavior and performance, permanent IS employees scored better than contract employees, and contracted IS workers scored poorly in behavior, having lower in-role and extra-role behavior 
scores. When it came to performance, the contract workers showed poor loyalty and scored lower in obedience and trust-worthiness compared to the permanent workers. To understand how job design could improve the findings, the authors carried out a second study, this time a qualitative one. Twelve interviews were conducted with permanent and contract workers on the five job characteristics given in the Hackman and Oldham job characteristics model. The interviews were carried out in three institutions, including the transportation agency where the initial study had been conducted. The qualitative results showed that the job designs for IS contract professionals were "narrow, limited, unchallenging, and lack[ed] autonomy" (Ang and Slaughter 2001, p. 344). From the qualitative data, it was found that IS contract workers do better if their jobs are designed to include job variety, job identity, significance, feedback and autonomy. The authors concluded that organizations need to enrich the design of their IS contract jobs if they expect better behavior, attitude and performance from contract employees.

Another concept that is emerging in organizational theory that is linked with better job outcomes is service orientation. Research has established that when individual work includes service orientation characteristics, this has led to better job outcomes for individuals in service organizations. Lytle, Hom, and Mokwa (1998) formulated four dimensions of service orientation, which they defined as service leadership (service leadership, service vision); service encounter (customer treatment, employee empowerment); service systems (service failure prevention and recovery, service technology, service standard communication); and human resource 
management (service training, service rewards). The scales used to measure these four dimensions are popularly called SERV*OR. The authors showed that when the four dimensions are present in an organization, the organization will become highly service oriented. Lytle et al.'s (1998) notion of service orientation was used by Saura, Contri, Taulet, and Velazquez (2005), who studied how customer orientation and service orientation impact job satisfaction in financial services. Customer orientation has been defined as "the set of beliefs that puts the customer's interest first, while not excluding those of all other stakeholders such as owners, managers, and employees, in order to develop a long-term profitable enterprise" (Deshpande, Farley, and Webster, 1999, p. 27). Using Lytle et al.'s (1998) four dimensions to measure service orientation, Saura et al. (2005) analyzed data from 72 employees in financial services and found that service orientation directly impacts job satisfaction in employees. The study also supported the hypothesis that service orientation plays a mediating role between customer orientation and job satisfaction. Gonzalez and Garazo (2006) studied the relationship between service orientation, job satisfaction and organizational citizenship behavior (OCB) among customer contact employees in hotel services. The researchers gathered data from 149 employees working in hotels and tested whether the four dimensions of SERV*OR-service leadership, human resource management, service systems practices, and service encounter practices-influence job satisfaction. The study also analyzed whether job satisfaction played a mediating role between the four dimensions and employee organizational commitment behavior (OCB). The study found that not all dimensions of service orientation influence job satisfaction in employees. Human 
resource management and service encounter practices significantly enhanced employee job satisfaction and also functioned in a mediating role in influencing OCB. In addition, service encounter practices also directly influenced employee OCB. On the other hand, service communication leadership did not influence job satisfaction in employees but remained influential by indirectly influencing employee OCB.

Yoon, Choi and Park (2007), using 292 questionnaires completed by the staff of a hospital, examined service orientation and its impact on employees satisfaction. The researchers used the four dimensions of service orientation (a total of 10 constructs as described above) defined by Lytle et al. (1998) to measure service orientation in this group. The study found that service orientation significantly influenced job satisfaction. Moreover, the confirmatory factor analysis found that service orientation factors (from the four dimensions of service orientation) such as service leadership, customer focus, employee empowerment, service reward, service training, service failure prevention and service standard communication enhanced job satisfaction in the hospital workers.

\subsection{Discussion of Work Design Literature}

The main use of meta-analysis is to synthesize the existing research on a topic and identify the primary emerging trends (Hunter and Schmidt, 2004). The metaanalyses performed by Fried and Ferris (1987) and Humphrey, Nahrgang and Morgeson (2007) are 20 years apart; however, both studies show the heavy influence of the job characteristics model on work design literature. Campion et al.'s 
(1985) distinct notion of different approaches to work design and realization of the necessity to balance the trade-offs among these approaches contributed significantly to the work design literature. It helped researchers not just to focus on the motivational approach, but also to propose other, wider sets of job characteristics that would improve efficiency at work for individuals. Humphrey, Nahrgang and Morgeson's (2007) extended work design model provides a wide range of job characteristics that lead to better job outcomes for individuals at work. Their model represents the most significant developments in the area of work design. Nevertheless, there are some caveats, and improvements are needed to further strengthen research on work design.

By including social and work context characteristics and testing them with a wide set of job outcomes, Humphrey, Nahrgang and Morgeson (2007) provided a new emphasis on job design. Morgeson and Humphrey (2006) reported that there are only a few studies on work design that focus on social characteristics and their impact on job outcomes. Moreover, in these studies, social characteristics have been studied as a single set of variables only, and not along with motivational and work context characteristics. Apart from Humphrey, Nahrgang and Morgeson's (2007) meta-analysis, there are no studies to show how motivational, social and work context characteristics are interrelated in terms of work outcomes. Therefore, empirically testing Humphrey, Nahrgang and Morgeson's (2007) extended model would bring a significant contribution to the field of job design. 
Social characteristics are particularly important when the work is coordinated outside the organizational boundaries. Work design has been studied in different work situations such as hospitals and small manufacturing plants; however, the data on what factors are important in motivating IS workers remain inconclusive. Gambill, Clark and Wikes (2000) found that work motivation was important to IS workers and identified eight factors that were associated with work motivation. Interestingly, Ang and Slaughter (2001) found that jobs designed with job variety, job identity, significance and autonomy can improve the performance of IS contract workers to the level of their permanent counterparts. These studies conclude only that job design is as important for IS professionals as it is for other employees in different occupations. Also, these studies are based solely on motivational factors and do not include social characteristics in their examination of impact on job outcomes for IS professionals.

Further, Morgeson and Humphrey (2006) and Humphrey, Nahrgang and Morgeson (2007) include work context characteristics that represent the performance context of the job. Ergonomics, physical demands, and work conditions were included as work context characteristics in Humphrey, Nahrgang and Morgeson's (2007) extended work design model. However, when we treat ergonomics, physical demands and work conditions as work context characteristics, we can also include other job characteristics that denote job performance contexts. For example, if an organization's main focus is on service excellence, then the organization needs to embrace service orientation at all levels, and this becomes a work context for its employees. Section 2.3.3 highlights the fact that the SSO organization needs to be a 
service oriented enterprise. Service orientation can be embraced through organizational polices, practices and procedures and by rewarding service-giving behavior (Lytle, Hom, and Mokwa (1998). We suggest that including service oriented characteristics in SSO job design will not only result in better organizational outcomes for SSOs, but research (Saura et al. 2005 ; Gonzalez and Garazo 2006 ; Yoon et al. 2007) has suggested that service orientation can contribute to better individual outcomes such as job satisfaction and organizational commitment.

Studies carried out by Saura et al. (2005), Gonzalez and Garazo (2006), and Yoon, Choi and Park (2007) established that service orientation can influence employee job satisfaction in service organizations. However, there is no work design literature that looks at service orientation as a job characteristic that enhances job outcomes, especially in organizations where service delivery is core. A work design model that includes service orientation as a work context characteristic is necessary to establish whether service orientation can function as a job characteristic that enhances job outcomes. Also, understanding how service orientation characteristics function along with motivational and social characteristics in improving employee job outcomes would contribute significantly to organizational theory knowledge.

In summary, this chapter first analyzed the existing literature on shared services and identified the issues that shared services employees face in their actual work activities. It was found that job design in shared services organizations is important 
but is an area that has not been well researched. Towards proposing a job design model for shared services employees, we examined the work design literature in the field of organizational theory. In particular, Humphrey, Nahrgang and Morgeson's (2007) extended work design model provides an invaluable aggregation of research on work design. The following chapter presents a conceptual framework for job design for shared services employees, specifically those working in IT shared services organization ( IT-SSO). 


\section{Chapter 3}

\section{Conceptual Framework for Job Design for IT Shared Services Organizations}

In the previous chapter, we analyzed the shared services literature to understand the work context in shared services organizations. The chapter also provided a synthesis of the literature on work design. In this chapter, we combine these two areas to propose a conceptual framework for a job design model for IT-SSO employees.

\subsection{Research Objective}

The overall research objective of this thesis is to present and test a conceptual framework for job design in an IT-SSO. We hypothesize that the elements of the framework when implemented can enrich work for IT-SSO employees.

\subsection{Research Questions}

The study will focus on four research questions:

1. What is the nature of work in an IT-SSO?

2. What job characteristics lead to better job outcomes for individuals working with an IT-SSO?

3. Do the type of skills used by individuals, and type of work in an IT-SSO relate to job outcomes?

In what follows, this thesis presents hypotheses based on motivational, social and service orientation job characteristics and job outcomes in the IT-SSO work context. In order to make it easier for the reader, the IT-SSO job design model is presented first, followed by the hypothesis development. 


\section{Figure 2. Conceptual Framework for Job Design for IT Shared Services}

\section{Organizations}

\begin{tabular}{|l|}
\hline Motivational \\
Characteristics \\
Autonomy \\
Skill variety \\
Task variety \\
Significance \\
Work satisfaction \\
Turnover intentions
\end{tabular}

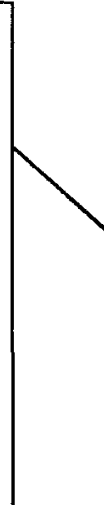

\begin{tabular}{|l|}
\hline$\frac{\text { Social }}{\text { Characteristics }}$ \\
Task interdependence \\
Feedback from others \\
Social support \\
Interaction outside the \\
organization
\end{tabular}

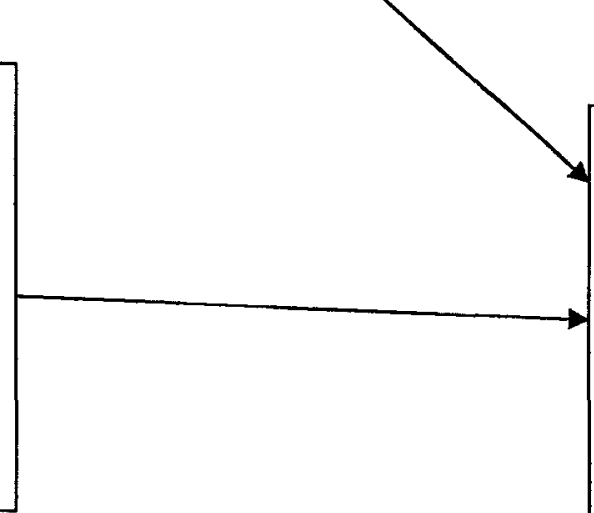

IT-SSO Job Outcomes Job performance

Work satisfaction

Service Orientation
Characteristics
Service technology
Service failure
prevention
Service failure recovery
Service standards
communication

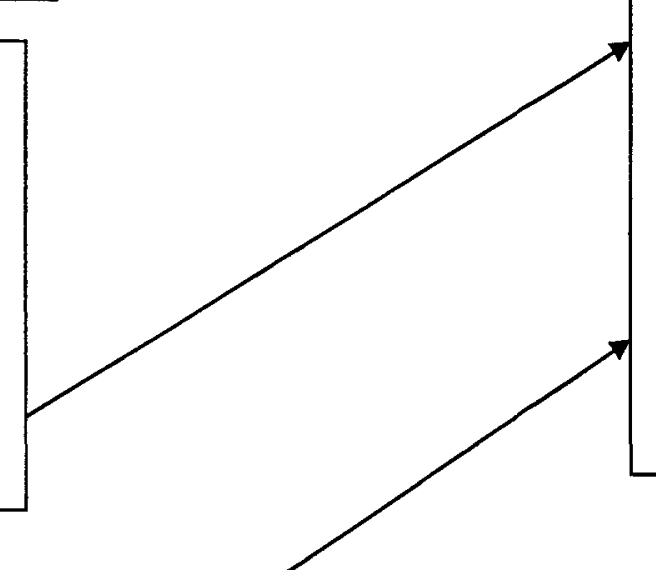

Turnover intentions

Occupation Variables
$\begin{aligned} & \text { Type of } \\ & \text { work }\end{aligned}$
Type of skills




\subsection{Motivational Characteristics}

The meta-analyses performed by Fried and Ferris (1987) and Humphrey, Nahrgang and Morgeson (2007) on job design confirm that motivational characteristics remain the fundamental job characteristics that enhance positive job outcomes at work. Autonomy, skill variety, task variety, significance, task identity, feedback from the job and information processing have been identified as job characteristics that enhance job outcomes for individuals. We will examine whether these motivational characteristics can be applied to the motivation of IT-SSO employees at work.

\subsubsection{Autonomy}

Autonomy can be defined as the freedom and independence the employee has in his or her job (Hackman and Oldham, 1976). The job characteristics model proposed that when individuals have a high level of autonomy in their jobs, they experience a psychological state where their jobs are very meaningful for them. This psychological state in individuals leads to internal work motivation, high quality performance and greater job satisfaction.

Hackman and Oldham (1976) used autonomy as a single variable. However, Breaugh (1985) divided autonomy into three different facets: work methods autonomy, work scheduling autonomy, and work criteria autonomy. Work methods autonomy denotes the extent to which the job incumbent has the freedom to choose the methods of carrying out his or her work. Work scheduling autonomy allows an individual to schedule, arrange and time work activities. Work criteria autonomy is the ability of employees to choose the criteria used to evaluate their job 
performance. Further, Karasek et al. (1998) refer to another form of autonomy, decision authority, which is basically the ability to make decisions about one's job. Karasek et al. (1998) developed a job content questionnaire scale that included decision latitude as one component. Within this decision latitude measure, decision authority was a sub-dimension. The study proposed three questions (allows own decisions, little freedom of decisions, a lot to say) to measure decision authority. This approach is very close to the single autonomy construct used by Hackman and Oldham (1975) and is quite well covered under work scheduling autonomy, work methods autonomy, and work criteria autonomy as proposed by Breaugh (1985).

In Fried and Ferris's (1987) meta-analysis, autonomy was a single variable and the results showed that, out of the five job characteristics, autonomy was most strongly related to growth satisfaction. However, Humphrey et al (2007) metaanalysis hypothesized that work scheduling autonomy, work methods autonomy, and decision making autonomy were positively related to positive behavioral and attitudinal outcomes, and negatively related to negative behavioral outcomes. Indeed, the Humphrey et al (2007) study found a strong correlation between these three variables. Though there were few studies in the job design literature that analyzed autonomy through these three dimensions, the Humphrey et al (2007) study showed partial support for the hypothesis. The study also showed that work scheduling autonomy did not interact with job satisfaction, whereas work methods and decision making autonomy had a stronger relationship to job satisfaction. In addition, out of all the job characteristics variables, autonomy (a combination of the 
three dimensions) correlated strongly with supervisor satisfaction, coworker satisfaction, and compensation satisfaction. The study also showed that autonomy was related to organizational commitment. On a negative note, the Humphrey et al (2007) study showed that autonomy was also related to anxiety and stress.

In an IT-SSO context, when the client organizations seek service delivery, they need to provide enough autonomy for the IT-SSO to deliver the required IT services. It is the same at the individual level of work. Redman et al. (2007) report two issues that can impact IT-SSO employee work autonomy and that require further investigation. The research reports that in an SSO work setting, individuals perform shared roles, and IT-SSO employees may perform shared roles with the client organizations. If the power balance in the relationship shifts to the client organization (and such incidents have occurred), the lack of autonomy at work can impact IT-SSO employee job outcomes. Humphrey, Nahrgang and Morgeson (2007), analyzing autonomy through work scheduling autonomy, work methods autonomy and decision-making autonomy, found that autonomy was one of the factors most highly correlated with job satisfaction. An IT-SSO employee may be required to provide services to many clients at the same time, and as a result, may have to queue the delivery of services to the different client organizations. To do this, an IT-SSO employee requires work scheduling autonomy. Similarly, the service provider has to offer services at a competitive cost and has to choose the appropriate methods for doing the various jobs, which requires work methods autonomy for the employees. In the course of service delivery, IT-SSO employees may have to make spontaneous 
decisions to balance the needs of many clients and to run the IT-SSO smoothly. This requires decision-making autonomy. Therefore, we hypothesize the following.

H1: For an IT-SSO worker, work scheduling autonomy, work methods autonomy, and decision making autonomy will positively relate to (a) job performance, and (b) job satisfaction, and (c) negatively relate to intention to leave.

\subsubsection{Skill Variety}

According to Hackman and Oldam (1976), skill variety, task identity, and task significance are job dimensions that make employees feel that their jobs are meaningful. Here, skill variety refers to the different skills that the job allows the job holder to use in performing the job. The Fried and Ferris (1987) meta-analysis revealed that among the job characteristics, skill variety had the strongest relationship to internal motivation. In the Humphrey, Nahrgang and Morgeson (2007) study, skill variety was positively related to job satisfaction, growth satisfaction, and internal work motivation. Skill variety also impacted on organizational commitment, but did not relate to turnover intentions.

Another notion somewhat akin to skill variety, which has been popular in work design literature, is skill utilization. Skill utilization can be defined as the opportunity to learn and apply skills (Morrision et al., 2000). Morrision et al. (2000) hold that job demand and job control (autonomy) lead to skill utilization. They proposed that when the job holder is given the freedom to make decisions on 
the job and has less control imposed as to how his or her work should be performed, the result can be the unrestricted application of skills by the employee. The authors found that high skill utilization influenced employees' sense of selfefficacy, provided opportunities to learn, and increased their knowledge, all of which provided employee job satisfaction. Further evidence for the relationship between skill utilization and job satisfaction was provided by the 1999 study of Morrison, Upton and Cordery (1999), which found that good supervisory behavior creates a climate for skill utilization, and this in turn leads to intrinsic satisfaction in individuals.

Recent studies on job design have indicated that when organizations exercise lean production practices, skill utilization is reduced and employee outcomes can be affected. Parker's (2003) study, based on data collected from 368 employees, found that lean teams reduced skill utilization, leading to negative employee outcomes. Similarly, Sprigg and Jackson (1996) found that two lean characteristics - dialog scripting and performance monitoring - led to less skill utilization and can result in job-related strain.

In the shared services context, Redman et al (2007) found that one of the greatest advantages for employees in this environment is that it allows individuals to use a variety of skills and gain a greater amount of work experience. When assigning responsibilities, IT-SSO managers need to analyze the degree to which a job facilitates the use of different skills and talents of each individual. Therefore we 
suggest that work design for shared service organizations needs to include skill variety.

H2: For an IT shared services worker, skill variety is positively related to (a) job performance, and (b) job satisfaction, and (c) negatively related to intention to leave.

\subsubsection{Task Identity}

Task identity describes how an employee identifies his or her job within the bigger picture of the workplace. In Fried and Ferris's (1987) study, task identity showed the strongest relationship with job performance. In the Humphrey, Nahrgang and Morgeson (2007) study, task identity related positively to internal work motivation and job performance, and negatively to absenteeism. Task identity was also related to supervisor satisfaction, compensation satisfaction, promotion satisfaction, and organizational commitment. On the negative side, Humphrey, Nahrgang and Morgeson (2007) revealed that task identity was related to role conflict and stress.

Apart from having an impact on work performance and job satisfaction, task identity has also been associated with organizational commitment. Steer(1977) studied how personal characteristics, job characteristics, and work experience impacted organizational commitment in 382 hospital employees and 119 scientists. The study found that task identity correlated significantly to organizational commitment. There was also a positive relationship between organizational commitment and desire to remain in the organization. Ogilvie (1986) explained how 
Human Resource Management (HRM) practices influence organizational commitment in employees. In this study, task identity, which was one of the variables representing HRM practices, had strong correlations with organizational commitment as well as with other variables such as merit accuracy.

In an IT-SSO work setting, employees perform IT services on behalf of client organizations. In this process, they may work on some tasks that constitute only part of the total IT services required by the client organization and may be joined by the client's in-house IT service staff to carry out certain tasks. In such circumstances, the IT-SSO employees may not be able to see the entire finished product, and thus they may not feel that they have contributed to the accomplishment of the whole task. This perception could impact negatively on their job outcomes. To feel responsible for their work, IT-SSO employees need to be able to easily identify their role in the IT service delivery process. Therefore, we suggest the following:

H3: For an IT shared services worker, task identity is positively related to (a) job performance and (b) job satisfaction and (c) negatively related to intention to leave.

\subsubsection{Task Significance}

Task significance describes a job where an individual's work is very influential, both inside and outside of the organization (Morgeson and Humphrey, 2006). Fried and Ferris's (1987) study showed that task significance was positively related to work 
outcomes. Humphrey, Nahrgang and Morgeson (2007) found that task significance was related to behavioral outcomes and positive attitudinal outcomes, and was negatively related to behavioral outcomes. They also found that task significance was related to supervisor satisfaction, compensation satisfaction, and promotion satisfaction, as well as to organizational commitment. In addition, the study found that task significance was related to work overload.

Out of all the motivational characteristics presented in the IT-SSO job design model, task significance can be rated to be the highest in the IT-SSO work setting. This is because IT-SSO employees are involved in the delivery of services to support the IT function of many member organizations. A brief interruption in service delivery can have a heavy impact across many member organizations. Thus, IT-SSO employees' work becomes very significant, and this significance can be related to positive job outcomes. Therefore, we propose that:

H4: For an IT shared services worker, task significance is positively related to (a) job performance and (b) job satisfaction and (c) negatively related to intention to leave.

\subsubsection{Task Variety}

Task variety refers to the many different tasks a job holder performs in his or her job (Morgeson and Humphrey, 2006). Hackman and Lawler (1971) suggest that the ideal situation is when the job presents the individual with a variety of tasks that can put to use the assortment of skills and talents the individual possesses. However, 
organizations need to strike a balance between skill variety and task variety. If the job presents a variety of tasks, and yet the job incumbent is not able to accomplish them because he or she lacks the necessary skills, negative work outcomes can result. Sims, Szilagyi and Keller (1976) developed a job characteristics inventory and studied its reliability and validity in two organizations. In this study, variety was defined as "the degree to which a job requires employees to perform a wide range of operations in their work and or the degree to which employees must use a variety of equipment and procedures in their work" (Sims et al, 1976, p.193). Variety was measured using questions such as "How much variety is there in your job?" and "How repetitive are your duties?" In Hackman and Oldham's (1985) job characteristics model, skill variety was defined to include both skill and task variety in jobs, and studies that followed the job characteristics model used skill variety to measure both task and skill variety in jobs. Fried and Ferris (1987) used skill variety in the analysis of their results. However, the Humphrey, Nahrgang and Morgeson (2007) study used both skill variety and task variety separately to analyze the outcomes. There were only a few studies that analyzed task variety, and the results showed partial support for the influence of task variety on a positive work outcome.

According to Redman et al. (2007), shared services managers report that because they deal with many client organizations on a daily basis, a high level of task variety is required in their jobs. The broad exposure allows them to enjoy a wide range of work experience, which can only be obtained by working with many different 
organizations. On the other hand, Reilly and William (2003) state that shared services employees who perform transactional work require job rotation because they lack task variety. When employees are required to perform dull and repetitive work, in the long run their job outcomes will be affected. There is some ambiguity as to whether all jobs in an IT-SSO include task variety. Through proper job design, IT-SSO management can provide task variety to all the workers and not just one group. Therefore, we hypothesize:

H5: For an IT shared services worker, task variety is positively related to (a) job performance, and (b) job satisfaction, and (c) negatively related to intention to leave.

\subsubsection{Feedback from the job}

The job characteristics model shows that, for the individual, receiving feedback gives rise to the critical psychological state of knowing the actual results of the work activities, and this in turn leads to positive work outcomes. Here, feedback is the degree to which individuals get clear information from the job about the effectiveness of their performance. In the Fried and Ferris (1987) study, two kinds of feedback -from the job itself and from others - were analyzed as a single variable. The results showed that job feedback had the strongest relationship to job satisfaction. In the Humphrey, Nahrgang and Morgeson (2007) study, feedback from the job and feedback from others, such as from coworkers and supervisors, were analyzed separately; feedback from the job was classified as a motivating characteristic, while feedback from others was related to social characteristics. The 
IT-SSO job design model also classifies feedback from others as a social characteristic. Humphrey, Nahrgang and Morgeson's (2007) meta-analysis of the job design literature found that feedback from the job was related to job satisfaction, growth satisfaction, and internal motivation. In addition, feedback from the job correlated significantly with promotion satisfaction, and also correlated well with organizational commitment. On the negative side, feedback from the job was related to role conflict and anxiety.

IT-SSO employees require feedback for the tasks they perform for client organizations. At times, when IT-SSO employees have completed an IT service delivery, they might have to wait for a response from the client organization for confirmation that the work has been accomplished. This should not be the case. When an IT-SSO employee delivers an IT service, feedback that the task is finished needs to come from the job itself. Constantly waiting for the client organization's approval of their task accomplishment can dampen the motivation of IT-SSO workers. Therefore, feedback from the job itself is important for positive job outcomes. Hence,

H6: For an IT shared services worker, feedback from the job is positively related to (a) job performance, and (b) job satisfaction, and (c) negatively related to intention to leave.

\subsubsection{Information Processing}

Humphrey, Nahrgang and Morgeson (2007) included information processing as an additional motivational factor. They defined it as the extent to which an individual 
has to focus and manage information related to work. Although there were only a few studies linking information processing to job outcomes, Humphrey et al.'s (2007) analysis showed that information processing was related to job satisfaction.

According to Tushman and Nadler (1978), "Information processing is gathering, interpreting and synthesis of information in the context of organizational decision making" (p. 614) Daft and Macintosh (1981) found that both information amount and equivocality of task information are related to task characteristics. Here, information amount is the quantity of data about organizational activities that is gathered and interpreted by organizational participants; and information equivocality is defined as the multiplicity of meanings conveyed by information about organizational activities. When information can mean only one thing, there is no equivocality; however, when information can be interpreted in many different ways, there can be equivocality. The Daft and Macintosh (1981) study found that when a work unit has task variety, individuals experience more information processing than when task variety is low. Also, when tasks are analyzable, there is no information equivocality, because when tasks are well analyzed, there is precise, clear information.

Daft and Lengel (1986) proposed ways that organizations can be designed to meet the information needs of technology, interdepartmental relations, and organizational environment. The authors hypothesized that the two forces of information processing - information uncertainty and equivocality - can produce four types of 
situations, and the organizational structure can be different depending on the type of situation the organization is facing. Firstly, there are situations where the information is high in equivocality and low in uncertainty. In these situations, managers encounter problems but are not able to locate their origin. They need to get together and start identifying the problems the information is indicating and establish common ground. In the second situation, the information has both high equivocality and high uncertainty. This kind of information provides individuals with very poor understanding of the situation and leads to many unsolved issues. Such situations require greater discussion between managers and employees. The opposite situation is one where information has both low equivocality and low uncertainty. The information provided is quite clear and the issues are well understood. Lastly, when the situation presents low equivocality and high uncertainty, managers face many problems but these are well-defined and allow individuals to seek the answers. Daft and Lengel (1986) conclude that organizations need to create organizational structures that can produce information that would reduce equivocality and uncertainty. They list seven structural mechanisms in a continuum, which organizations can design to provide information with less equivocality and less uncertainty.

Thomas and Trevino (1993) focus on the role of information processing in three types of inter-organizational relationships - federal, joint venture, and joint program. They found that how organizations manage information processing is a major determining factor in the success of strategic alliance building. The study 
found that uncertainty reduction and equivocality reduction are important elements in inter-organizational relationships. When strategic alliance organizations used lean information processing, such as written reports, this reduced uncertainty but did not reduce equivocality. To reduce equivocality, rich information processing mechanisms involving social interaction were required.

Both Daft and Lengel (1986) and Thomas and Trevino (1993), suggest that equivocality and uncertainty are two issues that need to be managed for effective organizational performance in special organizational formations, such as shared services. This study takes this line of reasoning one step further and state that the amount of information processing individuals handle impacts their job outcomes. When work involves transactions across organizational boundaries, as in the ITSSO, employees process large amounts of information in their day-to-day work routine. Through their interpersonal skills and by maintaining good interpersonal relationships, IT-SSO employees are in a position to acquire volumes of information regarding the functioning of the service delivery process. When IT-SSO services are delivered as preplanned shared services, employees have to exchange information about the progress of the service delivery. In times of trouble, putting the service delivery process back in order means that a lot of information has to be processed through many different channels at different organizational levels. When employees are able to reduce uncertainty and equivocality at work, they can perform better, which can lead to increased job satisfaction. However, if their daily work involves a lot of information uncertainty and equivocality, having to constantly seek 
large amounts of information to reduce the uncertainty and equivocality may be a daunting task. This situation can affect IT-SSO employee performance and job satisfaction. However, there are exceptions to this situation. For some IT employees, information equivocality in their jobs can be a challenge and overcoming challenge can make them feel more satisfied with their jobs. For such individuals, equivocality can function as a motivator. Nevertheless, the role of information equivocality as a contributor or non-contributor to individual outcomes in an IT-SSO setting needs to be empirically studied. Therefore we propose,

H7(a): For an IT shared services worker, information uncertainty in IT-SSO work is negatively related to (a) job performance and (b) job satisfaction, and (c) positively related to the intention to leave.

H7(b): For an IT shared services worker, information equivocality in IT-SSO work is negatively related to (a) job performance and (b) job satisfaction, and (c) positively related to the intention to leave.

Before we discuss the social characteristics of the IT-SSO job design model, it must be noted that Humphrey, Nahrgang and Morgeson's (2007) extended job design model listed job complexity, specialization and problem solving as motivational characteristics. Job complexity was not included in the IT-SSO job design framework because in the IT-SSO context, the proposed model is using a somewhat similar notion - types of jobs - as a control variable to analyze whether the job 
characteristics and job outcomes differ in relationship depending on the type of job. And although Humphrey, Nahrgang and Morgeson (2007) listed specialization and problem solving as motivational characteristics, they were not able to include them in the meta- analysis because there were very few studies that used them as job design variables. Because only a few studies include these job design variables, and in order to present a parsimonious IT-SSO job design model, this study will not include these variables.

\subsection{Social Characteristics}

Humphrey, Nahrgang and Morgeson (2007) identify interdependence, feedback from others, social support, and interaction outside the organization as social characteristics that affect work outcomes. In what follows, we discuss these social characteristics in the IT-SSO context and propose hypotheses.

\subsubsection{Task Interdependence}

Task interdependence is another job dimension that has been frequently studied as a motivational job design characteristic. Kiggundu $(1981,1983)$ is credited with integrating task interdependence into the Hackman and Oldham job characteristics model. In this study, task interdependence is viewed as initiated task interdependence and received task interdependence. Kiggundu (1983) hypothesized that initiated task interdependence leads to experienced responsibility and can increase positive work outcomes, but received task interdependence leads to the opposite result. When a job is affected by workflow from other jobs, negative work outcomes can result. Data from a sample of 138 employees showed that initiated 
task interdependence (based on the two dimensions of resources and criticality) was significantly correlated with critical psychological states. Initiated task interdependence also correlated positively with the other three work outcomes: job satisfaction, growth satisfaction and tendency to leave. On the basis of these results, Kiggundu (1983) concluded that when job task interdependence was based on providing resources, and if it was critical to the accomplishment of the task, it provided a psychological state conducive to positive work outcomes. Received interdependence, on the other hand, did not show similarly strong results (under received interdependence, resources was positively related to psychological state). After Kiggundu (1981) integrated task interdependence into job design, several other studies supported the notion. For example, Wong and Campion (1991) studied whether task interdependence, motivational task design, and task similarity predicted motivational work design. The study found that task interdependence did not significantly influence motivational job design. However, the study revealed the existence of an inverted $\mathrm{U}$ relationship with motivational values. Medium task interdependence in a job related to higher motivational values, and jobs with low or high task interdependence had lower motivational values. These findings lead to the conclusion that managers have to design work with the right amount of task interdependence; otherwise, the lower or higher level of task interdependence can negatively impact motivation in the job.

The meta-analysis performed by Humphrey, Nahrgang and Morgeson (2007) showed interdependence as related to job satisfaction, supervisor satisfaction, co- 
worker satisfaction, compensation satisfaction and promotion satisfaction. Interdependence was also related to organizational commitment, job involvement and internal work motivation. In an IT-SSO, work has to be interdependent with the client organizations. Client organizations may not have moved all of their IT services to an IT-SSO and may still have some in-house IT services. In this case, the IT-SSO and the client organization may depend on each other for total service delivery. At the individual level, the IT-SSO workers and in-house IT staff may have to interact or depend on each other in order to provide complete IT services to the client organization. Further, task interdependence for IT-SSO employees may also depend on how work is arranged within the IT-SSO. When an IT-SSO employee feels that his or her work needs to be finished in order for other staff to start their work, this is initiated task interdependence and, as Kiggundu (1983) suggested, can lead to enhanced work outcomes. Thus,

H8(a): For an IT shared services worker, initiated task interdependence is positively related to (a) job performance, and (b) job satisfaction, and (c) negatively related to the intention to leave.

In the same way, IT-SSO employees may have to wait for IT employees of a client organization to accomplish their internal IT tasks so that the IT-SSO employees can start work on the services that have been requested through the services agreement. Constant waiting for a client organization's IT staff to finish their IT tasks can dampen work outcomes for IT-SSO employees. Received task interdependence can 
increase when a breakdown in service delivery occurs. In these circumstances, ITSSO employees and the IT staff of the client organization may depend on each other for work accomplishment. Hence,

H8(b): For an IT shared services worker, received task interdependence is negatively related to (a) job performance, and (b) job satisfaction, and (c) positively related to the intention to leave.

\subsubsection{Feedback from Others}

Feedback from others refers to how much feedback the job holder would receive from others about his or her performance (Moregeson and Humphrey, 2006). In the Humphrey, Nahrgang and Morgeson (2007) study, feedback from others was related to supervisor satisfaction, co-worker satisfaction, compensation satisfaction, promotion satisfaction, work involvement and internal work motivation.

When IT-SSO employees perform work on behalf of many other client organizations, they need to receive feedback, not only from their jobs, but from others as well. According to Herbert and Seal (2009) "Tensions between the SSC and divisional directors is natural. It is part of a recursive process of feedback, adjustment and improvement. Without it, services would not be continually improved and could ultimately become misaligned with the business" (p. 47.) Feedback from others can come not only from the IT-SSO worker's colleagues, but also from peers, managers and contact persons from the many IT-SSO clients. Feedback from others can be either formal or informal. Formal feedback is received during meetings between the 
IT-SSO personnel and members of the client organizations. This feedback helps ITSSO employees assess how they are performing in their jobs. Likewise, IT-SSO employees may also get feedback on their performance through informal channels. For example, an IT-SSO employee who wants to know how he or she has performed a particular task could contact a colleague in another department. This kind of informal feedback can be more immediate than that received through formal channels. A timely phone call from a friend working at the partner organization to alert one to a possible problem can contribute significantly to the job outcomes of an IT-SSO employee.

H9: For an IT shared services worker, feedback from others about the job performed can be positively related to (a) job performance, and (b) job satisfaction, and (c) negatively related to the intention to leave.

\subsubsection{Social Support}

Social support is the amount of advice and assistance the job holder receives from peers and supervisors (Morgeson and Humphrey 2006). In Humphrey, Nahrgang and Morgeson's (2007) study, after autonomy, social support was most highly related to job satisfaction. It was also related to absenteeism, turnover intentions, supervisor satisfaction, co-worker satisfaction, promotion satisfaction, organizational commitment and internal work motivation.

In proposing a job characteristics inventory, Sims et al. (1976) included "friendship opportunity" as a variable to measure job outcomes. But in the final analysis, this 
variable did not appear and was not included in the job characteristics model. Karasek and Theorell (1979) proposed the Demand-Control-Support (DCS) model and suggested that the right balance needs to be achieved between job demands, job control, and support from co-workers and management. According to the DCS model, in jobs that are high demand with low control, employees may experience social isolation, leading to the highest levels of stress.

IT-SSO employee social supports come in the form of the relationships (discussed in section 2.3.2) they maintain with the client organizations in the course of service delivery. IT-SSOs deliver IT services to many client organizations, and this provides IT-SSO employees with the opportunity to develop close relationships with employees in other organizations. They encounter a lot of opportunities in their jobs to get to know many professionals from other organizations. The IT-SSO members and the client organizations meet regularly and discuss outcomes and the areas that need improvement. IT-SSO employees have opportunities to form lasting work relationships during these meetings, which contribute to feeling positive about their jobs. The IT-SSO employee receives support not only from his or her immediate supervisor, but also from many other individuals from the client organizations, who may take personal interest in how the work is been performed at the IT-SSO. These situations provide good social support for IT-SSO employees and can enrich their job outcomes. Therefore, we suggest that 
H10: For an IT shared services worker, social support available at work is positively related to (a) job performance, and (b) job satisfaction, and (c) negatively related to the intention to leave.

\subsubsection{Interaction Outside the Organization}

Morgeson and Humphrey (2006) were the first to include interaction outside the organization in the work design model. In their extended model, Humphrey, Nahrgang and Morgeson (2007) included interaction outside the organization as a social characteristic, and the meta-analysis related it to job satisfaction. The relationship between this variable and other outcomes such as performance and turnover were not indicated.

We include interaction outside the organization in the construction of the IT-SSO job design framework because of its relevance to the IT-SSO work setting. IT-SSO employees at different levels have regular contact with client organizations, and there are even opportunities for IT-SSO employees to be physically located at the client organizations to observe and record the delivery of services. IT-SSO employees can spend a great deal of time with people outside their organization to monitor whether the required IT services are delivered in accordance with service level agreements. Also, IT-SSO employees need to maintain regular communication with the IT staff of the client organizations. IT staff with good interpersonal skills are able to solve the political and interpersonal problems that can arise in IT-SSO projects (Nelson and Joshi, 1995). Engaging in interaction outside the SSO is a positive experience for ITSSO employees and increases positive job outcomes. Hence, 
H11: For an IT shared services worker, interaction outside the organization at work is positively related to (a) job performance, and (b) job satisfaction, and (c) is negatively related to the intention to leave.

\subsection{Service Orientation Characteristics}

Work context characteristics represent the broad performance context of a job and they influence job outcomes (Humphrey, Nahrgang and Morgeson, 2007). In a shared services setting, client organizations choose what types of services are to be delivered. The quality of these services and the terms of delivery are clearly set out in the service agreement, which is signed by the service provider and the client organizations. Maintaining service orientation is important to keep the client organization happy and to attract more customers to the IT-SSO. To succeed as a high quality service provider, organizations such as the IT-SSO need to cultivate service orientation at the organizational, group, and individual levels.

SERV*OR has been used to measure both organizational level service orientation and individual service orientation. At the individual level, researchers have used this measure to link service orientation with job outcomes. For example, out of the four dimensions of service orientation proposed by Lytle et al. (1998), it can be argued that service systems practices are very important for the IT-SSO to build a service-oriented organization. Service leadership, service encounter practices and human resource management skills are necessary for a service-oriented organization; however, the service system practices proposed by SERV*OR 
emphasize providing reliable and quality service to the customers and focus on issues such as how technology is used in the organization, service failure and its prevention, and how service communications to all service staff can help them become more service oriented. Ensuring reliable and quality service is the core of any IT-SSO; therefore, service system practices need to be exercised at both the organizational and individual levels. Here we set out to explain why this service dimension can impact job outcomes in an IT-SSO setting.

\subsubsection{Service Technology}

Service system practices in the SERV*OR include constructs such as service technology, service prevention, service failure recovery, and service standards communication. According to Lytle et al (1998), service technology is all about providing "state of the art" technology that enhances service capabilities. Client organizations seek the services of the IT-SSO because the IT-SSO can provide top quality IT services at a more affordable price than the client organizations can provide for themselves. Service technology has implications at the individual level as well. When employees have access to state-of-the-art service technologies, as opposed to basic technologies, they can more easily deliver quality IT services as set out in the service agreement. With basic technologies, IT-SSO employees may find it difficult to provide top quality services across many client organizations. In such situations, employees can feel frustrated and dissatisfied with their work. Implementation of appropriate technology has been reported as a perceived critical success factor for an SSO (Farndale, Paauwe and Hoeksema 2009). Moreover, when 
high-level technology is used to support the IT-SSO, it will be a source of pride for the IT-SSO employees. Therefore, we hypothesize that .

H12: For an IT shared services worker, service technology provided by an ITSSO is positively related to (a) job performance, (b) job satisfaction, and (c) negatively related to the intention to leave.

\subsubsection{Service Failure Prevention}

Service failure prevention means taking all necessary precautions to avoid a disruption of services (Lytle et al, 1998). Herbert and Seal (2009) report that SSOs need to have a management style that proactively diagnoses problems and designs solutions for problems the client organizations may not yet know they have. For ITSSOs, service failure prevention is critical; they need to provide IT services across many organizations with minimum service interruptions. Even a short interruption in services can affect the organizational operations of clients. When such interruptions occur, individuals from the client organizations will call the members of the service organization at different levels to get the services back up and running. IT-SSOs need to implement the best possible service failure prevention procedures. IT-SSO employees need to feel that their organization goes out of the way to prevent or avoid customer problems, rather than reacting to problems once they have occurred. When effective service failure prevention procedures are not in place, constant service interruptions can cause the IT-SSO employees to feel that they are not able to prevent customer problems, and listening to frequent customer complaints can create negative 
feelings towards the job itself. Therefore, we hypothesize that the IT-SSO's ability to prevent service interruptions can have an impact on job outcomes.

H13: Service failure prevention provided by an IT-SSO is positively related to (a) job performance and (b) job satisfaction, and (c) negatively related to the intention to leave.

\subsubsection{Service Failure Recovery}

No system is fault proof. This applies to the IT-SSO as well. When a database server maintained by the IT-SSO on behalf of a client organization suddenly goes down, data cannot be accessed by any of the client organizations. When such a temporary failure occurs, the IT-SSO needs to have a recovery plan that can minimize the damage the system failure might have caused. Service failure puts a lot of strain on IT-SSO employees. They have to fix the problem and get service up and running as soon as possible. Service guarantees are essential for the SSO, and the procedures the SSO follows in the event of a service delivery failure need to be reassuring. When a good service recovery program is in place to take effect during service interruption, IT-SSO employees need not worry about explaining the system failure and the recovery process to each and every individual who might call from the client organizations. When no effective service failure recovery plans are in place, IT-SSO employees may feel under pressure because they may not be able to handle customer complaints from various quarters. When service interruptions are frequent, and when IT-SSO employees constantly have to put up with such chaos, we hypothesize that this will negatively impact job outcomes. This leads to the following hypothesis: 
H14: For an IT shared services worker, service failure recovery provided by an IT-SSO is positively related to (a) job performance and (b) job satisfaction, and (c) negatively related to the intention to leave.

\subsubsection{Service Standard Communications}

Service standard communications are service standards or benchmarks which all the employees in a service organization need to understand to deliver quality service (Lytle et al., 1998) . To provide the best services, all member of an IT-SSO need to understand the service standards that are expected by the client organizations. When IT-SSO employees understand the service standards,, everyone who is working in the delivery of services is on the same page, which enables easy achievement of targets. Service standard communications also allow IT-SSO employees to recover swiftly from service failures. This is because employees can quickly find out communications where the breakdown has occurred and locate and repair it. Service standard communications also allow IT-SSO employees to distinguish a problem from an issue, for reporting purposes. Service documentation is important in the ITSSO setting because transparency has to be maintained by the SSO when serving many client organizations. In order to document the activities of an IT-SSO, service standard communication is critical. When service standards are not communicated well across the IT-SSO, workers may make incorrect service standard interpretations. Such misinterpretations of service standards can create ambiguity in service delivery, and can impact individual work outcomes. Therefore, we hypothesize: 
H15: For an IT shared services worker, service standards communications provided by an IT-SSO are positively related to (a) job performance, and (b) job satisfaction, and (c) negatively related to the intention to leave.

\subsection{Occupation Variables}

This study proposes the use of two occupation variables - the type of work performed by shared service employees, and the type of skills used in their occupation at ITSSO. How different types of work impact job outcomes in a shared services is not clear (Redman, 2007). Empirically studying their effect on job outcomes can highlight differences if there were any. The literature review in section 2.3.1 revealed that there are mainly three types of work in SSO. The first is related to transactional activities, the second is transformational, and the third is related to professional advisory and policy making. This study will analyze the relationship of these job types on job outcomes in IT-SSO.

The second occupation variable that is used in this research is the types of skills required to perform the different forms of work at an IT-SSO. Since the shared services program is for IT services, we differentiate the skills sets used by the shared service employees as IT and non IT skills. By using these two categories as occupation variable, this study will try to establish whether the different skills sets relate to job outcomes at an IT-SSO. This study examines sixteen variables and their relationships with three job outcomes, therefore to be parsimonious, only the direct relationship of these occupation variables are studied and not their moderating, mediating effects. 


\subsection{Outcome Variables}

In their extended work design model, Humphrey, Nahrgang and Morgeson (2007) present 19 work outcomes classified as behavioral, attitudinal, role perception, or well being. Researchers warn against including too many variables, since it goes against the principle of scientific parsimony (Stevens, 1996). Thus we select only job performance, job satisfaction and turnover intentions as the three job outcomes that will be studied. The main reasons for selecting these three job outcomes are outlined in the remainder of this chapter.

Firstly, job satisfaction is defined as an employee's affective reactions to a job, based on comparing actual outcomes with desired outcomes (Cranny, Smith \& Stone, 1992). There are more than 5000 articles on the topic of job satisfaction. (Spinelli and Canavos, 2000). It has been noted that at the organizational level, organizations with higher than average levels of job satisfaction outperform their competitors (Ostroff, 1992). Job satisfaction has been particularly studied with IS personnel and has been found to relate to IS personnel motivation (Igbaria and Guimaraes, 1993; Mak and Sockel, 1999 ; and Chen, 2008). When an IT-SSO wants to outperform other service providers, having employees who are satisfied with their jobs is very important. Thus, job satisfaction is included as an outcome variable in the IT-SSO job design model.

McCloy, Campbell, and Cudeck (1994) define job performance "as behaviors or actions that are relevant to the goals of the organization in question (p. 493). Job 
performance is one of the most common variables studied in organizational behavior and human resource management (Bommer, Johnson, Rich, Podaskoff and MacKenzie,1995). When IT-SSO members perform well in their individual jobs, the organizational performance can be improved by superior service delivery; therefore, we include job performance as an outcome variable.

Schaubroeck, Cotton and Jennings (1989) refer to turnover intentions as the activity of contemplating and planning to leave the organizations by individuals. Cotton and Tuttle (1986) report that since 1900 there have been hundreds of studies, both qualitative and quantitative, examining employee turnover. They carried out a metaanalysis, reviewing 120 sets of data, which revealed that 26 variables were related to employee turnover. Several shared services implementation studies have reported that the best people leave SSOs or move to different departments of the organization (Ulrich 2007, Bangemann, 2005). To maintain high levels of performance, IT-SSOs need to retain their knowledgeable and skilled staff as well as those who have built up good relationships with the client organizations.

In summary, this chapter explained the hypotheses related to job design in an ITSSO. It examined the different job characteristics and the control variables that make up the proposed IT-SSO job design model. The next chapter outlines the methodology that will be used to collect data to empirically test these hypotheses. 


\section{Chapter 4}

\section{Methodology}

This thesis uses mixed methodologies to empirically test the hypotheses presented in the job design model for IT-SSO members. This chapter begins with a brief explanation of why the mixed method approach was chosen and how the qualitative and quantitative data was integrated. Barriers that exist in using mixed methods in research are also addressed. This is followed by a discussion on the measurement items used to collect data for the motivation, social, service, job outcomes and occupation variables.

\section{1 The Mixed Method Approach}

The mixed method approach to data collection involves the use of both qualitative and quantitative methods to gather data to test the hypotheses of the research (Creswell, 2009). Drawing on various studies of mixed methods, Caraceli and Greene (1993) outlined five purposes of the mixed methods approach. The most popular purpose, triangulation, is used to establish convergence of results across different research methods. The second purpose is complementarity, where the results of one method are used to clarify and enhance the results of the other. The third is developmental, where first stage results, obtained through one method, are used in developing the second stage of the research, with the two methods generally employed sequentially. The fourth purpose is termed initiation: results obtained through one method are re-cast using a contrasting method. Here the main objective is 
to identify contradictions. Finally, mixed methods can be used for the purpose of expansion, where two methods are used to expand the breadth of the analysis; that is, one method is used to assess one part of the research and the other method is used to analyze another part. By using mixed methods to empirically examine the proposed IT-SSO job design model, this study hopes to achieve two of the five purposes outlined above. First, by using mixed methods, this study will triangulate the survey results with the results from the interviews to confirm or disconfirm the findings. Second, for the purpose of complementarity, the survey results will be enhanced, illustrated and clarified with the results from the interviews.

The main challenge in using mixed methods in research is determining how to integrate the data obtained through the quantitative and qualitative methods (Caracelli and Greene, 1993; Bazeley, 2009). Woolley (2009), in his definition of integration, states: "Quantitative and qualitative components can be considered 'integrated' to the extent that these components are explicitly related to each other within a single study and in such a way as to be mutually illuminating, thereby producing findings that are greater than the sum of the parts" (pg. 204). In this study, the quantitative results is presented first, followed by the qualitative results. The results of the two methods will then be discussed and merged to present a more wellrounded picture. Bryman (2007) stressed that several barriers can arise when using mixed methods. Understanding these barriers at the outset can help the researcher avoid them. The nature of the barriers is outlined in the following table. 
Table 2: Barriers of Mixed Methods

\begin{tabular}{|c|c|}
\hline Barriers & Description \\
\hline $\begin{array}{l}\text { Different } \\
\text { Audiences }\end{array}$ & $\begin{array}{l}\text { When the research is written for a specific audience, the } \\
\text { researcher tends to lean towards the preferences of that group. } \\
\text { For example, if the research is written for an audience that } \\
\text { focuses on qualitative research methods, the researcher may } \\
\text { tend to write more on the qualitative research findings and } \\
\text { neglect the results of the other method. }\end{array}$ \\
\hline $\begin{array}{l}\text { Structure of the } \\
\text { Research Project }\end{array}$ & $\begin{array}{l}\text { When using mixed methods in research, the researcher can } \\
\text { incorporate the results obtained from one method in the second } \\
\text { method. In such situations the first method may drive the focus } \\
\text { of the second. }\end{array}$ \\
\hline $\begin{array}{l}\text { Methodological } \\
\text { Preferences }\end{array}$ & $\begin{array}{l}\text { Researchers using mixed methods may have their own } \\
\text { methodological preferences. A researcher who prefers one } \\
\text { method over the other may emphasize the results obtained by } \\
\text { the preferred method. }\end{array}$ \\
\hline Role of Timelines & $\begin{array}{l}\text { When the mixed methods approach is used, the qualitative and } \\
\text { quantitative research needs to be performed within a short time } \\
\text { frame. When a long period of time elapses between the } \\
\text { completion of the two, there may be pressure to publish the } \\
\text { results of the first study only. }\end{array}$ \\
\hline Skill Specializ & $\begin{array}{l}\text { The researcher conducting mixed methods research may not } \\
\text { have the specialized skills required for using both the } \\
\text { qualitative and quantitative methods. }\end{array}$ \\
\hline Nature of the Data & $\begin{array}{l}\text { When using mixed methods, results from one method may be } \\
\text { "striking" and "interesting". If that is the case the researcher } \\
\text { may tend to give this method more prominence than the other } \\
\text { method(s). }\end{array}$ \\
\hline $\begin{array}{l}\text { Bridging } \\
\text { Ontological } \\
\text { Divides }\end{array}$ & $\begin{array}{l}\text { Epistemological and ontological issues may arise when it is } \\
\text { very difficult to merge the positivist views from the qualitative } \\
\text { study and the interpretive data that arise from the quantitative } \\
\text { study. }\end{array}$ \\
\hline Publication Issues & $\begin{array}{l}\text { The emphasis in some journals on publishing only qualitative } \\
\text { or quantitative research can become a barrier to integration in } \\
\text { mixed methods research. }\end{array}$ \\
\hline $\begin{array}{l}\text { Problem of } \\
\text { Exemplars }\end{array}$ & $\begin{array}{l}\text { There is no accepted "best practice" as to how integration } \\
\text { should be accomplished when mixed methods are used. }\end{array}$ \\
\hline
\end{tabular}

Adopted from Bryman, (2007)

In this research, the barriers of different audiences and methodical preferences will be minimized because the research does not specifically target either the quantitative or 
the qualitative research audience, but is used for analytic integration. Bridging ontological divides will also not be an issue because the survey questions and the corresponding interview questions are directed at the same variable. The quantitative research will identify the job characteristics that relate or do not relate to job outcomes, while the qualitative approach will provide the contextual explanations as to why the job characteristics are important or not important. The structure of the research projects and the timelines will not be a barrier because the quantitative and qualitative data collection will take place simultaneously. We do intend to publish this research; however, at this point no specific journal has been targeted. Therefore, publication issues will not affect the integration of the data sets.

Bryman (2007) states that when integrating the data from qualitative and quantitative research, the researcher must ask the question, "Has my understanding of my quantitative/qualitative findings been substantially enhanced by virtue of the fact that I also have qualitative/quantitative findings, and have I demonstrated that enrichment?" If the answer to this question is no, then there has been no integration of the research findings. Keeping this in mind, this research has integrated both data sets, forging connections between the qualitative and the quantitative data, and vice versa. By using a structured interview guide that mirrored the survey structure for each of the variables, it enabled the collection of qualitative data that related directly to the variable of interest. Caracelli and Greene (1993) outline four strategies that can be used in integrating qualitative and quantitative research findings. These are data transformation, typology development, extreme case analysis, and data 
consolidation/merging. Data transformation refers to the process whereby qualitative data is numerically coded and included in the quantitative data, or quantitative data are transformed into narratives and included in the qualitative data for pattern analysis. Typology means that the results from one methodology are used to create categories of data, and these categories are analyzed by the second research method. With extreme case analysis, one research method is used to establish results and the other method is used to further examine the findings. The main objective of this strategy is to test and refine the initial explanation of extreme cases. In data consolidation or merging, data from both qualitative and quantitative methods are merged into a single data set. This consolidated data base can be in either quantitative or qualitative form. This study uses this data consolidation or merging as the strategy to integrate the two data sets.

\subsection{Integrating the Quantitative and Qualitative Data Sets}

In describing the use of mixed methods, Creswell (2009) states that there are four aspects - timing, weighting, mixing and theorizing that need to be taken into consideration. The timing aspects involves the sequence of the methods used, while weighting refers to which method is given more priority in a research design. According to Creswell (2009), when mixing data, researchers should focus on the question of when and how the mixing of the two type of data occurs. The author describes connecting, integrating and embedding as mechanism of mixing two different types of data sets. The final aspect to be considered in the use of mixed methods, theorizing, pertains to the theoretical perspective guiding the whole research. 
In this study, the timing of the data collection was concurrent. While the IT-SSO job design questionnaire was sent to the survey participants, interviews were conducted with a random sample of those interview participants. When comparing the weight of the research methods, the primary way of collecting data was through the surveys, while the interviews were used to provide supportive contextual details. This thesis explores job characteristics in an IT -SSO shared setting by using work design theories, thus the theoretical focus originates from those job design theories. In merging the two data sets the approach taken is consistent with the integrating style where the finding from the quantitative data is integrated with the qualitative data. These four elements of mixed methods also reflects the "concurrent triangulation strategy' as described by Creswell (2009).

In the concurrent triangulation strategy, data is collected using both methods at the same time but often one method is given prominence. Findings from one method is "confirmed", "disconfirmed", "cross validated "or "corroborated" by the findings of the other method. (Creswell, 2009. pg. 213). Other researchers refer to this as "weaving together" findings of both approaches ( Scheremerhorn, Williams and Dickison, 1982). In this thesis, the findings from the quantitative and qualitative data were woven together to examine existing themes in work design, and also to identify emerging themes or patterns. For example, the IT-SSO job design model proposed in chapter three has motivational, social and service characteristics relating to three job outcomes. The quantitative analysis may indicate that particular items under the 
motivational constructs are significantly influential to the job outcomes. This finding will be then analyzed using the qualitative data to find the context as to why they are significant or non significant.

\subsection{Measurement Scales for Motivational and Social Characteristics}

The first part of the job characteristics survey for SSOs includes motivational characteristics such as autonomy, skill variety, task variety, task significance, task identity, feedback from the job, and others. The measurement scales for these characteristics are those designed by Morgeson and Humphrey (2006), who maintain that their scales are the most updated and validated versions available because they are based on 40 years of job design studies and rectify the limitations contained in previous studies, such as complex scales and negatively worded questions. Their new questionnaire showed high internal consistency reliability (which will be discussed shortly), provided a 21 -factor work design model with fewer inconsistent factor solutions, and used scales related independently to job-based databases rather than relying only on job incumbents' responses.

This research uses Morgeson and Humphrey's (2006) scales to measure social and motivational characteristics (except for information processing) for two reasons. Firstly, it uses the most popular measure for a particular independent variable and also updates the measures with new questions created by the authors. For example, task interdependence measures used by Kiggundu (1983) are used in Morgeson and Humphrey's (2006) measures along with another item created by them. Secondly, Morgeson and Humphrey's (2006) measures have not yet been tested in studies other 
than those done by them; using these measures in this research can provide further confirmation of their reliability. The measurement scales used are the five-point Likert scales because the majority of job design studies have used these scales (Campion and Thayer, 1985).

\subsubsection{Measures for Motivational Job Characteristics}

In the Morgeson and Humphrey (2006) study autonomy is measured through three dimensions: work scheduling autonomy, decision-making autonomy and work methods autonomy. To measure work scheduling autonomy, Morgeson and Humphrey (2006) created two items and combined them with another adapted from Campion and McClellan (1991). The internal consistency for work scheduling autonomy was .85 . Similarly, decision-making autonomy was measured by three items: one item from Idaszak and Drasgow (1987), another from Karasek et al. (1998), and the third created by Morgeson and Humphrey (2006). The internal validity for decision- making autonomy was .85 . Work methods autonomy was also assessed using three items: one item from Campion and McClellan (1991), one from Idaszak and Drasgow (1987), and the third from Morgeson and Humphrey (2006). The internal consistency for this variable was .88 .

Skill variety measures the variety of skills used by a job holder in his/her job. Four items were used to measure skill variety: one from Campion and McClellan (1991), another from Hackman and Oldham (1980), and two from Morgeson and Humphrey (2006). Skill variety showed an internal consistency of .86 . Task variety, which 
refers to the level of variety in a task, was measured using four items in Morgeson and Humphrey (2006), one of which was from Sims, Szilagyi \& Keller (1976) and the rest created by Morgeson and Humphrey (2006). The measures showed an internal consistency of 95 . Task significance was measured by Morgeson and Humphrey (2006) using four items, of which two were selected from Hackman and Oldham and the other two were original. The variable showed an internal consistency of .87 . Task identity was measured by Morgeson and Humphrey (2006) using four items, three of them from Hackman and Oldham (1980) and the fourth selected from Sims, Szilagyi and Keller (1976). The variable showed an internal consistency of .88. Feedback was measured by three questions, one from Hackman and Oldham and the other two from the Morgeson and Humphrey (2006). Internal consistency for job feedback was .86.

In the proposed job design model for an IT-SSO, information processing is measured through the information amount and information equivocality. The measurement used was adopted from Daft and Macintosh (1981). The information amount had four items with an internal reliability of .71 , and information equivocality had three items, with an internal reliability of .73 . As in other motivational measurements, a five point Likert scale was used as the response measure.

The following table presents the definitions of these variables, the sources of the measure, number of items used, the questions related to the variable in the survey (Appendix 1) and the reliability of the measure. 
Table 3: Scales for the Motivational Characteristics

\begin{tabular}{|c|c|c|c|c|}
\hline $\begin{array}{l}\text { Definition of the } \\
\text { Variable }\end{array}$ & $\begin{array}{l}\text { Source of the } \\
\text { Measure }\end{array}$ & $\begin{array}{l}\text { Number of } \\
\text { Items }\end{array}$ & $\begin{array}{l}\text { Questions in the } \\
\text { Survey }\end{array}$ & $\begin{array}{l}\text { Reliability of } \\
\text { the Measure }\end{array}$ \\
\hline $\begin{array}{l}\text { Autonomy } \\
\text { Work Scheduling } \\
\text { Autonomy } \\
\text { The amount of freedom } \\
\text { and independence an } \\
\text { individual has in terms } \\
\text { of scheduling his/her } \\
\text { work }\end{array}$ & $\begin{array}{l}\text { Morgeson \& } \\
\text { Humphrey (2006) }\end{array}$ & Three & B7, B3, B4 & .85 \\
\hline $\begin{array}{l}\text { Decision-making } \\
\text { Autonomy } \\
\text { The amount of freedom } \\
\text { and independence an } \\
\text { individual has in terms } \\
\text { of decision making in } \\
\text { his/her work }\end{array}$ & $\begin{array}{l}\text { Morgeson \& } \\
\text { Humphrey (2006) }\end{array}$ & Three & $\mathrm{B} 8, \mathrm{~B} 27, \mathrm{~B} 6$ & .85 \\
\hline $\begin{array}{l}\text { Work Methods } \\
\text { Autonomy } \\
\text { The amount of freedom } \\
\text { and independence an } \\
\text { individual has in terms } \\
\text { choosing work methods } \\
\text { in his or her work }\end{array}$ & $\begin{array}{l}\text { Morgeson \& } \\
\text { Humphrey (2006) }\end{array}$ & Three & $\mathrm{B} 1, \mathrm{~B} 13, \mathrm{~B} 9$ & .88 \\
\hline $\begin{array}{l}\text { Skill Variety } \\
\text { The variety of skills } \\
\text { required in a job }\end{array}$ & $\begin{array}{l}\text { Morgeson \& } \\
\text { Humphrey }(2006)\end{array}$ & Four & $\mathrm{B} 23, \mathrm{~B} 10, \mathrm{~B} 12, \mathrm{~B} 2$ & .86 \\
\hline $\begin{array}{l}\text { Task Variety } \\
\text { The different tasks in a } \\
\text { job }\end{array}$ & $\begin{array}{l}\text { Morgeson \& } \\
\text { Humphrey (2006) }\end{array}$ & Four & $\mathrm{B} 11, \mathrm{~B} 18, \mathrm{~B} 22, \mathrm{~B} 17$ & .95 \\
\hline $\begin{array}{l}\text { Task Significance } \\
\text { The level of influence a } \\
\text { job has within and } \\
\text { outside the organization }\end{array}$ & $\begin{array}{l}\text { Hackman \& } \\
\text { Oldham (1980) } \\
\text { Morgeson and } \\
\text { Humphrey (2006) } \\
\end{array}$ & Four & $\mathrm{B} 16, \mathrm{~B} 19, \mathrm{~B} 21, \mathrm{~B} 20$ & .87 \\
\hline
\end{tabular}


Table 3: Scales for the Motivational Characteristics (continuation)

\begin{tabular}{|c|c|c|c|c|}
\hline $\begin{array}{l}\text { Definition of the } \\
\text { Variable }\end{array}$ & $\begin{array}{l}\text { Source of the } \\
\text { measure }\end{array}$ & Number of Items & $\begin{array}{l}\text { Questions in the } \\
\text { survey }\end{array}$ & $\begin{array}{l}\text { Reliability of the } \\
\text { measure }\end{array}$ \\
\hline $\begin{array}{l}\text { Task Identity } \\
\text { Task identity reflects the } \\
\text { degree to which a job } \\
\text { involves a whole piece } \\
\text { of work. }\end{array}$ & $\begin{array}{l}\text { Morgeson and } \\
\text { Humphrey (2006) }\end{array}$ & Four & $\mathrm{B} 15, \mathrm{~B} 14, \mathrm{~B} 5, \mathrm{~B} 25$ & .88 \\
\hline $\begin{array}{l}\text { Feedback from the Job } \\
\text { The degree to which the } \\
\text { job itself provides the } \\
\text { job holder clear and } \\
\text { direct feedback about } \\
\text { the task performance. }\end{array}$ & $\begin{array}{l}\text { Morgeson and } \\
\text { Humphrey (2006) }\end{array}$ & Three & B26, B24, B28 & .86 \\
\hline $\begin{array}{l}\text { Information } \\
\text { Processing } \\
\text { Information Amount } \\
\text { The amount of } \\
\text { quantitative data about } \\
\text { organizational activities } \\
\text { that is gathered and } \\
\text { interpreted }\end{array}$ & $\begin{array}{l}\text { Daft and Macintosh } \\
\text { (1981) }\end{array}$ & Four & $\begin{array}{l}\text { B31, B30, B34, } \\
\text { B29 }\end{array}$ & .71 \\
\hline $\begin{array}{l}\text { Information } \\
\text { Equivocality } \\
\text { Multiplicity of meaning } \\
\text { conveyed by } \\
\text { information }\end{array}$ & $\begin{array}{l}\text { Daft and Macintosh } \\
\text { (1981) }\end{array}$ & Three & B35, B32, B33 & .73 \\
\hline
\end{tabular}

\subsubsection{Measures for Social Job Characteristics}

Social support, task interdependence, interaction outside the organization, and feedback from others make up the social characteristics of the job design survey for IT-SSO employees. Social support was measured by the scales provided by Morgeson and Humphrey (2006). These scales measured friendships and opportunities to meet other in job. Social support was measured by the scale used by Lim (1996) which combined supervisor and co-workers support subscales into a 
single measure of work based support. In this study, the internal consistency for social support variable was .80 . Task Interdependence, which measures the level of initiated and received task interdependence was measured by initiated interdependence and received interdependence; initiated interdependence was measured by two items from Kiggundu's (1983) study along with one from Morgeson and Humphrey (2006). The three items used to measure received interdependence come entirely from Kiggundu (1983). Initiated interdependence and received interdependence have an internal consistency of .80 and .84 respectively. Morgeson and Humphrey (2006) created four items to measure Interaction outside the Organization; the variable showed an internal consistence of .91. The feedback from others variable was measured by three items, one from Sims, Szilagyi and Keller (1976), one from Campion and McClellan (1993), and the third created by Morgeson and Humphrey (2006). This variable showed an internal consistency of .88 . 
Table 4: Scales for the Social Characteristics

\begin{tabular}{|c|c|c|c|c|}
\hline $\begin{array}{l}\text { Definition of the } \\
\text { Variable }\end{array}$ & $\begin{array}{l}\text { Source of the } \\
\text { Measure }\end{array}$ & $\begin{array}{l}\text { Number of } \\
\text { Items }\end{array}$ & $\begin{array}{l}\text { Questions in the } \\
\text { Survey }\end{array}$ & $\begin{array}{l}\text { Reliability of } \\
\text { the Measure }\end{array}$ \\
\hline $\begin{array}{l}\text { Task Interdependence } \\
\text { Initiated Interdependence } \\
\text { Focal job affects other } \\
\text { jobs }\end{array}$ & $\begin{array}{l}\text { Morgeson \& } \\
\text { Humphrey (2006) }\end{array}$ & Three & $\mathrm{C} 6, \mathrm{C} 13, \mathrm{C} 7$ & .80 \\
\hline $\begin{array}{l}\text { Received } \\
\text { Interdependence } \\
\text { Other jobs affect the } \\
\text { focal job }\end{array}$ & $\begin{array}{l}\text { Morgeson \& } \\
\text { Humphrey (2006) }\end{array}$ & Three & $\mathrm{C} 12, \mathrm{C} 5, \mathrm{C} 9$ & .84 \\
\hline $\begin{array}{l}\text { Feedback from Others } \\
\text { The degree of feedback a } \\
\text { job holder receives about } \\
\text { task performance from } \\
\text { others in the organization } \\
\text { (e.g. co-workers and } \\
\text { supervisors) }\end{array}$ & $\begin{array}{l}\text { Morgeson \& } \\
\text { Humphrey (2006) }\end{array}$ & Three & $\mathrm{C} 3, \mathrm{C} 1, \mathrm{C} 2$ & .88 \\
\hline $\begin{array}{l}\text { Social Support } \\
\text { The amount of advice } \\
\text { and assistance the job } \\
\text { holder gets from peers } \\
\text { and supervisors }\end{array}$ & $\operatorname{Lim}(1996)$ & Eight & $\mathrm{C} 14-\mathrm{C} 21$ & .80 \\
\hline $\begin{array}{l}\text { Interaction outside the } \\
\text { Organization } \\
\text { The amount of } \\
\text { interaction outside the } \\
\text { organization }\end{array}$ & $\begin{array}{l}\text { Morgeson \& } \\
\text { Humphrey (2006) }\end{array}$ & Four & $\begin{array}{l}\mathrm{C} 8, \mathrm{C} 4, \mathrm{C} 11, \\
\mathrm{C} 10\end{array}$ & .91 \\
\hline
\end{tabular}

\subsection{Measurement Scales for Service Orientation Characteristics}

Measurements for service orientation are selected from the SERV*OR measurements from Lytle et al. (1998). As explained previously, only the constructs of service systems practices were selected to make up the service orientation characteristics for the IT-SSO service questionnaire. Service technology and service failure prevention were measured by three items each; service failure recovery and service standard communication were measured by four and five items respectively. Lytle et al. (1998) carried out a large-scale construct validity process in three organizations in 
two different service sectors. Although the Lytle et al. (1998) study does not provide individual internal validity scores for the items in the service system practices, SERV*OR has undergone rigorous methodological processing to make the instrument reliable. The scale has proven to be robust through multiple rounds of pre-testing and testing in different organizations and multiple industries. Its reliability has also been confirmed in many studies that measure service orientation (Lynn et al. 2000, Harris \& Ogbonna, 2005) and studies that focus on service orientation and job satisfaction (Saura et al. 2005).

Table 5: Scales for the Service Orientation Characteristics

\begin{tabular}{|l|l|l|l|}
\hline Definition of the Variable & $\begin{array}{l}\text { Source of the } \\
\text { measure }\end{array}$ & $\begin{array}{l}\text { Number of } \\
\text { Items }\end{array}$ & $\begin{array}{l}\text { Questions in the } \\
\text { survey }\end{array}$ \\
\hline $\begin{array}{l}\text { Service Technology } \\
\text { technolof- the-art }\end{array}$ & Lytle et al. (1998) & Three & D5, D3, D7 \\
\hline $\begin{array}{l}\text { Service Failure Prevention } \\
\text { Precautions to avoid disruption of } \\
\text { services }\end{array}$ & Lytle et al. (1998) & Three & D4, D1, D6 \\
\hline $\begin{array}{l}\text { Service Failure Recovery } \\
\text { Procedures in place to recover from } \\
\text { disruption of services }\end{array}$ & Lytle et al. (1998) & Four & D2, D15, D9, D14 \\
\hline $\begin{array}{l}\text { Service Standards Communication } \\
\text { Benchmarks of services delivery }\end{array}$ & Lytle et al. (1998) & Five & $\begin{array}{l}\text { D11, D8, D13, D10, } \\
\text { D12 }\end{array}$ \\
\hline
\end{tabular}

In addition to questions on motivation, social and service characteristics, the questionnaire will have a single question to ask the survey participant's opinion about what job characteristics are very important for the nature of work at an IT-SSO. Respondents will write their answer on the survey, and the answers will be analyzed to understand whether any unique job characteristics are emerging that are specific to IT-SSO employees. 


\subsection{Measurements for Occupation Variables}

As discussed in the previous chapter the job design survey for IT-SSO workers has two occupation variables: the types of work at IT-SSO and the type of skills used by individuals in their job occupation. The majority of the SSO literature (Redman et al., 2007; Bergeron, 2003; Reilly and William, 2003) divides IT-SSO work into three areas: transactional, transformational and professional advisory. Researchers (Bergeron, 2003; and Quinn et al. 2000) refer transactional IT work as data center operations, network services, maintenance, help desk and data support. Transformational work are generally focuses on application development, application architecture, software/hardware installations, telecommunication strategy and training. On the other hand professional advisory and policy making deals with enterprise-wide standards support for software/hardware, corporate purchasing policy, IT strategy, and infrastructure investment strategy. In the IT-SSO job design questionnaire respondents had to indicate the type of IT work they perform for more than $80 \%$ of their time.

The second occupation variable in the survey is the type of skills used by IT-SSO employees at their current work at the IT-SSO. Since the focus of the study is on an IT shared service the skills used were classified as IT and non- IT skills. The national survey on information technology occupations (2002) performed by Statistics Canada named twenty five occupations with IT specific skills. The IT-SSO job design questionnaire listed the twenty five occupations and added a twenty sixth occupation of "others" to indicate non IT- skilled jobs. When completing the questionnaire those 
respondents who performed jobs that used mostly IT skills marked one of the IT occupation among the twenty five occupations, while those who held non - IT job marked "others". In the IT-SSO job design questionnaire, data pertaining to these two control variables is gathered from the question number (b) and (d) in work information section of the survey (see Appendix one.)

\subsection{Measurements for Outcome Variables}

\subsubsection{Job Satisfaction}

Job satisfaction can be measured as global job satisfaction, which measures overall satisfaction with the job without reference to any specific factor; or it can be determined by measuring several aspects of the job such as pay, supervision, promotion, co-workers, and the job itself, from which an average can be calculated to give an overall job satisfaction measure (Fields, 2002). According to Morgeson and Humphrey (2006), most job characteristics studies use a global job satisfaction measure to assess job satisfaction. Maintaining this approach, the IT-SSO job characteristics survey also uses a global job satisfaction measure, which was originally developed by Quinn and Shepard (1974) and was modified by Pond and Geyer (1991). This measure was chosen because its six items had a good internal validity of .89 , and the questions were more focused on the different facets of the job. 


\subsubsection{Job Performance}

Job performance reviews can be performed by a subordinate, supervisor, peer, and by self-rating. We use self-evaluation to measure the job performance of the IT-SSO employees. Self-rating of job performance has received wide attention from researchers. Heike, Heidemeier and Moser (2009), Harris and Schaubroeck (1988), and Conway and Huffcute (1997) found that self-ratings are higher than supervisors' ratings. At the same time, some studies (e.g., Mabe \& West, 1982; Wexley \& Klimoski, 1984) show that self-rating can be a good development tool. Selfevaluation of job performance was chosen because a random sample was used to administer the questionnaires at various IT-SSO sites, and therefore tracing the supervisors of those chosen and administering a matching supervisor-performance rating could be challenging. Also, using a supervisor rating scale would breach the confidentiality assurance given to the survey participants.

The self-evaluation job rating scale that we proposed comes from a study done by Welbourne, Johnson and Erez (1998). The main reason for choosing this selfevaluation tool is that it measures many dimensions of the job and provides a wider understanding of how the job-holder feels about the different aspects of his/her ITSSO job. Welbourne et al. (1998) propose a role-based performance scale (RBPS) for measuring job performance. The researchers argue that most performance measurements assume that job holders fill only a single role in an organization, and therefore do not cover all the work behaviors that are closely related to the job itself. Welbourne et al. (1998) provide a performance measure based on identity theory and 
role theory to assess five roles (organization, job, career, team, and innovator) that an employee takes on in an organization. In the RBPS, role performance in the organization refers to how well a job holder performs for the firm's advancement; job role performance relates to how well the job holder performs in relation to his or her job description; and career performance focuses on how well a job holder does in obtaining the necessary skills to progress through the organization. The innovator role performance measure indicates to what extent the job holder is creative on the job and for the organization as a whole, whereas team role performance focuses on understanding how well the individual performs as part of a team. In the RBPS, the organization role performance measure includes three questions, and career, team, job and innovator role measures have four questions each. Welbourne et al. (1998) provide coefficient alphas to validate their scales: the job performance measure showed .75 reliability; the innovator was .90 ; career role was .90 ; team performance was .87 ; and organization was .84 .

\subsubsection{Turnover Intentions}

Turnover intentions are measured with two items used by Schaubroeck, Cotton and Jennings (1989) in their study of the effects of stress on work outcomes, such as job tension, job satisfaction and turnover intentions. The turnover intentions were measured by two items: contemplating and planning to leave the organization. Schaubroeck et al. (1989) report a reliability coefficient of .70. This measure has acceptable psychometric properties; it was used by Clugston (2000) to measure the mediating effects of affective, continuance and normative commitment on job 
satisfaction and intention to leave. The Clugston (2000) study showed a reliability of .89 for these scales.

Table 6: Measures for Outcome Variables

\begin{tabular}{|l|l|l|l|l|}
\hline $\begin{array}{l}\text { Definition of the } \\
\text { Variable }\end{array}$ & $\begin{array}{l}\text { Source of the } \\
\text { Measure } \\
\text { Items }\end{array}$ & $\begin{array}{l}\text { Questions in the } \\
\text { Survey }\end{array}$ & $\begin{array}{l}\text { Reliability of } \\
\text { the Measure }\end{array}$ \\
\hline $\begin{array}{l}\text { Job satisfaction } \\
\text { job }\end{array}$ & $\begin{array}{l}\text { Pond and Geyer } \\
(1991)\end{array}$ & Six & E1 - E6 & .89 \\
\hline $\begin{array}{l}\text { Job performance } \\
\text { Behavior and actions } \\
\text { that are furthering } \\
\text { organizational goals }\end{array}$ & $\begin{array}{l}\text { Welbourne, Johnson } \\
\text { \& Erez (1998) }\end{array}$ & Nineteen & & \\
\hline $\begin{array}{l}\text { Job } \\
\text { Career }\end{array}$ & Four & E26, E21, E10, & .75 \\
\hline $\begin{array}{l}\text { Innovator } \\
\text { Team }\end{array}$ & F15 & E11, E23,E13, E8 & .90 \\
\hline $\begin{array}{l}\text { Contemplating and } \\
\text { orgation }\end{array}$ & $\begin{array}{l}\text { Schaubroeck et al. } \\
(1989)\end{array}$ & Two & E27, E28 & .70 \\
\hline Organization & Four & E24, E12,E14, & .87 \\
\hline Turnover intentions & E22 & E20, E19, E17,E7 & .84 \\
\hline
\end{tabular}

\subsection{Questions on the Interview Schedule}

Qualitative data are words rather than numbers; they provide rich contextual description (Miles \& Huberman, 1994). In addition to the data collected through the questionnaire, to understand further the motivational, social and service orientation 
characteristics of jobs in the IT-SSO context, 15 face-to-face interviews with individuals working at an IT-SSO organization were conducted . An interview schedule (attached in Appendix 2) was developed and was used for data collection. Like the IT-SSO job design questionnaire, the interview schedule begins with questions relating to personal (individual's age and gender) and work information. Questions in the latter category ask what IT shared services are provided by the ITSSO, how many years the interviewee has worked in an IT-SS organization, the nature of the work the individual performs, and his or her job title. Part two of the interview schedule concerns motivational characteristics, part three covers social characteristics, and part four deals with service orientation characteristics. Part five of the interview schedule asks questions related to job outcomes. The following table presents the constructs and their corresponding question numbers in the interview schedule.

Table 7: Motivation Characteristics Question for the Interview

\begin{tabular}{|l|l|}
\hline Motivational Construct & Questions in the Interview Schedule \\
\hline Work Scheduling Autonomy & Part Two-1 \\
\hline Decision-making Autonomy & Part Two - 1 \\
\hline Work Methods Autonomy & Part Two-1 \\
\hline Skill Variety & Part Two - \\
\hline Task Variety & Part Two-3 \\
\hline Task Significance & Part Two -4 \\
\hline Task Identity & Part Two -5 \\
\hline Feedback from the Job & Part Two -6 \\
\hline $\begin{array}{l}\text { Information Processing } \\
\text { Information Amount/Information Equivocality }\end{array}$ & Part Two - 7,8 \\
\hline
\end{tabular}


Table 8: Social Characteristics Questions for the Interviews

\begin{tabular}{|l|l|}
\hline Social Characteristics & Questions in the Interview Schedule \\
\hline $\begin{array}{l}\text { Task Interdependence } \\
\text { Initiated Interdependence } \\
\text { Received Interdependence }\end{array}$ & Part Three -1 \\
\hline Feedback from Others & \\
\hline Social Support & Part Three -2 \\
\hline Interaction Outside Organization & Part Three -3 \\
\hline
\end{tabular}

Table 9: Services Orientation Characteristics Questions for the Interview

\begin{tabular}{|l|l|}
\hline Service Orientation Characteristics & Questions in the Interview Schedule \\
\hline Service Technology & Part Four - 1 \\
\hline Service Failure Prevention & Part Four - 2 \\
\hline Service Failure Recovery & Part Four - 3 \\
\hline Service Standards Communication & Part Four -4 \\
\hline
\end{tabular}

Table 10: Job Outcomes Questions for the Interview

\begin{tabular}{|l|l|}
\hline Job Outcomes & Questions in the Interview Schedule \\
\hline Job Satisfaction & Part Five $-1-2$ \\
\hline Job Performance & Part Five $-3-7$ \\
\hline Turnover Intentions & Part Five -8 \\
\hline
\end{tabular}

At the conclusion of the interview, each interviewee was asked a general open-ended question inviting their opinion about what characteristics are very important for the nature of the work at an IT-SSO. The responses allowed the study to gather 
information about whether any unique job characteristics are emerging that are specific for IT-SSO employees.

In the next two chapters the thesis presents a detailed description of the quantitative and qualitative data analysis. 


\section{Chapter 5}

\section{Quantitative Analysis}

This chapter presents the results of the quantitative data that was collected through the IT-SSO questionnaire. It consists of five sections. The first section presents a description of the sample. The second section presents the responses from the descriptive questions of the IT-SSO survey. Section three covers the factor analysis results on items measuring motivational, social, service and job outcome variables. In the fourth section, the reliability and validity of these items are examined. The chapter concludes with hierarchical multiple regression analysis where the relationships between the constructs in the IT-SSO model is examined.

\subsection{Sample}

Information Technology Service Branch (ITSB) of the Public Works and Government Services (PWGSC) moved into Information Technology Services (ITS) in the year 2005. Since then ITS has achieved many advancements - and, although it will take time to implement a full Government of Canada wide IT shared services, ITS aims to achieve cost saving of $15-25 \%$ percent for the Canadian government (ITS Factsheet, 2009). By implementing 'daylight saving time', ITS has introduced more than 500 changes across many infrastructure components without a problem. Further, through consolidation in mobile wireless products and services, the Government of Canada has achieved approximately a 50\% saving in these core IT costs. ITS also has introduced information management tools such as Records, Document and Information Management System (RDIMS) and a Content Management System 
(CMS) to assists many government departments and agents. (ITS Fact sheet, 2009). It is important to note that ITSB refers to its IT shared services as ITS, as oppose to IT-SSO which is used often in shared services literature. Thus, whenever ITS is used in the study it refers specifically to the site where the study was undertaken and ITSSO is the general IT shared services.

In May of 2010, there were 1190 employees working within ITS. These employees were distributed across seven units including the office of the CEO/COO, Service Transition \& Major Projects (STAMP), Enterprise Partnership Management (EPM), Product Management (PM), Business Planning and Management Services (BPMS), Office of the Chief Technology Officer (OCTO) and Service Management \& Delivery ( SMD). The executive management of the IT- SSO gave permission only to administer the survey to a group of 200 employees in order to avoid additional lengthy approval from multiple stakeholders of ITSB that is necessary if the survey was to be administered to the entire population of the organization. In order to obtain an equal representation from all seven units, a stratified random sampling method was adopted. In stratified random sampling, strata are created representing the proportion of the total population; then random sampling is used to select the participants from each strata ( Bryman and Bell, 2003). The following tables show the number of individuals employed in the seven units of the ITS and the number of respondents that had to be randomly selected for the survey. 
Table 11: Stratified Sampling of ITS employees

\begin{tabular}{|l|l|l|}
\hline Name of the unit & Number employed & $\begin{array}{l}\text { Number of } \\
\text { employees selected } \\
\text { for the survey }\end{array}$ \\
\hline CEO/COO office & 8 & 2 \\
\hline STAMP & 15 & 3 \\
\hline EPM & 65 & 11 \\
\hline PM & 78 & 13 \\
\hline BPMS & 150 & 28 \\
\hline OCTO & 94 & 17 \\
\hline SMD & 780 & 136 \\
\hline TOTAL & 1190 & 210 \\
\hline
\end{tabular}

Once it was established how many employees were required from each department, an email containing the information in the table above was sent from the CEO's office to all directors of ITSB asking them to randomly select the requisite number of employees to participate in the ITSS job design survey (appendix one). Names and email addresses of randomly selected employees were then provided to the researcher to prepare an initial communication requesting their participation in our survey. In June, of 2010, a cover letter and ITS job design questionnaire (in French and English) was emailed to the sample of 210 employees. The respondents were asked to mail their sealed and completed questionnaires directly back to the Sprott School of Business. A total of 105 usable questionnaires were received resulting in a response rate of 50percent. The final sample is slightly higher than the initially proposed target of 100 . Thus, the sample is adequate given the exploratory nature of this study. 


\subsection{Descriptive Analysis}

\subsubsection{Data Preparation}

Data preparation is the first step in the data analysis process (Field, 2005). The questionnaires were first screened for missing values and to see whether they were random or particularly related to some questions. There were few missing values which appeared to be randomly distributed. Kline (1998) suggest that there are three ways to deal with missing values such as delete them, replace them or to estimate them based on certain parameters. Listwise and pair wise delegation are two methods used to delete missing values from the data set. Pairwise deletion where all other data is included other than the missing cases was chosen to treat missing data in this study. The data was coded into an SPSS spreadsheet. The SPSS spreadsheet was organized according to each measurement item and the raw data was entered carefully. The data set was reviewed several times to ensure that the data entry was accurate. Correlations were calculated for items in motivational, social, service and outcome variables. No correlation was near the cutoff point of.8, which could have highlighted multicollinearity problems ( Stevens, 1996). Further, a bivariate correlations analysis was performed between the mean scores of all the three constructs in the IT-SSO model to examine the correlations between them. As shown in the following table, the correlations are also below .8. In addition, correlation between motivational, social characteristics and service characteristics are presented in Appendix three. These correlation tables indicate that items representing the three different constructs are not highly correlated. This simple statistical test shows that the three constructs 
are different. Mean and Standard deviation for the items in these three constructs are given in Appendix four.

Table 12: Correlations between the Motivational, Social and Service Orientation Constructs

\begin{tabular}{|c|c|c|c|}
\hline Construct & Motivation & Social & Service \\
\hline Motivation & W & 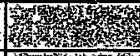 & 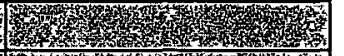 \\
\hline Social & .607 & & \\
\hline Service & .546 & .283 & 1 \\
\hline
\end{tabular}

\subsubsection{Respondent Characteristics}

In part A of ITS job design questionnaire respondents were asked to provide information regarding the nature of their work. The first question confirmed that all respondents were responsible for work directly related to an IT -SSO. All respondents ticked "yes" for this question. On the gender status question, among the 105 respondents 69 of them were male and 36 were female. Further the questionnaire asked the respondent to check the nature of work that they perform most often at the IT-SSO. In this sample 49 respondents were performing transactional work, 29 were performing professional advisory and policy making and 24 were performing transformational work. 
Table 13: Type of Work Performed by the ITS employees

\begin{tabular}{|l|r|r|}
\hline Type of work & Frequency & Percent \\
\hline Transactional work & 49 & 46.7 \\
\hline Transformational work & 24 & 22.9 \\
\hline Professional advisory and policy making & 29 & 27.6 \\
\hline Total & 102 & 97.1 \\
\hline Missing System & 3 & 2.9 \\
\hline Total & 105 & 100 \\
\hline
\end{tabular}

The questionnaire also asked the respondents about their work experience. Interestingly, the majority of the respondents (73\%) had more than 5 years of work experience at ITS; 7 respondents had more than 2.5 years of experience; 15 respondents had work experience between 1.5 years to 2 years; 9 respondents had work experience between 6 months to 1 year.

Table 14 Work Experience of ITS employees

\begin{tabular}{|l|r|r|r|r|}
\hline Work Experience & Frequency & \multicolumn{1}{|c|}{ Percent } & Valid Percent & $\begin{array}{l}\text { Cumulative } \\
\text { Percent }\end{array}$ \\
\hline 6 months - 1year & 9 & 8.5 & 8.7 & 8.7 \\
\hline 1.5 years - 2 years & 15 & 14.2 & 14.4 & 23.1 \\
\hline 2.5 - 3 years & 3 & 2.8 & 2.9 & 26 \\
\hline 3.5 years - 4 years & 4 & 3.8 & 3.8 & 29.8 \\
\hline 5 years or more & 73 & 68.9 & 70.2 & 100 \\
\hline Total & 104 & 98.1 & 100 & \\
\hline
\end{tabular}


In the questionnaire the age level was categorized into 8 groups. In the sample, distribution of respondents is: under $29,8.6$ percent; $30-35$ years, 12.4 percent; 36-40 years, 14.4 percent, $41-45$ years, 11.4 percent; $46-50$ years, 23.8 percent; 51 55 years, 17.1 percent ; 56-60 years, 9.6 percent and 1.9 percent were over 60 years. Most of our respondents were over 30 years of age which is re-assuring as it implies our responses are from potentially experienced employees. The survey also asked respondents to provide us with their job title as the study wished to categorize respondents jobs as being either IT-skilled vs. non-IT skilled. The results showed that 70 respondents who held IT skills based jobs while 35 had non- IT skill based jobs at ITS

Table 15: Type of Skills

\begin{tabular}{|l|r|r|}
\hline Frequency & Number & Percent \\
\hline IT skill & 70 & $67 \%$ \\
\hline Non- IT skill & 35 & $33 \%$ \\
\hline Total & 105 & $100 \%$ \\
\hline
\end{tabular}

\subsubsection{Sequence of Analysis Procedure}

The quantitative analysis of this study used three different statistical techniques. As a first step an exploratory factor analysis was performed on items measuring the dependent, independent variables and outcome variables. Secondly, confirmatory factor analysis was performed to confirm the reliability and validity of the items used to measure the dependent and independent variables. Lastly, hierarchical multiple linear regression was used to test the associations between the independent variables (motivational, social and service) and the dependent variables in ITS job design 
model. Three sets of separate regression analysis were performed instead of examining all predictor variables by a single multiple regression analysis. When more variables are entered into the regression model there is greater variance, resulting in a R2 that can have high values. The more numerous the variables added to a regression model the greater the compromise of statistical power (Stevens, 1996).

There is debate among researchers as to whether EFA and CFA can be used in the same sample (Stevens, 1996; Hurley et al, 1997). However, researchers have indicated that EFA does a better job in identifying cross loading of items and that CFA is more appropriate for understanding the invariance of the measurement scales (Hurley et al, 1997; Farrell, 2010). This research uses both techniques to find different pieces of information. EFA is used first to identify cross loading of items. CFA is used to specifically calculate the average variance extracted in the observed variable that a latent construct is able to explain, and also to estimate the shared variance between each construct.

\subsection{Factor Analysis}

Factor analysis is appropriate for scale development, to understand non hypothesized factor loading (Kelloway, 1995) and to reduce the number of items in a measurement scale (Norusis, 2004). In this research, although our constructs, measurement scale items and hypotheses for causal relationships are based on an extensive literature review on job design, the measures have not been used in a sample of individuals working in IT-SSO. A factor analysis with principal axis factoring using direct obilimin rotation was performed to see whether measures are loading together as 
predicted. Principle axis factoring is a common factor model allowing the analysis of the common, unique and error variances ( Ford, MacCallum and Tait, 1986) and since there is always variance in research (Stevens, 1996), principal axis factoring is a suitable approach to use in this study. Since we have prior knowledge that the items correlate, direct oblique rotation seemed to be the right method for this research (Stevens, 1996.). The important step in factor analysis is deciding on the number of factor extraction. Kaiser (1958) suggests a criterion of retaining all those components that have an Eigenvalue greater than one to identify principal factor components (Stevens, 1996). Additionally, Scree plots were analyzed to identify the point of inflection for differentiating factors (Cattell, 1966). According to Stevens (1996), a variable needs to share at least 15 percent variance with construct it is used to measure and states that factor loading needs to be at least .40 or greater. Therefore, a cut off point for factor loadings was set at .40 or greater for this study.

\subsubsection{Factor Analysis on Motivational Characteristics}

In the IT-SSO job design model proposed, motivational characteristics include autonomy, skill variety, task variety, task identity, task significance, feedback from the job and information processing. Autonomy was measured along three dimensions - ability to self dictate work schedule, level of decision making autonomy and method of working. Each of these variables were measured by three questions on the questionnaire. The factor analysis showed that all three sets of questions loaded cleanly on to the first component which had an Eigenvalue of 5. 695. As shown in Table 15 the factor loadings of these ranged between .620 to .857 and accounted for a total variance of 63 percent All nine items were retained. 
Table 16: Factor loadings for Autonomy

\begin{tabular}{|l|r|}
\hline Items & Factor One \\
\hline Work Method 1 (B1) & 0.62 \\
\hline WorkScAut2 (B3) & 0.632 \\
\hline WorkScAut3 (B4) & 0.744 \\
\hline Dec-makingauto1 (B8) & 0.793 \\
\hline Dec-makingauto3 (B6) & 0.828 \\
\hline WorkScAut1 (B7) & 0.739 \\
\hline Work Method 3 (B9) & 0.852 \\
\hline Work Method 2 (B13) & 0.808 \\
\hline & 0.857 \\
\hline
\end{tabular}

Eigenvalue: 5. 695, AVE-63\%

Factor analysis on items which measure skill variety showed that only the first component had an Eigenvalue of 2.691 accounting for a variance of 67 percent. The factor loadings for skill variety ranged from .629 to .822 , high enough to allow all four items to be retained for the analysis. 
Table 17: Factor loadings for Skill Variety

\begin{tabular}{|l|l|}
\hline Items & Factor One \\
\hline $\begin{array}{l}\text { Skill Variety 4 } \\
\text { (B2) }\end{array}$ & \\
\hline $\begin{array}{l}\text { Skill Variety 2 } \\
\text { (B10) }\end{array}$ & 0.629 \\
\hline $\begin{array}{l}\text { Skill Variety 3 } \\
\text { (B12) }\end{array}$ & 0.769 \\
\hline $\begin{array}{l}\text { Skill Variety 1 } \\
\text { (B23) }\end{array}$ & 0.782 \\
\hline \begin{tabular}{l} 
Eigenvalue : 2.691, AVE 67\% \\
\hline
\end{tabular}
\end{tabular}

Factor analysis on task identity showed that the first component had the an Eigenvalue of 2.981 and accounted for a variance of 74 percent. All four factors had high loadings ranging from .72 to .909 and accounted for a variance of 74 percent. All four items were retained.

Table 18: Factor loadings for Task Identity

\begin{tabular}{|l|l|}
\hline Items & Factor One \\
\hline $\begin{array}{l}\text { Task identity2 } \\
\text { (B14) }\end{array}$ & \\
\hline $\begin{array}{l}\text { Task identity1 } \\
\text { (B15) }\end{array}$ & 0.812 \\
\hline Task identity3 (B5) & 0.726 \\
\hline $\begin{array}{l}\text { Task identity4 } \\
\text { (B25) }\end{array}$ & 0.803 \\
\hline
\end{tabular}

Eigenvalue: 2.981, AVE 74\%

Next, factor analysis were carried out on four questions pertaining to task significance. The first factor had a Eigenvalue of 2.70. The factor loadings ranged from .487 to .966 and accounted for a variance of 67 percent. All four items were retained. 
Table 19: Factor loading for Task significance

\begin{tabular}{|l|l|}
\hline Items & Factor One \\
\hline $\begin{array}{l}\text { Task significance1 } \\
\text { (B16) }\end{array}$ & 0.487 \\
\hline $\begin{array}{l}\text { Task significance2 } \\
\text { (B19) }\end{array}$ & 0.646 \\
\hline $\begin{array}{l}\text { Task significance3 } \\
(\mathrm{B} 21)\end{array}$ & 0.904 \\
\hline $\begin{array}{l}\text { Task significance4 } \\
\text { (B20) }\end{array}$ & 0.966 \\
\hline
\end{tabular}

Eigenvalue of 2.70 , AVE $67 \%$

Factor analysis on items related to task variety loaded onto the first component and had an Eigen value of 3.249 and accounted for 81 percent of variance. The factor loading ranged from .649 to .970 leading to all four items being selected.

Table 20: Factor loading for Task Variety

\begin{tabular}{|l|r|}
\hline Items & Factor One \\
\hline $\begin{array}{l}\text { Task Variety1 } \\
\text { (B11) }\end{array}$ & 0.649 \\
\hline $\begin{array}{l}\text { Task Variety4 } \\
\text { (B17) }\end{array}$ & 0.918 \\
\hline $\begin{array}{l}\text { Task Variety3 } \\
\text { (B22) }\end{array}$ & 0.922 \\
\hline $\begin{array}{l}\text { Task Variety2 } \\
\text { (B18) }\end{array}$ & 0.97 \\
\hline
\end{tabular}

Eigen value: 3.249 , AVE $81 \%$

Feedback from the job was measured by three questions in the questionnaire, all three questions loaded on to a single factor which had an Eigenvalue of 2.502 . The factor loadings were from .805 to .819 and the variance accounted by these items amounted to 83 percent. 
Table 21: Factor loadings for Feedback from Job

\begin{tabular}{|l|r|}
\hline Item & Factor One \\
\hline $\begin{array}{l}\text { Feedbackjob2 } \\
\text { (B26) }\end{array}$ & 0.819 \\
\hline $\begin{array}{l}\text { Feedbackjob3 } \\
\text { (B28) }\end{array}$ & 0.980 \\
\hline $\begin{array}{l}\text { Feedbackjob1 } \\
\text { (B24) }\end{array}$ & .806 \\
\hline
\end{tabular}

Eigenvalue of 2.502, AVE $83 \%$

In this research information processing was is measured by information amount and information equivocality. On the IT-SSO job design questionnaire information amount was measured with four items and information equivocality three questions to probe the level of information processing on ITS employee work. In the factor analysis the question related to information amount loaded onto four factors but only the first factor had a large Eigenvalue (2.30) and accounted for a variance of 57 percent. The factor loadings in first factor ranged from .541 to .852 . All four items were retained for analysis.

Table 22: Factor loadings for Information Amount

\begin{tabular}{|l|l|}
\hline Item & Factor One \\
\hline $\begin{array}{l}\text { Information Amount4 } \\
\text { (B29) }\end{array}$ & 0.852 \\
\hline $\begin{array}{l}\text { Information Amount 2 } \\
\text { (B30) }\end{array}$ & 0.728 \\
\hline $\begin{array}{l}\text { Information Amount1 } \\
\text { (B31) }\end{array}$ & 0.509 \\
\hline $\begin{array}{l}\text { Information Amount3 } \\
\text { (B34) }\end{array}$ & 0.541 \\
\hline
\end{tabular}

Eigenvalue: 2.30 , AVE 57\% 
Similarly, the factor analysis on information equivocality showed that the first factor had an greater Eigenvalue of 1.855 , which was the only factor greater than one. The amount of variance accounted for by this factor was 57 percent. The factor loadings ranged from .594 to .731 . All three items were retained for further analysis.

Table 23: Factor loadings for Equivocality

\begin{tabular}{|l|r|}
\hline Item & Factor One \\
\hline Information Equivo3 (B32) & 0.594 \\
\hline Information Equivo2 (B32) & 0.731 \\
\hline $\begin{array}{l}\text { Information Equivo1 } \\
\text { (B35) }\end{array}$ & 0.639 \\
\hline
\end{tabular}

Eigen value: 1.855 , AVE $57 \%$

\subsubsection{Factor Analysis on Social Characteristics}

Task interdependence, feedback from others, social support and interaction outside the organization were the four social characteristics in ITS. In the questionnaire the task interdependence was measured by two subscales, initiated task interdependence and received interdependence. Both types of interdependence were measured by three questions in the survey. First factor analysis was performed on the questions measuring initiation task interdependence. As shown in the following table all three questions loaded on to the first factor. The first factor had an Eigenvalue of 2.041 accounting for a variance of 68 percent. The factor loadings for these items was from .540 , to .683 . All three items were retained for analysis. 
Table 24: Factor loadings for Initiated Task Interdependence

\begin{tabular}{|l|r|}
\hline Item & Factor One \\
\hline Initiated task interdependence 1(C6) & 0.683 \\
\hline Initiated task interdependence3 (C7) & 0.964 \\
\hline Initiated task interdependence2 (C13) & 0.54 \\
\hline
\end{tabular}

Eigen value: 2.041 , AVE $68 \%$

Secondly factor analysis was performed on items that measured the received interdependence. The analysis showed all three questions loaded on to a single factor which had an Eigen value of 1.721 accounted for 57 percent of variance. The factor loadings were $.492, .466$ and .879 and all three items were retained.

Table 25: Factor loadings for Received Task Interdependence

\begin{tabular}{|l|l|}
\hline Item & Factor One \\
\hline Received interdependence2 (C5) & 0.492 \\
\hline Received interdependence1 (C12) & 0.879 \\
\hline Received interdependence3 (C9) & 0.466 \\
\hline
\end{tabular}

Eigen value: 1.721 , AVE $57 \%$

The second social characteristics,feedback from others was measured by three questions. The factor analysis showed that all these items loaded on to the first factor which had an Eigenvalue of 2.424 and accounted for 80 percent of the variance. All three items showed higher factor loadings. 
Table 26: Factor loadings for Feedback from Others

\begin{tabular}{|l|r|}
\hline Item & Factor One \\
\hline $\begin{array}{l}\text { Feedback from others2 } \\
(\mathrm{C} 1)\end{array}$ & 0.795 \\
\hline $\begin{array}{l}\text { Feedback from others3 } \\
\text { (C2) }\end{array}$ & 0.942 \\
\hline $\begin{array}{l}\text { Feedback from others1 } \\
(\mathrm{C} 3)\end{array}$ & 0.798 \\
\hline
\end{tabular}

Eigenvalue: 2.424 , AVE $80 \%$

Factor analysis was performed on the social characteristic - interaction outside the organization. The results showed all four questions loading on to a single factor which had an Eigenvalue of 3.38 and the factor accounted a variance of 78 percent. All four items had high loadings and were retained.

Table 27:Factor loadings Interaction Outside the Organizations

\begin{tabular}{|l|l|}
\hline Item & Factor One \\
\hline Interaction outside1 (C4) & 0.809 \\
\hline Interaction outside4(C10) & 0.919 \\
\hline Interaction outside3 (C11) & 0.879 \\
\hline Interaction outside2 (C8) & 0.771 \\
\hline
\end{tabular}

Eigenvalue: 3.38 , AVE 78\%

Factor analysis was performed on the remaining social variable social support, it showed that the items loaded onto two factors. In the first factor questions that measure social support from friends loaded heavily. This factor had an Eigenvalue of 4.081 and accounted for a variance of 60 percent. In the second factor questions related to social support from supervisors loaded heavily. The second factor had an 
Eigenvalue of 1.22 and accounted for a variance of 15 percent. The first factor had higher loading for questions related to social support from friends, this factor was named as "support from friends". The second factor which had higher loadings for questions related to social support from supervisor was named "support from supervisor".

Table 28: Factor loadings for Social Support

\begin{tabular}{|l|l|l|}
\hline Item & Factor One & Factor Two \\
\hline $\begin{array}{l}\text { Social support supervisor 1 } \\
\text { (C14) }\end{array}$ & 0.441 & 0.799 \\
\hline $\begin{array}{l}\text { Social support friend 2 } \\
\text { (C15) }\end{array}$ & 0.741 & 0.516 \\
\hline $\begin{array}{l}\text { Social support supervisor3 } \\
\text { (C16) }\end{array}$ & 0.588 & 0.667 \\
\hline $\begin{array}{l}\text { Social support friend 4 } \\
\text { (C17) }\end{array}$ & 0.771 & 0.448 \\
\hline $\begin{array}{l}\text { Social support friend 5 } \\
\text { (C18) }\end{array}$ & 0.888 & 0.488 \\
\hline $\begin{array}{l}\text { Social support friend 6 } \\
\text { (C19) }\end{array}$ & 0.891 & 0.581 \\
\hline $\begin{array}{l}\text { Social support supervisor7 } \\
\text { (C20) }\end{array}$ & 0.507 & 0.917 \\
\hline $\begin{array}{l}\text { Social support supervisor 8 } \\
\text { (C21) }\end{array}$ & 0.625 & 0.826 \\
\hline
\end{tabular}

Social support from friends eignvalue:4.081, AVE $60 \%$

Social support from supervisor eignvalue: 1.22 , AVE $15 \%$

\subsubsection{Factor Analysis on Service Orientation Characteristics}

The IT-SSO job design model has four service characteristics which are service technology, service failure prevention, service failure recovery and service standard communication. Factor analysis was carried out on all four variables. First, factor 
analysis was performed on the four questions that measure service technology. The results showed that all three questions on service technology loaded heavily on the first factor with high factor loadings. The component had an Eigenvalue of 2.298 and accounted for variance of 76 percent.

Table 29: Factor loadings on Service Technology

\begin{tabular}{|l|r|}
\hline Item & Factor One \\
\hline Service technolog2 (D3) & 0.847 \\
\hline Service technolog1(D5) & 0.885 \\
\hline Service technolog3 (D7) & 0.688 \\
\hline
\end{tabular}

Eignvalue: 2.298 , AVE $76 \%$

Next, factor analysis was carried out on the three questions that measure service failure prevention. As shown in the Table 30 below the three question loaded heavily on the first factor. This factor had an Eigenvalue of 2.132 and explained 71 percent of variance.

Table 30: Factor loadings on Service Failure Prevention

\begin{tabular}{|l|l|}
\hline Item & Factor One \\
\hline $\begin{array}{l}\text { Service failure prevention2 } \\
\text { (D1) }\end{array}$ & \\
\hline $\begin{array}{l}\text { Service failure prevention1 } \\
\text { (D4) }\end{array}$ & 0.823 \\
\hline $\begin{array}{l}\text { Service failure prevention3 } \\
\text { (D6) }\end{array}$ & 0.894 \\
\hline
\end{tabular}

Eignvalue: 2.132 , AVE $71 \%$ 
The factor analysis on service failure recovery showed that the four questions that measured this item in ITS job design questionnaire loaded heavily on the first component. This component had an Eigenvalue of 2.024 and accounted for the 50 percent of the variance.

Table 31: Factor loadings on Service Failure Recovery

\begin{tabular}{|l|r|}
\hline Item & Factor One \\
\hline $\begin{array}{l}\text { Service failure recovery1 } \\
\text { (D2) }\end{array}$ & 0.588 \\
\hline $\begin{array}{l}\text { Service failure recovery3 } \\
\text { (D9) }\end{array}$ & 0.758 \\
\hline $\begin{array}{l}\text { Service failure recovery4 } \\
\text { (D14) }\end{array}$ & 0.492 \\
\hline $\begin{array}{l}\text { Service failure recovery2 } \\
\text { (D15) }\end{array}$ & 0.5 \\
\hline
\end{tabular}

Eigenvalue: 2.024; AVE 50

Lastly a factor analysis was carried out on the five questions that measured service standards communication. All five items loaded on to a single factor and showed factor loadings from .589 to .793 . The Eignvalue for the first factor was 2.823 and accounted $56 \%$ of the variance.

Table 32: Factor loadings on Service Standard Communication

\begin{tabular}{|l|r|}
\hline Item & Factor One \\
\hline $\begin{array}{l}\text { Service Standard 3 } \\
\text { (D11) }\end{array}$ & \\
\hline $\begin{array}{l}\text { Service Standard 4 } \\
\text { (D12) }\end{array}$ & 0.793 \\
\hline $\begin{array}{l}\text { Service Standard 2 } \\
\text { (D10) }\end{array}$ & 0.589 \\
\hline $\begin{array}{l}\text { Service Standard 5 } \\
\text { (D13) }\end{array}$ & 0.606 \\
\hline Service Standard 1 (D8) & 0.715 \\
\hline
\end{tabular}

Eignvalue: 2.823 , AVE $56 \%$. 


\subsubsection{Factor Analysis on Outcome Variables}

Job satisfaction, job performance and turnover are three outcome variables in the study. Job satisfaction was measured by six questions and the factor analysis showed all six questions loading highly on component one. The Eigenvalue for this factor was 4.746 and it explained a variance of 79 percent.

Table 33: Factor Loadings on Job Satisfaction

\begin{tabular}{|l|r|}
\hline Item & Factor One \\
\hline Job satisfaction1 (E1) & 0.885 \\
\hline Job satisfaction2 (E2) & 0.838 \\
\hline Job satisfaction3 (E3) & 0.831 \\
\hline Job satisfaction4 (E4) & 0.819 \\
\hline Job satisfaction5 (E5) & 0.903 \\
\hline Job satisfaction6 (E6) & 0.916 \\
\hline
\end{tabular}

Eignvalue: 4.746 , AVE 79\%

Next, factor analysis was done on questions that measured job performance. Job performance was measured in five different roles that ITS employees can perform. All five roles were measured by four questions and factor analysis was done on all five different roles. Factor analysis on job role was carried out and all four items loaded well onto the first factor as shown in the table above Table 32. The factor loadings ranged from .457 to .868 . The first factor had an Eigenvalue of 2.314 and explained a variance of 57 percent. The factor analysis of job performance career loaded on to the first factor which had an Eigenvalue of 2.451 and explained a variance of 61 percent. The factor loading for these items ranged from .602 to .863 . 
Innovation loaded on to the first factor and the Eigen value for this factor was 2.690 and the variance extracted was 67 percent. The factor loadings for these items were from .589 to .834 .

Table 34: Factor loadings on Job performance (Job)

\begin{tabular}{|l|l|}
\hline Item & Factor One \\
\hline Job performance - Job3(E10) & 0.457 \\
\hline Job performance - Job4 (E15) & 0.619 \\
\hline Job performance - Job2 (E21) & 0.702 \\
\hline Job performance - Job1 (E26) & 0.868 \\
\hline
\end{tabular}

Eigenvalue : 2.314 , AVE $57 \%$

Table 35: Factor loadings on Job performance (Career)

\begin{tabular}{|l|l|}
\hline Item & Factor One \\
\hline $\begin{array}{l}\text { Job performance-Career3 } \\
\text { (E13) }\end{array}$ & 0.863 \\
\hline $\begin{array}{l}\text { Job performance-Career1 } \\
\text { (E11) }\end{array}$ & 0.629 \\
\hline Job performance-Career4 (E8) & 0.602 \\
\hline $\begin{array}{l}\text { Job performance- Career 2 } \\
\text { (E23) }\end{array}$ & 0.689 \\
\hline
\end{tabular}

Eigenvalue : 2.451 , AVE $61 \%$ 
Table 36: Factor loadings on Job performance (Innovator)

\begin{tabular}{|l|l|}
\hline Item & Factor One \\
\hline $\begin{array}{l}\text { Job performance- } \\
\text { Innovator3(E25) }\end{array}$ & 0.744 \\
\hline $\begin{array}{l}\text { Job performance-Innovator4 } \\
\text { (E18) }\end{array}$ & 0.834 \\
\hline $\begin{array}{l}\text { Job performance-Innovator2 } \\
\text { (E16) }\end{array}$ & 0.834 \\
\hline $\begin{array}{l}\text { Job performance- } \\
\text { Innovator1(E9) }\end{array}$ & 0.589 \\
\hline
\end{tabular}

Eigenvalue : 2.690 , AVE $67 \%$

Table 37: Factor loadings on Job performance (Team)

\begin{tabular}{|l|l|}
\hline Item & Factor One \\
\hline $\begin{array}{l}\text { Job performance - } \\
\text { Team2(E12) }\end{array}$ & 0.466 \\
\hline $\begin{array}{l}\text { Job performance - Team3 } \\
\text { (E14) }\end{array}$ & 0.796 \\
\hline $\begin{array}{l}\text { Job performance - Team4 } \\
\text { (E22) }\end{array}$ & 0.627 \\
\hline $\begin{array}{l}\text { Job performance - } \\
\text { Team1(E21) }\end{array}$ & 0.594 \\
\hline
\end{tabular}

Eigenvalue : 2.155 , AVE 53\%

Table 38:Factor loadings on Job performance (Org)

\begin{tabular}{|l|l|}
\hline Item & Factor One \\
\hline Job performance -Org3 (E17) & 0.593 \\
\hline Job performance -Org2 (E19) & 0.891 \\
\hline Job performance -Org1 (E20) & 0.664 \\
\hline Job performance -Org4 (E7) & 0.51 \\
\hline
\end{tabular}

Eigenvalue : 2.323 , AVE $58 \%$ 
The team also loaded to the first factor and the Eigen value was 2.155 and accounted for a variance of 53 percent with factor loading from .466 to .796 . Lastly, job performance (organization) loaded to the first factor which had an Eigen value of 2.323 and a variance of 58 percent with factor loadings from .510 to .891 . All factor loadings were greater than .40 , and were therefore retained.

The last factor analysis was done on the two questions that ask respondents about their turnover intention. As shown in the following table both items measuring turn over loaded together on the first factor and with high factor loadings. The Eigenvalue for this factor was 1.546 and it accounted for 77 percent of variance.

Table 39 : Factor Loadings on Turnover

\begin{tabular}{|l|r|}
\hline Item & Factor One \\
\hline Turnover1 (E27) & 0.738 \\
\hline Turnover2 (E28) & 0.738 \\
\hline
\end{tabular}

Eigenvalue : 2.314 , AVE $57 \%$

5.4 Examining the Reliability and Validity of the scales through Confirmatory Factor Analysis (CFA)

\subsubsection{Reliability}

Reliability is an indicator of the internal consistency of the measurement instrument, and indicates whether the measurement scale produces the same answer every time we use it. Validity on the other hand tries to establish that the measures really measure what they are supposed to measure in a sample (Kirk and Miller, 1986). One 
of the main advantages of CFA is its ability to quantitatively assess the reliability and construct validity of items (Hurley et al, 1997). In order to perform confirmatory factor analysis a minimum of 100 subjects is necessary ( Bearden, Sharma and Teel, 1982) which is the case in this study. Therefore CFA was used to establish the reliability and validity of the measurement scales in this study.

Reliability is often measured by Cronbach's alpha. Reliability is normally established when the values for Cronbach Alpha exceed the bench mark of .7 (Nunnally, 1978; Cortina, 1993) Composite reliability also measures the reliability of the scales and can be calculated by the following formula provided by Fornell $\&$ Larcker (1981).

Composite reliability (CR): (sum of standardized loading) ${ }^{2} /[$ (sum of standardized loading) ${ }^{2}+$ sum of indicator measurement error]

A high construct reliability indicates that internal consistency exists and implies that the measures consistently represent what they are intended to. Generally, when Composite reliability is .7 or greater it is an indication that the scale has good composite reliability (Hair et al,1998).

\subsubsection{Construct Validity}

Construct validity, is defined broadly as operationalization of the concept that is supposed to be measured (Cook and Campbell, 1979). Construct validity must be established before hypotheses from a research are accepted or rejected because of the 
adequacy of theory and not because of influences of random error or method variance (Bagozzi, Yi, and Phillips,1999). Convergent and discriminant validation are common methods used to establish construct validity. Convergent validity can be defined as the extent to which indicators of a specific construct 'converge' or share a high proportion of variance in common and discriminant validity is the extent to which a construct is truly distinct from other constructs. Convergent validity of scales can be assessed by following these rules.

1. Average Variance Extracted (AVE) is the variance that is due to the latent variable. AVE can range between 0 to 1 and it needs to be greater than .50 which indicates that 50percent of the variance in a measure is due to the hypothesized underlying trait. (Dillon et al., (1984); Fornell \& Larcker, 1981).

2. Convergent validity can be also analyzed through the standardized loading. Loadings above .71 are excellent, .63 very good, .55 good, .45 fair and .32 poor (Tabachnic \& Fidell, 2007).

3. Reliability measured by calculating Cronbach's alpha also indicates convergence. Reliability is when the values exceed the bench mark of .7 ( Nunnally , 1978)

\subsubsection{Discriminant Validity}

Discriminant validity is the extent to which latent variables differ from one another; and is established when all construct average variance extracted (AVE) estimates are larger than the corresponding squared inter-construct correlation estimates (SIC) (Fornell \& Larcker, 1981). 


\subsubsection{Calculating AVE, Composite Reliability, Convergence validity and Discriminant validity}

To calculate the reliability and validity of the measures CFA was performed using the SPSS AMOS software while Cronbach alpha was calculated using SPSS base edition.

Whenever a variable had an item dropped because of poor factor loading, CFA analysis was performed again with the remaining items and AVE was calculated. Task significance, information amount, information equivocality, service failure recovery had items dropped, however, CFA for these variables were not performed again because there were only two items remaining. CFA cannot be carried with only two items. On the other hand, service standards and job performance ( job, career team) had more than two items, therefore CFA was performed again and new factor loadings were obtained to calculate AVE.

CFA on motivation characteristics autonomy, skill variety, task identity, feedback from job all had good factor loadings. The Cronbach alpha and composite reliability were above .7 showing internal reliability. The AVE exacted was also greater than .5 establishing convergent validity. The mean values of these items made up autonomy, skill variety, task identity and feedback from job. The CFA factor loadings for task significance indicated that question B16 (The results of my work are likely to significantly affect the lives of other people) had a poor loading and was not retained. Similarly, question B20 (The job has a large impact on people outside the organizations) had a factor loading greater than 1 . When CFA analysis shows a factor loading greater than one, it is problematic and can be an indication of multicolinarity (Brown, 2006). Therefore this item was also removed from the items representing task significance. 
Only items B19 and B21 made up the task significance variable. These two items had an AVE of .58 indicating convergence, a composite reliability of .81 and the Cronbach alpha was .68 .

The CFA analysis on items representing information amount showed that two items [ B31 (I have to wait until all relevant information is examined before deciding something) and B34 (I acquire all possible information before making a final decision)] had poor factor loadings. The other two items B30 and B29 had factor loadings greater than .70 and formed the information amount variable. The AVE was .76 indicating good convergence. The composite reliability and Cronbach alpha was greater than .7 . The CFA analysis on items measuring information equivocality showed factor loadings of $.583, .683$ and .761 . 
Table 40: Reliability and Validity of Motivational Characteristics

\begin{tabular}{|l|l|l|l|l|l|l|l|}
\hline Autonomy & $\begin{array}{l}\text { Factor } \\
\text { loadings from } \\
\text { CFA }\end{array}$ & $\begin{array}{l}\text { Squared } \\
\text { factor } \\
\text { loadings }\end{array}$ & $\begin{array}{l}\text { Standardized } \\
\text { error variance }\end{array}$ & AVE & CR & $\alpha$ & $\begin{array}{l}\text { Number of } \\
\text { Dimensions }\end{array}$ \\
\hline VARB8 & 0.801 & 0.642 & 0.358 & .58 & .92 & .92 & 9 \\
\hline VARB27 & 0.866 & 0.750 & 0.250 & & & & \\
\hline VARB6 & 0.827 & 0.684 & 0.316 & & & & \\
\hline VARB1 & 0.611 & 0.373 & 0.627 & & & & \\
\hline VARB13 & 0.814 & 0.663 & 0.337 & & & & \\
\hline VARB9 & 0.846 & 0.716 & 0.284 & & & & \\
\hline VARB7 & 0.747 & 0.558 & 0.442 & & & & \\
\hline VARB3 & 0.610 & 0.372 & 0.628 & & & & \\
\hline VARB4 & 0.725 & 0.526 & 0.474 & & & & \\
\hline Skill Variety & & & & & & & \\
\hline VARB23 & 0.822 & 0.676 & 0.324 & .56 & .83 & .83 & 4 \\
\hline VARB10 & 0.750 & 0.563 & 0.438 & & & & \\
\hline VARB12 & 0.802 & 0.643 & 0.357 & & & & \\
\hline VARB2 & 0.622 & 0.387 & 0.613 & & & & \\
\hline Task \\
Identity
\end{tabular}


Table 41: Reliability and Validity of Motivational Characteristics (Continued)

\begin{tabular}{|c|c|c|c|c|c|c|c|}
\hline & $\begin{array}{l}\text { Factor } \\
\text { loadings } \\
\text { from CFA }\end{array}$ & $\begin{array}{l}\text { Squared factor } \\
\text { loadings }\end{array}$ & $\begin{array}{l}\text { Standardized } \\
\text { error variance }\end{array}$ & $\overline{\text { AVE }}$ & $\overline{\mathbf{C R}}$ & $\alpha$ & $\begin{array}{l}\text { Number of } \\
\text { Dimensions }\end{array}$ \\
\hline \multicolumn{8}{|l|}{$\begin{array}{l}\text { Feedback from } \\
\text { Job }\end{array}$} \\
\hline VARB24 & 0.809 & 0.654 & 0.346 & .74 & .89 & .89 & 3 \\
\hline VARB28 & 0.978 & 0.956 & 0.044 & & & & \\
\hline VARB26 & 0.798 & 0.637 & 0.363 & & & & \\
\hline \multicolumn{8}{|l|}{ VARB31 } \\
\hline \multicolumn{8}{|l|}{$\begin{array}{l}\text { Information } \\
\text { amount }\end{array}$} \\
\hline VARB30 & 0.739 & 0.546 & 0.454 & .76 & .86 & .84 & 2 \\
\hline VARB29 & 0.990 & 0.980 & 0.020 & & & & \\
\hline \multicolumn{8}{|c|}{ 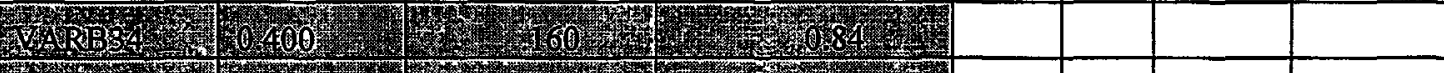 } \\
\hline \multicolumn{8}{|c|}{ YAB } \\
\hline \multicolumn{8}{|l|}{$\begin{array}{l}\text { Information } \\
\text { Equivocality }\end{array}$} \\
\hline ( & 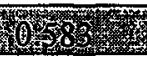 & 0734019 & $\mathrm{~g}^{2}$ & .52 & .68 & .67 & 2 \\
\hline VARB35 & 0.683 & 0.466 & 0.534 & & & & \\
\hline VARB33 & 0.761 & 0.579 & 0.421 & & & & \\
\hline
\end{tabular}

When AVE was calculated with all three items the variance extracted was .46. In order to improve this further, item B32 (The Information used in making decisions means different things to different people) with the lowest factor loading was dropped. After doing this, the AVE increased to .52. These two items which had loadings of .693 and .781 were retained and their mean values represented information equivocality. As shown on table 41 the AVE for this was above .5 but both composite reliability and Cronbach alpha were a little below the cutoff mark of.7. 
Table 42: Reliability and Validity of Social Characteristics

\begin{tabular}{|c|c|c|c|c|c|c|c|}
\hline & $\begin{array}{l}\text { Factor loadings } \\
\text { from CFA }\end{array}$ & $\begin{array}{l}\text { Squared } \\
\text { factor } \\
\text { loadings }\end{array}$ & $\begin{array}{l}\text { Standardized } \\
\text { error variance }\end{array}$ & AVE & $\overline{\mathbf{C R}}$ & $\alpha$ & $\begin{array}{l}\text { Number of } \\
\text { Dimensions }\end{array}$ \\
\hline \multicolumn{8}{|c|}{$\begin{array}{l}\text { Initated task } \\
\text { Interdependence }\end{array}$} \\
\hline VARC6 & 0.741 & 0.549 & 0.451 & .57 & .79 & .76 & 3 \\
\hline VARC13 & 0.567 & 0.321 & 0.679 & & & & \\
\hline VARC7 & 0.920 & 0.846 & 0.154 & & & & \\
\hline \multicolumn{8}{|c|}{$\begin{array}{l}\text { Received } \\
\text { Interdependence }\end{array}$} \\
\hline VARC5 & 0.485 & 0.235 & 0.765 & .51 & .66 & .60 & 2 \\
\hline VARC12 & 0.892 & 0.796 & 0.204 & & & & \\
\hline$y<\operatorname{Rin} \theta$ & $647)^{2}$ & 0221 & 6/2 & & & & \\
\hline $\begin{array}{l}\text { Feedback } \\
\text { From othe }\end{array}$ & & & & & & & \\
\hline VARC1 & 0.794 & 0.630 & 0.370 & .71 & .88 & .88 & 3 \\
\hline VARC3 & 0.797 & 0.635 & 0.365 & & & & \\
\hline VARC2 & 0.943 & 0.889 & 0.111 & & & & \\
\hline \multicolumn{8}{|c|}{$\begin{array}{l}\text { Social support } \\
\text { friends }\end{array}$} \\
\hline VARC17 & 0.704 & 0.496 & 0.504 & .66 & .89 & .87 & 4 \\
\hline VARC15 & 0.781 & 0.610 & 0.390 & & & & \\
\hline VARC18 & 0.879 & 0.773 & 0.227 & & & & \\
\hline VARC19 & 0.877 & 0.769 & 0.231 & & & & \\
\hline \multicolumn{8}{|c|}{$\begin{array}{l}\text { Support from } \\
\text { supervisors }\end{array}$} \\
\hline VARC21 & 0.838 & 0.702 & 0.298 & .66 & .88 & .87 & 4 \\
\hline VARC20 & 0.925 & 0.856 & 0.144 & & & & \\
\hline VARCI4 & 0.799 & 0.638 & 0.362 & & & & \\
\hline VARC16 & 0.678 & 0.460 & 0.540 & & & & \\
\hline \multicolumn{8}{|c|}{$\begin{array}{l}\text { Interaction } \\
\text { outside the } \\
\text { organization }\end{array}$} \\
\hline VARC8 & 0.723 & 0.523 & 0.477 & .70 & .90 & .90 & 4 \\
\hline VARC4 & 0.762 & 0.581 & 0.419 & & & & \\
\hline VARC11 & 0.912 & 0.832 & 0.168 & & & & \\
\hline VARCI0 & 0.945 & 0.893 & 0.107 & & & & \\
\hline
\end{tabular}


As shown in table 42 , in the social characteristics, items measuring - initiated task interdependence, feedback from others, social support from friends, social support from supervisor and interaction outside organization all showed good factor loadings from the CFA analysis. The mean value of these items made up the respective independent variables. The AVE was .greater than .5 for all of these variables indicating convergence. The composite reliability and the Cronbachs alpha were greater than .7 indicating internal consistency. The CFA analysis for received interdependence showed that three items had a factor loadings of $.485, .892$ and .470 . The AVE with all three items was 41 percent, which is less than the expected AVE threshold. Therefore the item with the lowest loading [ question C9 (My job cannot be done unless others do their work) with a factor loading of .470) ] was dropped and this resulted in an average variance extraction of 51 percent. Only these two items with a loading of .470 and .892 were retained. Since AVE is greater than .5 it confirms convergence. The composite reliability and Cronbach alpha were greater than .7 establishing internal validity. 
Table 43:Reliability and Validity of Service Orientation Characteristics

\begin{tabular}{|c|c|c|c|c|c|c|c|}
\hline & $\begin{array}{l}\text { Factor loadings } \\
\text { from CFA }\end{array}$ & $\begin{array}{l}\text { Squared } \\
\text { factor } \\
\text { loadings }\end{array}$ & $\begin{array}{l}\text { Standardized } \\
\text { error variance }\end{array}$ & $\overline{\text { AVE }}$ & $\overline{C R}$ & $\alpha$ & $\begin{array}{l}\text { Number of } \\
\text { Dimensions }\end{array}$ \\
\hline \multicolumn{8}{|c|}{$\begin{array}{l}\text { Service } \\
\text { technology }\end{array}$} \\
\hline VARD5 & 0.882 & 0.778 & 0.222 & .65 & .84 & .84 & 3 \\
\hline VARD3 & 0.838 & 0.702 & 0.298 & & & & \\
\hline VARD7 & 0.688 & 0.473 & 0.527 & & & & \\
\hline \multicolumn{8}{|c|}{$\begin{array}{l}\text { Service failure } \\
\text { prevention }\end{array}$} \\
\hline VARD4 & 0.896 & 0.803 & 0.197 & .59 & .80 & .79 & 3 \\
\hline VARD1 & 0.821 & 0.674 & 0.326 & & & & \\
\hline VARD6 & 0.551 & 0.304 & 0.696 & & & & \\
\hline \multicolumn{8}{|c|}{$\begin{array}{l}\text { Service failure } \\
\text { recovery }\end{array}$} \\
\hline VARD2 & 0.602 & 0.362 & 0.638 & .47 & .64 & .64 & 2 \\
\hline A & 0.50 & 0250 & 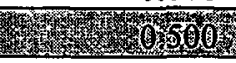 & & & & \\
\hline VARD9 & 0.763 & 0.582 & 0.418 & & & & \\
\hline XW & 4048 & 0234 & 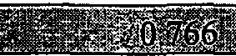 & & & & \\
\hline \multicolumn{8}{|l|}{$\begin{array}{l}\text { Service } \\
\text { standards }\end{array}$} \\
\hline S. & 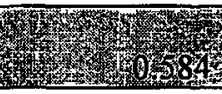 & 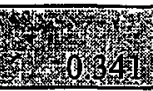 & (2) & .50 & .80 & .78 & 4 \\
\hline VARD11 & 0.868 & 0.753 & 0.247 & & & & \\
\hline VARD8 & 0.578 & 0.334 & 0.666 & & & & \\
\hline VARD13 & 0.632 & 0.399 & 0.601 & & & & \\
\hline VARD10 & 0.719 & 0.516 & 0.484 & & & & \\
\hline
\end{tabular}

The CFA analysis on service orientation characteristics which included items representing service technology, and service failure prevention had good factor loadings. The mean value of these items made up the respective independent variables to measure the service characteristics of ITS work design. The AVE for all three variables were greater than .5 showing convergence. The composite reliability and the Cronbach alpha were greater than .7 indicating internal consistency. The factor loadings for items measuring service failure recovery were $.484, .500, .602$, 
.763 , and .484 respectively. When AVE was calculated with all four factor loading it extracted only an average variance of .41 . In order to improve this, the items with lowest factor loading (.484 and .500) were not retained. The AVE with the remaining two items was . 47. Although this AVE is not more than .5 it is pretty close. Thus, this was the only scale in this research that fell below the .5 threshold. The composite reliability was .64 , not beyond .7 again but very close to it. The CFA factor loadings for service standard communication had factor loadings ranging from .585 to .812 . When AVE was calculated with all five items it was .47 , below the required .5 cut off point for convergence. Therefore, the lowest loading (.585) was dropped, since there were more than two items, CFA was performed again with the remaining items and AVE was calculated.

The CFA analysis on items measuring job satisfaction showed high factor loadings. The AVE was greater than.5, indicating good convergence. The composite reliability and Cronbach alpha was greater than.7, indicating internal consistency. In ITS questionnaire the job performance was measured by job, innovation, career, team and organizations roles. The questions in measuring job performance (in innovator and organization) all had good factor loadings, therefore all items were retained. Items measuring job performance pertaining to career had factor loadings ranging from .597 to .857 . 
Table 44: Reliability and Validity of Outcome Variables

\begin{tabular}{|c|c|c|c|c|c|c|c|}
\hline & $\begin{array}{l}\text { Factor loadings } \\
\text { from CFA }\end{array}$ & $\begin{array}{l}\text { Squared } \\
\text { factor } \\
\text { loadings }\end{array}$ & $\begin{array}{l}\text { Standardized } \\
\text { error variance }\end{array}$ & $\overline{A V E}$ & $\overline{C R}$ & $a$ & $\begin{array}{l}\text { Number of } \\
\text { Dimensions }\end{array}$ \\
\hline \multicolumn{8}{|c|}{ Job satisfaction } \\
\hline VARE6 & 0.923 & 0.852 & 0.148 & .74 & .99 & .94 & 6 \\
\hline VARE5 & 0.912 & 0.832 & 0.168 & & & & \\
\hline VARE1 & 0.882 & 0.778 & 0.222 & & & & \\
\hline VARE2 & 0.824 & 0.679 & 0.321 & & & & \\
\hline VARE3 & 0.828 & 0.686 & 0.314 & & & & \\
\hline VARE4 & 0.814 & 0.663 & 0.337 & & & & \\
\hline \multicolumn{8}{|c|}{$\begin{array}{l}\text { Job } \\
\text { performance - } \\
\text { Job }\end{array}$} \\
\hline VARE15 & .615 & 0.378 & 0.622 & .55 & .78 & .76 & 3 \\
\hline VARE26 & .947 & 0.897 & 0.103 & & & & \\
\hline VARE21 & .628 & 0.394 & 0.606 & & & & \\
\hline (1) & 1) & 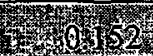 & $4 x+3)$ & & & & \\
\hline \multicolumn{8}{|c|}{$\begin{array}{l}\text { Job } \\
\text { performance - } \\
\text { Career } \\
\end{array}$} \\
\hline VARE23 & 0.651 & 0.424 & 0.576 & .52 & .76 & .75 & 4 \\
\hline VARE11 & 0.628 & 0.394 & 0.606 & & & & \\
\hline VARE13 & 0.870 & 0.757 & 0.243 & & & & \\
\hline (6) & 10. & 36) & 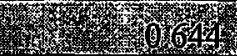 & & & & \\
\hline \multicolumn{8}{|c|}{$\begin{array}{l}\text { Job } \\
\text { performance - } \\
\text { Innovator }\end{array}$} \\
\hline VARE16 & 0.858 & 0.736 & 0.264 & .65 & .85 & .84 & 3 \\
\hline VARE25 & 0.778 & 0.605 & 0.395 & & & & \\
\hline VARE18 & 0.774 & 0.599 & 0.401 & & & & \\
\hline \multicolumn{8}{|c|}{$\begin{array}{l}\text { Job } \\
\text { performance } \\
\text { Team } \\
\end{array}$} \\
\hline VARE22 & 0.712 & 0.507 & 0.493 & .50 & .80 & .62 & 2 \\
\hline VARE14 & 0.677 & 0.458 & 0.542 & & & & \\
\hline VARE24 & 0.649 & 0.421 & 0.579 & & & & \\
\hline 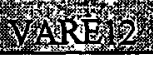 & 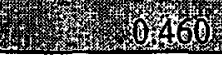 & 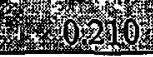 & 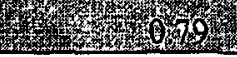 & & & & \\
\hline
\end{tabular}


Table 45: Reliability and Validity of Outcome Variables

\begin{tabular}{|l|l|l|l|l|l|l|l|}
\hline & $\begin{array}{l}\text { Factor loadings } \\
\text { from CFA }\end{array}$ & $\begin{array}{l}\text { Squared } \\
\text { factor } \\
\text { loadings }\end{array}$ & $\begin{array}{l}\text { Standardized } \\
\text { error variance }\end{array}$ & AVE & CR & $\alpha$ & $\begin{array}{l}\text { Number of } \\
\text { Dimensions }\end{array}$ \\
\hline $\begin{array}{l}\text { Job } \\
\text { performance } \\
\text { organization }\end{array}$ & & & & & & & \\
\hline VARE7 & 0.501 & 0.251 & 0.749 & .55 & .69 & .75 & 4 \\
\hline VARE17 & 0.584 & 0.341 & 0.659 & & & & \\
\hline VARE20 & 0.710 & 0.504 & 0.496 & & & & \\
\hline VARE19 & 0.907 & 0.823 & 0.177 & & & & \\
\hline Turnover & & & & & & & \\
\hline CFA not possible & & & & & & & \\
\hline
\end{tabular}

In job performance (job) the CFA analysis showed factor loadings from .390 to .858 . E10 (in general how is your customer service) was not included because of poor factor loading; CFA was performed again with the remaining items for this variable. The resulting AVE was .55 . Similarly, job performance (career and team) had items (E8 and E12) with low factor loadings which were eliminated and CFA was performed to obtain new factor loadings. Overall, all job performance measures had an AVE of .5 or greater confirming convergence. Composite and Cronbach alpha very close to .7 for one scale and was greater than .7 for the rest, strengthening reliability. Lastly, the final outcome variable turnover had only two items on the questionnaire thus CFA was not performed on these scales 


\subsubsection{Establishing Discriminant Validity}

Discriminant validity examines how constructs are different from one another. This is important so that constructs are not over estimated and their real relationship can be interpreted with confidence (Farrell, 2010). In the IT-SSO model, there are three main constructs indicating motivational, social and service characteristics. In order to establish the discriminant validity of these different constructs, CFA techniques were used. The CFA results could not establish discriminant validity between motivational and social characteristics: the average variance extracted (AVE) estimates for these constructs were not larger than the corresponding squared interconstruct correlation estimates (SIC). However, the following points have to be taken into consideration when calculating the discriminant validity for these constructs. Firstly, in the early job design literature, the motivational characteristics were considered as the predictors of motivation (Hackman \& Oldham, 1980). Motivational characteristics mainly looked into the task characteristics of work, but as research in job design progressed, scholars also identified the importance of social characteristics for individual workers and the need to include these characteristics in job design (Parker \& Wall, 2001; Morgeson \& Humphrey, 2006; Grant, 2007). Some of the motivational predictors were examined through the social interaction lens and were then classified as social job characteristics variables. A good example of this is task interdependence as proposed by Kiggundu (1981). Thus there is a common theoretical basis underlying some motivational and social constructs in the job design literature. This impacts the discriminant validity between the two constructs. 
Secondly, a majority of the scales used for the motivational and social variables were adopted from Moreson and Humphrey (2006). In this study, construct validity was established by examining how the constructs converge with the existing published job occupational databases such as the Occupational Information Network (O*NET) and the Dictionary of Occupational Titles (DOT).

Thirdly, the most stringent test to determine discriminant validity is the average variance extracted versus shared variance test (Farrell, 2010). When examined using this test, the motivational and social job characteristics did not show discriminant validity Further, Farrell (2010) suggests that to determine discriminant validity, researchers can also perform EFA to see whether any items show cross loading, and also calculate the AVE for each construct. Both of these analyses have been performed in this study. Therefore, when assessing discriminant validity between the motivational and social job characteristics, the fact that they share a common theoretical background and that Morgeson and Humphrey (2006) have established construct validly for the measurement scales should be taken into account. With this in mind, it can be understood that the failure to establish discriminant validity between the motivational and social job characteristics will not seriously impact the results these constructs predict. However, Farrell (2010) also suggests that when there is poor discriminant validity between two constructs, researchers need to acquire additional data in order to establish discriminant validity; if discriminant validity is still not sufficiently established, researchers need to think about combining these constructs. This approach can be applied to the motivational and social job characteristics: In subsequent studies, if these two constructs continue to show poor 
discriminant validity, job design researchers should consider combining these two constructs into one.

We have introduced a new construct called service characteristics, which must be differentiated from existing job characteristics. Discriminant validity was assessed between the motivation characteristics, social characteristics and service characteristics. The results are given below.

Table 46: CFA results for Discriminant Validity - Service Variables

\begin{tabular}{|l|r|l|l|l|l|}
\hline & Factor loadings & AVE & & $\begin{array}{l}\text { Interconstruct- } \\
\text { Correlations }\end{array}$ & $\begin{array}{l}\text { Squared } \\
\text { Interconstruct- } \\
\text { Correlations }\end{array}$ \\
\hline $\begin{array}{l}\text { Service } \\
\text { technology }\end{array}$ & 0.67 & 0.54 & $\begin{array}{l}\text { Service - } \\
\text { Motivation }\end{array}$ & .714 & .56 \\
\hline $\begin{array}{l}\text { Service } \\
\text { failure }\end{array}$ & 0.85 & & $\begin{array}{l}\text { Service - } \\
\text { Social }\end{array}$ & .618 & .38 \\
\hline $\begin{array}{l}\text { Service } \\
\text { recovery }\end{array}$ & 0.70 & & & & \\
\hline $\begin{array}{l}\text { Servicer } \\
\text { standard }\end{array}$ & 0.71 & & & & \\
\hline
\end{tabular}

To establish discriminant validity, the AVE of a construct must be higher than the squared inter-construct (SIC) correlation, which is defined as the shared variance of those constructs (Fornell \& Larcker, 1981). As shown in table 5.27, the AVE for the service construct is greater than the shared variance of the service and social constructs, thereby establishing discriminant validity among the constructs. However, the AVE for the service construct and the shared variance between the motivation and service constructs is not greater than the SIC but is almost at par, showing some discriminant validity. 


\subsection{Hierarchical Regression}

In chapter four, this report presented the hypotheses related to ITS work. To examine these hypotheses, three sets of hierarchical regressions were carried out. Hierarchical multiple regression allows us to specify a fixed order of entry for variables in order to control for the effects on a set of predictors, independent of the influence of other factors (Stevens, 1996; Field, 2009). In the hierarchical regressions in this study, the two occupation variables 'type of work' and 'type of skill' were entered in the first block and their influence on job outcomes was observed. The types of work included transactional work (type 1), transformational work (type 2), and professional and advisory work (type 3). The second occupation variable, "type of skill', included IT skills and non-IT skills. In the second block, the job characteristics predictors were entered and the significant predictors were identified.

\subsubsection{Hierarchical Regression with Motivational Characteristics}

\subsubsection{Motivational Characteristics and Job Satisfaction}

Job satisfaction was the dependent variable. The occupation variables 'type of work' and 'type of skill' were entered in the first block and all eight motivational characteristics were entered in the second.

Table 47: Model Summary of Occupation Variables, Motivational Variables and Job satisfaction

\begin{tabular}{|l|r|r|r|r|}
\hline Model & $\mathbf{R}$ & \multicolumn{1}{|c|}{$\mathbf{R}^{\mathbf{2}}$} & Adjusted $\mathbf{R}^{2}$ & $\begin{array}{c}\text { Std. Error } \\
\text { of the } \\
\text { Estimate }\end{array}$ \\
\hline 1 & $.230 \mathrm{a}$ & .053 & .016 & .95673 \\
\hline 2 & $.716 \mathrm{~b}$ & .512 & .435 & .72516 \\
\hline
\end{tabular}


As shown in the above table, in the first model with only two control variables the $\mathrm{R}^{2}$, which measures the variability on the dependent variable, was only 5 percent. But when the eight motivation variables were entered, the amount of variance increased to over 51 percent. The analysis of variance showed that the first model with only the control variables was not significant in predicting job satisfaction $(p=.241)$, but the second model with all eight motivation variables was significant, with a $p$ value $<.05$ . The coefficient output from the SPSS provided the following results.

Table 48: Coefficient Table for Occupation Variables, Motivational Variables and Job Satisfaction

\begin{tabular}{|c|c|c|c|c|c|c|}
\hline \multirow{2}{*}{\multicolumn{2}{|c|}{ Model }} & \multicolumn{2}{|c|}{$\begin{array}{c}\text { Unstandardized } \\
\text { Coefficients }\end{array}$} & \multirow{2}{*}{$\begin{array}{c}\begin{array}{c}\text { Standardized } \\
\text { Coefficients }\end{array} \\
\text { Beta } \\
\end{array}$} & \multirow[b]{2}{*}{$\mathbf{t}$} & \multirow[b]{2}{*}{ Sig. } \\
\hline & & B & $\begin{array}{l}\text { Std. } \\
\text { Error }\end{array}$ & & & \\
\hline \multirow[t]{4}{*}{1} & (Constant) & 3.383 & .236 & & 14.340 & .000 \\
\hline & Type of Work 1 & .430 & .257 & .224 & 1.671 & .099 \\
\hline & Type of Work 2 & .346 & .310 & .156 & 1.114 & .269 \\
\hline & Skill Two & -.206 & .237 & -.101 & -.868 & .388 \\
\hline \multirow[t]{12}{*}{2} & (Constant) & -.913 & .726 & & -1.258 & .213 \\
\hline & Type of Work 1 & .158 & .221 & .082 & .713 & .478 \\
\hline & Type of Work 2 & .323 & .249 & .145 & 1.299 & .198 \\
\hline & Skill Two & -.136 & .193 & -.067 & -.706 & .482 \\
\hline & Anivonominy & 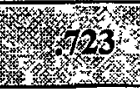 & 1 & 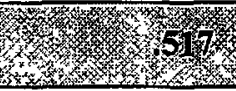 & 4 & tion \\
\hline & Skill Variety & .083 & .199 & .055 & .416 & .679 \\
\hline & Task Variety & .015 & .201 & .011 & .073 & .942 \\
\hline & Task Significance & .031 & .100 & .035 & .312 & .756 \\
\hline & Task Identity & .091 & .126 & .088 & .719 & .474 \\
\hline & Feedback from Job & .154 & .156 & .127 & .986 & .327 \\
\hline & Information Amount & .075 & .097 & .071 & .768 & .445 \\
\hline & Information Equivocality & .017 & .100 & .016 & .170 & .865 \\
\hline
\end{tabular}

* significant level $\mathrm{P}<.01$ 
Among the eight motivational variables, autonomy was the only significant contributor to the model with a beta value of .517 and a $p=.000$ and was highly significant $(\mathrm{P}<.01)$. The other variables did not significantly impact job satisfaction.

\subsubsection{Motivational Characteristics and Job Performance}

Job performance (job, career, innovator, team, organization) was entered as the dependent variable in a sequence of regressions. The control variables 'type of work' and 'type of skill' were entered in the first block and the eight motivational variables were entered in the second block as independent variables. As shown in Table 49, the models with only control variables showed very insignificant variance on the dependent variable. But when the motivational variables were entered in the second block, the value for $\mathrm{R}^{2}$ changed significantly. Motivational characteristics and control variables had significant influence on three of the job performance roles performance in job, career, and organization. In the first regression, the control variable 'type of work 1' (transactional work) significantly influenced job performance in the job role. However, when the motivational characteristics were added to the second model, the variable lost its significance. Results of the hierarchical regression analysis where job performance in the career role was the dependent variable showed that autonomy was the significant predictor. The beta value of .440 and a $p$ value $=.007$ indicate that autonomy is a very significant predictor $(\mathrm{p}<.01)$. Similarly, the hierarchical regression where the dependent variable was job performance - organization showed that the model with two control variables explained a variance of only 04 percent, which was not significant. The second model 
with the motivation variables very significantly predicted ITS employee job performance in the organizational context. The output showed that the second model was significant with a $\mathrm{p}$ value of .001 (significant at .01 percent). The coefficient table presented below shows that autonomy and skill variety were both contributing significant predictors. Autonomy was a more significant predictor than skill variety: autonomy had the largest beta value (.378) with a $p$ value of $.012(p<.01)$, followed by skill variety with a beta value of .365 and a $p$ value $=.028(p<.05)$.

Table 49: Hierarchical Regressions when Job Performance is the Dependent Variable with Motivational Variables

\begin{tabular}{|c|c|c|c|c|c|c|c|c|}
\hline $\begin{array}{l}\text { Job } \\
\text { performance }\end{array}$ & $\begin{array}{l}1 \\
\text { step } \\
\text { R2 }\end{array}$ & $\begin{array}{l}\text { Model } \\
\text { significance }\end{array}$ & $\begin{array}{l}\text { Significant } \\
\text { predictors }\end{array}$ & $\begin{array}{l}\text { P value } \\
\text { \& Beta }\end{array}$ & $\begin{array}{l}2 \\
\text { step } \\
\mathbf{R 2}\end{array}$ & $\begin{array}{l}\text { Model } \\
\text { significance }\end{array}$ & $\begin{array}{l}\text { Significant } \\
\text { predictors }\end{array}$ & \begin{tabular}{|l|}
$\mathbf{P}$ \\
value \\
$\&$ \\
Beta \\
\end{tabular} \\
\hline (6) & 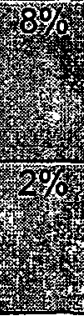 & 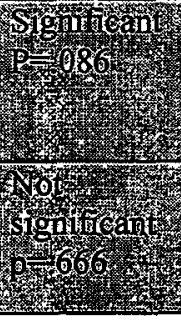 & Sy & & 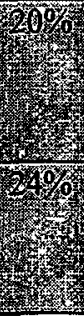 & 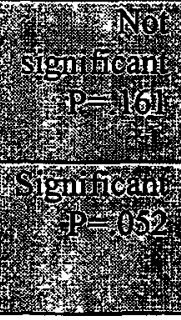 & $y^{2}$ & 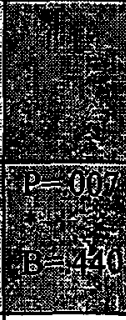 \\
\hline Innovator & $5 \%$ & $\begin{array}{l}\text { Not } \\
\text { significant } \\
p=.267\end{array}$ & & & $17 \%$ & $\begin{array}{r}\text { Not } \\
\text { Significant } \\
\mathrm{P}=.293\end{array}$ & & \\
\hline Team & $4 \%$ & $\begin{array}{l}\text { Not } \\
\text { significant } \\
p=.368\end{array}$ & & & $18 \%$ & $\begin{array}{r}\text { Not } \\
\text { Significant } \\
P=.196\end{array}$ & & \\
\hline$y^{2}$ & 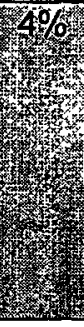 & Pof & $\begin{array}{l}3 \\
4 \\
4\end{array}$ & H) & 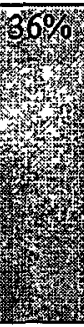 & (3) & $\begin{array}{l}3 \\
4 \\
4\end{array}$ & 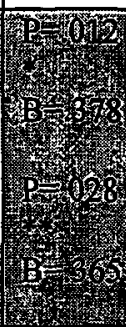 \\
\hline
\end{tabular}




\subsubsection{Motivational Characteristics and Turnover}

The last hierarchical regression with the motivational variables was performed to determine how motivational variables affect turnover intentions of ITS employees. As in previous instances, the control variables 'type of work' and 'type of skills' were entered in the first block and the eight motivational variables were entered in the second block. Turnover was placed as the dependent variable. The regression analysis for the first model with the two variables showed an $R^{2}$ of only 8 percent. In the second model with the motivational variables, the $\mathrm{R}^{2}$ increased to 36 percent. Both models were significant, with the first model having a $\mathrm{p}$ value $=.074$ and the second having a $\mathrm{p}$ value $=.001$.

Table 50: Model Summary of Occupation Variables, Motivational Variables and Turnover

\begin{tabular}{|l|r|r|r|r|}
\hline Model & \multicolumn{1}{|c|}{$\mathbf{R}$} & \multicolumn{1}{|c|}{$\mathbf{R}^{2}$} & \multicolumn{1}{|c|}{ Adjusted $\mathbf{R}^{2}$} & \multicolumn{2}{c|}{$\begin{array}{c}\text { Std. Error of the } \\
\text { Estimate }\end{array}$} \\
\hline 1 & .295 & .087 & .051 & 1.14338 \\
\hline 2 & .605 & .366 & .264 & 1.00704 \\
\hline
\end{tabular}

The coefficient table showed that in the first model, 'type of work 1' (transactional work) influenced turnover. Transactional work had a negative beta value of .223 with a $\mathrm{p}$ value of .101 , signifying that individuals who performed transactional work at ITS had greater turnover intentions than those performing transformational work. In the second model, autonomy, with a negative beta value of .238 and a $p$ value of .045 , was the sole predictor influencing turnover intentions. The negative beta indicates 
that an increase in autonomy was associated with a decrease in turnover intentions among ITS employees.

Table 51: Coefficient Table for Occupation Variables, Motivational Variables and Turnover

\begin{tabular}{|c|c|c|c|c|c|c|}
\hline \multirow{2}{*}{\multicolumn{2}{|c|}{ Model }} & \multicolumn{2}{|c|}{$\begin{array}{l}\text { Unstandardized } \\
\text { Coefficients }\end{array}$} & \multirow{2}{*}{$\begin{array}{c}\begin{array}{c}\text { Standardized } \\
\text { Coefficients }\end{array} \\
\text { Beta }\end{array}$} & \multirow[b]{2}{*}{$\mathbf{T}$} & \multirow[b]{2}{*}{ Sig. } \\
\hline & & $\mathrm{B}$ & Std. Error & & & \\
\hline \multirow[t]{4}{*}{1} & (Constant) & 2.308 & .291 & & 7.934 & .000 \\
\hline & Type of Work $\mathbf{1}^{2}$ & 5520 & $4=y^{3}=313$ & 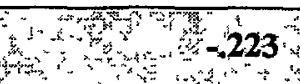 & 1,662 & $401 \times 6$ \\
\hline & Type of Work 2 & -.575 & .377 & -.213 & -1.523 & .132 \\
\hline & Skill Two & .411 & .286 & .167 & 1.439 & .154 \\
\hline \multirow[t]{12}{*}{2} & (Constant) & 6.605 & 1.013 & & 6.521 & .000 \\
\hline & Type of Work 1 & -.263 & .310 & -.113 & -.848 & .399 \\
\hline & Type of Work 2 & -.392 & .350 & -.145 & -1.121 & .266 \\
\hline & Skill Two & .350 & .272 & .142 & 1.287 & .202 \\
\hline & Hiteplom & 8 & 2,88 & 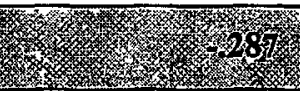 & 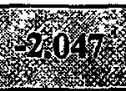 & 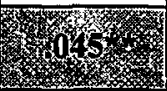 \\
\hline & Skill Variety & -.114 & .277 & -.063 & -.413 & .681 \\
\hline & Task Variety & -.271 & .279 & -.172 & -.970 & .336 \\
\hline & Task Significance & -.100 & .139 & -.092 & -.721 & .473 \\
\hline & Task Identity & -.162 & .175 & -.128 & -.925 & .358 \\
\hline & Feedback from Job & .052 & .218 & .035 & .237 & .813 \\
\hline & Information Amount & .143 & .135 & .111 & 1.054 & .296 \\
\hline & $\begin{array}{l}\text { Information } \\
\text { Equivocality }\end{array}$ & -.220 & .139 & -.173 & -1.583 & .118 \\
\hline
\end{tabular}




\subsubsection{Hierarchical Regression with Social Characteristics and Outcome Variables}

\subsubsection{Social Characteristics and Job Satisfaction}

First, regression analysis was performed placing job satisfaction as the dependent variable. In the first block, the control variables 'type of work' and 'type of skill' were entered. In the second block, 'initiated interdependence', 'received interdependence', 'social support from supervisor', 'social support from friends', 'feedback from others' and 'outside interaction' were entered. The model summary showed that the first model provided an $\mathrm{R}^{2}$ of .08 while the second block showed a much improved $\mathrm{R}^{2}$ of .43 Both models appear to significantly predict job satisfaction, though the first model is less significant than the second.

Table 52: Model Summary of Occupation Variables, Social Variables and Job Satisfaction

\begin{tabular}{|l|c|r|r|r|}
\hline Model & $\mathbf{R}$ & $\mathbf{R}^{2}$ & ${\text { Adjusted } \mathbf{R}^{2}}^{2}$ & Std. Error of the Estimate \\
\hline 1 & $.286 \mathrm{a}$ & .082 & .049 & .96040 \\
\hline 2 & $.657 \mathrm{~b}$ & .432 & .366 & .78390 \\
\hline
\end{tabular}

In the model with only the control variables, the most significant predictors for job satisfaction were transactional work ( $p$ value of .039 , with a beta of .261 ) and transformational work ( $\mathrm{p}$ value of .050 with a beta of .249 ). When the six social characteristics were entered into the regression, four of them - 'received interdependence', 'feedback from others', 'support from friends', and 'social support from supervisor' - were seen to influence job satisfaction. 'Social support from supervisor' had the largest beta of .286 and a p value of .015 , while 'social support from friends' had a beta coefficient of .277 and a $p$ value of .019 ; both variables 
were significant at the .05 level. For the predictor variable 'feedback from others', beta was .160 and $p$ value was .089 ; received interdependence had a negative beta of .181 and $\mathrm{p}$ value of .049 . Both predictors were significant at a .10 level.

Table 53: Coefficient Table for Occupation Variables, Social Variables and Job Satisfaction

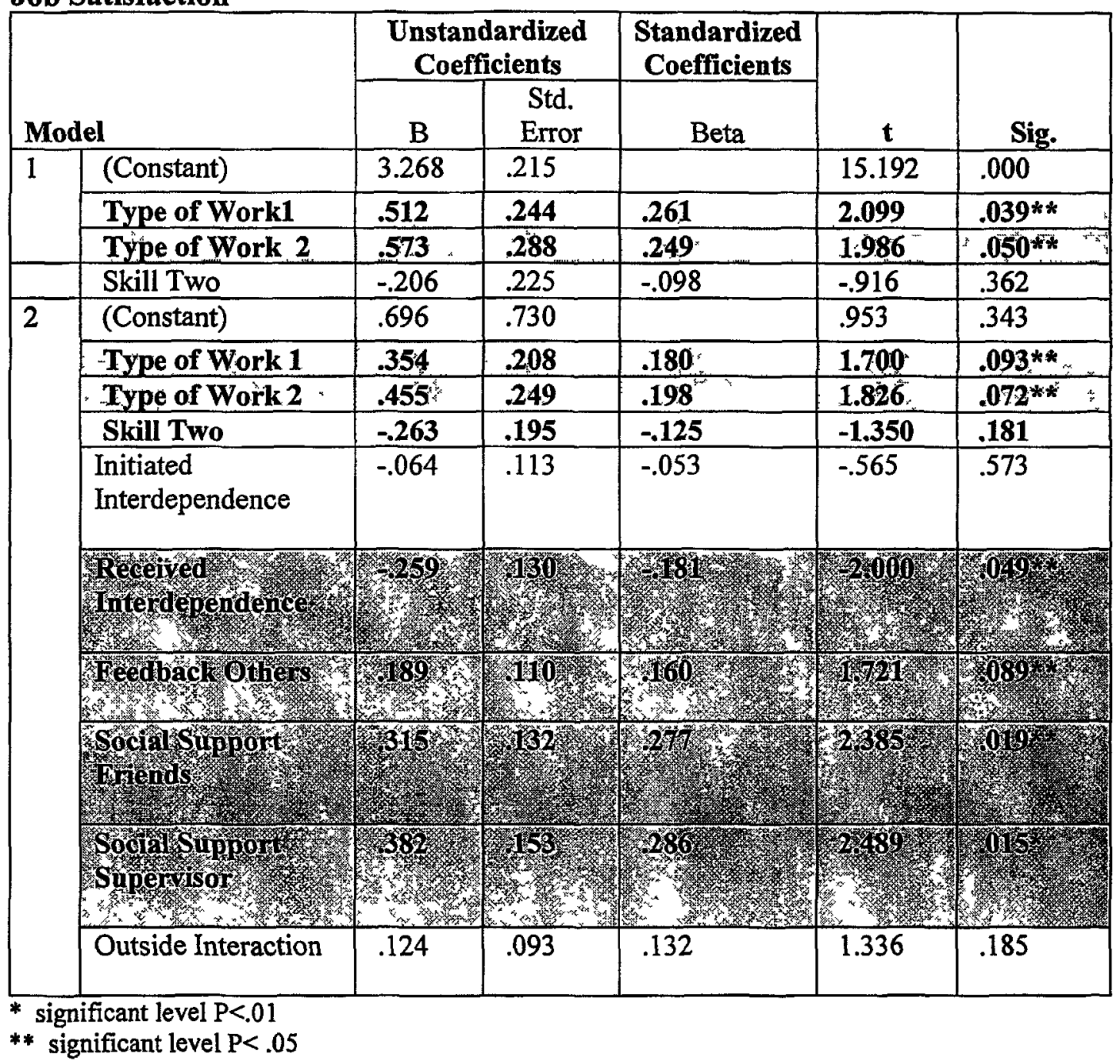




\subsubsection{Social Characteristics and Job Performance}

Next, when job performance (in job, career, innovator, team and organization) was the dependent variable, the first model with only the two control variables presented a very small variance on job performance in different roles. But when the social variables were entered in the second block, the $R^{2}$ of the regressions increased significantly. The regression analysis with social characteristics as predictors was only significant for job performance in the career, team, and organization roles. In the regression with social characteristics and job performance in the career role, 'social support from friends' had the highest beta value of .414 and a $p$ value of .001 , and was highly significant at the .01 level. 'Received interdependence' had a negative beta, indicating a negative relationship between this predictor variable and job performance in the career role. In the same regression, 'feedback from others' (beta of .180 and $\mathrm{p}$ value .082 ) and 'outside interaction' (beta of .185 and $\mathrm{p}$ value .093 ) were the other predictors (both significant at the .10 level) influencing job performance in the career role. Interestingly, in the second model along with the social variables, 'type of work 1 ' was also significant at the .10 level.

In the regression where job performance in the team role was the dependent variable, 'feedback from others' was the only significant predictor with a beta value of .252 and a $p$ value of .022 , and was significant at the .05 level. Further, the regression results where job performance - organization was the dependent variable showed 'feedback from others' and 'received interdependence' to be significant predictors. 'Received independence' had a negative beta value of .180 and a $p$ value of .109 and 
was significant at .10. 'Feedback from others' had a beta of .267 with $p$ value of .020 and was significant at .05 . It is notable that 'initiated interdependence' was the only social variable that did not have any influence on job performance for these ITS employees.

Table 54: Hierarchical Regressions when Job Performance is the Dependent Variable with Social Variables

\begin{tabular}{|c|c|c|c|c|c|c|c|}
\hline $\begin{array}{l}\text { Job } \\
\text { performance }\end{array}$ & $\begin{array}{l}1 \\
\text { step } \\
\mathbf{R}^{2}\end{array}$ & \begin{tabular}{|l} 
Model \\
significance
\end{tabular} & $\begin{array}{l}\text { Significant } \\
\text { predictors }\end{array}$ & $\begin{array}{l}2 \\
\text { step } \\
\mathbf{R}^{2}\end{array}$ & $\begin{array}{l}\text { Model } \\
\text { significance }\end{array}$ & $\begin{array}{r}\text { Significant } \\
\text { predictors }\end{array}$ & $\begin{array}{r}\text { P value } \\
\text { \& Beta }\end{array}$ \\
\hline Job & $1 \%$ & \begin{tabular}{|l|} 
Not \\
significant \\
$\mathrm{P}=.757$ \\
\end{tabular} & & $13 \%$ & $\begin{array}{l}\text { Not } \\
\text { significant } \\
\mathrm{P}=.284 \\
\end{array}$ & & - \\
\hline 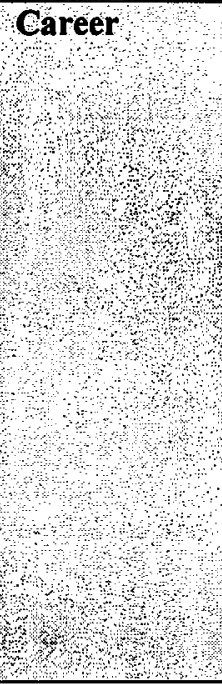 & $1 \%$ & $\begin{array}{l}\text { Not } \\
\text { significant } \\
\mathrm{P}=732\end{array}$ & & 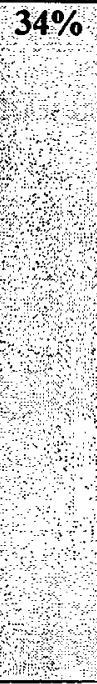 & $\begin{array}{ll}\text { Significant } \\
\mathrm{P}=000 \\
\end{array}$ & $\begin{array}{l}\text { Type of } \\
\text { work } \\
\text { One } \\
\text { Received } \\
\text { inter } \\
\text { dependence } \\
\text { Feedback } \\
\text { from others } \\
\text { Social } \\
\text { support } \\
\text { from friends } \\
\text { Outside } \\
\text { interaction }\end{array}$ & $\begin{array}{l}\mathrm{P}=069^{* * *} \\
\mathrm{~B}=.220 \\
\mathrm{P}=054^{* *} \\
\mathrm{~B}=195 \\
\mathrm{P}=0 \mathrm{082} \\
\mathrm{B}=180 \\
\mathrm{P}=0.01 \% \\
\mathrm{~B}=\mathrm{421} \\
\mathrm{P}=0.093^{* * *} \\
\mathrm{~B}=185\end{array}$ \\
\hline Innovator & $1 \%$ & $\begin{array}{l}\text { Not } \\
\text { significant } \\
P=.864\end{array}$ & & $12 \%$ & $\begin{array}{l}\text { Not } \\
\text { significant } \\
\mathrm{P}=.294\end{array}$ & None & - \\
\hline Team & $2 \%$ & $\begin{array}{l}\text { Not } \\
\text { significant } \\
\mathbf{P}=.543\end{array}$ & & $24 \%$ & $\begin{array}{l}\text { Significant } \\
\mathrm{P}=009\end{array}$ & $\begin{array}{l}\text { Feedback } \\
\text { from others }\end{array}$ & $\begin{array}{l}\mathrm{P}=022^{\star *} \\
\mathrm{~B}=252\end{array}$ \\
\hline Organization & $1 \%$ & $\begin{array}{l}\text { Not } \\
\text { significant } \\
\mathbf{P}=769\end{array}$ & & $18 \%$ & $\begin{array}{l}\text { Significant } \\
\mathrm{P}=0 \mathrm{3}\end{array}$ & $\begin{array}{l}\text { Rec inter } \\
\text { dependence } \\
\text { Feedback } \\
\text { from others }\end{array}$ & $\begin{array}{l}\mathrm{P}=108^{* * *} \\
\mathrm{~B}=180^{\circ} \\
\mathrm{P}=.020^{*} \\
\mathrm{~B}=267\end{array}$ \\
\hline
\end{tabular}




\subsubsection{Social Characteristics and Turnover}

Next, a hierarchal regression with social characteristics and control variables as independent variables and turnover as the dependent variable was performed. For the control variables 'type of skill' and 'type of work' the $\mathrm{R}^{2}$ was only 9 percent but was significant at the .05 level with a $\mathrm{p}$ value of .038 . In step two with the social variables, the $R^{2}$ increased to 36 percent. This produced a significant model with a $p$ value of .000 .

Table 55: Model Summary of Occupation Variables, Social Variables and Turnover

\begin{tabular}{|r|r|r|r|r|}
\hline Model & $\mathbf{R}$ & $\mathbf{R}^{2}$ & $\begin{array}{r}\text { Adjusted } \\
\text { R Square }\end{array}$ & $\begin{array}{c}\text { Std. Error of the } \\
\text { Estimate }\end{array}$ \\
\hline 1 & $.310 \mathrm{a}$ & 0.096 & 0.063 & 1.12216 \\
\hline 2 & $.604 \mathrm{~b}$ & 0.365 & 0.291 & 0.97632 \\
\hline
\end{tabular}

The coefficient table showed that in the first model, 'type of work 2' and 'skill two' had significant influence on turnover intentions. Transformational work had a negative beta value of -.211 and a $p$ value of .099 . Non-IT skills had a beta value of .203 and a $p$ value of .062 . In the second model along with social variables, non-IT skills still showed significant influence on turnover, such that an increase in non-IT skills corresponded to an increase in turnover intentions. 
Table 56: Coefficient Table for Occupation Variables, Social Variables and Turnover

\begin{tabular}{|c|c|c|c|c|c|c|}
\hline \multirow{2}{*}{\multicolumn{2}{|c|}{ Model }} & \multicolumn{2}{|c|}{$\begin{array}{l}\text { Unstandardized } \\
\text { Coefficients }\end{array}$} & \multirow{2}{*}{$\begin{array}{c}\begin{array}{c}\text { Standardized } \\
\text { Coefficients }\end{array} \\
\text { Beta } \\
\end{array}$} & \multirow[b]{2}{*}{$\mathbf{t}$} & \multirow[b]{2}{*}{ Sig. } \\
\hline & & $\mathrm{B}$ & Std. Error & & & \\
\hline \multirow[t]{3}{*}{1} & (Constant) & 2.259 & .258 & & 8.761 & .000 \\
\hline & Type of Work 1 & -.418 & .289 & -.181 & -1.447 & .152 \\
\hline & 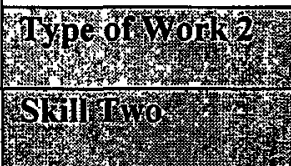 & 3019 & 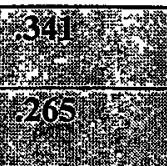 & 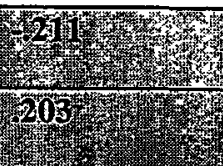 & 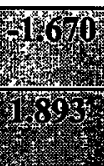 & 06 \\
\hline \multirow[t]{9}{*}{2} & (Constant) & 4.188 & .931 & & 4.500 & .000 \\
\hline & Type of Work 1 & -.267 & .261 & -.115 & -1.020 & .311 \\
\hline & Type of Work 2 & -.504 & .313 & -.187 & -1.610 & .111 \\
\hline & 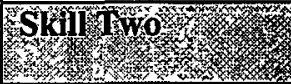 & sol & 16. & 2047 & os & (6) \\
\hline & $\begin{array}{l}\text { Initiated } \\
\text { Interdependence }\end{array}$ & .083 & .141 & .058 & .586 & .560 \\
\hline & 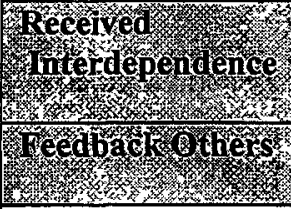 & 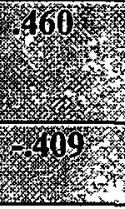 & 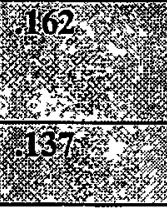 & $\frac{2}{2}$ & 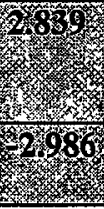 & 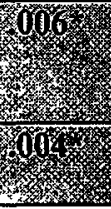 \\
\hline & $\begin{array}{l}\text { Social Support } \\
\text { Friends }\end{array}$ & -.265 & .166 & -.191 & -1.599 & .114 \\
\hline & $\begin{array}{l}\text { Social Support } \\
\text { Supervisor }\end{array}$ & -.259 & .192 & -.162 & -1.351 & .181 \\
\hline & Outside Interaction & -.138 & .117 & -.124 & -1.180 & .242 \\
\hline
\end{tabular}

* significant level $\mathrm{P}<.01$

** significant level $\mathrm{P}<.05$

*** significant level $\mathrm{P}<.10$

In the second model, in addition to the non IT- skills, 'received interdependence' and 'feedback from others' predicted turnover. 'Received interdependence' was significant with a beta of .274 and a p value of .006 . Similarly, 'feedback from others had a beta of .293 and $p$ value of .004 . Both predictors were highly significant at the .01 level. 


\subsubsection{Hierarchical Regression with Service Orientation Characteristics and Outcome Variables}

\subsubsection{Service Characteristics and Job Satisfaction}

The last set of hierarchical regressions was done with the service orientation variables ('service technology', 'service failure prevention', 'service recovery' and 'service communication standards') and job satisfaction. In the regression analysis, type of skill and type of work were entered in the first block, and all four service variables were entered in the second block with job satisfaction as the dependent variable.

The model summary showed that the first step with the control variables influenced the $\mathrm{R}^{2}$ by 11 percent, while in the second model the service variables increased the $\mathrm{R}^{2}$ to 31 percent. As shown in the following table, both steps provided significant models showing influence on job satisfaction for ITS workers.

Table 57: Model Summary of Occupation Variables, Service Orientation Variables and Job Satisfaction

\begin{tabular}{|l|r|r|r|r|}
\hline Model & $\mathbf{R}$ & $\mathbf{R}^{2}$ & Adjusted $\mathbf{R}^{2}$ & Std. Error of the Estimate \\
\hline 1 & $.341 \mathrm{a}$ & .116 & .087 & .91531 \\
\hline 2 & $.562 \mathrm{~b}$ & .316 & .260 & .82377 \\
\hline
\end{tabular}

In the first model, the two control variables 'type of work 1' and 'type of work 2' were very significant predictors. Transactional work was a more significant predictor with a beta of .382 . Transformational work on the other had a beta of .274 and a $\mathrm{p}$ value of .02 . Both transactional and transformational work were highly significant at the .01 level. 
Table 58: Coefficient Table for Occupation Variables, Service

Orientation Variables and Job Satisfaction

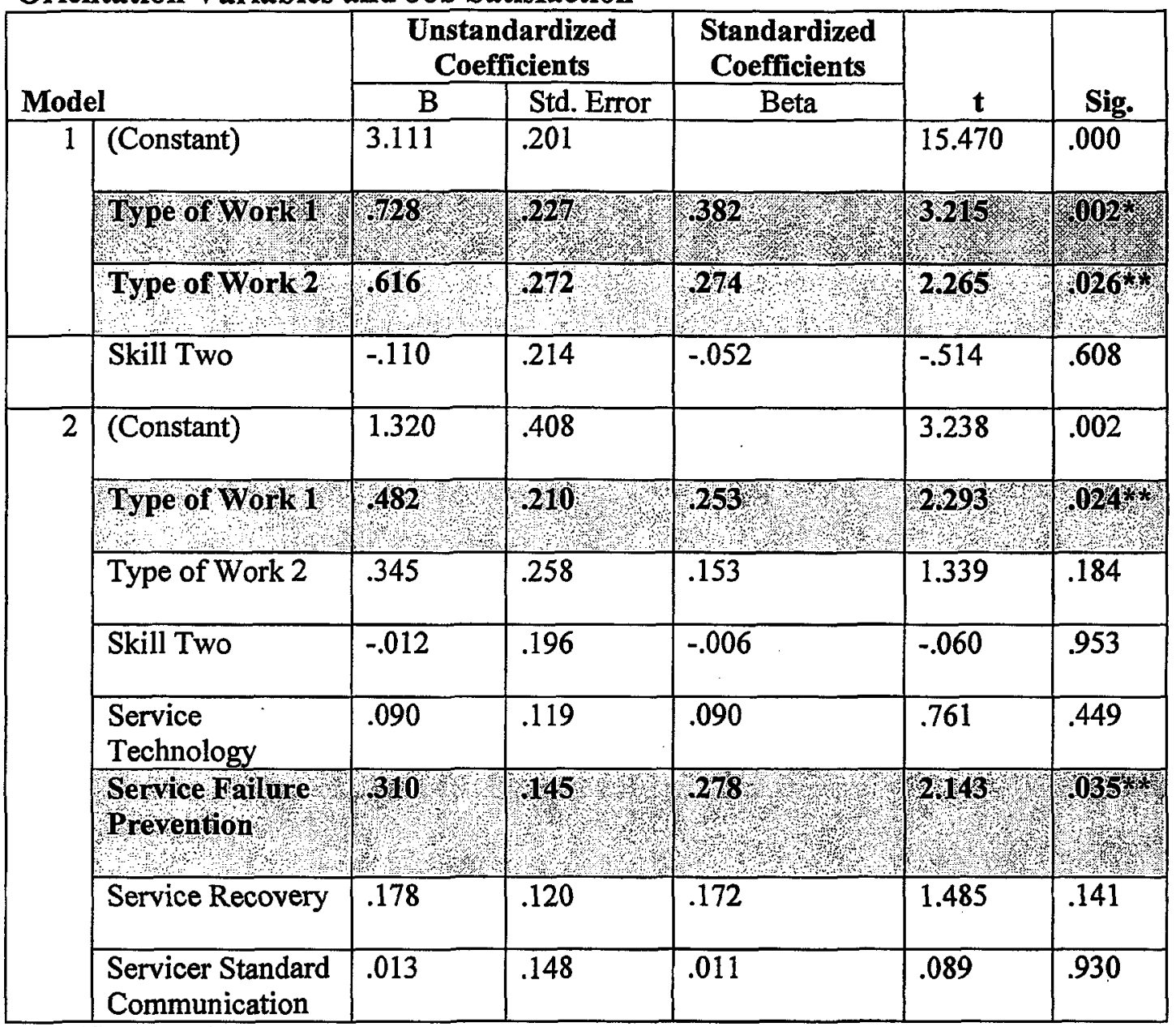

* significant level $\mathrm{P}<.01$

** significant level $\mathrm{P}<.05$

In the second model also, transactional work continued to be significant. Among the four service variables only 'service failure prevention' had a significant effect on job satisfaction. The regression beta was .278 with a $p$ value of .035 . 


\subsubsection{Service Characteristics and Job Performance}

Subsequently, regression was carried out with job performance outcomes as the dependent variable. When the two control variables were entered into the regression model in step one, as shown in the following table, they did not influence job performance substantially.

Table 59: Hierarchical Regressions when Job Performance is the Dependent Variable with Service Orientation Variables

\begin{tabular}{|c|c|c|c|c|c|c|c|}
\hline $\begin{array}{l}\text { Job } \\
\text { performance }\end{array}$ & $\begin{array}{l} \\
\text { step } \\
\mathbf{R}^{2}\end{array}$ & $\begin{array}{l}\text { Model } \\
\text { significance }\end{array}$ & \begin{tabular}{|l|} 
Signifficant \\
predictors
\end{tabular} & \begin{tabular}{|l|}
2 \\
step \\
$\mathbf{R}^{2}$
\end{tabular} & \begin{tabular}{|l|}
$\begin{array}{l}\text { Model } \\
\text { significance }\end{array}$ \\
\end{tabular} & $\begin{array}{l}\text { Significant } \\
\text { predictors }\end{array}$ & $\begin{array}{l}\text { P value \& } \\
\text { Beta }\end{array}$ \\
\hline Job & $4 \%$ & $\begin{array}{l}\text { Not } \\
\text { significant } \\
\mathrm{P}=.219\end{array}$ & & $11 \%$ & \begin{tabular}{|l|} 
Not \\
significant \\
$P=.156$
\end{tabular} & - & - \\
\hline Career & $0 \%$ & $\begin{array}{l}\text { Not } \\
\text { significant } \\
P=.849\end{array}$ & & $7 \%$ & $\begin{array}{l}\text { Not } \\
\text { Significant } \\
\\
\mathrm{P}=.432\end{array}$ & - & - \\
\hline Innovator & $1 \%$ & $\begin{array}{l}\begin{array}{l}\text { Not } \\
\text { significant }\end{array} \\
\mathrm{P}=.684\end{array}$ & & $7 \%$ & $\begin{array}{l}\text { Not } \\
\text { significant } \\
\mathrm{P}=.488\end{array}$ & -- & - \\
\hline $\begin{array}{l}\text { Team } \\
\\
\end{array}$ & $3 \%$ & $\begin{array}{l}\text { Not } \\
\text { significant } \\
P=.427\end{array}$ & 繁要 & $\begin{array}{l}16 \% \\
\vdots \\
*\end{array}$ & $\begin{array}{l}\text { Significant } \\
\mathbf{P}=\mathbf{0 3 5} \\
x_{n}\end{array}$ & None & 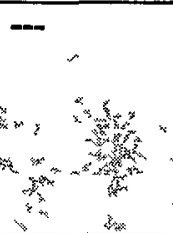 \\
\hline Organization & $2 \%$ & $\begin{array}{l}\text { Not } \\
\text { significant } \\
\mathrm{P}=.505\end{array}$ & * & $21 \%$ & $\begin{array}{l}\text { Significẩnt } \\
\mathrm{P}=.005\end{array}$ & $\begin{array}{l}\text { Service } \\
\text { Failure } \\
\text { Prevention } \\
\text { Service } \\
\text { Recovery } \\
\end{array}$ & $\begin{array}{l}\overrightarrow{\mathbf{P}}=.045_{k}^{*} \\
\mathrm{~B}=.279 \\
\mathrm{P}=0.063^{* * *} \\
\mathrm{~B}=.232 \\
\end{array}$ \\
\hline
\end{tabular}

* significant level $\mathrm{P}<.01$

** significant level $\mathrm{P}<.05$

*** significant level $\mathrm{P}<.10$ 
After the service variables were introduced into the regression, the value of $R^{2}$ increased; the largest and most significant increase was in job performance in the team and organization roles

When job performance - team was the dependent variable in the second step with all the service variables, the model was significant at the .05 level with a $p$ value of .020. However, when the coefficient table was examined for significant predictors, none of the predictors proved to be significant. This may be due to the fact that when the service variables were entered into the regression, the variance shared between the first independent variable and dependent variable overlapped with the variance that is shared between the other independent variables. In such a case it would be possible to have a significant $R^{2}$ yet have no significant independent variables (Tabachnick \& Fidell, 1996). The service variables 'service failure prevention' and 'service recovery' significantly influenced job performance - organization. 'Service failure prevention' had a beta value of .279 and a p value of .045 (significant at the .05 level). 'Service recovery' was significant at .10 with a beta value of .232 and a $p$ value of .063 .

\subsubsection{Service Orientation Characteristics and Turnover}

Lastly, the impact of the service variables on turnover was analyzed through a hierarchical multiple regression. In the first step with only the control variable, the variance on turnover was only 08 percent; however, this was significant for this group of ITS employees. 'Type of work 1' and 'type of work 2' were identified as significant predictors. With a $\mathrm{p}$ value of .026 , transactional work was more 
significant than transformational work. Both had negative beta which indicated a negative relationship with turnover intentions.

Table 60: Model summary of Occupation Variables, Service Orientation Variables and Turnover

\begin{tabular}{|c|c|c|c|c|}
\hline Model & $\mathbf{R}$ & $\mathbf{R}^{2}$ & Adjusted $\mathbf{R}^{2}$ & $\begin{array}{l}\text { Std. Error of the } \\
\text { Estimate }\end{array}$ \\
\hline 1 & $.292 \mathrm{a}$ & .085 & .055 & 1.10195 \\
\hline 2 & $.548 \mathrm{~b}$ & .300 & .243 & .98605 \\
\hline
\end{tabular}

Returning to the regression model with the four service variables, when they were entered into the model the $\mathrm{R}^{2}$ increased to 30 percent. In the second step the model was very significant with a $p$ value of .000 . The significant indictors influencing turnover were 'service failure prevention' and 'service recovery'. 'Service failure prevention' had a higher negative beta of .253 , with a $\mathrm{p}$ value of .05 , while service recovery had a negative beta of .222; both had a $\mathrm{p}$ value of .05 . In the second model with the other service predictors, type of work did not emerge as a significant variable in influencing turnover. 
Table 61: Coefficient Table for Occupation Variables, Service Orientation Variables and Turnover

\begin{tabular}{|c|c|c|c|c|c|c|}
\hline \multirow{2}{*}{\multicolumn{2}{|c|}{ Model }} & \multicolumn{2}{|c|}{$\begin{array}{c}\text { Unstandardized } \\
\text { Coefficients }\end{array}$} & \multirow{2}{*}{ 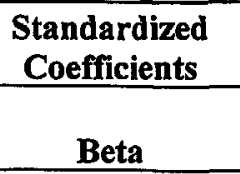 } & \multirow{3}{*}{$\frac{t}{10.019}$} & \multirow{3}{*}{$\begin{array}{r}\text { Sig. } \\
.000\end{array}$} \\
\hline & & \multirow{2}{*}{$\frac{\mathrm{B}}{2.470}$} & \multirow{2}{*}{$\begin{array}{c}\begin{array}{c}\text { Std. } \\
\text { Error }\end{array} \\
.247\end{array}$} & & & \\
\hline 1 & (Constant) & & & & & \\
\hline & 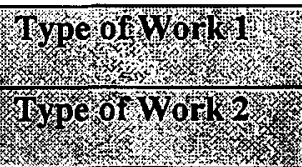 & 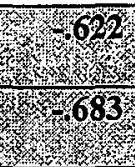 & 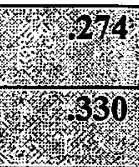 & 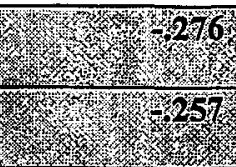 & 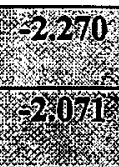 & 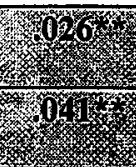 \\
\hline & Skill Two & .231 & .257 & .094 & .900 & .370 \\
\hline 2 & (Constant) & 4.740 & .508 & & 9.333 & .000 \\
\hline & Type of Work1 & -.373 & .250 & -.165 & -1.491 & .140 \\
\hline & Type of Work2 & -.394 & .309 & -.148 & -1.274 & .206 \\
\hline & Skill Two & .095 & .233 & .038 & .406 & .686 \\
\hline & Service Technology & -.125 & .139 & -.104 & -.897 & .372 \\
\hline & 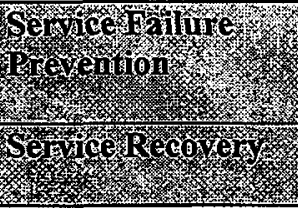 & & $\frac{1}{9}$ & $\sqrt{x}$ & 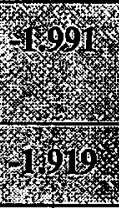 & 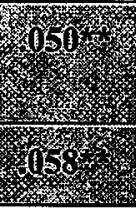 \\
\hline & Servicer Standard & .005 & .177 & .003 & .026 & .979 \\
\hline
\end{tabular}

* significant level $\mathrm{P}<.01$

** significant level $\mathrm{P}<.05$

In addition to separate regression analysis on motivation, social and service characteristics, regression analysis was performed to see the incremental regression results for outcomes by these three job characteristics. 
Table 62: Incremental Regression Results for Outcomes

\begin{tabular}{|c|c|c|c|c|c|}
\hline $\begin{array}{l}\text { Job } \\
\text { Outcomes }\end{array}$ & $\begin{array}{l}\text { Occupation } \\
\text { Variables } \\
\text { Step } 1 \\
\mathbf{R}^{2} \\
\end{array}$ & $\begin{array}{l}\text { Motivational } \\
\text { Characteristics } \\
\text { Step } 2 \\
\Delta \mathbf{R}^{2} \\
\end{array}$ & $\begin{array}{l}\text { Social } \\
\text { Characteristic } \\
\text { Step } 3 \\
\qquad \Delta \mathbf{R}^{2} \\
\end{array}$ & $\begin{array}{l}\text { Service } \\
\text { Characteristics } \\
\text { Step } 4 \\
\quad \Delta \mathbf{R}^{2} \\
\end{array}$ & $\begin{array}{l}\text { Total } \\
\text { R2 } \\
\end{array}$ \\
\hline Job Satisfaction & 0.06 & 0.44 & 0.10 & 0.04 & 0.64 \\
\hline Job Performance & & & & & \\
\hline Job & 0.11 & 0.14 & 0.07 & 0.06 & 0.38 \\
\hline Career & 0.04 & 0.30 & 0.16 & 0.01 & 0.51 \\
\hline Innovation & 0.08 & 0.10 & 0.12 & 0.02 & 0.32 \\
\hline Team & 0.07 & 0.17 & 0.15 & 0.06 & 0.45 \\
\hline Organization & 0.06 & 0.28 & 0.08 & 0.08 & 0.5 \\
\hline Turnover & 0.09 & 0.24 & 0.16 & 0.05 & 0.54 \\
\hline
\end{tabular}

As show in table 62 , the incremental regression results show that motivational characteristics significantly influence job outcomes specially job satisfaction and turn over intensions. Social characteristics influence job outcomes more than service characteristics. The two occupation variables job types and type of skills influence job outcome as much as service orientation characteristics.

This chapter has presented the results obtained from factor analysis. Factor analysis with principal axis factoring and oblique rotation was performed on all items measuring motivational, social service and outcome variables. With the exception of the social support variable, all factors were loaded on to a single factor. Social support was loaded on two components that we classified as 'social support from friends' and 'social support from supervisors'. All questions had a factor loading 
greater than .4 and were retained for further analysis. The study also established the reliability and validity of the measurement scales through the use of CFA. Average variance extracted, composite reliability, Cronbach alpha, convergence validly and discriminant validity were calculated for all scales and satisfactory. results were obtained. With the exception of 'service failure recovery', all items measured had an average variance of more than 50 percent. Composite reliability was more than .7 for all measurement scales. Cronbach alpha was greater than .7 for the majority of the scales, indicating good reliability and consistency. As a result of this analysis, a new construct has been added to the job design model that we have called 'service characteristics'. There was very good discriminant validity between social and service constructs and a moderate level of discriminant validity between motivational and service characteristics. We have also presented regression analysis between the job characteristics model and job outcomes. The analysis showed that the motivational characteristics influenced the job outcomes significantly but social characteristics had the highest number of significant predictors influencing job outcomes. In the next chapter, the report presents the results of the qualitative data collection and analysis to support the quantitative findings of this chapter. 


\section{Chapter 6}

\section{Qualitative Data Analysis}

This chapter presents the qualitative data gathered through an interview process with ITS employees and through a short question on the IT-SSO questionnaire. First a brief description of the interview sample is given, followed by an analysis of the respondents' characteristics. Then, tables that display the qualitative data gathered on motivational, social, and service characteristic and job outcomes are presented with narratives.

\subsection{The Sample}

The thesis proposal called for interviews to be conducted with 15 ITS employees. To facilitate random selection and to ensure the anonymity of the interview participants, divisional heads of seven units of ITS were asked to select around 20 participants to take part in the interviews. They were specifically asked to use a stratified sampling method in making the selection. The following table shows the number of people selected from each unit to allow for proportional representation of the overall population in the sample of interviewees.

Table 63: Stratified Sampling of ITS Interview Participants

\begin{tabular}{|l|l|l|}
\hline Name of the unit & Number Employed & Selected for interview \\
\hline CEO/COO office & 8 & 1 \\
\hline STAMP & 15 & 1 \\
\hline EPM & 65 & 1 \\
\hline PM & 78 & 1 \\
\hline BPMS & 150 & 3 \\
\hline OCTO & 94 & 2 \\
\hline SMD & 780 & 12 \\
\hline TOTAL & 1190 & 21 \\
\hline
\end{tabular}


When the names of interviewee participants were received by the researcher, each name was tagged with a number and put in a bowl. Fifteen numbers were then selected at random to form a pool of 15 ITS interview participants. Once the sample was created, each interviewee was contacted by phone and a brief introduction of the research was given, after which an appointment was made to conduct the face-to-face interview at a convenient time.

\subsubsection{Data collection}

A structured interview employs a technique whereby a researcher interviews respondents using a structured interview schedule (Bryman and Bell, 1996). This technique was used to collect data from our sample of ITS managers. Structured interviews were conducted in a quiet area of the ITSB building using the interview schedule provided in Appendix two. First the researcher explained the research to the interviewee through the introductory speech which is outlined in beginning of Appendix two. Once the research was introduced, the managers were asked to fill in a form to collect the demographic data of the interviewees. The respondents were then verbally asked whether the interview could be recorded and were reminded that they could choose to decline the request. All fifteen interviewees consented to having the interviews recorded. After this, the researcher conducted the interviews by going through each question on the interview schedule. The recorded interviews were later transcribed. 


\subsubsection{Analyzing qualitative data}

In their discussion of qualitative analysis, Miles and Huberman (1984) identified data reduction, data display and conclusion drawing as key components of qualitative research. They refer to data reduction as the process of selecting, abstracting, and transforming the "raw data that appear in written up field notes" $(1994,21)$. In data reduction, large volumes of data are reduced to smaller components so that these can be presented to a focal audience. In this study, the motivational, social, and service characteristics and outcome variables probe the level of these characteristics as expressed by the respondents. Therefore levels such as "high," "low," and "medium" were used as the coding scheme to display the qualitative data. A fourth category referred to as "other" was also included to record unique responses that did not match with the other three categories. At the end of the IT-SSO questionnaire and at the end of each interview, the respondent was asked the question, "In your opinion what job characteristics are very important for the nature of work at an IT shared service organization?" To code the data for responses to this question, first one of the interviews was coded to create an initial coding scheme. For the balance of the interviews, when the interviewee's statements matched with the initial coding frame, the statements were coded similarly. Whenever there was a new or different statement, an additional category was created to include the observation. After reducing the data to match the context in which they occur, narratives describing these contexts are presented. This leads to the second step, which is the data display as described by Miles and Huberman (1994). The authors refer to data display as the organization of information so as to allow the researcher to draw conclusions. In this 
thesis, the quantified data is first presented in tables. After the title of each table, the question is stated to enable the reader to relate the data to the specific question. Each data table is presented along with examples of narratives from which the quantified data are derived. Lastly, the drawing of conclusions, which is the third aspect of qualitative research, is completed in chapter seven. In this study the qualitative data is used as part of the mixed methods research. In chapter seven the qualitative data is combined with the results of the quantitative data and conclusions regarding the research questions are drawn.

\subsubsection{Establishing Reliability and Validity of the Qualitative Data Analysis}

Bryman and Bell (2003), drawing on research done by Lincoln and Guba (1984, 1994), identify trustworthiness and authenticity as the two core criteria that need to be established in qualitative research to maintain reliability and validity. Trustworthiness comprises credibility, transferability, dependability and confirmability. Credibility in qualitative research can be maintained by validating a concept through multiple accounts. In ITS job design research, the qualitative data came from 15 interviews conducted with ITS managers. A theme being confirmed or disconfirmed across 15 interviews provides strong credibility for the qualitative data. Transferability in qualitative research involves obtaining rich and detailed descriptions of issues in the research. In this research, in many instances the interview schedule encouraged the interviewee to provide detailed commentary. This helped in gathering detailed descriptions about the issues related to the research. Further, dependability of qualitative research is related to having complete records of the qualitative data. The interviews conducted with ITS employees were recorded with their permission and 
transcribed. This allowed the researcher to maintain the data in a complete and accessible manner. In addition, for all 15 interviews the researcher spent a period time at the actual ITS site and developed in-depth knowledge and understanding as to how the organization functions.

Confirmability means ensuring that the researcher does not allow his or her personal values or theoretical background to interfere with how the qualitative research is conducted. Being aware of this potential pitfall early in the research process helped the researcher avoid it. In addition, a colleague helped quantify the qualitative data according to high, moderate and low levels. This was later reconciled by the researcher. Involving a third person, who is not related to the study, early in the process helps reduce biases and further validates the results.

\begin{abstract}
Along with trustworthiness, the second criteria in evaluating qualitative research is authenticity, which means maintaining fairness in the sense of being impartial and permitting the representation of the different viewpoints expressed by ITS members regarding job characteristics and job outcomes. When presenting ITS employees' views on job characteristics, this research presents both positive and negative views; by presenting both sides this research offers a realistic and balanced picture.
\end{abstract}




\subsection{Respondent characteristics}

The sample from which the qualitative data was collected consisted of six professional policy advisors, five individuals performing transactional work and four doing transformational work. Nine respondents held job titles where $80 \%$ of their work required doing IT-related work. The rest held non IT-skill jobs. The sample consisted of eleven males and four females. The respondents' average duration of work experience was 3.5 years at this ITS and the majority of them were in the age group of 51-55 years. The sample composition reveals that most of them were mature professionals with enhanced IT skills.

Table 64: Demographic Information

\begin{tabular}{|l|l|l|}
\hline Gender & Male & 11 \\
\hline & Female & 4 \\
\hline Work Experience & 6 months - 1year & 1 \\
\hline & 1.5 years - 2 years & 4 \\
\hline & $2.5-3$ years & 2 \\
\hline Age & 5 years or more & 8 \\
\hline & $30-35$ years & 2 \\
\hline & $41-45$ years & 3 \\
\hline & $46-50$ years & 2 \\
\hline Type of Skill & $51-55$ years & 5 \\
\hline & $56-60$ years & 3 \\
\hline Type of work & IT skill & 9 \\
\hline & Non- IT skill & 5 \\
\hline Transactional work & 5 \\
\hline $\begin{array}{l}\text { Number } \\
\text { Interviewed }\end{array}$ & $\begin{array}{l}\text { Transformational work } \\
\text { and policy making }\end{array}$ & 4 \\
\hline
\end{tabular}




\subsection{Motivational Characteristics}

The interviewees were asked questions about the levels of autonomy, skill variety, task variety, task significance, task identity, information amount and information equivocality they experience in the jobs they perform at ITS.

\subsubsection{Autonomy}

First the interviewees were asked about how much autonomy they have in three areas: decision making, scheduling and the methods they can use in performing their work. The following tables present the interviewees' responses.

Table 65: Decision Making Autonomy

The first question is about the level of autonomy in your job. Tell us how much autonomy you have in terms of scheduling your work, the methods you choose to accomplish tasks, and decision making in general.

\begin{tabular}{|r|l|l|l|l|}
\hline Interviewee & High & Medium & Low & Other \\
\hline 1 & & $\mathrm{X}$ & & \\
\hline 2 & & & $\mathrm{X}$ & \\
\hline 3 & & $\mathrm{X}$ & & \\
\hline 4 & & $\mathrm{X}$ & & \\
\hline 5 & & $\mathrm{X}$ & $\mathrm{X}$ & \\
\hline 7 & & & & \\
\hline 8 & & $\mathrm{X}$ & & \\
\hline 9 & $\mathrm{X}$ & $\mathrm{X}$ & & \\
\hline 10 & $\mathrm{X}$ & & & \\
\hline 11 & & & & \\
\hline 12 & $\mathrm{X}$ & & Did not answer \\
\hline 13 & & $\mathrm{X}$ & & \\
\hline 14 & $\mathrm{X}$ & $\mathrm{X}$ & & \\
\hline 15 & & $\mathrm{X}$ & & \\
\hline Total & 4 & 8 & & 1 \\
\hline
\end{tabular}


For decision making, four individuals indicated a high level of autonomy while eight individuals said they have a moderate level of decision making autonomy. Two individuals stated their jobs provide them with low decision making autonomy. Those who said that they have a high level of autonomy attributed this to their immediate individual supervisors.

"I do not know whether it is in the entire ITSSO, but I work for a DG who gives me a lot of autonomy and broad directions. This can be because of my personality because I take a lot of initiative. I am able to look outside the box and look at problems in terms of opportunities. My boss gives me a lot of autonomy figuring out when I am going to do my work, how I am going to do my work and generally how I report back to him. When it comes to planning of my work I can carry it out as I can, my boss can give me deadlines - oh my god this needs to be done today or in an hour. I can manage my schedule. I feel I have enough autonomy in my job."

(\# 9 ITS member)

"Decision making - again I think somewhat dictated by your immediate supervisor. Mine is great for giving me a lot of autonomy but obviously there is a hierarchy to be followed and I'm more at the recommending sort of layer. So I recommend solutions for decision making by the senior management." (\# 12 ITS member)

Interestingly, one of the respondents who had high decision making autonomy on the job related it to the strong relationships and trust built by him/her within ITS. This suggests that good work relationships are not only related to the social aspects of work but also can be a deciding factor in decision making autonomy.

"We've been very successful you know, over the years. Maybe in the first year we were working around maybe $\$ 3-4$ million. It's actually grown up to about $\$ 10$ million a year, so there is like a lot of money marketing or whatever, so it involves a lot of motivation, a lot of passion, don't take no for an answer. So in that sense I would say pretty much full autonomy. But autonomy is linked to relationships and as long as you have those strong relationships and trust, it's fairly easy to, you know, call the shots." (\#14 ITS member) 
Further, more than half of the respondents felt that they have a fair amount of autonomy in decision making within their role in the organizational structure even though there is a governance body and a gating process to oversee the level of decision making autonomy. The general tone of the responses suggests that the individuals gained a significant amount of decision making autonomy when they possessed technical information, finance information and supported their decisions through historical data.

"The autonomy is quite autonomous. Like I said, in project management it's a matrix environment so we work with teams. There are actually gating processes when we have decision making - decision making is done by senior management on the gating process. So there is a whole process for a project in IT: first of all the approval of funding, the approval of the projects and then we move on to execute the projects with the teams that provide services." (\# 13 ITS member)

"I am at a level that is fairly autonomous. I have to make decisions and improve processors. That is the nature of my job. Yes, I do have enough autonomy. "( \# 8 ITS member) 
Table 66: Results for Autonomy in Methods

\begin{tabular}{|r|l|l|l|l|}
\hline Interviewee & High & Medium & Low & Other \\
\hline 1 & & $X$ & & \\
\hline 2 & & $X$ & & \\
\hline 3 & $X$ & $X$ & & \\
\hline 5 & & & & $\begin{array}{l}\text { Did not answer the } \\
\text { question }\end{array}$ \\
\hline 6 & & $X$ & & \\
\hline 7 & & $X$ & & \\
\hline 8 & & $X$ & & \\
\hline 9 & $X$ & & & \\
\hline 10 & $X$ & & & Fairly new to the job \\
\hline 11 & & & & \\
\hline 12 & & $X$ & & \\
\hline 13 & & $X$ & & Did not answer the \\
\hline 14 & & & & \\
\hline 15 & & 9 & & \\
\hline Total & 3 & & & \\
\hline & & 9 & & \\
\hline
\end{tabular}

When autonomy in methods was discussed, the majority of the respondents felt that they have a medium level of autonomy in choosing the methods for accomplishing tasks. None of the interviewed participants said the level was low. There might have been limited ways of doing the task, but they had the freedom to choose among those limited options.

"Yes. Well I can schedule my own time, I have a fair scope for making decisions, and in terms of methods, methods of decision making or methods of work, either way I have, I can choose how I do that." (\# I ITS member)

"Methods I would say medium. I have some latitude in choosing the methods, but sometimes feel restricted in that we have no choice other than to use a method although it is inadequate, so that we can deliver the data." (\# 2 ITS member)

"Yes, I think I have that. Obviously there is some pressure that comes down, things that have deadlines, but I generally have the choice to do things when Ineed to. In terms of how I choose to do my work, I can do, I can delegate, I can work with 
somebody else, I can not do it, I can do in paper and electronically. Power point for the senior management seems to be a preferred method, although in my other job I do a lot of briefing notes." (\#4 ITS member)

Table 67: Results for Autonomy in Scheduling

\begin{tabular}{|r|l|l|l|l|}
\hline Interviewee & High & Medium & Low & Other \\
\hline 1 & & $X$ & $X$ & \\
\hline 2 & & & & \\
\hline 3 & $X$ & & & \\
\hline 4 & & $X$ & & Around priorities \\
\hline 5 & & $X$ & & \\
\hline 7 & & $X$ & & \\
\hline 8 & & $X$ & & \\
\hline 9 & $X$ & & & \\
\hline 10 & & $X$ & & $\begin{array}{l}\text { Did not answer the } \\
\text { question }\end{array}$ \\
\hline 11 & & & & \\
\hline 12 & & $X$ & & \\
\hline 13 & & $X$ & & \\
\hline 14 & & & & \\
\hline 15 & & & 1 & \\
\hline Total & 2 & & & \\
\hline
\end{tabular}

When it comes to scheduling autonomy the respondents indicated that they have a fair amount of autonomy in sequencing their work, but the general tone of responses indicated two issues limiting scheduling autonomy. Individuals complained that the calendar was full of meetings and at times managers were at meetings the whole day. As well, they indicated that they may have scheduled their work but there would always be a job with top priority that would arrive at the last moment, greatly reducing scheduling autonomy. 
"It is difficult to answer straightforwardly because the priorities of the job take over as to when things are done. So quite often I will list my tasks or activities which I have to do, and the organization will prioritize what I have to do because of where I sit in the organization, which one is the most important, and I schedule my other work around these priorities." (\#6 ITS member)

"I have some degree of autonomy which is reasonable. But the calendar is full of meetings so the nature of the work requires me to be in multiple committees that makes it less - the autonomy part of scheduling." (\#2 ITS member)

"We always have to juggle with new priorities, so everyday and even throughout the day I have to look back at what's the priority, what do we have to focus on, where should I align our DG's, so it's always changing. There is a lot of pressure, a lot of stress, time is always an issue. There is not a lot of satisfaction at the end of the day because there is too much to do. It's not like if you're working on a project and you complete your project and you go, great, well I've done all that - it's always having the ball rolling so you end the day and have your file and that's for tomorrow." (\# 15 ITS member)

\subsubsection{Skills Variety}

Work at ITS required a high level of skill variety; managers needed both IT skills and non-IT skills. The majority of the IT skills employed were IT project management skills, understanding software interfaces, managing multiple IT platforms and IT technical writing. Among the non-IT skills participants listed were human resource management, procurement, negotiation skills, management skills, communications skills and problem solving skills. 
Table 68: Results for Skills Variety

How does your job require you to use a variety of skills? In general how many different types of skills do you use in your job?

\begin{tabular}{|r|l|l|l|l|}
\hline Interviewee & High & Medium & Low & Other \\
\hline 1 & & $X$ & & \\
\hline 2 & & & $X$ & \\
\hline 3 & $X$ & & & \\
\hline 4 & $X$ & & & \\
\hline 5 & $X$ & & & \\
\hline 6 & $X$ & & & \\
\hline 7 & $X$ & & & \\
\hline 8 & $X$ & & & \\
\hline 9 & $X$ & & & \\
\hline 10 & $X$ & & & \\
\hline 11 & & $X$ & & \\
\hline 12 & & $X$ & & \\
\hline 13 & & $X$ & & \\
\hline 14 & & & & $\begin{array}{l}\text { Did not answer the } \\
\text { question }\end{array}$ \\
\hline 15 & & & $X$ & \\
\hline Total & 8 & 4 & 2 & \\
\hline & & & & \\
\hline
\end{tabular}

"I have a highly diverse job. I am a business manager and I work for a director general who gives me broad directions. It could be administrative, human resources, finance, or it could be contracting, asset management, or it could be a presentation deck to the CEO or a briefing note to the CEO or deputy minister. I am also involved in problem solving - something happening between two different sectors or between us or a client, so I have to think about things and go and talk to them, do. some stakeholder analysis and use the interpersonal skills and talk to people. I also do a lot of writing, research, analysis and synthesis as well. Yes, so there are a lot of skills used." (\# 9 ITS member)

"Whole skill sets for resource management, for staffing, budgeting, contract management, IT management for multiple platforms, multiple IT component. I have to deal with various clients to some extent and various other intra-branch organizations, involving a lot of negotiation skills, management skills, communication skills, so there is a very wide variety of skills." (\# 7 ITS member) 


\subsubsection{Task Significance}

The majority of the respondents felt that their work at ITS was very significant, mainly because it enhanced the scope of ITS in helping the Canadian government and the taxpayers save money. Respondents took pride in the notion that although shared services had been tried in the government context before, it was their ITS that was able to get established and is showing signs of success. They felt engaged in performing something new in the government and considered their work to be part of one of the largest government IT-shared services organizations. Those who worked directly in business lines felt that their tasks were very significant because they were able to influence the quality of services offered by ITS. Further, most of the managers interviewed had worked at this organization for a long time and had gained experience in many IT projects. These individuals had expert knowledge as to what contributes to project success and how to identify and avoid potential pitfalls, and their knowledge is critical to the performance of ITS. These individuals commented that, because of their extensive experience, if they were to leave the organization it would be hard for ITS to replace them; thus they feel their work is extremely significant. 


\section{Table 69 : Results for Task Significance}

Do you think that your job itself is very significant and important in the broader scheme of things? Give us an example when you felt like this? Can you let us know how your job impacts people outside the organization?

\begin{tabular}{|r|l|l|l|l|}
\hline Interviewee & High & Medium & Low & Other \\
\hline 1 & & & $X$ & \\
\hline 3 & & & $X$ & \\
\hline 4 & & & & \\
\hline 5 & $X$ & & & yes/no \\
\hline 6 & $X$ & & & \\
\hline 7 & & $X$ & & \\
\hline 8 & $X$ & & & \\
\hline 9 & $X$ & & & \\
\hline 10 & & $X$ & & \\
\hline 11 & $X$ & & & \\
\hline 12 & & & $X$ & \\
\hline 13 & & $X$ & & \\
\hline 14 & $X$ & & & \\
\hline 15 & $X$ & & & \\
\hline Total & 8 & 3 & 3 & 1 \\
\hline
\end{tabular}

"My boss is able to take the broad direction, whether they are the throne speech or the budget or the deputy minister or the media minister, and he can translate that into my job and what I am trying to achieve. So I see the line of sight. Let's say now we are trying to cut cost and bring the government toward recovery. We just spent 50 billion dollars last year. So my boss explains to me that we are operating a project management center of excellence, and we try to keep the projects on time, under budget and within the scope. We are trying to achieve excellence and for Canadians it is quantifiable and that is significant." (\# 9 ITS member)

"I do think that it is significant in the broader scheme of things. Because we have an influence not only within our ministry as to how we deliver services, which has an effect on costs and expense, which affects the taxpayers in the end, but also on the quality of service that we deliver. We print all the cheques for the government of Canada. If we do not keep our infrastructures updated, current and operational people would not get the old age cheques, pension cheques, we would not be able to pay bills for the whole country, so it has influence outside of the organization, the average Canadians, but at the same time it affects not only how public works operates, but because we are chartered services, the services we deliver and the decisions we make affect other things as well." (\# 3 ITS member) 
But a few respondents felt that their work at ITS was not very significant. This happened only when they felt that they were helping another individual advance in their work rather than enhancing the organization, or when they felt that their position was not given due recognition within the sector.

"Generally, I feel that the job is not significant and it should be significant. However there are instances where I do feel it is significant. That is when the data that I provide is to make strategic decisions and I put more attention there." (\#2 ITS member)

"Within the context, within the organization itself, I would say somewhat, not really significant or important. I. think my job is to make sure that our organization is well taken care of and I try to contribute to making things easier to do in the organization. I want to serve my boss and my boss's boss well, so arm them with the things that they need, for they do have significant and important roles." (\# 1 ITS member)

\subsubsection{Task Identity}

When it came to task identity, a number of managers stated that they were able to identify their work in the whole scheme of things at ITS. The interviewees experienced a high level of task identity when they were able to identify their task delivering a specific service or function to a client organization. There is also evidence of an organizational culture that recognizes the efforts of individual employees. Individuals commented that whenever somebody does a good piece of work it is always attributed to that individual in presentations and briefing notes. The majority of the work is identifiable when a business plan or performance matrix is put together; these updates go straight into the sector business plan and then get 
integrated into the assistant deputy minister's business plan. This transition allowed individuals to interpret their work in the management accountability framework.

Table 70: Results for Task Identity

How often can you identify your work in the whole scheme of things?

\begin{tabular}{|c|c|c|c|c|}
\hline Interviewee & High & Medium & Low & Other \\
\hline 1 & & & $x$ & \\
\hline 2 & & & & Missing data \\
\hline 3 & $x$ & & & \\
\hline 4 & $x$ & & & \\
\hline 5 & $x$ & & & \\
\hline 6 & $x$ & & & \\
\hline 7 & & & $x$ & \\
\hline 8 & $x$ & & & \\
\hline 9 & & $x$ & & \\
\hline 10 & $x$ & & & \\
\hline 11 & & $x$ & & \\
\hline 12 & $x$ & & & \\
\hline 13 & & & $x$ & \\
\hline 14 & & & & $\begin{array}{l}\text { did not answer the } \\
\text { question }\end{array}$ \\
\hline 15 & & & $x$ & \\
\hline Total & 7 & 2 & 4 & 2 \\
\hline
\end{tabular}

"That is very easy. Very easy. We are responsible for the service catalogue so it is visible for our clients and for our managers who are responsible for orchestrating product planning sessions across the organization yearly. We either fail or succeed. We see the impact, we are responsible for each of these things to create a standard agreement. It is being used on a daily basis. We know what we are doing rightly or poorly. Very eminent. We are tracking product maturity, so we are measuring and we know where we are." (\# 6 ITS member)

"I would say we are pretty good about that. Certainly it's a culture of, like folks are really good at saying this is a piece of work, taking a piece of work and using it with some tweaks and improvement and whatnot but using it more or less in it's original form and basically labeling it 'this piece of work was done by', so it's a good culture for that type of thing." (\# 12ITS member) 
However, some interviewees were not able to identify their work in the whole scheme of things. This was due to the fact that they were performing too many tasks and many of their tasks went unnoticed, or they were too busy to be noticed, even by themselves. Some were not able to identify their work because they did not have expertise in the area of focus and had only contributed marginally.

"I would say that I do play a role but like I said, I'm not a subject expert in anything so I see that I still play a role in the big picture, but I'm not developing any specific project." (\# 15 ITS member)

"No. It is more like keeping the ship running. It is not like building a new board." ( \# 7 ITS member)

\subsubsection{Feedback from Job}

As shown in the table, interviewees responded to the feedback from job question quite diversely. Five respondents spoke of having a high level of feedback from the job and an equal number of interviewees stated that the feedback was either medium or low. Those who said that they have a high level of feedback were satisfied as to how the work itself is providing them with recognition. 
Table 71: Results for Feedback from Job

How much feedback do you receive from the job itself? Can you give us an example?

\begin{tabular}{|r|l|l|l|l|}
\hline Interviewee & High & Medium & Low & Other \\
\hline 1 & & $X$ & & \\
\hline 2 & & $X$ & & \\
\hline 3 & & & $X$ & \\
\hline 5 & & $X$ & & \\
\hline 6 & $X$ & & & \\
\hline 7 & & & & I do not know \\
\hline 8 & $X$ & & & \\
\hline 9 & & & & \\
\hline 10 & & $X$ & & I do not know \\
\hline 11 & & & $X$ & \\
\hline 12 & & & & \\
\hline 13 & $X$ & & $X$ & \\
\hline 14 & $X$ & & & 2 \\
\hline 15 & & & & \\
\hline Total & 5 & & $X$ & \\
\hline
\end{tabular}

"Yes. We worked on a project with Veterans Affairs to convert their technology to a platform which will be more effective and have a longer life cycle. We got a certificate of appreciation for doing that. It is just a piece of paper and it is not very expensive but it makes you feel good about it. Through emails when you do a good job, get a pat on the back, there is recognition. " (\#5 ITS member)

"Every year we set a target for the key performance indicators and monitor during the year. So we get that on a monthly basis. If we orchestrate the product planning session it requires a lot of preparation, lots of coordination, planning, and at the event itself we have feedback forms to fill out and after a few days of this event we will know how we did perform. We also participate in the governance that involves CEOs of other departments, so when presenting to them we know how we stand. It is ongoing feedback in that respect. " (\# 6 ITS member)

When work provided both positive and negative feedback, individuals considered it to be moderate. Often employees received feedback from the job when they were directly involved in delivering services to the clients. 
"I do forecast and when someone from a different sector does not agree I hear about $i t$, and when the data does not support it fully I hear about it. So when things don't go well I hear about it. But when the things go well I do not hear about it. There is feedback one way or another, yes." (\# 2 ITS member)

"More for part of it. Because we have a team that represents the clients and monitors the service delivery for our services to the clients, and I think in that sense there is a large impact and large presence there. Other times I don't see it, and I do it because I think there is value. I don't always get a sense of the value, or maybe perceive it, or I might see what I think as being important. It may not necessarily be in the big picture." (\# 4 ITS member)

Those who complained that there is no feedback from the job stated that they would deliver a service or a report and get a receipt for doing so but get no specific feedback on the quality of the work. The general sense was that when the quality of work was not up to standard they would receive feedback, but this did not occur often.

"I don't know. Tasks don't talk to me. People do." (\# 11 ITS member)

"That's a tough one. Government, at least our department here, is so big and so broad that sometimes things are done in baby steps and they are very important baby steps that you need to make, but things can sometimes take a lot longer so the feedback chain is there but it's stretched over such a wide timeline that you don't necessarily remember by the time you reach the conclusion." (\# 12 ITS member)

\subsubsection{Task Variety}

Like skills variety, task variety also figures largely in IT-SSO jobs. A significant majority of the interviewees stated that they have a high to moderate level of task variety in their jobs. These tasks were built around quality assurance, project management, supervising peers, mentoring, career development for subordinates, participating in various meetings, linking sectors and bringing them to the same 
phase. Further, checking the levels of resources for each project as they progress and producing lots of written and verbal communications were some of the tasks mentioned by ITS members.

Table 72 : Results for Task Variety

Tell us how many different tasks you carry out in your job?

\begin{tabular}{|r|l|l|l|l|}
\hline Interviewee & High & Medium & Low & Other \\
\hline 1 & & $X$ & & \\
\hline 2 & $X$ & & & \\
\hline 3 & & $X$ & & \\
\hline 5 & $X$ & $X$ & & \\
\hline 6 & $X$ & & & \\
\hline 7 & & $X$ & & \\
\hline 8 & & $X$ & & \\
\hline 9 & $X$ & & & \\
\hline 10 & $X$ & & & \\
\hline 11 & $X$ & & & \\
\hline 12 & $X$ & & & \\
\hline 13 & $X$ & & & \\
\hline 14 & $X$ & & & \\
\hline 15 & & & & did not answer the \\
\hline question
\end{tabular}

"Wow, that is very hard to elaborate on because there are so many. We tend to work in a project management-type setting, so for every initiative or delivery we use project management. So there is scheduling, assigning of work, verifying that the work is of the quality that we want and within the time frame." (\# 11 ITS member)

"Linking different sectors, bringing them to the same page. The product that has been launched has been well understood by the client service management committee. Really getting people together on a move-forward service, whether it is a new process to launch, a new price, a new feature, or a new product. But also analyzing data in various financial forecasting systems to ensure that the revenue forecasts and revenue pipeline is reported properly, understood and approved by the different sectors." (\# 2 ITS member) 


\subsubsection{Information Amount}

One of the notions the interviewees agreed on most readily was the amount of information they had to process while performing their jobs at ITS. Many of the business plans require information from all the different sectors of ITS, which means pulling together large quantities of information. The respondents also felt that the amount of information processing is high because there are many organizations with service requests at different stages of approval and to process them one has to deal with a lot of information. When the subject matter was new and when it made a large impact on the affairs of ITS, the respondents stated that they processed greater amounts of information before a decision was made. But when there was historical data to support a decision, the information processed was very little. Some respondents stated that deciding how much information they need to process is a judgment call, and that information quantity is often subjective. Whatever the nature of work, some managers said they often just did not have enough time to collect all the information they would have liked to review before making a decision because they were too busy and therefore had to be satisfied with the amount of information they already had. 
Table 73: Results for Information Amount

Tell us how much information you have to gather before you arrive at an excellent solution. Do you process a lot of information before you arrive at a decision?

\begin{tabular}{|r|l|l|l|l|}
\hline Interviewee & High & Medium & Low & Other \\
\hline 1 & $\mathrm{X}$ & & & \\
\hline 2 & $\mathrm{X}$ & & & \\
\hline 4 & & & & \\
\hline 5 & $\mathrm{X}$ & $\mathrm{X}$ & & \\
\hline 6 & $\mathrm{X}$ & & & \\
\hline 7 & $\mathrm{X}$ & & & \\
\hline 8 & $\mathrm{X}$ & & & \\
\hline 9 & $\mathrm{X}$ & & & \\
\hline 10 & $\mathrm{X}$ & & & \\
\hline 11 & & $\mathrm{X}$ & & \\
\hline 12 & & $\mathrm{X}$ & \\
\hline 13 & $\mathrm{X}$ & & & \\
\hline 14 & & & & \\
\hline 15 & $\mathrm{X}$ & & did not answer the \\
question
\end{tabular}

"Actually yes, I do happen to gather a lot of information from various sources in order to come up with a final result. For example, not very long ago we got our extension to operate our IT-SS infrastructure that is issued by the Government of Canada information chief technical officer, a part of the Treasury Board Secretariat. That internal authority was granted only after we put together a rather complicated, comprehensive, well documented and substantiated request for the extension. So to do that involved a number of data gathering and information from different stakeholders, negotiations with treasury board officers, and that is an example." (\# 1 ITS member)

"Generally the decision making requires a lot of information. There are so many different sources of information. It is often a judgment call. It is not an easy call to make, often there is a lot of subjective material. In operations, how much operations proceed with new products as opposed to old products and decisions around that, there's a lot of impact and financial discussions." (\# 7 ITS member) 


\subsubsection{Information Equivocality}

When information equivocality was discussed, ITS managers explained that there are high to moderate levels of information uncertainty in their jobs. Respondents remarked that because their ITS is a government concern, to make the best decisions one has to consider the impacts on and possible reactions of multiple stakeholders. Whose welfare has to be considered first, how to balance equity, and how to maintain transparency are questions frequently faced by decision makers. The responsibilities that come with being in a government work setting contribute to information equivocality at ITS. Further, factors such as multiple IT services offered to different departments, diversified groups of people employed in the government bringing unique viewpoints, individuals moving within government departments, and multiple sectors within ITS still working in silos contribute to information equivocality.

Table 74: Results for Information Equivocality Can the information that you receive in your job be interpreted in several ways and can it lead to different but acceptable solutions?

\begin{tabular}{|r|l|l|l|l|}
\hline Interviewee & High & Medium & Low & Other \\
\hline 1 & & $X$ & & \\
\hline 2 & & & $X$ & \\
\hline 3 & $X$ & & & \\
\hline 4 & $X$ & & & \\
\hline 5 & & & $X$ & \\
\hline 6 & $X$ & & & \\
\hline 7 & & & $X$ & \\
\hline 8 & $X$ & & & \\
\hline 9 & & $X$ & & \\
\hline 10 & & $X$ & & \\
\hline 11 & & $X$ & & \\
\hline 13 & $X$ & $X$ & & \\
\hline 14 & & & & \\
\hline 15 & & $X$ & & $\begin{array}{l}\text { did not answer } \\
\text { the question }\end{array}$ \\
\hline & 5 & 6 & 3 & 1 \\
\hline Total & & & & \\
\hline
\end{tabular}


"We live in a complex world. Our senior executives have very large portfolios of things. It is impossible for them to know all the intricacies of what is going on in their own area. It is impossible. So sometime we are trying to communicate an issue or ask a question for a decision to be made. And although you try to provide as much information as you have you may not be clearly understood by your senior executive. So you will obtain an answer back and obviously you see the answer and say O.K., I did not get to him or her. This was not understood." ( \# 6 ITS member)

"Well, most definitely. There are always multiple solutions to a problem. You always try to assess the best solution. Yes, always. It is best to have multiple solutions and the next challenge is taking the best out of the bunch. You have multiple solutions from listening to multiple people and their ideas. Interpretation, lack of knowhow of process, lack of knowing who is doing what, the problem of crossover and not allowing people to do their jobs and doing it for them." (\# 8 ITS member)

The information had more clarity and less ambiguity when it was technical in nature.

The interpretation was easier and more precise, and could be understood in only one way for everyone.

"Not in general, no. Because it is technical information. There can be options, but generally speaking when you look at the technical requirements it is pretty definitive as to what the answer is." (\# 5 ITS member)

In summary, information processing was measured by information amount and information equivocality. Data from the interviews shows that the amount of information processed by ITS members was particularly high. In terms of level among the motivational characteristics, information processing was followed in turn by task variety, skill variety and task significance. Feedback from the job and information equivocality provided blended results. The overall results suggest that all three aspects of autonomy are moderate in ITS. 


\subsection{Social Characteristics}

The job design model for IT-SSO examined the job characteristics related to task interdependence, feedback from others, soical support and interaction outside of the organization. The qualitative data gathered on these items are illustrated below.

\subsubsection{Initiated and Received interdependence}

ITS members viewed their work as being highly interdependent. The interdependence occurred mostly when individuals had to share joint resources for projects, or put together business plans for senior management when inputs were needed from various government departments and/or from within different sectors of ITS.

\section{Table 75: Results for Initiated and Received interdependence}

How do your work activities affect other people? Are there instances where you have to wait until others finish their work so that you can begin yours? Or, on the other hand, are there times when others must wait until you finish your work so that they can begin theirs?

\begin{tabular}{|r|l|l|l|l|}
\hline Interviewee & High & Medium & Low & Other \\
\hline 1 & $X$ & & & \\
\hline 2 & & & $X$ & \\
\hline 3 & $X$ & & & \\
\hline 4 & & $X$ & & \\
\hline 5 & $X$ & & & \\
\hline 6 & $X$ & & & \\
\hline 7 & $X$ & & & \\
\hline 8 & $X$ & & & \\
\hline 9 & & $X$ & & \\
\hline 10 & $X$ & & & \\
\hline 11 & & $X$ & & \\
\hline 12 & $X$ & & & \\
\hline 13 & & $X$ & & \\
\hline 14 & $X$ & & & \\
\hline 15 & & $X$ & & \\
\hline & 9 & 5 & 1 & \\
\hline Total & & & \\
\hline
\end{tabular}


Many interviewees stated that high interdependence at work slows down the information flow, and this has become a frustrating problem. Another problem that was identified with both initiated and received interdependence at ITS is that they are caused by the notion of 'moveable' deadlines. Employees perceive that a given deadline on a task is not fixed and that it can be pushed forward and therefore do not take it seriously. ITS members believe this is not productive because people deliberately miss deadlines knowing they will be given more time. This stifles the desire for excellence. The general tone was that getting things done when they actually need to be done would greatly reduce interdependence.

"Yes. Yes. Lots of times. For example we are waiting for resources to come in and other people have to do their work to bring resources. Because it is government there is a lot of bureaucracy." (\# 5 ITS member)

"It happens all the time. This is normal. Oh god it is a lot. High dependency. Because there is more and more interdependence it is slowing down the flow of information." (\# 6 ITS member)

\subsubsection{Feedback from Others}

Six respondents felt that they received a high level of feedback from others such as supervisors and peers, while seven individuals commented that the feedback they received from others was moderate. Respondents stated that feedback from others often came in the form of a performance evaluation that was done semi annually and gave a moderate amount of feedback. The respondents felt that this was not adequate and desired more feedback about their work from others. 
Some individuals commented that their supervisors were too busy to provide timely feedback on accomplished work. Feedback was given to individuals in management meetings, through emails and by verbal reinforcement. Interestingly, one respondent stated that whatever a task was performed, he or she would seek out feedback and would not wait until others provided the feedback.

\section{Table 76: Results for Feedback from Others}

Describe to us a few instances where others (peer, supervisor) have given you good feedback as to how you perform your job.

\begin{tabular}{|r|l|l|l|l|}
\hline Interviewee & High & Medium & Low & Other \\
\hline 1 & & $X$ & & \\
\hline 2 & $X$ & & & peer support more \\
\hline 3 & $X$ & & & \\
\hline 4 & & $X$ & & \\
\hline 5 & & & & \\
\hline 7 & & $X$ & & \\
\hline 8 & $X$ & $X$ & & \\
\hline & & & & \\
\hline 9 & & & & $\begin{array}{l}\text { I am proactive in } \\
\text { getting feedback from } \\
\text { others }\end{array}$ \\
\hline 10 & $X$ & & & \\
\hline 11 & & $X$ & & \\
\hline 12 & & $X$ & & \\
\hline 13 & $X$ & & & \\
\hline 14 & $X$ & & & \\
\hline 15 & & $X$ & & \\
\hline Total & 6 & 7 & & 2 \\
\hline
\end{tabular}


"When we produce these reports when we have a management meeting on the last Monday of each month, the CEO or the COO will often say that this is excellent work. When we produce our monthly report to the deputy minister, which is quite a timely process, we always receive feedback on the adequacy or absence of the work. The total number of times that we are told how we are doing a job whether individually or as a group is once or twice a month, which is a lot. For us it is a lot, but there are many people in the government who are rarely told how important their work was or what the quality of their work was." (\# 3 ITS member)

"I have to fuel the tank in order to keep the operation running and I get positive feedback on that from my supervisor and staff." ( 7 ITS member)

\subsubsection{Social Support}

Many of the respondents felt that they received very good social support at work; four respondents said they received a moderate level of support. Those who reported high to moderate social support felt that they received great support from peers and supervisors equally. Individuals who reported having great peers at work would cover each others' work to ensure that nobody was slacking. Similarly, supervisors showed their support to their team by balancing work within the team and by understanding the personal demands of the individuals. However, during the interviews certain interesting notions related to social support at work came up. First, respondents felt that it is difficult to build lasting relationships because people leave to go to other departments after one or two years; secondly, for managers, the relationships with peers depends on their relationship with their supervisor. When managers are able to get the needed support and resources from their senior management, their peers align it with equal social support. Also individuals tend to judge social support from managers according to how much financial support they receive when implementing projects. 


\section{Table 77: Results for Social Support}

How do your supervisors and peers provide support at work? What forms of support do you receive?

\begin{tabular}{|r|l|l|l|l|}
\hline Interviewee & High & Medium & Low & Other \\
\hline 1 & & & & missing data \\
\hline 2 & & $X$ & & $\begin{array}{l}\text { more support from peers than } \\
\text { supervisor }\end{array}$ \\
\hline 3 & & $X$ & & \\
\hline 4 & & $X$ & & \\
\hline 5 & $X$ & & & \\
\hline 6 & & & & \\
\hline 7 & $X$ & & & \\
\hline 8 & $X$ & & & \\
\hline 9 & & $X$ & & \\
\hline 10 & & & $X$ & \\
\hline 11 & $X$ & & & \\
\hline 12 & $X$ & & & \\
\hline 13 & $X$ & & & \\
\hline 14 & & & & did not answer \\
\hline 15 & $X$ & & & \\
\hline Total & 7 & 4 & 1 & 3 \\
\hline & & & \\
\hline
\end{tabular}

"Yes, there is the social dimension. Nice job ------. But for the most part support within the government and the process as a whole is budgetary and human resource support. So when I say that I need six people to carry out that function on a monthly basis for the next 2 years, my supervisor has to approve that and that's where the original support comes." (\# 3 ITS member)

"Absolutely. I would say it's a culture. Like certainly my supervisor is really good about that. And his work style includes an element of education, which I think is great. It's a great style for me, so absolutely I get that kind of support there. And peers, again I think it's that kind of culture where folks want to help one another and share history and background and that type of thing. Sometimes it's tough getting access to your peers because there is so much going on it can be difficult for people to juggle more work on top of their job work, but certainly people want to try." (\#12 ITS member) 


\subsubsection{Interaction outside the Organization}

A number of respondents stated that interaction outside ITS was not frequent in their jobs. Employees who stated that outside interaction was low often worked on nonclient management jobs. Individuals working in these jobs were functioning as part of a support unit (planning and integration) within ITS and did not meet the clients or suppliers most of the time.

Table 78: Results for Interaction outside the Organization

Does your job require spending a great deal of time with people outside your organization? Give us examples as to how this happens?

\begin{tabular}{|r|l|l|l|l|}
\hline Interviewee & High & Medium & Low & Other \\
\hline 1 & & $X$ & & \\
\hline 2 & & & $X$ & \\
\hline 3 & $X$ & & & \\
\hline 4 & & $X$ & & \\
\hline 5 & $X$ & & & \\
\hline 6 & & & $X$ & \\
\hline 8 & & & $X$ & \\
\hline 9 & $X$ & & $X$ & \\
\hline 10 & & & & \\
\hline 11 & $X$ & & $X$ & \\
\hline 12 & & & $X$ & \\
\hline 13 & & & & Depends, \\
\hline 14 & $X$ & & & \\
\hline 15 & & $X$ & & \\
\hline Total & 5 & 3 & 6 & 1 \\
\hline
\end{tabular}

"Outside of shared services, no, because I belong to SMD, which is the operational organization. And we have a group that is supposed to be selling, another group which is managing the product and another group for billing. So they are the ones which deal with the outside clients. I have a role for some of our clients; hopefully it is at my manager's level, at an operational delivery prospective where they will deal with the clients. Sometimes when it gets escalated we have responsibilities for designated clients of the shared services." (\# 4 ITS member) 
But interaction outside the organization was significant for those who were working on client service management jobs. For these individuals, interaction outside the organization occurred when they met with officials from different government departments, when they had to explain the work of ITS to the different stakeholders, when selling IT products to other organizations or when dealing with Treasury Board. A few interviewees commented that they represented ITS at an IT service management forum and met with fellow ITS managers regularly to exchange best practice information.

"O.K. The group that I work with receives all of the inputs from outside of the organization and then it reports the analysis of those reports outside the organization to a different audience. Perhaps tying up to an earlier question, the reason that we know where we fit in the organization is that we link, or rather by reporting, link to the many parts of the organization, to the management, to the taxpayers. So obviously they are outside our organization." (\# 3 ITS member)

"Yes, From 8-10 this morning I was on a teleconference with Veterans Affairs from Charlottetown, We were discussing monthly business, how we are going to operate next month. So that was two hours I spent with them trying to understand the business needs so that as a shared services organization we could provide the services they need.".( \# 5 ITS member)

In summary the data from the interviews suggests that among the social characteristics there was a high level of initiated and received task interdependence at ITS. Social support that individuals received from peers and supervisors was high as well. Feedback from others received high and moderate ratings while interactions with outside organizations showed mixed results. 


\subsection{Service Job Characteristics}

The third section of the interview schedule asked the interviewees four questions related to the service characteristics of their jobs. These questions examined how the respondents felt about the level of service technology, service failure prevention, service failure recovery and standard service communication as practiced in their jobs. As before, the frequency counts of the service job characteristics are given, followed by detailed narratives offered by the participants.

\subsubsection{Service Technology}

Many respondents felt that the service technology available at ITS was not compatible with their desire to provide high quality IT service. ITS has implemented ITIL standards and ISO 9001, which are the standard processes among most ITS service providers. However, the respondents indicated that providing only standard services was not enough for clients who are generally IT-savvy. Many clients want ITS to provide all the leading-edge technologies at low cost. As a government IT shop, ITS faces procurement challenges and has to be fair and equal to all vendors, including the small ones. The services of ITS have not been set as a mandatory requirement for other government departments, so it has limited resources and has not been able to get more funding to invest in new technology.

The interviewees listed a few more problems ITS faces in investing in new technologies. Firstly, increased revenues have yet to materialize for the ITS, in part because the big government organizations have their own IT services and have not assigned any major IT services to the ITS. Secondly, the Treasury Board of Canada 
has not mandated that all government IT services should be delivered by ITS; therefore, the big government departments who prefer to maintain control of their own IT resources have not turned to ITS. In addition, the small government units that would benefit most from IT shared services have not been aggressively recruited by ITS. These issues have contributed to the lack of growth in revenues for ITS. Thirdly, ITS provides highly diversified IT services, and investing in state-of-the-art technology for all of these services would be challenging.

Table 79 : Results for Service Technology

How does the technology used in this IT-shared service organization allow you to build and develop higher levels of service quality?

\begin{tabular}{|r|l|l|l|l|}
\hline Interviewee & High & Medium & Low & Other \\
\hline 1 & & & $X$ & \\
\hline 2 & & & $X$ & \\
\hline 3 & $\mathrm{X}$ & & $\mathrm{X}$ & \\
\hline 4 & & & & \\
\hline 6 & & & $\mathrm{X}$ & \\
\hline 7 & & & $\mathrm{X}$ & \\
\hline 8 & & & $\mathrm{X}$ & \\
\hline 9 & & $\mathrm{X}$ & & \\
\hline 10 & & & $\mathrm{X}$ & \\
\hline 11 & & & $\mathrm{X}$ & \\
\hline 12 & & & $\mathrm{X}$ & \\
\hline 13 & & $\mathrm{X}$ & & \\
\hline 14 & & & $\mathrm{X}$ & \\
\hline 15 & & $\mathrm{X}$ & & \\
\hline Total & 2 & 3 & 10 & \\
\hline & & & & \\
\hline
\end{tabular}

While some interviewees commented on investing in new technologies, others talked about training in using new technologies. They stated that when new technologies are introduced, sufficient training has to be given to employees so that the new technologies can be used at an optimum level to provide quality service. In terms of 
IT training, many employees felt that they were always playing catch-up and people were being left behind, and that sufficient training levels and training standards need to be established before any new technology is rolled out. However, some interviewees were optimistic about the technologies and the service quality ITS can offer to its clients. They felt that over the years the technologies and the overall quality of services have been improved, when measured by system availability and lack of system failure. They believe that the combination of these factors will make ITS more attractive to other units, who will choose to make use of ITS services.

"Our service catalogue is a basic one and our CTO has great dreams and they are not given the money to implement. Our hands are tied, left and right. So we understand the power of technology and we are the IT shop - this is sad. In the end our clients are suffering, our processors are slowed, and they should not be." (\# 6 ITS member)

"The service technology is not very good. It is primitive. Our operational technology is fine. The service technology is very primitive. For example, we are on the pension system and the pension system works so people get their pension cheques. Our service technology, which would be allowing people do more self service, allowing people to buy more disk space or request through online - that is not good. Service technology on the help desk is not too bad, but when people ask for service from us as a shared serviced organization, that interface is still highly manual." (\# 7 ITS member)

\subsubsection{Service Failure Prevention}

The interview results for service failure prevention provided mixed responses, that is, an equal number of each response. Although four of the interview participants felt that the service technology could improve greatly, many others noted that the organization has really focused on being more proactive in service failure prevention. Four interviewees believed that ITS aggressively avoids service failures, while an 
equal number of interviewees rated the avoidance efforts as moderate. All eight felt that the many re-organizations that have taken place within ITS, the implementation of standardized processors to avoid service failure, and the increased maturity gained in delivering IT services, have made ITS more proactive in preventing service breakdowns.

\section{Table 80: Results for Service Failure Prevention}

Do you think that your organization goes out of its way to prevent customer problems rather than reacting to problems once they occur?

\begin{tabular}{|r|l|l|l|l|}
\hline Interviewee & High & Medium & Low & Other \\
\hline 1 & $\mathrm{X}$ & & & \\
\hline 2 & $\mathrm{X}$ & & & \\
\hline 3 & $\mathrm{X}$ & & & \\
\hline 4 & & $\mathrm{X}$ & & \\
\hline 6 & & $\mathrm{X}$ & & \\
\hline 7 & & $\mathrm{X}$ & & \\
\hline 8 & & $\mathrm{X}$ & & \\
\hline 9 & & & $\mathrm{X}$ & \\
\hline 10 & & & $\mathrm{X}$ & \\
\hline 11 & & & & Didn't really answer question \\
\hline 12 & $\mathrm{X}$ & & & no answer \\
\hline 13 & & & & \\
\hline & & & $\mathrm{X}$ & \\
\hline 14 & & & & $\begin{array}{l}\text { Talked about a RACI matrix but } \\
\text { did not really answer the } \\
\text { question }\end{array}$ \\
\hline 15 & & & $\mathrm{X}$ & \\
\hline & 4 & & 4 & 3 \\
\hline Total & & & \\
\hline
\end{tabular}

"I believe the organization is trying hard to prevent customer problems. For example, in the data center business we try to do ongoing maintenance, emergency schedule to avoid major service breakdowns. We have exceptions in the other way also sometimes we are only reacting, so this is not an indication of full control but it is an indication that we are actually trying our best." (\# 2 ITS member)

"I think so, as an organization we try to be proactive and anticipate if something is going to cause a problem and take action before it becomes a crisis." (\# 1 ITS member) 
Four individuals who mentioned that the level of service failure recovery was low, felt that ITS is reactive rather than proactive in preventing service failures. In their view, ITS was formed too quickly; it was an IT service provider that became a shared services organization and there was not enough time to build the necessary infrastructure that could provide proactive services to its clients. Furthermore, they felt that as a government organization that has a centralized approach, it is a daunting task to provide proactive IT services; therefore a new integrated service is required.

"No. We are pretty much reactive and have not got to the stage of proactive." (\#8 ITS member)

"No. I do not think so whatsoever. We are highly reactive to our customers." (\#9 ITS member)

\subsubsection{Service Failure Recovery}

On the failure recovery side, the majority of the respondents felt that ITS has a very good governance system for service recovery whenever a service breakdown occurs. There are classified frameworks for the nature of incidents and a very structured response mechanism for service breakdowns, whereby every service breakdown is monitored.

In cases involving large incidents, ITS has a formal series of processes to escalate the classification of the seriousness of the incident as necessary. They have "tiger teams" that investigate every breakdown and analyze the initial cause and how it can be 
prevented in the future. The general feeling of the interview participants was that since its establishment, ITS has become more lean and efficient in terms of service failure recovery

\section{Table 81: Results for Service Failure Recovery}

Has the organization established problem-solving groups to enhance the ability to resolve service breakdowns?

\begin{tabular}{|r|l|l|l|l|}
\hline Interviewee & High & Medium & Low & Other \\
\hline 1 & & & & couldn't answer \\
\hline 2 & & & & no answer \\
\hline 3 & $\mathrm{X}$ & & & \\
\hline 4 & $\mathrm{X}$ & & & \\
\hline 5 & $\mathrm{X}$ & & & \\
\hline 6 & $\mathrm{X}$ & & & \\
\hline 7 & $\mathrm{X}$ & & & \\
\hline 8 & $\mathrm{X}$ & & & \\
\hline 9 & & $\mathrm{X}$ & & \\
\hline 10 & & $\mathrm{X}$ & & \\
\hline 11 & $\mathrm{X}$ & & & \\
\hline 12 & $\mathrm{X}$ & & & \\
\hline 13 & & $\mathrm{X}$ & & \\
\hline 14 & $\mathrm{X}$ & & & \\
\hline 15 & $\mathrm{X}$ & & & \\
\hline & 10 & 3 & -- & \\
\hline Total & & & & \\
\hline
\end{tabular}

"Yes. We have tiger teams. They are led by a very senior member like the director general and staff are taken from operations, sales and services groups. The sole purpose is resolving previously unresolved problems." (\# 3 ITS member)

"Yes. Whenever we have a service disruption we have a log of the service disruption and in significant service disruptions we have a review board." (\#7ITS member)

"Yes. We are pretty good on that. As I said, reactive. So once a breakdown happens we have a pretty good system that tracks it, which is part of the ITIL incident management. We are very good at fixing IT disruptions and service disruptions, which are becoming far and few. In the last few years we have improved and have a solid infrastructure. May not be that up to date but they are pretty solid." (\#6 ITS member) 


\subsubsection{Service Standards Communication}

In general the respondents felt that they have received either a high or a medium level of communication on how well the organization performs in reporting the level of performance standards. There is a "dashboard" available on the intranet that displays the various performance levels of ITS. This allows employees to keep abreast of the quality of the services provided and indicates whether they have met the service levels as defined in the service agreements.

\section{Table 82: Results for Service Standards Communication}

What measures are taken by the organization to communicate service performance measures to employees regardless of position or function?

\begin{tabular}{|r|l|l|l|l|}
\hline Interviewee & High & Medium & Low & Other \\
\hline 1 & $X$ & & $X$ & \\
\hline 2 & & & & \\
\hline 3 & $X$ & $X$ & & \\
\hline 5 & $X$ & & & \\
\hline 6 & & & $X$ & \\
\hline 7 & & $X$ & & \\
\hline 8 & $X$ & & & \\
\hline 10 & & & $X$ & \\
\hline 11 & & $X$ & $X$ & \\
\hline 12 & $X$ & & & \\
\hline 13 & & $X$ & & \\
\hline 14 & & $X$ & & \\
\hline 15 & & $X$ & & \\
\hline & 5 & 6 & 4 & - \\
\hline
\end{tabular}

"Right off the bat, we have a web site which is called the dashboard. Just like how you would see on a car. On this dashboard a number of people post information regarding performance, availability or outages or telecommunication time, the number of changes that month, how much capacity has been used, what free space has been there, looking at revenue. There is a wide range of information related to our performance, the quality of service we deliver and how effective we are. Everything is there. For example, our print shop prints all the cheques for the 
Government of Canada, and if some delay happens it is up on the dash board." (\# 5 ITS member)

A few respondents felt that not every employee is made aware of the performance of ITS and wished there was more communication from the management.

"Occasionally. We have every year - we may have an employee get together and the CEO presents a large PowerPoint presentation and inside it there would be data and $I$ would not say that regular information is given to the employees." (\# 2 ITS member)

In brief, qualitative results on service characteristics show that service failure recovery was impressive at ITS. Service failure prevention and service standards communication received moderate scores from the interviewed participants. Among the service characteristics, service technology received the greatest number of low ratings.

\subsection{Job Outcomes}

During the last portion of the interview respondents were asked how they felt about their job outcome at ITS. The questions were on job satisfaction and job outcomes. These results are summarized as follows.

An equal number of participants stated that their ITS job only moderately compares to their ideal job or that their job does not compare to what they think of as an ideal job. Those who said that it does not compare to their ideal job found their work in ITS to be very stressful: there was too much work with competing priorities; the concept 
of ITS was very complex; and they had difficulty grasping the broader picture (mainly because there was lack of vision at the top). Many complained that too much work produced work-related stress in their lives. The stress at work arises because employees have to perform challenging work and demonstrate a high level of efficiency with limited resources. Some said that many of their colleagues have gone on stress leave. One ITS employee remarked that individual work performance is dependent on the performance of many others, making it less of an ideal job.

\section{Table 83: Results for Ideal Job}

How does this job compare with the ideal job you would most like to have?

\begin{tabular}{|l|l|l|l|l|}
\hline Interviewee & Highly compare & $\begin{array}{l}\text { Moderately } \\
\text { compare }\end{array}$ & $\begin{array}{l}\text { Does not } \\
\text { compare }\end{array}$ & Others \\
\hline 1 & & & $X$ & \\
\hline 2 & & $X$ & $X$ & \\
\hline 3 & & $X$ & & \\
\hline 4 & & & $X$ & \\
\hline 5 & & & $X$ & \\
\hline 6 & & $X$ & & \\
\hline 7 & & $X$ & & \\
\hline 8 & & & $X$ & \\
\hline 9 & $X$ & & & didn't \\
\hline 10 & & & $X$ & \\
\hline 11 & & & & \\
\hline 12 & & $X$ & & \\
\hline 13 & & $X$ & 6 & 1 \\
\hline 14 & & 6 & & \\
\hline 15 & 2 & & & \\
\hline Total & & & & \\
\hline
\end{tabular}

"You want an honest answer. I think we are very far. I do not know how to articulate that in order to make sense. The level of disparity on some days is greater than the amount of joy you should have in performing a job like this." (\# 6 ITS member)

"A lot more stress in this job. A lot of people go on stress leave. Ideally I would not like to have much stress. Secondly we would like to have the funding to do what we want to do. Sometimes we know what needs to be done, we know how to do it, we would like to deliver it but we do not have the funding. In the long run it is beneficial 
to both the government and to the citizens and the country. In an ideal job I would like the funding to deliver quality service." (\# 12 ITS member)

Some respondents who thought that their job was approaching their ideal job or that it was the ideal job for them stated that ITS provided them with opportunities to learn about IT and IT management, a sense of accomplishment, and opportunities to work in diversified areas.

My career has been satisfactory. After graduation I actually wanted to be a CEO in the private industry but now I am a director in the government. I worked 8 years in the private sector and joined the government. I have been very satisfied (\# 8 ITS member)

"My goal is to make a difference and benefit Canadians in the long run, but in the end it is to improve efficiency. When it comes to my personal goal, I would say that right now quality of life is important for me and I like the people that I work with and the work that I do."(\# 11 ITS member)

\subsection{Job Satisfaction}

When the discussion of job satisfaction came up in the interview, the majority of the interviewees indicated their level as moderate. Many of them stated that satisfaction in their job comes largely from the fact that the people are great at ITS, and they offered many compliments about the good supervisors and good peers, noting that there were few interpersonal conflicts. The interviewees also were satisfied to be working in a shared services work environment. However, this job satisfaction reaches only a moderate level because of such factors as too much work, the need for work to be more organized at the managerial levels, and frustration with processing, declining budgets, and the inability to deliver the work that has been assigned. 
Table 84: Results for Job Satisfaction

All things considered, how satisfied are you with your current job?

\begin{tabular}{|c|c|c|c|c|}
\hline Interviewee & Very & Moderately & Low & Others \\
\hline 1 & & $x$ & & \\
\hline 2 & & & $x$ & \\
\hline 3 & & $x$ & & \\
\hline 4 & & $x$ & & \\
\hline 5 & & $x$ & & \\
\hline 6 & & $x$ & & \\
\hline 7 & & $x$ & & \\
\hline 8 & $x$ & & & \\
\hline 9 & & $x$ & & \\
\hline 10 & & $x$ & & \\
\hline 11 & $x$ & & & \\
\hline 12 & & $x$ & & \\
\hline 13 & & $x$ & & \\
\hline 14 & $x$ & & & \\
\hline 15 & & $x$ & & \\
\hline Total & 3 & 11 & 1 & $=$ \\
\hline
\end{tabular}

"Pretty satisfied. I am in the business for the last 37 years. It is not bad here. It has a lot to do with my boss here, people who I work with, my peers. I must say that I do not wake up in the morning and go, Oh I have to go work." (\# 5 ITS member)

"Put it as average. The issue is declining budget, increasing amount of work, and inability to deliver what you have been asked. Hence, you are running everywhere and the quality of the work is . . . . How can you like that?" (\# 9 ITS member)

"Very satisfied. I need the high pace and the IT. It is perfect." (\# 8 ITS member)

\subsubsection{Quality, Quantity and Accuracy}

In commenting about the quality, quantity and accuracy of their work, seven respondents felt that it was high, four assessed it as moderate, and four could not really answer the question. Many respondents thought that the quality of their work would be much better if the organization provided more resources and the necessary tools. At ITS, the ability to deliver quality work was hampered whenever the senior 
management set timelines that were so short that accomplishing the required tasks was difficult. Individuals who put their work quality as moderate stated that they were still adapting to ITS environment and felt that as they became accustomed to the many projects, their quality of output would be much better.

\section{Table 85: Results for Quality}

How would you rate the quality, quantity and accuracy of your work?

\begin{tabular}{|c|c|c|c|c|}
\hline Interviewee & High & Medium & Low & Others \\
\hline 1 & & $x$ & & \\
\hline 2 & $x$ & & & \\
\hline 3 & $x$ & & & \\
\hline 4 & $x$ & & & \\
\hline 5 & $x$ & & & \\
\hline 6 & & $x$ & & \\
\hline 7 & & $x$ & & \\
\hline 8 & & & & $\begin{array}{l}\text { didn't really } \\
\text { answer }\end{array}$ \\
\hline 9 & & & & $\begin{array}{l}\text { didn't really } \\
\text { answer }\end{array}$ \\
\hline 10 & & $x$ & & \\
\hline 11 & $x$ & & & \\
\hline 12 & & & & $\begin{array}{l}\text { didn't really } \\
\text { answer }\end{array}$ \\
\hline 13 & $x$ & & & \\
\hline 14 & $x$ & & & \\
\hline 15 & & & & $\begin{array}{l}\text { didn't really } \\
\text { answer }\end{array}$ \\
\hline Total & 7 & 4 & $\ldots$ & 4 \\
\hline
\end{tabular}

"On the quality, I could have done the job better. For example we are supposed to review all the service level agreements and ensure consistency with the standards that are set up, consistency with figures, consistency of service definition. With the resources I have I will just look whether the finances are covered properly and for the rest we do not have the time." (\#6 ITS member)

"Quality, $70-80 \%$, the quantity, 60\%. I am probably being hard on it. I am hoping that it is possible to do more but it is not always. And my accuracy probably is 70 to 85\%." (\# 4 ITS member) 
On the other hand, the majority of the respondents when talking about the quantity said that it was high. Some felt that the quantity of work was so high it impacted the quality of their work. They may want to achieve a top quality outcome on the job but are pressured to move on to the next task at hand.

"I definitely feel the quantity is too much now. Sometimes because there is too much work my quality goes down. I tell my boss the more you give the less quality that you are going to get. Accuracy I would say is about 75\%." (\# 9 ITS member)

"Excellent quality, quantity that matched the requirement of this job and the accuracy is around moderate." (\# 3 ITS member)

In terms of evaluating their individual accuracy at work, the respondents stated that accuracy is very important because their work affects not only one sector of ITS but other government departments as well. The majority of them assess the accuracy of their work as high.

"Quality - what we do, we are the strategic aspect of ITS. To a large extent we try to strategically improve what we do throughout the year, what we will do next year and in three years, and how to improve things. Quality and accuracy is very important and it is visible to all of the organization. Although we are located within one sector, a lot of what we do affects the whole branch and not only their sector. And because we have this link to other sectors, they may not like to hear from other sectors as to how we have to do things. So it is important for us to maintain extremely good quality." (\# 11 ITS member) 
Table 86: Results for Quantity

\begin{tabular}{|r|l|l|l|l|}
\hline Interviewee & High & Medium & Low & Others \\
\hline 1 & $\mathrm{X}$ & & & \\
\hline 2 & $\mathrm{X}$ & & & \\
\hline 3 & $\mathrm{X}$ & $\mathrm{X}$ & & \\
\hline 4 & & & & \\
\hline 5 & $\mathrm{X}$ & & & \\
\hline 6 & & & & $\begin{array}{l}\text { didn't } \\
\text { really } \\
\text { answer }\end{array}$ \\
\hline 7 & $\mathrm{X}$ & & \\
\hline 8 & $\mathrm{X}$ & & & \\
\hline 9 & $\mathrm{X}$ & & & \\
\hline 10 & $\mathrm{X}$ & & & \\
\hline & & & & $\begin{array}{l}\text { didn't } \\
\text { really } \\
\text { answer } \\
\text { question }\end{array}$ \\
\hline 11 & & & & \\
\hline 12 & $\mathrm{X}$ & & & \\
\hline 13 & $\mathrm{X}$ & & & \\
\hline 14 & $\mathrm{X}$ & & & $\begin{array}{l}\text { didn't } \\
\text { really } \\
\text { answer }\end{array}$ \\
\hline & & & & 3 \\
\hline 15 & & 1 & & \\
\hline & 11 & & & \\
\hline
\end{tabular}

Table 87 : Results for Accuracy

\begin{tabular}{|r|l|l|l|l|}
\hline Interviewee & High & Medium & low & Others \\
\hline 1 & $\mathrm{X}$ & & & \\
\hline 2 & & $\mathrm{X}$ & & \\
\hline 3 & & $\mathrm{X}$ & & \\
\hline 4 & $\mathrm{X}$ & & & \\
\hline 6 & & & & no answer \\
\hline 7 & & & & didn't really answer \\
\hline 8 & & $\mathrm{X}$ & & \\
\hline 9 & $\mathrm{X}$ & & & didn't really answer \\
\hline 10 & $\mathrm{X}$ & & & \\
\hline 11 & $\mathrm{X}$ & & & \\
\hline 12 & $\mathrm{X}$ & & & \\
\hline 13 & $\mathrm{X}$ & & & \\
\hline 14 & $\mathrm{X}$ & & & \\
\hline 15 & & & & \\
\hline & 8 & 3 & & didn't really answer \\
\hline
\end{tabular}




\subsubsection{Progress in Career}

The general sense from the interviews was that ITS is not a work place where individuals have many opportunities for career advancement. Seven respondents rated career prospects in ITS as low, and an equal number considered career prospects to be moderate. Some felt that ITS is too big and that it might have to downsize when reorganizing, which would likely result in even fewer progressive career paths for the remaining workforce. Those interviewees who were in middle-level management positions believed that the next level, executive management, might require more ITrelated background. The interviewees also felt that ITS is a complex organizational unit and making a difference in such a place is harder than in other units within the government. Some interviewees felt that other government organizations might also try to implement their own shared services, creating direct competition for this ITS. These issues have an impact on the prospects for a progressive career at ITS. 
Table 88: Results for Progress in Career

How do you feel about the progress you are making in your career within the ITS?

\begin{tabular}{|r|l|l|l|l|}
\hline Interviewee & High & Medium & Low & Others \\
\hline 1 & & & $\mathrm{X}$ & \\
\hline 2 & & $\mathrm{X}$ & & \\
\hline 3 & & & $\mathrm{X}$ & \\
\hline 5 & & $\mathrm{X}$ & & \\
\hline 6 & & & $\mathrm{X}$ & \\
\hline 7 & & & $\mathrm{X}$ & \\
\hline 8 & & & $\mathrm{X}$ & \\
\hline 9 & & & $\mathrm{X}$ & \\
\hline 10 & & $\mathrm{X}$ & & \\
\hline 11 & $\mathrm{X}$ & $\mathrm{X}$ & & \\
\hline 12 & & & & \\
\hline 13 & & $\mathrm{X}$ & & \\
\hline 14 & $\mathrm{X}$ & & $\mathrm{X}$ & \\
\hline 15 & & & & \\
\hline & 2 & $\mathrm{X}$ & & \\
\hline Total & 6 & 7 & \\
\hline
\end{tabular}

"At this point I am a little frustrated, because I do not see any advancement in the organization for me. The next level up is - the pyramid is getting smaller and the next level up is at the director general level and the organization is going through realignment, in the sense that with the changes in the higher level and in general there is going to be a reduction in the number of senior level positions. As we bring/merge sectors together we don't need people in charge of sectors and for the next year there is going to be more people at that level than there are jobs."

(\# 1 ITS member)

"I have reached the top. I can retire with full pension in three years. I am not even going to try to get to a different level." (\# 6 ITS member)

"Well my career is at an end. I have two years to go before retirement. I have no gas left. I am too burned out." (\# 7 ITS member)

"Well the ITS is definitely challenging. We are not progressing as we should. It is a large scope and you are a small piece in it. You are not too sure that you're making a 
dent in it. That is a little de-motivating. Making a difference is hard."(\# 8 ITS member)

\subsubsection{Innovative Ideas}

Interviewees felt that they make a significant contribution to their work setting by bringing forward new ideas. The general sense was that senior management encouraged new ideas and different ways of thinking. Individuals felt that within their own work area implementing ideas was easier, but also that the governance structure accommodated new ideas at a broader level.

\section{Table 89: Results for Innovative Ideas}

Do you come up with new ideas and then implement them at work?

\begin{tabular}{|r|l|l|l|l|}
\hline Interviewee & All the time & Sometimes & Seldom & Others \\
\hline 1 & $\mathrm{X}$ & & & \\
\hline 2 & & $\mathrm{X}$ & & \\
\hline 3 & $\mathrm{X}$ & & & \\
\hline 4 & $\mathrm{X}$ & & & \\
\hline 5 & $\mathrm{X}$ & & & \\
\hline 6 & & $\mathrm{X}$ & & \\
\hline 7 & $\mathrm{X}$ & $\mathrm{X}$ & & \\
\hline 9 & $\mathrm{X}$ & & & \\
\hline 10 & & & & \\
\hline 11 & $\mathrm{X}$ & $\mathrm{X}$ & & \\
\hline 12 & & & & \\
\hline 13 & $\mathrm{X}$ & $\mathrm{X}$ & & \\
\hline 14 & $\mathrm{X}$ & & & \\
\hline 15 & & $\mathrm{X}$ & & \\
\hline & 10 & 5 & & \\
\hline
\end{tabular}

"I try to. I'm very big on process improvement and again, this is an environment I think where that is encouraged across the board for all employees. We do have a really good management team that's very open to people coming to the forums with new ideas, new proposals. Obviously there is a governance before you can implement, unless it's in your own personal area of responsibility. So there is 
freedom and flexibility within my own area, my own span of control, to come up with ideas and implement them. But others that are broader need to go through that governance, but there are opportunities within our org to take them through that structure for sure." (\#12 ITS member)

"Yes. Quite often you have to come up with ideas, document it, get approval, present it to your manager, and if it is a good idea they will let you go for it. They are quite accepting of ideas -I mean encouraging." (\# 5 ITS member)

\subsubsection{Team Work}

When it comes to working in a team, five respondents felt very happy and eight respondents felt moderately happy about their contribution within a team. Many also felt that they made a significant contribution to the overall performance of ITS. They considered their contribution to the team and the overall organization in the context of ITS starting from scratch: each of them had played a significant role in forming the largest government IT shared services organization in Canada. The general sense was that if employees did not contribute significantly in their jobs it would be noticeable, and that would not be good for them, for the team or for the sector. In order to maintain their role as valuable, productive employees, team members work together at their maximum level. 
Table 90: Results for Team Work

Are you happy about the contribution you make in the group that you work in?

\begin{tabular}{|c|c|c|c|c|}
\hline Interviewee & Very happy & Happy & Not happy & Others \\
\hline 1 & & $x$ & & \\
\hline 2 & & & $x$ & \\
\hline 3 & $x$ & & & \\
\hline 4 & & $x$ & & \\
\hline 5 & $x$ & & & \\
\hline 6 & & $x$ & & \\
\hline 7 & & $x$ & & \\
\hline 8 & & $x$ & & \\
\hline 9 & & $x$ & & \\
\hline 10 & & $x$ & & \\
\hline 11 & $x$ & & & \\
\hline 12 & & & $x$ & \\
\hline 13 & $x$ & & & \\
\hline 14 & & $x$ & & \\
\hline 15 & $\bar{x}$ & & & \\
\hline Total & 5 & 8 & 2 & \\
\hline
\end{tabular}

"Yes. Yes. I feel that my contribution is high, the team we have is a really strong team, and also personality wise I think I'm bringing a lot to our team." (\# 15 ITS member)

"My performance is very important because I am overseeing a team of 200 people. If they are not motivated or challenged then..... I mean it is a small number in the scheme of 6000 but we do here is keep all those computer going on the desktop of 16000 of them. It is pretty detrimental and important. We strive to keep the productivity of the individual going. That has been our motto. On that prospective we are major contrition and are motivated by that". (\# 8 ITS member)

"Well. I think if I do not do my job, my manager will have gaps in his knowledge and will not be able to do proper decisions in time. I think some of my colleagues might not be able to finish their work because I have not done my part. There are so many other people down the line within the organizations that will be affected. There will be an influence down the line." (\# 5 ITS member) 


\subsubsection{Overall Good of the Company}

Many individuals who were interviewed said that their overall contribution towards the betterment of the organization was high; a number of them rated their contribution as moderate. They believed that they contribute to the better performance of ITS by helping fulfill the mandate of their sector, providing their managers with support to run the unit so that he or she can focus on the entrepreneurial efforts that are necessary for ITS. Some also contribute by taking up an acting position when a supervisor or manager has to go on leave; in this way, an experienced and knowledgeable member ensures the work of sector is carried on. A few observed that they not only work in their sector's line of business but also collaborate with people who work in other ITS lines of business and thus have influence across several sectors.

Table 91: Results for the Overall Good of the Company

Tell us how your performance is related to the overall good of the company?

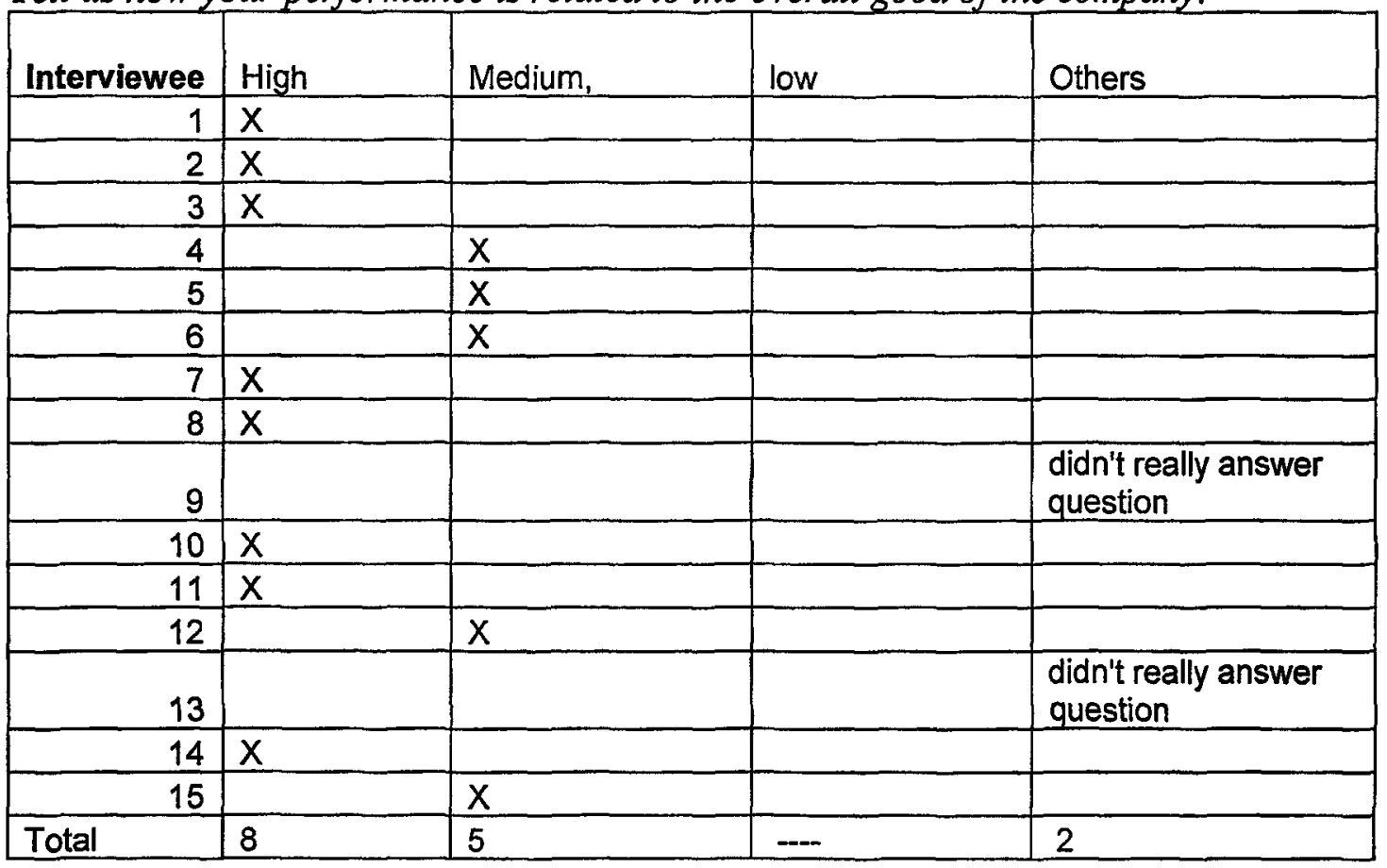


"So, I think there are couple of things within the line of business - I have had the opportunity to influence the line of business a lot. So I think I am seeking a lot of progress there. I also have taken the opportunity to try and influence other things that can have broader prospects in different places. Not that it is good for my line of business or for me but it is better for the whole." (\# 4 ITS member)

The company depends on me to keep it going. To keep the priorities bounded, staffed and resourced. And to keep people focused. If I do not perform then things can get out of hand pretty quickly."( \# 7 ITS member)

\subsubsection{Turnover}

Finally, when the individuals were asked about their turnover intentions, the majority of them said that they would like to leave ITS for another career within the government of Canada. The main reasons for such high turnover intentions were heavy work load, stressful work environment, limited resources and the perception that they could put their knowledge into better use in other government agencies and advance more quickly.

Table 92: Results for Turnover

Do you ever think of quitting and looking out for another job?

\begin{tabular}{|r|l|l|}
\hline Interviewee & Yes & No \\
\hline 1 & $X$ & \\
\hline 2 & $X$ & \\
\hline 3 & $X$ & \\
\hline 4 & $X$ & $X$ \\
\hline 5 & $X$ & \\
\hline 6 & $X$ & \\
\hline 7 & $X$ & $X$ \\
\hline 8 & & \\
\hline 9 & $X$ & \\
\hline 10 & $X$ & \\
\hline 11 & & $X$ \\
\hline 12 & $X$ & \\
\hline 13 & & \\
\hline 14 & $X$ & \\
\hline 15 & $X$ & \\
\hline Total & 11 & \\
\hline
\end{tabular}


"Yes. More so this year than ever. The challenges and it is hard."(\# 6 ITS member)

"No. But sometimes I think of going into another department, because when I integrate and see what are the problems they undergo and you have the experience in solving them, that I could make difference there." (\#1I ITS member)

In summary, when respondents were asked whether their job at ITS was an ideal job, an equal number evaluated the job at moderate and low levels; job satisfaction, on the other hand, received more moderate ratings. When assessing the quality, quantity and accuracy of their work, ITS members put all of these at a high level, especially the quantity of work. Career opportunities at ITS were ranked as only moderately or not very progressive. Individuals identified themselves as innovative at work and their contributions towards the success of ITS as moderate when working in groups. Respondents also felt that they contributed to the overall good of ITS at high to medium levels. The turnover intentions were very high among ITS members.

\subsection{Analyzing Data from the Short Question}

In ITS job design questionnaire, a short question asked respondents for their opinion as to what job characteristics were very important for the nature of work at an IT shared services organization. Out of the 105 respondents, 34 respondents chose to answer the question in writing. The responses were carefully analyzed by the researcher and a colleague. The job characteristics identified by ITS members fell into three broad categories, including individual level characteristics, personal skill sets, and organizational level characteristics. 
Table 93 : Individual Characteristics Identified by ITS Members

\begin{tabular}{|l|l|}
\hline Individual Characteristics & Number of counts \\
\hline Team Player & 17 \\
\hline Strong work ethics & 9 \\
\hline Proactive, take initiative, think ahead & 6 \\
\hline Flexibility & 6 \\
\hline Creativity & 5 \\
\hline Patience & 5 \\
\hline Desire to learn & 3 \\
\hline Detail oriented & 3 \\
\hline Work under pressure & 2 \\
\hline Positive attitude & 2 \\
\hline
\end{tabular}

The individual characteristic most frequently identified by the respondents was that of being a team player with strong work ethics, which included producing good quality work and being reliable and committed. Strategic thinking, patience and creativity were also recognized by these ITS employees.

Table 94: Individual Skill Sets Identified by ITS Members

\begin{tabular}{|l|l|}
\hline Individual skill sets & Number of counts \\
\hline Client focus & 14 \\
\hline Technical competence & 12 \\
\hline Communication skills & 8 \\
\hline Problem solving skills & 6 \\
\hline Planning and organizing skills & 5 \\
\hline Leadership skills & 5 \\
\hline Interpersonal skills & 5 \\
\hline Management skills & 2 \\
\hline Financial management skills & 3 \\
\hline Negotiation skills & 3 \\
\hline Project management skills & 2 \\
\hline
\end{tabular}

ITS employees described their jobs as requiring a great variety of skills. Having client focus, technical competence and communication skills were identified as the 
most important. These were closely followed by problem solving skills, planning, organizational, leadership and interpersonal skills.

At the organizational level, ITS employees expected to be allocated more tools and technologies to enhance their jobs. In addition, they expected more guidelines on roles and standards from the senior management. Employees wanted their upper management to have a clear vision. Individuals also pointed out that senior management needs to have trust in the abilities of the employees. Providing more onthe-job training and being more client focused were identified as important organizational characteristics.

Table 95: Organizational Level Characteristics Identified by ITS members

\begin{tabular}{|l|r|}
\hline Organizational level characteristics & $\begin{array}{r}\text { Number } \\
\text { of counts }\end{array}$ \\
\hline Need access to tools, resources and technologies & 7 \\
\hline Need clear guidelines for roles and standards at organization level & 5 \\
\hline Need better leadership at the upper levels (trust and set vision) & 4 \\
\hline Provide training opportunities & 4 \\
\hline Ensure client focus & 3 \\
\hline Important to have clear organizational processors & 3 \\
\hline Be proactive and think ahead strategically & 2 \\
\hline Ensure that employees can understand how they contribute to the bigger picture & 2 \\
\hline Organization has to be flexible and adoptive & 2 \\
\hline Important to have interaction across team and organizational boundaries & \\
\hline
\end{tabular}


The short question asked on the questionnaire was also asked at the end of each interview with ITS members. When analyzed, these responses also were based on individual skills, individual characteristics and organizational characteristics. The individual skills identified as being required in ITS job were business skills and mindset, technical skills, and being service oriented. At the individual level, managers indicated that to perform ITS job well, individuals need to understand the information flow, have the ability to see the bigger picture, and be able to take multiple streams of information and pull them together into a cohesive whole. Having access to better technology, being an expert in one's area of operation, and the ability to learn were noted as well. At the organizational level, ITS managers mentioned that upper management needs to communicate a clearer vision for the organization, understand economies of scale, and project ITS as an efficient engineering organization. The need for government support in identifying the ITS as the IT service provider of choice was also alluded to. 
Table 96: Job Characteristics Identified by Interview Participants

\begin{tabular}{|c|c|c|c|}
\hline Interview & \begin{tabular}{l|} 
Individual \\
Skill sets
\end{tabular} & Individual level & Organizational level \\
\hline 1 & $\begin{array}{l}\text { Business } \\
\text { skills }\end{array}$ & $\begin{array}{l}\text { Insight as to how all the } \\
\text { parts fit together }\end{array}$ & $\begin{array}{l}\text { Vision, where economies } \\
\text { can be added for efficiency }\end{array}$ \\
\hline 2 & Efficiency & $\begin{array}{l}\text { Access to information, } \\
\text { empowerment }\end{array}$ & $\begin{array}{l}\text { Cost optimization and } \\
\text { decision making are not } \\
\text { punished. }\end{array}$ \\
\hline 3 & & Technology & Sales and marketing \\
\hline 4 & & $\begin{array}{l}\text { Client focus, service focus, } \\
\text { communication }\end{array}$ & \\
\hline 5 & & Will to succeed & $\begin{array}{l}\text { An efficient engineering } \\
\text { organization, proper vision }\end{array}$ \\
\hline 6 & & & $\begin{array}{l}\text { Not too much focus on IT but } \\
\text { emphasis on business, } \\
\text { business discipline }\end{array}$ \\
\hline 7 & & $\begin{array}{l}\text { Enduring sprit, operate in } \\
\text { uncertainty, balance your } \\
\text { autonomy with other areas, } \\
\text { teamwork }\end{array}$ & \\
\hline 8 & & & $\begin{array}{l}\text { Clear direction, get } \\
\text { government buy in, overall } \\
\text { government understanding }\end{array}$ \\
\hline 9 & $\begin{array}{l}\text { Service } \\
\text { orientation }\end{array}$ & $\begin{array}{l}\text { Understanding the work } \\
\text { flow }\end{array}$ & Financially savvy \\
\hline 10 & & & $\begin{array}{l}\text { Try to become the service } \\
\text { provider of choice, building } \\
\text { image, providing quality } \\
\text { service, fast response }\end{array}$ \\
\hline 11 & & & $\begin{array}{l}\text { Building service that is } \\
\text { robust and scalable }\end{array}$ \\
\hline 12 & & $\begin{array}{l}\text { An ability to see the bigger } \\
\text { picture and be able to take } \\
\text { multiple streams of } \\
\text { information and pull them } \\
\text { into a cohesive whole. }\end{array}$ & Customer service \\
\hline 13 & & Ability to learn & \\
\hline 14 & $\begin{array}{l}\text { Technical } \\
\text { skills }\end{array}$ & & Client service management \\
\hline 15 & & Being subject matter expert & \\
\hline
\end{tabular}


This chapter presented the qualitative analysis from the interviews along with the data collected from the answers to the short question. In the next chapter, this thesis will discuss these findings along with the quantitative analysis presented in Chapter five. 


\section{Chapter Seven}

\section{Discussion: Integrating Qualitative and Quantitative Analysis}

The main objective of this research is to identify job characteristics that enhance job outcomes for ITS employees. The previous chapters presented findings from the quantitative and qualitative data. In this chapter we combine both the data sets and discuss which job characteristics influenced job outcomes for ITS members. For those job characteristics that did not have an impact we attempt to identify the reasons behind such findings. Firstly, this chapter answers the second research question of the

study given in chapter three: "What job characteristics lead to better job outcomes for individuals working within an IT-SSO." This is done through the analysis of motivational, social, and service characteristics with outcome variables. While addressing this main research question, the discussion provides a description of the nature of work at an IT-SSO, answering the first research question: "What is the nature of work in an IT-SSO?" Finally, occupation variables and their relationship with outcome variables are presented, answering the third research question of this study.

\subsection{Motivational Job Characteristics and Job Outcomes}

Chapter 5 presented the hierarchical regression of job characteristics and job outcomes. The results show that when motivational characteristics were entered into the regression model, the variances on the dependent variables were significant. The inclusion of the motivational characteristics led to an increase of $51 \%$ in job satisfaction and a variance of $20 \%$ in job performance (job), $24 \%$ in enhanced job performance (career), $30 \%$ in job performance (organization), and $35 \%$ in turnover 
intentions. Autonomy was the most significant predictor of all three job outcomes.

The other motivational variable that had an impact on job outcomes was skill variety.

Table 97: Hypotheses Related To Motivational Job Characteristics

\begin{tabular}{|c|c|c|c|}
\hline & Supported & $\begin{array}{c}\text { Partially } \\
\text { Supported }\end{array}$ & $\begin{array}{c}\text { Not } \\
\text { Supported }\end{array}$ \\
\hline $\begin{array}{l}\text { H1: For an IT-SSO worker, work scheduling autonomy, work } \\
\text { methods autonomy, and decision making autonomy will } \\
\text { positively relate to (a) job performance, and (b) job } \\
\text { satisfaction, and (c) negatively relate to intention to leave. }\end{array}$ & $\sqrt{ }$ & & \\
\hline $\begin{array}{l}\text { H2: For an IT shared services worker, skill variety is } \\
\text { positively related to (a) job performance, and (b) job } \\
\text { satisfaction, and (c) negatively related to intention to leave. }\end{array}$ & & $\sqrt{ }$ & \\
\hline $\begin{array}{l}\text { H3: For an IT shared services worker, task identity is } \\
\text { positively related to (a) job performance and (b) job } \\
\text { satisfaction and (c) negatively related to intention to leave. }\end{array}$ & & & $\sqrt{ }$ \\
\hline $\begin{array}{l}\text { H4: For an IT shared services worker, task significance is } \\
\text { positively related to (a) job performance and (b) job } \\
\text { satisfaction and (c) negatively related to intention to leave. }\end{array}$ & & & $\sqrt{ }$ \\
\hline $\begin{array}{l}\text { H5: For an IT shared services worker, task variety is } \\
\text { positively related to (a) job performance, and (b) job } \\
\text { satisfaction, and (c) negatively related to intention to leave. }\end{array}$ & & & $\sqrt{ }$ \\
\hline $\begin{array}{l}\text { H6: For an IT shared services worker, job feedback from the } \\
\text { job is positively related to (a) job performance, and (b) job } \\
\text { satisfaction, and (c) negatively related to intention to leave. }\end{array}$ & & & $\sqrt{ }$ \\
\hline $\begin{array}{l}\text { H7(a): For an IT shared services worker, information } \\
\text { uncertainty in IT-SSO work is negatively related to (a) job } \\
\text { performance and (b) job satisfaction, and (c) positively related } \\
\text { to the intention to leave. } \\
\text { H7(b): For an IT shared services worker, information } \\
\text { equivocality in IT-SSO work is negatively related to (a) job } \\
\text { performance and (b) job satisfaction, and (c) positively related } \\
\text { to the intention to leave }\end{array}$ & & & $\sqrt{ }$ \\
\hline
\end{tabular}

This discussion begins with the relationship between autonomy and job outcomes in

ITS. The survey results showed that autonomy is the only variable influencing job

satisfaction, job performance and turnover intentions. These results are very similar to

those reached by Humphrey, Nahrgang and Morgeson (2007) in their meta-analysis.

The survey results support H1, which hypothesized that for an ITS worker, work-

scheduling autonomy, work-methods autonomy, and decision-making autonomy 
will positively relate to (a) job performance and (b) job satisfaction, and (c) negatively relate to intention to leave. The qualitative data also showed that interviewees experienced high to moderate levels of autonomy in their job. Autonomy at work remains one of most significant factors in determining job outcomes in organizations (Spector, 1986), showing a consistently positive relationship with job outcomes. In ITS, the greater the autonomy given to an employee, the greater the level of job satisfaction he or she enjoyed. Not only did autonomy enhance job performance at the career and organizational levels, but it also related negatively to employee turnover. ITS operates in a matrix structure, which is defined by Ford and Randolph as "cross functional overlays that create multiple lines of authority and that place people in teams to work on tasks for finite periods of time" (1992, 270). Unlike the traditional bureaucratic structure, which can impede the individual autonomy of an organization's employees, the matrix structure provides the different units of ITS with enough authority to make decisions related to their respective functions. Although in the factor analysis all three types of autonomy loaded on to one factor, the qualitative results indicated that there were some limitations on work-methods autonomy and work-scheduling autonomy. In terms of choosing the methods required to perform a task, there often were only a few ways to actually do the job, but within these limited choices the employees had the freedom to choose the method(s) they deemed most suitable. At times these procedures had to match those that had been set out by the governance body; specifically, if the work involved cross-sectional activities, then the methods had to be approved by the governance body. During the interviews and in responses to the short-answer 
question, a frequent comment by participants was, "Give us the tools." This indicates that the methods or procedures for carrying out work at ITS need to be diversified. Further, among the three dimensions of autonomy, work scheduling autonomy seemed to be the one hampered most by the prioritization of tasks and frequent all day meetings, which take time away from work. Parker and Price (1994) suggest that greater empowerment at the middle level of management can help employees gain more control over their autonomy. In ITS, greater empowerment of middle level managers is critical. Middle-level managers need to create a flexible work schedule and set out the priorities for their work unit. This would lead to greater scheduling autonomy for individual workers. Interview participants observed that managers who took control of competing priorities by re-assigning them appropriately and reducing work load pressure were much appreciated by their employees. Therefore, empowering middle managers to better schedule work is important at ITS; it increases autonomy for ITS workers and positively impacts job outcomes.

Along with autonomy, motivational characteristics and skill variety were also found to enhance job performance. This partially supports $\mathrm{H2}$ (a), which hypothesized that for an IT shared services worker, skill variety is positively related to job performance. This finding is in line with studies done by Hackman and Oldham (1976), Fried and Ferris (1987), and Humphrey, Nahrgang and Morgeson (2007), which established that skill variety leads to better job outcomes. The qualitative data in our study indicated that ITS employees are required to use a wide range of both IT and non-IT skills, and that skill variety in ITS jobs leads to better job performance at 
the organizational level. Analysis of the data from the short question and the interviews indicates that workers have strong opinions about skills competence in ITS. Some indicated that since ITS needs to function as a business entity, business skills are an important requirement; at the same time, they stated, strong IT skills are required to understand the multiple functions of the IT service provider. In addition, respondents noted that to advance further within ITS, they needed stronger IT competence. The strong relationship between skill variety and job performance at the organizational level indicates that the use of multiple skills by individuals can be key to efficiency. The data suggests that ITS often prefer technical competence and tend towards hiring more IT-skilled individuals (70 respondents used more IT skills at their jobs); however, business skills are also needed for ITS to become the service provider of choice, to build their image and to provide quality service. When hiring or promoting workers, ITS managers need to identify the correct balance of required IT and business skills; only then will the skill requirements of the job match the skill set of the individual and lead to a meaningful job. The right balance will also enhance the overall performance of ITS employees. Morrison et al. (1999) propose that good supervision provides a better organizational climate for employees to use their skills and knowledge unrestrictedly. Under such supervision, employees are given leeway to make mistakes and are given valuable feedback on how to correct and avoid mistakes. The interview data show that the majority of managers at ITS provided good supervision and created a climate where feedback was offered and successful results were attributed to those who had performed the tasks. Maintaining this level 
and quality of managerial supervision is important so that supervisory behavior itself becomes a tool for skill utilization among the workers.

Among the motivational characteristics, task significance, task identity, feedback from the job, and task variety did not have any impact on job outcomes for ITS employees. Thus, H3 - H6 are not supported in this study. Task significance was found to be the weakest contributor to job outcomes in the meta analysis carried out by both Fried and Ferris (1987) and Humphrey, Nahrgang and Morgeson (2007). The interview data suggest that many ITS members experienced a high degree of task significance. ITS is a service organization, and, in their answers to the short question, survey participants as well as the interview participants expressed the need for both service and customer orientation. Grant (2008) noted that when individuals perceive their task as leading to greater social benefits for others, task significance influences job performance. This observation can be applied to ITS setting. During the interviews, ITS members said that they thought of their work as significant because they took pride in their ITS being the most successful shared services organization in the government, and also because it was set up to save tax dollars and thus their work was contributing to that as well. However, they also believed that ITS was not similar to departments like HRDC or Revenue Canada, where services are offered directly to the general public which would make them feel even more significant. In that case, their work would directly affect another human's well being. This feeling of significant is not there in ITS services because the services are offered to another 
department and how it affects that department functioning can be hard to fathom for individual employees.

Next, task identity did not correlate with any of the three job outcomes. In the interviews, seven participants indicated that they were able to see where their work began and ended in the big picture. However, during the interviews and in answering the short question, participants talked about certain themes as important aspects of work at ITS, including the importance of having clear organizational processes, ensuring that employees can understand how they contribute to the bigger picture, understanding the work flow, and pulling multiple streams of information into a cohesive whole. These concerns show that ITS members had some difficulties in identifying their own work within the entire work flow. Further, the current ITS had been functioning as an IT provider for the PWGSC before the decision to move to shared services was made. This was a big transition for the employees; in the midst of such changes, it can be difficult for individuals to understand how their work fits into the whole process. Some further suggested that the vision and goals of ITS need to be more clear, while others felt that they needed clear guidelines as to their roles and the standards of the organization. Reichers (1986) suggests that when individual goals and management goals are in harmony, organizational participants experience little psychological conflict. This absence of psychological conflict allows workers to identify their role within the organization. Here we can ask whether the work-related goals of individuals at ITS matched the overall managerial goals. Results indicate that 
there were instances of mismatch. Such situations could lead to individual task identity not being significantly related to job outcomes.

Among the motivational characteristics, feedback from the job did not significantly impact job outcomes. During the interview, when asked about feedback from the job, many respondents found it difficult and asked whether this meant feedback from the task itself. After confirming the question many wondered how the task could provide feedback. As one respondent commented, "Tasks don't talk, only people do." The interviews yielded mixed responses for this construct. This result is contrary to that reported by Fried and Ferris (1987) and Humphrey, Nahrgang and Morgeson (2007), who found that feedback from the job was related to many job outcomes. But for individuals working at ITS, it was just about performing tasks and waiting for supervisors or peers to provide feedback. This may be the reason why feedback from others (social characteristics, which are discussed shortly) is significant in predicting the three job outcomes in ITS survey results.

Task variety was another variable that did not relate to the outcome variable. In their study, Humphrey, Nahrgang and Morgeson (2007) found that task variety did not relate to objective behavior outcomes (job performance, turnover intentions) but was related to subjective performance and job satisfaction; it was also related to work load. Our reason for hypothesizing that task variety can lead to better job outcomes was based on the study by Reilly and William (2003), who found that shared services employees who perform transactional work require job rotation. Their finding on 
task variety, however, was ambiguous. Nevertheless, it was deemed prudent to include task variety in this job design research and examine its significance. In fact, ITS interview participants indicated that the level of skill variety required in their work was high, and the information they provided suggests that they performed both IT- and non-IT-related tasks. However, our results show that high task variety did not relate positively to job outcomes; rather, it related positively to work overload, as reported by Humphrey, Nahrgang and Morgeson (2007). One possible explanation for this finding is the notion that task variety impedes other organizational behaviors. For example, Narayanan, Balasubramaniam and Swaminathan (2009), in a study of 88 individuals working to support 5,711 maintenance workers in a software support service operation, noted that when individuals experience too much job variety, especially in a technical work setting, they don't have enough time to learn new skills, and this impacts on their ability to learn and their job performance. This might have been the case within ITS work setting, where the high level of task variety may have impacted employees' ability to learn and thus did not contribute positively to job outcomes. Further, in terms of job dissatisfaction, though some considered ITS job to be an ideal one or at least moderately ideal, more respondents talked about the heavy work load. This echoes the result obtained by Humphrey, Nahrgang and Morgeson (2007), who found that task variety was related to work overload. In our study, an overall analysis of the impact of the motivational characteristics on job outcomes shows that it is minimal. This leads to the conclusion that, except for autonomy and skill variety, the motivational characteristics did not contribute to a sense of the meaningfulness of their work for these ITS employees. 
In hypothesis 7(a) and (b) this study proposed that information uncertainty and information equivocality will negatively relate to job outcomes for IT shared services employees. The survey results do not support these hypotheses. The interview results suggest that the amount of information processed by ITS members was very high, and that information equivocality ranged from high to moderate. In their study, Daft and Lengel (1986) proposed that the amount of task information processed by an individual is related to task variety; that is, the higher the level of task variety, the greater the amount of information that must be analyzed, with each task requiring the processing of unique information. At ITS, task variety was required in the job, but this variable did not significantly affect job outcomes. Individuals processed a lot of information, but many said that unless the issue was critical, they used historical results to make decisions since there was always work pending and there was no time to go through a large amount of information. So the work at ITS may in fact have required an analysis of a lot of information, but in actual practice the employees frequently made decisions on the basis of their experience and knowledge. Seventy-three percent of our survey participants had more than five years of work experience at ITS - enough experience to enable them to handle information uncertainty at work more efficiently. Therefore, information amount did not relate to any job outcomes. Likewise, equivocality had no impact on job outcomes. When information is equivocal, individuals must work with poorly defined or unclear information, which can cause frustration and confusion. Such situations often negatively affect job outcomes. This was the finding of researchers Daft and 
Lengel (1986) and Thomas and Trevino (1993), who studied information uncertainty and information equivocality as two dimensions of information processing in relation to organizational structure and inter-organizational relationships. In the present study, however, the interview data suggest that when individuals at ITS were faced with unclear information they sought the help of peers and managers. This allowed them to work together to resolve unclear issues and contributed to a reduction in job stress. During the interviews many workers indicated that the main responsibility of their managers was to clarify the correct meaning of information and guide their team through different points of view. They also said that the experience of managers and the people involved in decision making contributed to clear final decisions. Thus, information equivocality had no significant impact on job outcomes.

\subsection{Social Characteristics and Job outcomes}

When combining both qualitative and quantitative data, it can be concluded that ITS members clearly indicated that social characteristics at work was as important as motivational characteristics. In the regression analysis, the entering of social characteristics resulted in a variance of $41 \%$ in job satisfaction, $34 \%$ in job performance (career), 24\% in job performance (team), $16 \%$ in job performance (organization), and $34 \%$ in turnover intentions. Although the qualitative data showed high levels of initiated and received task interdependence at ITS, the survey results showed that only received task interdependence was significant, being negatively related to job satisfaction and job performance (career, organization) and positively related to turnover intentions. This provides support to hypothesis 8(b), which proposed that for an IT shared services worker, received task interdependence 
is negatively related to (a) job performance and (b) job satisfaction, and (c) positively related to the intention to leave. Kiggundu (1983) concluded that initiated interdependence can lead individuals to feel and act responsibly and motivate them at work. On the other hand, received interdependence - where job incumbents must wait for others to finish tasks - does not contribute to an experience of responsibility and can negatively impact job outcomes. The study by Humphrey, Nahrgang, and Morgeson (2007), although it did not differentiate between these two different types of interdependence, showed that task interdependence as a whole related to job outcomes in several ways. The qualitative data in our study showed that individuals working on several business plans had to wait for input from other sectors within ITS to accomplish their tasks. There were also complaints that this situation affected information flow and it was seen as a serious issue impacting individual job satisfaction. Thompson (1967) classified interdependence as pooled, reciprocal, and sequential interdependence, while Kiggundu (1983) differentiated between initiated and received task interdependence (with sub-dimensions of scope, resource, and criticality). These sub-dimensions are often used to analyze the depth or type of interdependence in organizations. At ITS, all aspects of interdependence as classified by both Thomson and Kiggundu can be found, but the qualitative data and answers to the short question indicated that there was a greater degree of "pooled" interdependence.

While the different sectors within ITS are very close to functioning as silos, in order to carry out project delivery all sectors have to pool their efforts to make this happen. 
But when the timelines for accomplishing tasks are different for each sector, efforts at pooling become quite difficult. Kiggundu (1983) further states that this "resource" interdependence can apply to items as varied as material, tools, equipment, instructions, resources, personnel, and programs. At ITS, individuals from different sectors often had to seek resources from each other to complete work. Managers often requested greater access to technologies and tools; for example, they waited for the human resource department to hire more staff so that a project could be finished on time. When preparing performance reports, sectors waited for data from each other to complete the reports. Other employees experienced similar delays. Those who were putting together business plans had to wait for information required to correlate and analyze data to complete the final report; others stated that they had to wait for revenue to be realized - a constraint that occurs because ITS does not have a lender and has to wait until money is forwarded from the Treasury Board. These delays trickle down to individual units and increase resource dependence. The data suggest that this dependence occurs in both types of interdependence but is more pronounced in received interdependence, thus affecting job performance at both the organizational and career levels for ITS members. Since received interdependence had a critical impact on job performance at the career level, this in turn influenced intentions of ITS workers to leave the organization. Though received task interdependence showed results as hypothesized, the results for initiated task interdependence did not support H8(a), although interviewees suggested that it was high at ITS. This was the only social characteristic that did not have an impact on any of the three job outcomes. This denotes that when ITS members initiated task interdependence it was nothing 
special for them. ITS interview participants did state understanding the entire work flow was challenging for ITS members. This may be a possible reason as to why initiated task interdependence did not significant predictor like the other social job characteristics.

The second social characteristic, feedback from others, related positively with job outcomes. The regression results showed that the greater the amount of feedback, the greater the job satisfaction. Feedback from others correlated well with the three elements of job performance, showing positive results for career, team, and for the organization as a whole. Further, feedback from others was found to have a significant negative relationship to turnover intentions. The quantitative data overwhelmingly showed that none of the respondents said that feedback from others was low. ITS members received feedback on their performance from peers as well as other employees. There were also reward systems in place - management awards and informational awards - that encouraged individuals by giving positive feedback. After a presentation, the top management would verbally praise the performers; this was acknowledged by the individuals as a very positive thing. Small mementos, such as a greeting card or coffee cup, were also occasionally presented. Interview participants also stated that, at the end of the day, if someone told them they had made it possible for him/her to complete a job, this counted as positive feedback from others. All such instances contributed to results showing that feedback from others impacted job performance at the career, team, and organizational levels. Positive feedback from others receives recognition within the team and within the 
organization. It is also recorded in performance evaluations, which are done every six months in the government, making career promotions more likely. Therefore, the result that feedback from others negatively relates to turnover intention is not surprising. These relationships between feedback from others and job outcomes provide full support for $\mathrm{H} 9$, which proposed that for an IT shared services worker, feedback from others at work is positively related to (a) job performance, and (b) job satisfaction, and (c) negatively related to the intention to leave.

Table 98: Hypotheses Related To Social Job Characteristics

\begin{tabular}{|c|c|c|c|}
\hline & Supported & $\begin{array}{l}\text { Partially } \\
\text { Supported }\end{array}$ & \begin{tabular}{|l|} 
Not \\
Supported
\end{tabular} \\
\hline $\begin{array}{l}\text { H8(a): For an IT shared services worker, initiated } \\
\text { task interdependence is positively related to (a) job } \\
\text { performance, and (b) job satisfaction, and (c) } \\
\text { negatively related to the intention to leave. } \\
\text { H8(b): For an IT shared services worker, received } \\
\text { task interdependence is negatively related to (a) job } \\
\text { performance, and (b) job satisfaction, and (c) } \\
\text { positively related to the intention to leave. }\end{array}$ & $\sqrt{ }$ & & $\sqrt{ }$ \\
\hline $\begin{array}{l}\text { H9: For an IT shared services worker, feedback from } \\
\text { others about the job performed can be positively } \\
\text { related to (a) job performance, and (b) job } \\
\text { satisfaction, and (c) negatively related to the intention } \\
\text { to leave. }\end{array}$ & $\sqrt{ }$ & & \\
\hline $\begin{array}{l}\text { H10: For an IT shared services worker, social } \\
\text { support available at work is positively related to (a) } \\
\text { job performance, and (b) job satisfaction, and (c) } \\
\text { negatively related to the intention to leave. }\end{array}$ & & $\sqrt{1}$ & \\
\hline $\begin{array}{l}\text { H11: For an IT shared services worker, interaction } \\
\text { outside the organization at work is positively related } \\
\text { to (a) job performance, and (b) job satisfaction, and } \\
\text { (c) is negatively related to the intention to leave. }\end{array}$ & & $\sqrt{ }$ & \\
\hline
\end{tabular}

Social support loaded on to two components as social support from friends and support from supervisors. In the regression analysis, both forms of social support related positively to job satisfaction. Greater social support from peers and 
supervisors led to greater job satisfaction, as predicted by Humphrey, Nahrgang, and Morgeson (2007). The interview data suggested high to moderate levels of social support from both friends and supervisors, although the general sense was that there was more support from peers than from supervisors. This could be the reason why support from friends was more highly related to job outcomes than support from supervisors. When ITS employees talked about job satisfaction, they often mentioned that the people in their organization are great to work with and there is little interpersonal conflict. Bakker, Demerouti, and Verbeke (2004) suggest that job resources are the most important predictor of excellent role performance. They suggest that job resources come into play in three different ways: resource allocation at the organization level (pay and benefits); interpersonal relations; and social relations (supervisor/peer support and by organization of work [role clarity/role ambiguity]). The strong relationship between social support (from both friends and supervisors) and job satisfaction at ITS clearly suggests that ITS members consider this an important job resource. Another significant finding worth highlighting is that during the interviews the participants assessed their supervisor's support in terms of how much funding he/she was able to allocate for their individual projects. In a climate of limited resources and competing demands, individuals view a manager's willingness to allocate more resources towards their project so that the work can be completed on time as a sign of support. Otherwise they wonder if the manager expects each team member to do the work of five people. In organizational theory, social support from supervisors in the form of financial allocation and the relation of this to job outcomes in the job design context has not been studied. New measures 
are required to understand how financial resource support might constitute an aspect of social support. Further, social support showed a weak relation to subjective performance in Humphrey, Nahrgang and Morgeson's (2007) study. In our study, social support from friends related positively with job performance in the career dimension. This mirrors the social exchange framework put forward by Emerson (1981), where the author states that individuals form, maintain, and terminate relations with each other according to the perceived ratio of benefits to costs in the relationships. The relationship between social support from friends and job performance at the career level also indicates that in order to advance in an organization individuals have to maintain a good relationship with the top management and also with friends, a finding that is in line with Kram and Isabella's (1985) suggestion that one's relationships with peers can provide support at every stage of a career. These analyses provide support for hypothesis H10, which states that for an IT shared services worker, the social support available at work is positively related to (a) job performance and (b) job satisfaction. The H10 (c) hypothesis, that social support is negatively related to the intention to leave, was not supported by the survey results.

The last social characteristic, interaction outside the organization, had a positive relationship with job performance at the career level. This partially supports H11, which proposed that for an IT shared services worker, interaction outside the organization at work is positively related to (a) job performance and (b) job 
satisfaction, and (c) is negatively related to the intention to leave. The qualitative data show that many employees, other than those who worked with service delivery, reported they had limited relationships outside the organization. But for those who worked with service delivery, the interaction often occurred when they met with suppliers and clients to establish the service requirements. Through these interactions, individuals were able to initiate formal and informal relationships that helped them perform better career wise. Researchers suggest that relationship management is vital for the success of a shared services organization (A.T. Kearney, 2005; Cooke, 2006); indeed, the Conference Board of Canada (2006) considers relationship management a pillar for success in a shared services model. This is largely because transaction-based activities are prime targets for shared services (A.T. Kearney, 2005), and the success of shared services depends greatly on how the service providers develop key relationships, increase client satisfaction, and build a good reputation. The finding that outside relationships have a positive relationship to job performance at the career level indicates that ITS individuals were also able to use these relationships to advance in their career path.

\subsection{Service Characteristics and Job Outcomes}

Analysis of the survey results showed that service characteristics have a influence of $31 \%$ on job satisfaction, $21 \%$ on job performance (organization), and $30 \%$ on turnover intentions. This influence is significant, indicating that service characteristics are important as work context characteristics in the service delivery work setting. Of the four service characteristics, only service failure prevention and service failure recovery efforts related to job outcome, while service failure 
prevention was the only service characteristic that significantly correlated with job satisfaction. This finding is on par with the work of Yoon, Choi, and Park (2007), who found that service orientation had a significant effect on employee satisfaction; in their study, service failure prevention was the most significant predictor of job satisfaction. The qualitative data in our study showed mixed results for service failure prevention as addressed during the interviews; respondents were divided on whether ITS went out of its way to prevent customer problems. However, the service results show that the service failure prevention strategies used by ITS did contribute towards satisfaction at work for employees. ITSB has adopted standardized processors called the Information Technology Infrastructure Library (ITL), which is used by many service providers to integrate information systems. ITU has processor features - such as problem management, incident management, and service support that when implemented effectively, prevent major service breakdowns at ITS, providing confidence for the employees working with this integrated information system. During the interviews, individuals also commented that in past years ITS has been proactively aligning the different sectors to prevent service breakdowns. The RACI matrix, which is a tool used in project management to identify roles and responsibilities, has also helped ITS prevent service breakdowns. In the RACI matrix, $\mathrm{R}$ denotes who is responsible for accomplishing the task; $\mathrm{A}$, who is responsible for correlating and seeing through the projects; $\mathrm{C}$, who is providing subject matter on the project; and I, who is being informed about the progress of the project. This tool has not only prevented service breakdowns but has helped boost employee job satisfaction. Further, it has also prevented service failure within the job performance 
at the organizational level and was found to be negatively correlated with turnover. These findings support H13, which hypothesized that service failure prevention strategies provided by IT- shared services positively related to (a) job performance and (b) job satisfaction, and (c) negatively related to the intention to leave. The results show that with effective service failure prevention strategies the individual's performance level in the organization increases. The Lytle and Timmerman (2006) study showed that service orientation enhances the overall business performance of an organization; our finding further clarifies this by demonstrating that service failure prevention strategies enhance individual job performance, which in turn enhances the overall business performance. Other studies that have looked at service orientation through service system characteristics have not studied the impact of these characteristics on turnover. In this study, service failure prevention negatively related to turnover intentions. The qualitative data show that turnover intentions overall were quite high because ITS has been described as a stressful work environment where many workers have taken stress leave. Given these conditions, finding a way to reduce employee turnover in ITS is essential. It can be assumed that the strategies used by ITS to prevent service breakdowns have reduced work-related stress for its employees, leading to the negative effect on turnover intentions. This is a positive discovery because it shows that the investments made to prevent service breakdowns have not only contributed to overall service quality but also to the well being of the job incumbents. 
Table 99 : Hypotheses Related To Service Job Characteristics

\begin{tabular}{|l|l|l|l|}
\hline & Supported & $\begin{array}{l}\text { Partially } \\
\text { Supported }\end{array}$ & $\begin{array}{l}\text { Not } \\
\text { Supported }\end{array}$ \\
\hline $\begin{array}{l}\text { H12: For an IT shared services worker, service technology } \\
\text { provided by an IT-SSO is positively related to (a) job } \\
\text { performance, and (b) job satisfaction, and (c) negatively } \\
\text { related to the intention to leave. }\end{array}$ & & & \\
\hline $\begin{array}{l}\text { H13: Service failure prevention strategies provided by an } \\
\text { IT-SSO is positively related to (a) job performance and (b) } \\
\text { job satisfaction, and (c) negatively related to the intention to } \\
\text { leave. }\end{array}$ & $\sqrt{ }$ & & \\
\hline $\begin{array}{l}\text { H14: For an IT shared services worker, service failure } \\
\text { recovery provided by an IT-SSO is positively related to (a) } \\
\text { job performance }\end{array}$ & & $\sqrt{ }$ & \\
\hline $\begin{array}{l}\text { H15: For an IT shared services worker, service standards } \\
\text { communications provided by an IT-SSO are positively } \\
\text { related to (a) job performance, and (b) job satisfaction, and } \\
\text { (c) negatively related to the intention to leave }\end{array}$ & & & $\checkmark$ \\
\hline
\end{tabular}

The second service orientation characteristic that was significant in predicting job performance at the organizational level was service failure recovery. The interview data overwhelmingly supported this relationship; thus, H14 which proposed that for an IT shared services worker, service failure recovery provided by an IT-SSO is positively related to (a) job performance is partially supported. ITS has created "tiger teams" consisting of very senior members from operations, sales, and service delivery that look into the issue of service breakdowns. When a service distuption occurs, these teams analyze and address the fault in order to prevent its re-occurrence. Discussion groups are also set up when there is a gap between what has been asked for and what has been delivered to the clients. During the interviews, many participants stated that Service Management and Delivery (SBD) does a very good job in resolving service breakdown issues; whenever a problem is detected by 
multiple users it is examined right away and rectified. Further, whenever a service breakdown does take place, there is always an assessment, an incident report, and an evaluation as to whether it could happen again. All these measures taken by ITS have contributed to individual job performance. This may be the reason why service failure recovery correlated positively with job performance at the organizational level and had a negative relationship with turnover intentions.

Service technology and service standard communication did not relate to any job outcomes for ITS members. Therefore $\mathrm{H12}$ and $\mathrm{H15}$ are not supported by these findings. During the interviews, respondents noted that some of the service technology was good. For example, their email system and storage processes have become very compact and efficient. When ITS was started with four or five departments, the service technology in place was sufficient to deliver quality services. However, when the IT services were extended to more than 20 departments, ITS's technologies were not scalable and were primitive for the purpose. Many survey participants also indicated that the need to invest in new technologies was critical and that ITS was lacking good service technology. Heskett, Jones, Loveman, Sasser, and Schlesinger, in their 1994 article "Putting the Service-profit Chain to Work," stress that an organization's internal service quality leads to employee satisfaction, which impacts productivity in a positive way by leading to employee desire to stay with the same organization. This, in turn, increases the external service quality of the organization. The greater the external service quality, the better the customer service and customer growth. Heskett et al. (1994) point out that internal service quality can only be built on good workplace design, job design, and employee services. The 
starting point for internal service quality, which leads to external service quality, depends largely on service employee job satisfaction. Heskett et al. (1994) illustrate this through an example involving the American Automobile Association (AAA) in the U.S. When employee turnover was high, one of the steps the management took to remedy this was to provide employees with a sophisticated information system that allowed them easy access to customer information. This availability of state-of-the-art information technology enabled the integration of information and led to internal service quality and employee satisfaction. Further, other researchers (Parasuraman and Grewal, 2000; Bitner, Brown, and Meuter, 2000) have stressed that service technology can deliver superior customer service value and better job outcomes. At ITS, the available service technologies were not at a high enough level to provide employee satisfaction.

In the Saura et al. (2005) study, service standard communications were found to be a significant intervening variable between customer satisfaction and service orientation. In this study, the service standard communications did not influence any of the job outcomes. Before ITS was formed in 2003, it was the IT department of the PWGSC. After 2003 it had to continue in its role as the IT arm of the PWGSC and also to function as a shared services organization. When an organization functions as a single service provider and then is rolled over into a shared services provider, the transition can be very difficult for the employees (Redman et al., 2007). For the employees, understanding the new objectives and their roles and responsibilities in achieving these objectives can be challenging. ITS employees complained that understanding the whole work flow, contributing to the bigger picture, and needing 
clear guidelines on organizational standards are important and are missed by many. These were organizational issues that the respondents wanted improved. Further, the vision for ITS has to be clearly understood and needs to be communicated to the employees.

Against this backdrop, however, ITS has a dashboard that allows the employees to know the status of each service delivery. The service performance standards were commonly available and if employees wanted to know, they could view this dashboard. But this does not guarantee that every employee will become familiar with the performance benchmarks of the different services. During the interviews, members stated that the service standards and performance measures are communicated through emails and that this is done more at the management level. Sometimes they would receive these communications and at other times it was left to the discretion of a manager or supervisor to forward them to their employees. So it can happen that the service standard communications are sent down the line to some point - and then stop there. In some sectors these communications will reach down though the levels, but in others they will, unfortunately, be stuck if the manager or director doesn't choose to communicate further. For these reasons, the service standard communications may not be related to job outcomes for this group of ITS members.

\subsection{Occupation Variables and Job Outcomes}

The type of work and the type of skills were occupation variables in this research. Apart from the job characteristics described in the job design literature, the question 
of how the influence of the different types of work and how different types of skills affect the outcome variables needs to be understood.

\subsubsection{Type of Work and Outcomes}

Transactional work, transformational work, and professional and advisory work were used as the three types of work in this study. Transactional and transformational work influence job satisfaction, job performance, and job turnover. Shared services workers are seen as performing transactional work better than any other type of work (A.T Kearney). The basic shared services model is the transactional model (Quinn et al., 2002). Transactional work in a typical IT shared services organization has been classified as data center operations, network services, maintenance, help desk, and data support (Bergeron, 2003). In this study, transactional work was entered in the first block and the social characteristics were placed in the second block; in both models, transactional work related positively to job satisfaction. Transactional work was a significant predictor and, with social characteristics in the second model, the results indicated that transactional work has predictive power similar to that of social characteristics. Also, transactional work, when entered in the first block with service characteristics, had a positive impact on job satisfaction. Transactional work also continued to be significant along with service characteristics in the second model. Workers who perform transactional work carry out the day-to-day IT support needed by business units. According to Redman (2007), individuals working on transactional types of work in a shared services setting reported a high level of job dissatisfaction with their work; this study, however, did not support that finding. The transactional work in ITS is focused on data center operations, network services, and help desk 
data support. Therefore when interpreting the results, it is important to note that transactional work is the day to day activities of an organization, yet can differ significantly from one organization to another. This nature of transactional work referred to by Redman et al.'s ( 2007) study, which is based on human resource shared services (HRSS), can be different from an IT-SSO work setting. Transactional workers in Redman et al.'s (2007) study have reported that their work was "boring" and "repetitive" and none of ITS employees spoke of their work in this way. Further, when type of work was entered in the first block with motivational characteristics in the second block, transactional work influenced job performance (job) positively and had a negative influence on turnover intentions. The survey results showing that individuals performing transactional work scored higher on job performance than those doing other work are a very good indication that an important part of the work at ITS has been performed well. The negative relationship between transactional work and turnover intentions indicates that these individuals were not looking for work elsewhere. But this might reflect only the short term because transactional work showed a negative relationship with job performance in the career dimension when it was entered along with social characteristics. This shows that these transactional workers were satisfied with their jobs and their job performance, but were not optimistic about significant career advancement in ITS. In the long run, these individuals, who have solid experience in running a shared services organization, may leave to take up better positions in other organizations, which would be a real loss for ITS. ITS needs to develop better career advancement opportunities, especially for this group of employees. 
In contrast to transactional work, transformational work is considered as activities involving policy making and strategic decision making. Since its establishment in 2003, ITS has moved from providing transaction-based IT services to transformational IT services that build better application architecture and telecommunications strategy, assess the suitability of current enterprise architecture for client needs, and propose best practices. Initially ITS service catalog provided only limited services but now it lists a great number of IT services. Like their coworkers performing transactional work, transformational employees also experienced job satisfaction. When transformational work was entered in the first block and social characteristics in the second block, transformational work made a significant impact on job satisfaction in both models. Additionally, interview data indicate that many employees felt that ITS has really matured, growing from a centre providing shared services to four or five departments to a much larger organization offering more services to a much greater number of departments. These individuals have been involved in the maturing of ITS and were generally happy about how it has become the largest federal IT service provider in the country. Like transactional work, transformational work was negatively related to turnover intentions. But, unlike transactional work, transformational work was not negatively related to job performance in the career role, which is very good since it indicates that transformational workers who are mostly responsible for policy making in IT service delivery at ITS felt that they could advance in their careers within the unit. This is important because they are experienced individuals whose services are critical to ITS. 
This ITS sample also consisted of people who were in both the professional and advisory groups. Professional advisors are those individuals who provide advice and assistance to the senior management of ITS in making strategic decisions. Some of the areas in which they provide advice include enterprise-wide standards support for software/hardware, corporate purchasing policy, IT strategies, and infrastructure investment strategies. This type of work did not relate to any job outcomes either positively or negatively. Interestingly, the majority of the interviewees for this study were from the professional and advisory levels. It is possible that these individuals saw their job outcomes in much the same way as the transactional and transformational workers. The interview data suggest that career advancement opportunities were limited for ITS members who performed professional work because they might already have reached the highest possible career level within ITS. They were also performing consulting work and were responsible for moving the functions of ITS forward in a climate of shrinking budgets. With limited resources, the professional group may have found it necessary to identity a clear direction for ITS, and they wanted the government to propose mandatory use of ITS by other government departments. They also wanted new investment in the latest tools, such as client management, so that the business discipline could be strengthened to provide better IT services. These may be the reasons why professional work, unlike transactional and transformational work, did not have a positive influence on job outcomes. 


\subsubsection{Types of Skills and Job Outcomes}

The jobs performed by ITS workers included categories based on two skill sets: IT and non-IT. IT-skilled jobs were lower in the job hierarchy than jobs classified as non-IT-skilled jobs. Among the survey participants, 70 held IT-skilled jobs and 35 non-IT-skilled jobs. IT skills did not have any influence on job outcomes, either positively or negatively. On the other hand, non-IT skills positively related to turnover intentions. Data from the interviews suggest that work at ITS required technical competence, and individuals with non-IT skills may have found it difficult to understand the entire work flow of the IT service provider. Additionally, they may have found it challenging to work with the technical systems that are an integral part of the organizational processers. Also, the qualitative data show that to advance in their career within ITS, individuals required a high level of IT competence. The survey data show that skills variety significantly influenced job performance at the organizational level. This indicates that individuals need a variety of skills to perform well at the organizational level; individuals with only non-IT skills may have lacked some of the skills required to accomplish all tasks with excellence, which could have led increased intention to leave the organization. On the other hand, IT skills did not relate negatively to job satisfaction. The qualitative data show that although many individuals felt that the service technology needs to improve at ITS, IT skills did not relate negatively with job outcomes, indicating that the present service technologies allowed these individuals to utilize their IT skills adequately, to the extent that job outcomes were not negatively impacted. This is a positive finding for ITS as a whole, 
because it is important that individuals with good IT competence and experience remain in the organization.

\subsection{Revising the IT-SSO Job Design Model}

\subsubsection{Historical Motivational Characteristics}

Recapping the motivational results, only autonomy and skill variety influenced job outcomes for this group of ITS employees. As described in the job design literature, the factors of task significance, task identity, task variety, information amount, and information equivocality were hypothesized to have an impact on job satisfaction, job performance, and turnover intentions. In fact, the results did not support these hypotheses: these factors did not have any influence. 
Figure 3 : Motivational Characteristics at ITS

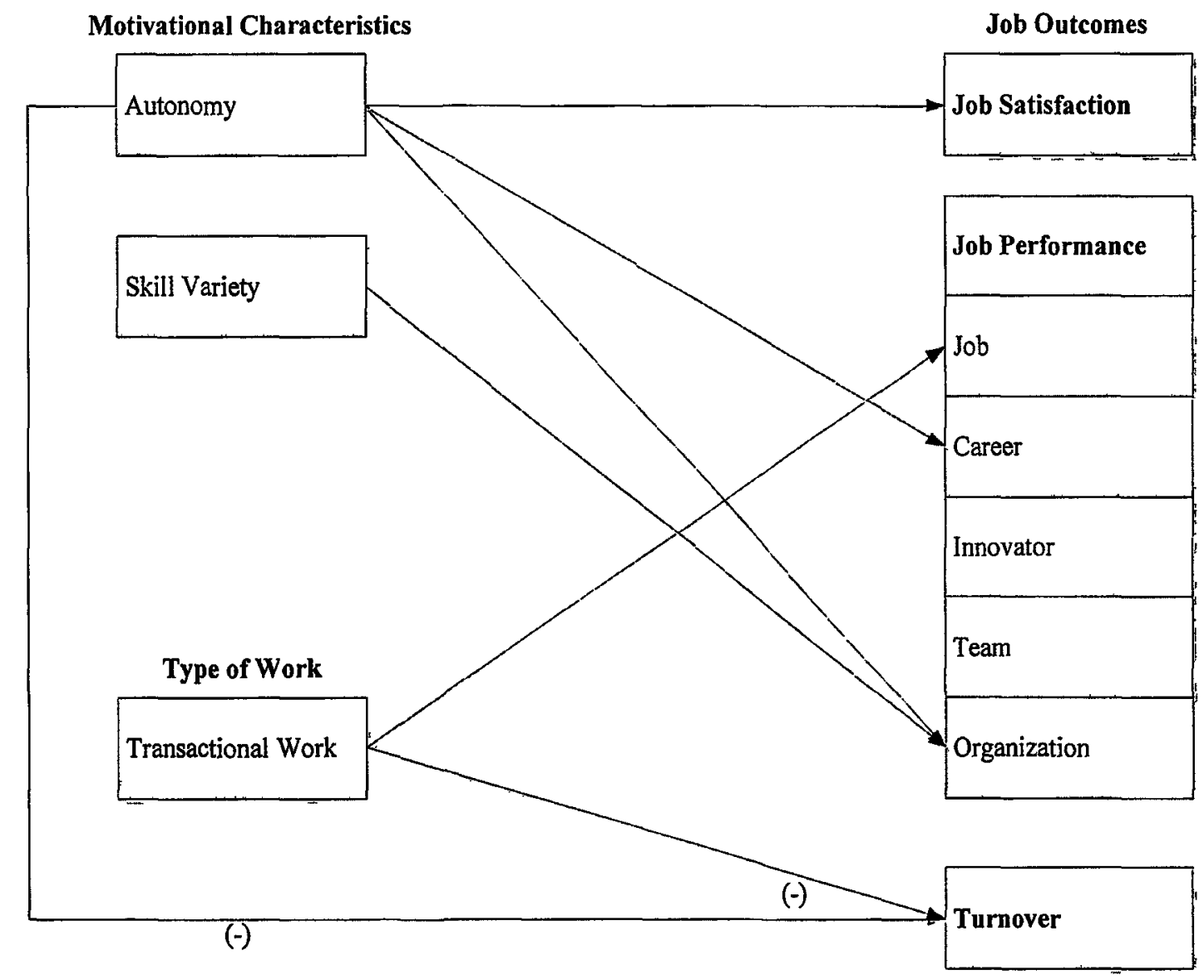


Task characteristics that are indicators of the nature of work (Hackman and Oldham) did not have a strong positive effect on ITS members. Task characteristics, which are often referred to as motivational characteristics, constitute one of the most common job design approaches. Campion and Thayer (1985), however, showed that their significance in enriching jobs is very small. The role of task characteristics and social characteristics in motivating people at work receives a very strong emphasis in job design literature. Fredrick Hertzberg (1959) and his colleagues presented the twofactor theory about what motivates people at work. They proposed that what makes people happy with their jobs is different from the factors that make people unhappy at work (Herzberg, Mausner, and Snyderman, 1959). Factors such as achievement, advancement, recognition, responsibility, and the nature of the job itself provide employee satisfaction. These were called the motivating factors. On the other hand, factors such as pay, benefits, job security, physical working conditions, supervision policies, relationships with co-workers, and company polices were labeled as hygiene factors. Herzberg, Mausner, and Snyderman (1959) believed that when hygiene factors fall below the expectations of the employees, job dissatisfaction can arise. In 1960, McGregor proposed Theory X and Theory Y, which outline assumptions about humans at work. McGregor's Theory $\mathrm{X}$ assumes that employees are lazy and unwilling to produce above the minimum requirements, and further that they have to be directed and motivated, and their actions need to be modified to fit the needs of the organization. By contrast, Theory $\mathrm{Y}$ assumes that people are not, by nature, passive or resistant to organizational objectives, and it is essential for management to arrange 
organizational conditions in such a way that employees achieve their own goals by directing their efforts towards organizational goals. Theory $\mathrm{Y}$ also emphasized employee participation in decision-making and personal control over work processes. According to McGregor (1960), this would improve efficiency, reduce conflict, and build greater commitment to organizational objectives. Building on Hackman and Lawler's (1971) work, Hackman and Oldham (1976) proposed a job characteristics model where they explain the function of task characteristics as "reinforcement" for motivation. The authors stress that people understand work differently, so reinforcement can be different for each individual.

Bringing this theoretical background to ITS sample, when considering strategies to motivate people at work and to gain better job outcomes, ITS management needs to look at motivational characteristics and social characteristics together. The motivational characteristics did not negatively relate to job outcomes in this sample. This indicates that the motivational characteristics were at a level where the individuals were satisfied, not exceedingly so, but at least moderately. They did not indicate frustration as to how their work was designed with motivational characteristics. But the more positive job outcome was dependent on the existence of "hygiene factors" as referred by Herzberg (1960) which are extrinsic to the work itself. These extrinsic factors were the social characteristics - feedback from others, social support from friends and supervisor, and outside interactions. While the task characteristics were certainly present, it was the stronger presence of social characteristics that enhanced job outcomes. ITS interview respondents frequently talked about the people aspect being nice; peers were always available when 
individuals needed help with work or personal issues. The supervisor balanced the work load effectively, and the overall culture was one that recognized individual contributions. These social characteristics, which stem from the people aspect of work, helped individuals to find the job meaningful and enjoyable. Further discussion on why social characteristics were critical for ITS members is given in the following section.

\subsubsection{The Importance of Social Characteristics in ITS}

Citing previous research, Humphrey, Nahrgang and Morgeson (2007) identified increased teamwork setting, work relationships, pro-social work behavior, and social contacts that reduce work-related stress as factors that contribute to the overall importance of social characteristics in the workplace. Many of these factors were already present in ITS work setting. First, interdependence at work was high in ITS, and this interdependence increased social contacts for ITS employees.

Especially when individuals worked in service delivery they interacted with many other individuals from different government departments. Sims et al. (1976) included "friendship opportunities" as a construct that enhanced job outcomes. Repeti and Cosmas (1991) explained that though support from one's supervisor and friends was linked to job satisfaction, supervisor support was more strongly linked to job satisfaction than support from friends. In the same study, researchers established that a common work environment (defined as the social climate shared by every employee in the work place) was a more significant predictor of job satisfaction than the individual work environment. When ITS employees discussed job satisfaction they 
indicated that work relationships and the people they work with were positive aspects of their job. This leads to the finding that social characteristics were as important as motivational characteristics for ITS employees.

\section{Figure 4: Social Characteristics at ITS}

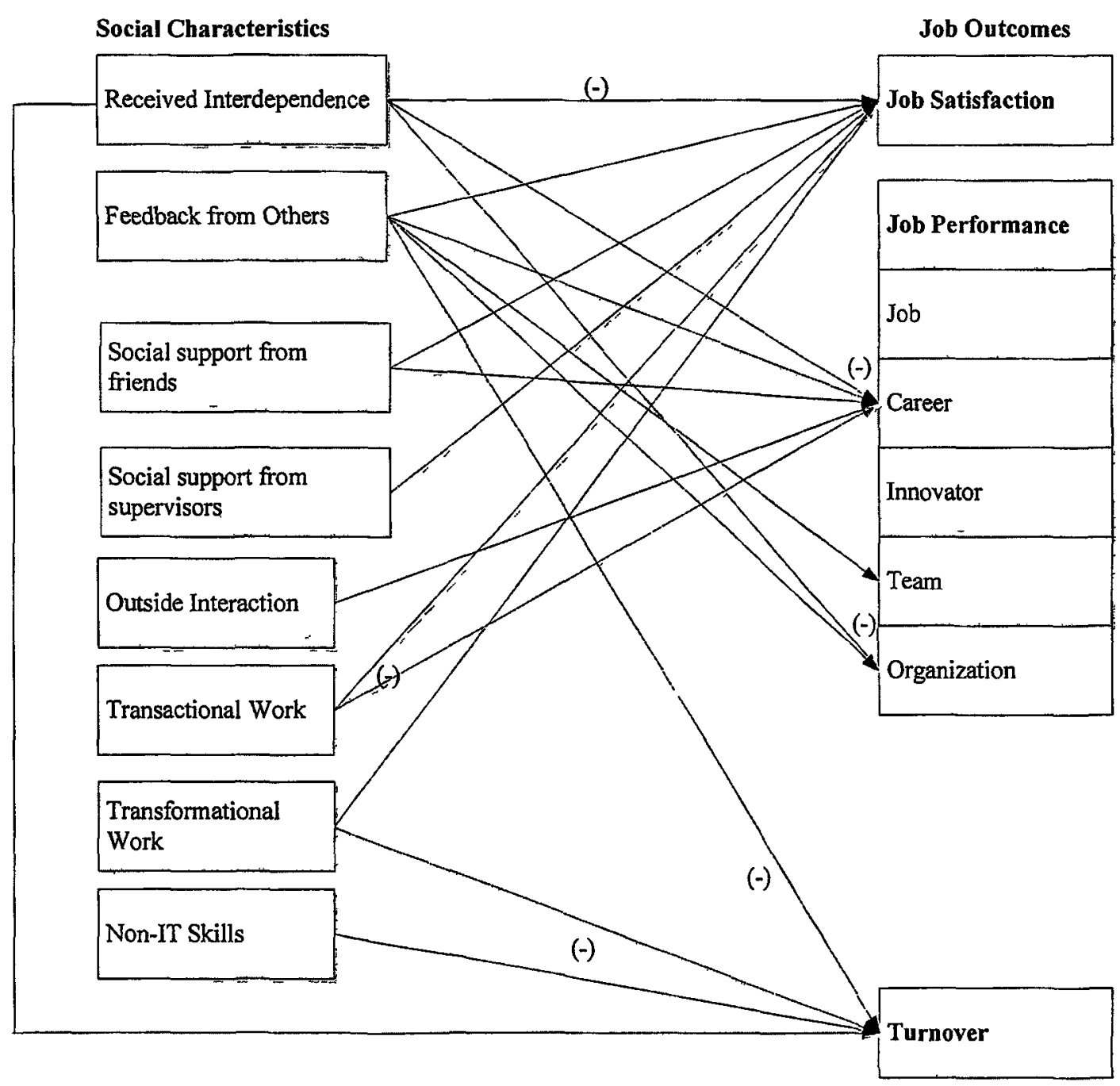


Second, in the survey many participants indicated that being a team player was the most important personal trait needed to work in ITS setting. Additionally, ITS functions in a matrix structure where there are dual lines of authority, responsibility, and accountability. In this work setting, groups performing different functions work together to accomplish business plans. This team setting increased social interactions, and in difficult times individuals sought peer support to manage challenging situations. Barrick et al (1998) found that social cohesiveness is important for team stability because of its mediating role between agreeableness, extraversion, and emotional stability. Thus, in terms of importance, social characteristics were equally important job characteristics in ITS work setting.

Third, many respondents indicated that job stress was high at ITS. Not only was the quantity of work high, but individuals also had to produce high quality work with good accuracy. All of this needed to be achieved in the face of competing priorities and limited resources. There were indications that many individuals have gone on stress leave. Many researchers have suggested that job stress can be reduced through enhanced social support at work. Turner (1981) found that social support was related to psychological well being and that it is critical in stressful work situations. Karasek and Theorell (1979, in explaining the Demand-Control-Support (DCS ) model, suggest that finding the correct balance between these three aspects in a job is important for the well being of the job incumbent. At ITS, social factors - such as feedback from others, support from friends, supervisor support, and outside 
interaction - helped reduce stress at work, and thus proved to be significantly related to job satisfaction and job performance.

\subsubsection{The New Work Context Characteristics - Service Orientation}

In the work design literature, work context has been studied at both the organizational and the occupational levels. At the individual level, the studies have focused on work context characteristics such as how ergonomics, physical demands and work conditions affect job outcomes (Humphrey, Nahrgang and Morgeson, 2007). In ITS job design model, this study included the service characteristics as work context characteristics.

\section{Figure 5 :Service Orientation Characteristics at ITS}

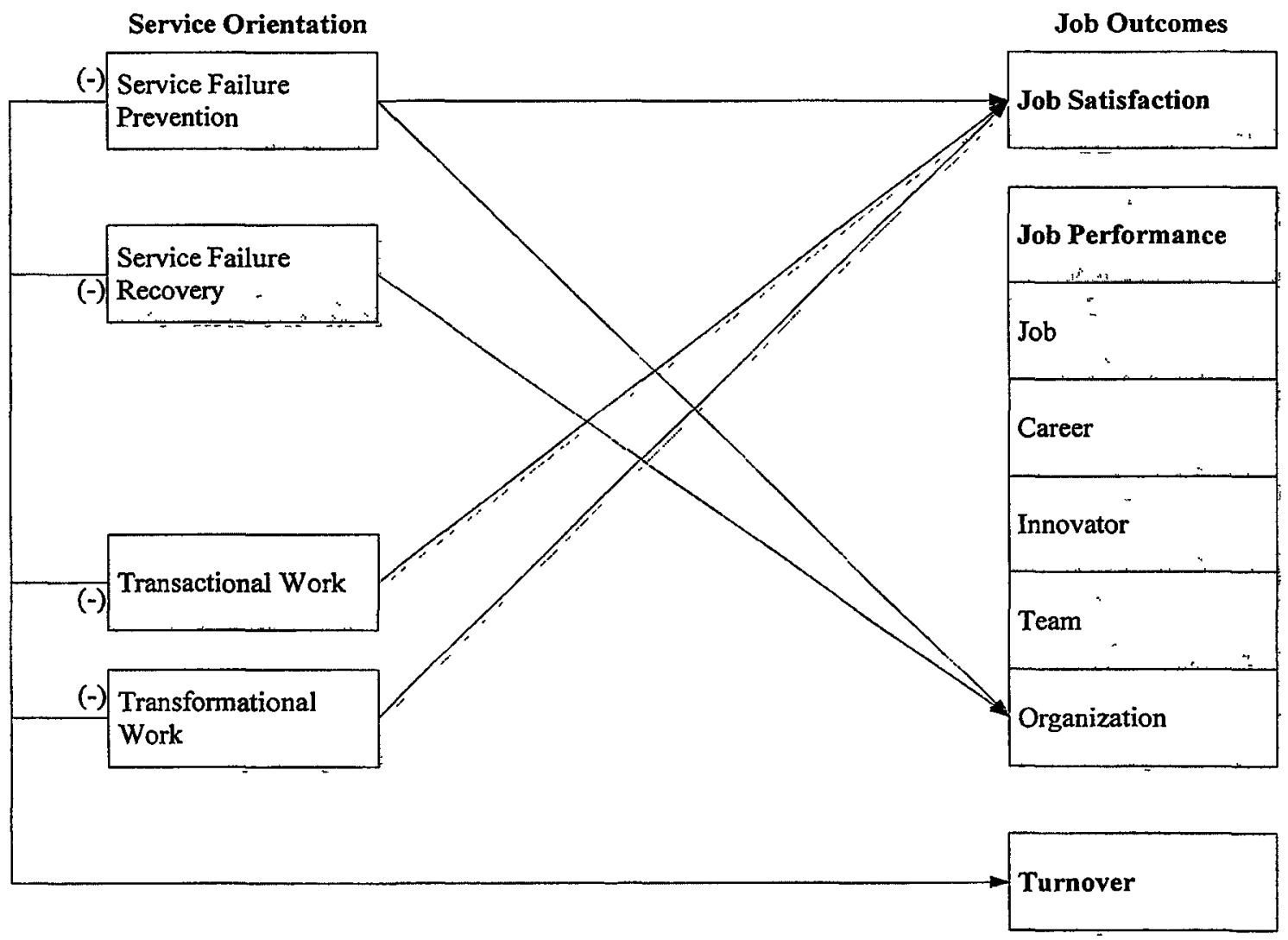


According to Field (2006), "The demand for valid measures of job characteristics is driven by continuing efforts in organizations to determine the features of a job that induce employees to work harder and perform better" (pg. 67). Of the four dimensions of service orientation proposed by Lytle et al. (1998), this study argued that service system practices are the most important for service employees who deliver IT services through service systems across many organizations. The service system practices proposed by SERV*OR emphasize how technology is used in service organizations, service failure and its prevention, and how service standards are communicated to service employees. These system characteristics are essential to the service employee whose work depends on the service system to deliver services to his or her clients. The results of the study showed that among the four system characteristics, service failure prevention and service failure recovery had a degree of influence on job outcomes similar to that of motivational and social characteristics. Lytle et al. (1998) based their observations on service orientation studies that had been carried out only in the private work setting, but our study has established that similar findings about service orientation can be derived from research conducted in a government setting as well. Service failure prevention and service failure recovery were important for individual public sector employees, showing that these employees were committed to service orientation, which is critical to the functioning of ITS. Further, Parkingston \& Schneider (1979) refer to service orientation discrepancy as the difference between the organization's service orientation and employees' 
perception of service orientation. In this study, service failure prevention and service failure recovery did not contribute to service orientation discrepancy between ITS and the employees. On the other hand, in the area of service technology and service communication, discrepancies were experienced. The service orientation discrepancies surrounding these two issues need to be rectified so that there is unanimous agreement on service orientation, which will enhance the quality of service delivery to the partner organizations.

This chapter integrates the findings of quantitative and qualitative data analysis and discusses how they support the hypotheses presented in chapter three. Among the fifteen hypotheses proposed, the study found evidence to fully support five; partial support was found for three hypotheses while seven were not supported. Based on the discussion presented here, the next chapter presents the conclusions, contributions, and limitations of this study. 


\section{Chapter Eight}

\section{Conclusion, Research Implication, Recommendations, Contributions, Limitations, and Future Directions}

\subsection{Conclusions}

The main research objective of this study was to understand the nature of the work at an IT-SSO and to identify the job characteristics that relate to enhanced job outcomes for IT-SSO members. The research also examined the influence of different types of work and skills on employee job outcomes. The IT-SSO job characteristics model was based on Humphrey, Nahrgang and Morgeson's (2007) extended work design model, which was developed through a meta-analysis of 259 studies on job design. Seven motivational characteristics (autonomy, skill variety, task variety, task significance, task identity, feedback from the job, information processing) and four social characteristics (interdependence, feedback from others, social support, outside interaction) were adopted from this study. In addition, service orientation characteristics were added to our IT-SSO model as work context characteristics, replacing the ergonomic characteristics often associated with work context in the job design literature. This chapter presents the research results as follows. First, description regarding the nature of the jobs performed by ITS workers is outlined. Then, conclusions on the main research question, "What job characteristics influence job outcomes in the IT-SSO," are given, followed by the findings on the role of 'type of work' and 'type of skill' in determining job outcomes. 
Research question 1: What is the nature of work in an IT-SSO?

At ITS, employees enjoyed good interpersonal relationships and took pride in the knowledge that they were serving Canadians through one of the largest shared services units in the federal government. Individuals were able to gain valuable experience through performing many different tasks, which provided them with many learning opportunities. A similar result related to employees working on many different tasks was reported by Redman et al. (2007). On the other hand, the quantity of work in the IT-SSO was very high, and individuals struggled to balance their work load while performing efficiently with limited funds. Individuals also talked of problems understanding their roles, responsibilities, and the overall vision of the ITSSO.

Research Question 2: What job characteristics influence job outcomes in the ITSSO?

Firstly, among the motivational characteristics, autonomy and skill variety were the only characteristics that related to job outcomes. Autonomy related to all three job outcomes, while skill variety related only to job performance at the organizational level. Autonomy is thus confirmed as one of the most important motivational characteristics, as it has been shown to be related to a number of job outcomes (Spector,1986). The nature of work at the IT-SSO was such that employees needed 
to use a variety of skills, including both IT and non-IT skills, to perform well at the organizational level. The study finds that both IT and non-IT skills were equally important to high levels of performance in the IT-SSO. The remainder of the motivational characteristics-task variety, task significance, task identity, feedback from the job, information processing-did not positively relate to job outcomes, but, interestingly, neither did they show negative relationships to job outcomes. The research demonstrates that the IT-SSO needs to continue to enhance these motivational characteristics so that they will influence positive job outcomes, as autonomy and skill do.

Secondly, social characteristics proved as important as the motivational characteristics predicting job outcomes for the IT-SSO members. In particular, increased social interaction, team work setting, and increased work load were important contributing factors. Received interdependence, where employees had to wait for information or resources or for others to finish their work so that they could complete their own project, affected both job satisfaction and job performance, a finding predicted by Kiggundu's (1983) study. In the social characteristics context, IT-SSO members depended heavily on peers and supervisors for support when things got tough on the job. They also highly valued feedback from others regarding their work performance. Therefore, we can conclude that the social environment at work was critical for these IT-SSO members, echoing the conclusion stated by Repeti \& Cosmas (1991). 
Thirdly, the introduction of service characteristics as work context characteristics was moderately useful in this sample. Two of the four service characteristics had a significant influence on job outcomes. The survey results showed that service characteristics have a $31 \%$ variance influence on job satisfaction, a $21 \%$ influence on job performance (organization), and a $30 \%$ variance on turnover intentions. This influence is substantial, indicating that service characteristics are non-redundant work context characteristics. Among the service characteristics, service failure prevention and service failure recovery were important for IT-SSO members. The finding that these two items related strongly to job outcomes indicates that the IT-SSO employee were truly committed to their work, cared about the functioning of the IT-SSO, and wanted to present their organization as an excellent IT service provider to other government departments.

Research question 3: Do the type of skills used by individuals, and type of work in an IT-SSO influence job outcomes?

The shared services literature does not provide clear documentation on how job outcomes affect different groups of employees. The shared services literature classifies employees as transactional, transformational, and professional, according to their type of work (Quinn et al. 2000; Redman, 2007). Studies have found that individuals who perform transactional work have reported job dissatisfaction (Redman, 2007). However, this study found evidence to the contrary: shared services transactional and transformational employees experienced job satisfaction and performed well in the job. But, transactional workers did express lack of satisfaction with career advancement opportunities at the IT-SSO, as career advancement was not 
progressive. Further, a wide range of both $\mathrm{IT}$ and non-IT skills was necessary to perform the many tasks and carry out responsibilities at the IT-SSO. Employees who used more non-IT skills reported greater intentions to leave ITS. These findings together indicate that individuals who perform transactional work and non-IT skilled workers need early career counseling and job rotation opportunities to gain more work experience and a wider variety of skills; this would decrease the likelihood of their leaving the IT-SSO in the long run (Campion, Cheraskin, and Stevens, 1994).

\subsection{Research Implications}

The findings of this research have a number of theoretical implications. Firstly, other than autonomy and skill variety, the motivational characteristics were not among the significant predictors of job outcomes; at the same time, they did not relate negatively to job outcomes. For the motivational characteristics, the qualitative and quantitative data indicated high levels of task variety and task significance. A number of interview participants indicated that their work involved too much task variety and they did not understand the significance of every task. This result leads to the question, What impact does task variety have on task significance? Researchers have suggested that too much task variety can slow the employee's learning experience (Narayanan et al., 2009). If a particular job requires handling many different tasks, the individual may not know which ones are most significant in the whole scheme of things in the workplace. Neither Hackman and Oldham (1976) nor Fried and Ferris (1987) examined task variety as a job characteristic in their model; Humphrey, Nahrgang and Morgeson (2007), on the other hand, did include task variety, as they 
considered it to be theoretically similar to the other motivational characteristics and believed that it should be included in job design. Our study found that task variety is related to many job outcomes; nevertheless, since we found scant evidence that task variety can impede task significance, including these factors together as motivational characteristics clearly calls for further research.

Another task characteristic that needs further examination is 'feedback from job'. In this study, respondents were unable to differentiate between 'feedback from job' and 'feedback from others'. Hackman and Oldham (1976) specifically differentiated between these two characteristics. To describe feedback from the job, the authors gave the example of an electrician who repairs a TV set and then turns it on and confirms that it functions. Here the work itself has provided feedback. Hackman and Oldham (1976) related feedback from the job to a critical psychological stateknowledge of the actual results of the work activities. It is important to note that in the Humphrey, Nahrgang and Morgeson (2007) study, feedback from the job showed the largest relationship with promotion satisfaction. At ITS, many workers did not see how the work itself could provide direct feedback; thus the study's findings showed 'feedback from job' as not related to any job outcomes. Many of the interviewees said that feedback comes from the supervisor or colleagues. Does this make feedback from the work itself a redundant motivational characteristics in work settings where there is a high level of received interdependence similar to that in the IT-SSO? When working in an IT environment with integrated IT systems, individuals may only work on one part of work, so until others finish their work they 
may not know whether their task is completed or not as oppose to an electrician who repairs a TV set and gets immediate feedback. There is little research in the job design literature that investigates which form of feedback is most important. Further research is needed to investigate the role of feedback from the job as opposed to feedback from others in highly interdependent work settings such as the IT-SSO.

Secondly, social characteristics were very important for the IT-SSO employees. Among the four social characteristics used in this study, social support related well with the job outcomes. The social support measures (Repeti \& Cosmas, 1991; Lim, 1996) described in the organizational theory literature measure social support from supervisor and friends in relation to emotional support or how social support makes things easier at work. However, in this study individuals clearly established that they expect their supervisor to support them by providing the necessary resource allocations. They judged social support from their supervisor according to the amount, specifically in monetary terms, that he or she was willing to allocate and that would help them perform their work or finish a project more quickly and easily. Therefore, scales to measure social support in the form of financial resources need to be developed. In addition, how resource allocations influence job outcomes along with the already existing forms of support need to be examined.

Thirdly, Hackman and Oldham's (1976) job characteristics model had three moderating variables: 'knowledge and skills', 'growth need strength', and 'context satisfaction'. However, many subsequent researchers in job design did not use these 
variables to establish how they moderate the relationship between job characteristics and job outcomes. In our research, 'type of work' and 'type of skill' influenced job satisfaction, job performance, and turnover intentions. Job design research needs to include variables such as 'knowledge and skills' and 'growth need strength'. For example, in this research individuals performing transactional work were happy about their job performance but were not happy about their career advancement possibilities at the IT-SSO. Only when variables such as 'knowledge and skills', 'growth need strength', and 'occupations' (as suggested by Hackman and Oldham) are brought into the study can their influence on job outcomes be understood. Therefore job design researchers need to include these factors as control or moderating variables in order to establish how the job characteristics they study in different organization affect the workers within those organization.

\subsection{Implications for the IT-SSO}

Through a review of the relevant literature, this research studied how motivational, social, and service characteristics can influence better job outcomes for those who are working at an IT-SSO. Data was collected using qualitative and quantitative methods, and statistical analysis allowed the identification of job characteristics that significantly predict job satisfaction, job performance, and turnover intentions among the workers. The qualitative data provided more contextual details as to why particular characteristics demonstrated more significance than others Based on these analyses, the following recommendations are provided to the IT-SSO. 


\section{Streamline Decision Making to Reduce the Number of Meetings}

Autonomy has been identified as a very strong predictor of job outcomes (Spector, 1986; Humphrey, Nahrgang and Morgeson, 2007). Loss of autonomy at different levels has been a concern for organizations moving into shared services (Redmand et al., 2007; Strikwerda, 2006). At the IT-SSO, individuals enjoyed autonomy to the extent that it significantly predicted job satisfaction, job performance, and turnover intentions. This is a positive finding. The top management should continue to provide such decision making powers to employees in the different levels of the organization. At the same time, however, data indicates that employees did not have enough scheduling autonomy at work, in particular because the number of meetings they had to attend and the multiple committees they served on interrupted their work schedules. To rectify this, the middle level managers should be given more empowerment so that decisions need not go to the top for discussion and then come down though a number of meetings. Middle level managers should be given the freedom to prioritize tasks and guide their subordinates as to the order in which activities are to be performed.

\section{When Recruiting Take into Consideration both IT and Non- IT skills}

Work at the IT-SSO required employees to use a wide range of skills, and this skill variety in jobs allowed the individuals to perform well at the IT-SSO. The jobs 
required both IT and non-IT skills. Many at the IT-SSO felt that non-IT skills were necessary to understand the business discipline that was essential to the overall functioning of the IT-SSO. Also, being proactive and thinking ahead strategically was necessary to succeed in a shared services work setting. Generally IT skills were referred to as technical competence, but when it came to non-IT skills, managers provided a long list. The general feeling was that IT/technical competence can be bought over the counter, but that non-IT skills are needed to understand how things fit together and to make strategic decisions. The commonly mentioned non-IT skill sets were communications skills, problem solving skills, planning and organizational skills, leadership skills, interpersonal skills, management skills, financial management skills, negotiation skills and project management skills. Therefore, when recruiting people to work at the IT-SSO, managers need to look at the project and its IT requirements and, at the same time, carefully consider candidates' non-IT skills.

\section{Enhance Informal Opportunities}

IT-SSO members placed a high value on social support from friends and supervisors. Managers could consider increasing openness of communication in order to further open up employees' opportunities to share their work-related issues. If required, managers should be given training on supervisory practices than can enhance their ability to provide a supportive working climate in their respective unit. Also, support from friends was valued even more than support from supervisors, so opportunities should be increased for employees to interact more often and build long-lasting friendships. According to Sims et al. (1976), friendship opportunities are " the degree 
to which a job allows employees to talk with one another on the job and to establish informal relationships with other employees at work" $(1976,197)$. Chan (2002), using eight case studies, found that informal structures are the most enduring aspect of IS alignment in organizations. For example, if a particular task can be accomplished more quickly through directly contacting a colleague in another department, this may be a much better approach than waiting for direction to be passed on through formal channels. A timely phone call from a friend working at a partner organization to alert one to a possible problem can contribute significantly to the quality of service delivery. So the individual relationships between shared service workers are critical in the functioning of a shared services organization. Therefore this study recommends that the development of ways to increase informal relationships among employees in different sectors at the IT-SSO be encouraged.

\section{Job Rotation and Short Term Replacements to Increase Opportunity for Employees to Understand other Areas of Work}

Among the seven units at the IT-SSO, individuals who worked in the service delivery sector (SMD) had the most opportunity to work with people outside of the IT-SSO. Others enjoyed such opportunities occasionally as well: for example, individuals from other units often attended conferences and participated in the IT service management forums. These outside contacts were considered to be positive aspects of their work by the IT-SSO employees. Also considered important aspects

of their work by the interviewees were the need for clear guidelines for roles and standards and ensuring that employees understand how they contribute to the bigger picture. All members of the IT-SSO need to be given opportunities to interact with 
suppliers, clients and other stakeholders in the unit; this would greatly improve their understanding of their sector's role and their own responsibility within the organization. Job rotation is a practice whereby employees take up other positions via lateral job transfers, thus increasing the range of their work experience (Campion, Cheraskin, and Stevens, 1994 ). Currently at the IT-SSO, when a senior manager takes a long leave, one of the team members is placed in that position as an acting senior manager. Job rotation and short-term replacements were favorable for ITSSO members, and are both recommended.

\section{Streamline Communication and Workflows to Reduce the Problems Associated with Received Interdependence}

The study finds that received interdependence, where employees must wait for others to finish a job, is high at the IT-SSO. Received interdependence impedes job satisfaction and job performance, and leads to increased turnover intentions for the IT-SSO members. Received interdependence slows down work and lessens the overall effectiveness of work. Managers at all levels need to take all possible steps to reduce received interdependence among their subordinates. Giving a tight deadline and then sticking to it strictly is a good way to reduce received interdependence. Although the IT-SSO set-up is a matrix structure, many responses indicated that the organization often works in silos, with decision makers not aware of how their functions affect others and processes not well communicated. Working groups must ensure that communication channels are open and that information is shared across the different sectors. The IT-SSO members stated that there had been many improvements in communication since the establishment of the IT-SSO in 2003, but 
further effort is clearly needed. Increased communication between the sectors and working committees is critical to reducing received interdependence. Also, turnover intentions were high at the IT-SSO, and one of the causes of this was received interdependence at work. Senior management needs to analyze how work is getting stuck at the different layers of the organizations and instruct managers to focus on reducing these bottlenecks.

\section{Make Greater Investment to Improve Service Technology}

The IT-SSO is home to some fine technologies. However, many respondents felt that service technology needs to be improved at the IT-SSO. Service orientation was measured by four items: service technology, service failure prevention, service failure recovery, and service standard communication. Of these four items, service technology was identified by the IT-SSO members as requiring significant improvement. Greater investments can allow the IT-SSO high quality IT services. This would attract more clients, make the IT-SSO more efficient and also help the ITSSO members to become more service oriented. Another important finding that pertains to service orientation is that service failure prevention and service failure recovery had an impact on employee job satisfaction, job performance, and turnover intentions. This indicates that the IT-SSO has a very dedicated team of individuals who are committed to responding quickly and providing quality service, building a good image for the IT-SSO, and making it an IT service provider of choice. This commitment of the IT-SSO work force is extremely valuable, and the senior management needs to continue strengthening the strategies they use to prevent service 
delivery failure and to support the service failure recovery process in order to promote a service orientation culture, which is necessary for the IT-SSO to be a competitive IT service provider.

\section{Greater Client Focus}

In addition to being service oriented, another important recommendation that comes out of this study relates to client focus: the IT-SSO members want the organization to be more client focused. The IT-SSO generally signs a memorandum of understanding between the client and the service provider which states the details of service delivery. In the shared services setting, as in any service delivery organization, being client focused is essential. According to Alfred and Speed (1996), client focus in a general sense is about communication and public relations, but in the public service context, the client focus of a regulatory agency is defined as " understanding clients" motivations better, and seeking to take account of those motivations as far as possible in the delivery of services, within the organization's economic and operational constraints" (pg. 315). The IT-SSO is not a regulatory agency, nor are its clients the general public; instead, the clients are other government organizations. To be more client focused, the IT-SSO must strive to understand the needs of the other organizations as much as possible, taking into account their own resource constraints. Interviewees highlighted the fact that not all requests from clients need to be processed, and that top management must turn down some requests that are simply not possible to deliver given the IT-SSO's available resources. The senior management of the IT-SSO needs to maintain a balanced approach between what 
clients request and what the IT-SSO can reasonably deliver. This will allow the ITSSO to be more client focused than their current level of client focus.

\section{Need to Provide More Career Advancement Opportunities for the Transactional Worker}

Individuals who were performing transactional work indicated that they were not happy with their career advancement opportunities at the IT-SSO. Transactional workers as a group did not relate to turnover intentions; however, since transactional work itself related negatively to turnover intentions, it may be fair to conclude that although in the short run individuals may not have turnover intentions, in the long run they may look for jobs elsewhere. Transactional work is the core of shared services activities; therefore those who perform this work must be retained and career advancement opportunities need to be developed for them. Managers need to identify the different levels of expertise in subordinates who work on transactional work and categorize them accordingly. As well, early career counseling to outline a career path whereby they can rise within the IT-SSO is recommended.

\section{Reduce Uncertainty about the future of the IT-SSO}

The study also found that many individuals were not very sure about the future prospects of the IT-SSO. They mentioned that since its establishment, revenues had risen steadily but have now begun to decline. The Treasury Board has not mandated that other government departments use the IT-SSO's services, and it's possible that these departments may also decide to try setting up their own shared 
services. This situation has cast doubt in the minds of some of the IT-SSO members as to the long- term viability of the IT-SSO and whether the government might try something new as opposed to shared services. Thus, it is important for the top senior management to clearly communicate a clear vision for the IT-SSO and the mandate for the next five years.

\subsection{Contributions}

This thesis research contributes to the existing shared services and organizational theory literature in four distinct ways.

Firstly, Humphrey, Nahrgang and Morgeson (2007) presented an extended job design model based on their meta-analysis of 259 studies on job design to date. Studying a wide range of motivational and social characteristics together is not common in the job design literature. Often the characteristics are analyzed separately or as moderating variables between job outcomes. By empirically studying motivational and social characteristics together, this study validates some of the results put forward by Humphrey, Nahrgang and Morgeson (2007). The finding of this study is based on data collected through mixed methods in a real work setting. It is a baseline study for other researchers who wish examine job characteristics in new forms of organizational arrangements.

Secondly, it is the first study that investigates the nature of work in a Canadian federal government IT-SSO work setting. Gaining access to carry out research in such a government organization is challenging. This study is unique in combining the 
results of a survey of more than 100 federal IT-SSO employees with qualitative data collected from a random sample of these workers. Further, many of the previous studies are based on case studies, or they are conceptual, or they have been carried out by private research firms (Accenture 2005; Oracle 2007), but there are no studies in academic journals based on large-scale surveys of shared services workers. This thesis fills this gap in the academic literature.

Thirdly, this research highlights the nature of work at an IT-SSO. Previous research on shared services mainly focused on how to adopt shared services (Janssen, Joha and Zuurmond, 2009; Ulrich, 1996; Day and Norris, 2006), or on the benefits of adopting shared services (Goh, Prakash and Yeo, 2007). This study, in contrast, brings out the nature of the work performed by individual shared services employees. It examines a variety of job characteristics and three job outcomes by merging data obtained using qualitative and quantitative research methods. The research can be used as a guide for those organizations preparing to move into shared services, and also for current shared services organizations who face challenges related to motivating people in their work, making the appropriate changes needed with respect to individual job design, and building long-term career advancement opportunities for individuals in the workplace.

Fourthly, the need to focus on contextual characteristics in job design has been raised before by organizational behaviour researchers (Jones, 2006; Morgeson, Dierdorff and Hmurovic, 2010). This study, however, is the first to examine service orientation 
as a work context characteristics along with motivational and social characteristics in a public sector sample. Moreover, the study has also validated the importance of including contextual job characteristics in job design models.

Finally, in general, the types of work performed at a shared-services organization can be classified as transactional work, transformational work, and professional work (Quinn et al., 2000; Bergeron, 2003). There is some indication that those who perform transactional work are not satisfied with their work; further, questions as to whether new kinds of skill sets are necessary for the different types of work have been also raised (Redman, 2003). It is important to look at the type of work in different work settings. Transactional work in one setting is not the same as transactional work in another setting. This study has allowed us to understand how the different types of work and IT and non-IT skills can influence job performance and enhance career prospects and job satisfaction in an IT-SSO. These results can be used as a guide in areas of recruiting, training, and career advancement by IT-SSO managers and those organizations who want to move into a shared services setting.

\subsection{Limitations and Future Research Directions}

Although this research offers many potential contributions, it is important to place the study in its proper perspective by noting its limitations

Firstly, the study is focused on data obtained from a government IT shared services organization and does not look at private sector IT-shared services. If we had 
conducted a similar study focused on a private sector IT-SSO, our research findings would have been further strengthened. This would have led to a more generalizable understanding of the nature of work at an IT-SSO.

Secondly, the proposed IT-SSO job design model includes most of the job characteristics variables used in the Humphrey, Nahrgang and Morgeson (2007) model, except for the work context characteristics, which were replaced by the service characteristics in our study. Researchers warn against taking up too many variables (Steven 1996), as this contradicts the principle of scientific parsimony. Nevertheless, care has been taken to limit the selection of variables to only those that relate closely to the IT-SSO work context. In future studies the two occupation variables (type of skills and type of jobs) may be used as moderating and mediating between the predictors and job outcomes in an SSO.

Thirdly, we sent out 210 questionnaires, of which 105 were completed and returned. Had we received more completed questionnaires, we would have been able to carry out more extensive statistical analysis and the findings would have represented a larger sample. When the questionnaires were first sent out, we asked that they be returned within two weeks, and in fact, the majority were. After the two weeks had elapsed, a follow-up call was made to each person on the recipient list to see whether they had completed the questionnaire. Those who had not offered excuses (lack of time, etc.) or said they were not interested. Therefore, we were not able to conduct an analysis on early and late respondents to determine a non-response bias. 
Fourthly, the questionnaire used a self-evaluated job performance rating scale (adopted from Welbourne et al., 1998). Even though job performance was measured over five different roles, there may still be an element of employees overrating their own performance. Often in research, the performance of the job incumbent is evaluated by a supervisor, which can involve its own biases. This study chose selfevaluation of job performance because the participants were selected through random sampling and tracking down each and every supervisor was not feasible. This would also have breached the confidentiality assurance given to the survey participants. Allowing the respondents to rate themselves was viewed as the best option. This limitation should be kept in mind when evaluating the job performance results.

Fifthly, the discriminant validity between motivational and social characteristics was poor. The study argues that motivational and social job characteristics have high inter-correlation, but previous research did not provide a baseline discriminant validity through CFA. The work context characteristics had good discriminant validity with social characteristics and some discriminant validity with motivational characteristics. Future research in this area with larger samples could establish better discriminant validity between motivational characteristics and service characteristics.

The conclusions and limitations of this research highlight the future directions that job design studies in a shared services setting could take. As discussed in the limitations section, the current research focuses on a federal IT-SSO work setting. 
There are many private IT enterprises that offer shared services to other organizations. Studying the IT-SSO job design model in a private IT-SSO setting and moving beyond the limitations set out in the previous section would be a useful direction for future research. 


\section{References}

Accenture. (2005). Driving high performance in government: Maximizing the value of public sector shared services. Retrieved January 15, 2009 from http://www.accenture.com

A. T. Kearney (2004) Success through Shared Services. From Back-Office Functions to Strategic Drivers, Chicago.

Alford, J. \& Speed, R. (2006). Client focus in regulatory agencies: Oxymoron or opportunity? Public Management Review 8 (2), 313-331.

Andriole, S.J. (2007). The 7 habits of highly effective technology leaders. Communications of the ACM, 50 (3), 67-72.

Ang, S., \& Slaughter, S.A. (2001). Work outcomes and job design for contract versus permanent information systems professionals on software development teams. MIS Quarterly, 25 (3), 321-350.

Bagozzi, R.P, Yi, Y., \& Phillips, L.W. (1991). Assessing construct validity in organizational research. Administrative Science Quarterly, 36, 421-458.

Bakker, A. B., Demerouti, E., \& Verbeke, W. (2004). Using the job demandsresources model to predict burnout and performance. Human Resource Management, 43, 83-104.

Bangemann, T. O. (2005). Shared services in finance and accounting Aldershot, England: Gower Publishing. 
Barrick, M.R., Stewart, G.L., Neubert, M.J., \& Mount, M.K. (1998). Relating member ability and personality to work-team processes and team effectiveness. Journal of Applied Psychology, 83, 377-391.

Bazeley, P. (2009). Integrating data analyses in mixed methods research. Journal of Mixed Methods Research, 3 (3), 203-207.

Bearden, W. O., Sharma, S., \& Teel, J. E. (1982). Sample size effects on chi square and other statistics used in evaluating causal models. Journal of Marketing Research, 19, 425-435.

Bergeron, B. (2003). Essentials of shared services. Hoboken, NJ: Wiley.

Bitner, M.J., Brown. S.W., \& Meuter, M.L. (2000). Technology infusion in service encounters. Journal of the Academy of Marketing Science, 28 (1), 138-149.

Bommer, W. H., Johnson, J. L., Rich, G. A., Podsakoff, P. M., \& MacKenzie , S. B. (1995). On the interchangeability of objective and subjective measures of employee performance: A meta-analysis. Personnel Psychology, 48, $587-605$.

Breaugh, J. A. (1998). The measurement of work autonomy. Human Relations, 38, $551-570$.

Brown, T.A. (2006). Confirmatory factor analysis for applied research. New York: Guilford Press.

Bryman, A. (2007). Barriers to integrating quantitative and qualitative research. Journal of Mixed Methods Research, 1 (1), 8-22.

Bryman, A., \& Bell, E. (2003). Business research methods. Oxford, UK: Oxford University Press. 
Burr, R., \& Cordery, J.L. (2001). Self-management efficacy as a mediator of the relationship between job design and employee motivation. Human Performance, 14 (1), 27-44.

Byrne, B. M. (2001). Structural equation modeling with AMOS: Basic concepts, application, and programming. London: Lawrence Erlbaum Associates.

Carr, M. (2009). Full disclosure: The basics of designing and implementing a shared services concept. Business Credit, 111 (1), 50-53.

Campion, M.A. (1989). Ability requirement implications of job design: A constructive replication with extensions. Journal of Applied Psychology, 73, 467-481.

Campion, M. A., Cheraskin, L., \& Stevens, M. J. (1994). Career-related antecedents and outcomes of job rotation. Academy of Management Journal, 37, 15181542.

Campion, M.A., \& McClelland, C.L. (1991). Interdisciplinary examination of the costs and benefits of enlarged jobs: A job design quasi-experiment. Journal of Applied Psychology, 76, 186-198.

Campion, M.A., \& Thayer, P.W. (1985). Development and field evaluation of an interdisciplinary measure of job design. Joumal of Applied Psychology, 78, 339-351.

Campion, M.A., \& Thayer, P.W. (1987). Job Design: Approaches, outcomes, and trade-offs. Organizational Dynamics, 15 (3), 66-79. 
Caplan, R.D., Cobb, S., French, J.R.P., Van Harrison, R., \& Pinneau, S.R. (1980). Job demands and worker health. Ann Arbor: University of Michigan, Institute for Social Research.

Caracelli, V.J., \& Greene. J. G. (1993). Data analysis strategies for mixed- method evaluation designs. Educational Evaluation and Policy Analysis, 15 (2),195-207.

Cattel, R.B. (1966). The Scree test for the number of factors. Multivariate Behaviour Research, 1, 245-276.

Chen, L. (2008). Job satisfaction among information system (IS) personnel. Computers in Human Behavior, 24, 105-118.

Clugston, M. (2000). The mediating effects of multidimensional commitment on job satisfaction and intent to leave. Journal of Organizational Behavior 21 (4), $477-486$.

Conference Board of Canada. (2005). Implementing shared services in the public sector: The pillars of success.

Conference Board of Canada. (2006). Implementing shared services in the public sector: Lessons for success

Conway, M.J., \& Huffcutt, A.I. (1997). Psychometric properties of multisource performance ratings: A meta-analysis of subordinate, supervisor, peer, and self-ratings. Human Performance, 10 (4), 331-360.

Cook, T.D. \& Campbell, D.T. (1979). Quasi-experimentation: Design and analysis for field settings. Chicago: Rand McNally. 
Cooke, F.L. (2006). Modeling and HR shared services center: Experience of an MNC in the United Kingdom. Human Resource Management, 25 (2), 211-227.

Cotton, J.L., \& Tuttle, J.M. (1986). Employee turnover: A meta-analysis and review with implications for research. Academy of Management Review, 1 (1), $55-70$.

Cran, D.J. (1994). Towards validation of the service orientation construct. Service Industries Joumal, 14 (1), 34-44.

Cranny, C.J., Smith, P.C., \& Stone, E.F. (1992) Job satisfaction: How people feel about their jobs and how it affects their performance. New York: Lexington Books.

Creswell, J.W. (2008). Research design: Qualitative, quantitative, and mixed methods approach. Thousand Oaks: SAGE Publications.

Crosby, L.A., Evan, K.R \& Cowles, D. (1990). Relationship quality in service selling: An interpersonal influence perspective. Journal of Marketing, 54, 68-81.

Daft, R.L. \& Lengel, R.H. (1986). Organizational information requirements, media richness and structural design. Management Science, 32, (5), 554-569.

Daft, R.L, \& Macintosh, N.B. (1981). A tentative exploration into the amount and equivocality of information processing in organizational work units. Administration Science Quarterly, 26, 207-224.

Davis, T.R.V. (2005). Integrating shared services with the strategy and operations of MNE's. Journal of General Management, 31 (2), 1-17. 
Day, K., \& Norris, A.C. (2006). Supporting information technology across health boards in New Zealand: The role of learning in adapting to complex change. Health Informatics Journal, 12 (1), 13-25.

Deshpande, R., Farley. J.U., Webster, F.E. Jr. (1993). Corporate culture, customer orientation and innovation in Japanese firms: A quadrate analysis. Journal of Marketing, 57 (1), 23-37.

Dillon, W., \& Goldstein, M. (1984). Multivariate analysis: Methods and application. New York: Wiley.

Dollery, B., \& Grant, B. (2010). Tortoises and hares: The race to shared services across Australian state and territory jurisdictions. International Journal of Public Administration, 33, 43-54.

Emerson, R.M. (1981). Social Exchange Theory. In M. Rosenberg \& R. Turner (Eds.), Social psychology: Sociological perspectives (pp. 30-65). New York: Academic Press.

Farndale, E., Paauwe, J., \& Hoeksema, L. (2009). In-sourcing HR: Shared service centre in the Netherlands. The International Journal of Human Resources Management, 20 (3), 544-561.

Farrell , A.M.(2009). Insufficient discriminant validity: A comment on Bove, Pervan, Beatty, and Shiu (2009). Journal of Business Research, 63, 324 - 327.

Field, A.P. (2005). Discovering statistics using SPSS. (2nd edition). London,UK: SAGE.

Fields, D.L. (2002). Taking the measure of work: A guide to validated scales for organizational research and diagnosis. Thousand Oaks: SAGE. 
Ford, J. K., MacCallum, R.C., \& Tait, M. (1986). The application of factor analysis in applied psychology: A critical review and analysis. Personnel Psychology, 39 (2), 295-314.

Fornell, C., \& Larcker, D. F. (1981). Evaluating structural equation models with unobservable variables and measurement error. Journal of Marketing Research, 18, 39-50.

Fried, Y., \& Ferris, G. R. (1987). The validity of the job characteristics model: A review and meta-analysis. Personnel Psychology, 40, 287-322.

Frost, L. (2001).Shared services grows up. Journal of Business Strategy, July/August, 13-15.

Gambill, S,E., Clark, W.J., \& Wilkes, R.B. (2000). Toward a holistic model of task design for IS professionals. Information \& Management, 37, 217-228.

Goh, M., Prakash, S., \& Yeo, R. (2007). Resource-based approach to IT shared services in a manufacturing firm. Industrial Management \& Data Systems, 107 (2), 251-270.

Gonzalez, J.V., \& Garaza, T. G. (2006). Structural relationships between organizational service orientation, contact employee job satisfaction and citizenship behavior. International Journal of Service Industry Management, $17(23), 23-50$.

Government Technology. (2007). Survey on services in state and local governments. Retrieved on March 12, 2011 from www.oracle.com/us/industries/046114.pdf 
Grant, A. M. (2008). The significance of task significance: Job performance effects, relational mechanisms, and boundary conditions. Journal of Applied Psychology, 93, 108-124.

Grant, G., McKnight, S., Uruthirapathy, A., \& Brown, A. (2007). Designing governance for shared services organizations in the public service. Government Information Quarterly, 24 (3), 522-538.

Hackman, J.R., \& Lawler, E. E. (1971). Employee reactions to job characteristics. Journal of Applied Psychology, 55, 259-286.

Hackman, J.R. \& Oldham, G. R. (1975). The development of the job diagnostic survey. Journal of Applied Psychology, 60, 159-170.

Hackman, J.R. \& Oldham, G.R. (1976). Motivation through the design of work: Test of a theory. Organizational Behaviour and Human Performance, 16, 250279.

Harris, M.M., \& Schaubroeck, J. (1988). A meta-analysis of self-supervisor, self-peer and peer-supervisor rating. Personnel Psychology, 41 (1), 43-62.

Harvey, R.J., Billings, R. S., \& Nilsan, K.J. (1985). Confirmatory factor analysis of the job diagnostic survey: Good news and bad news. Journal of Applied Psychology, 70, 461-468.

Hair, J.F. Jr., Anderson, R.E., Tatham, R.L. \& Black, W.C. (1998) Multivariate data analysis with reading (5th edition). Englewood Cliffs, NJ: Prentice Hall. 
Heidemeier, H., \& Moser, K. (2009). Self-other agreement in job performance ratings: A meta-analytic test of a process model. Journal of Applied Psychology, 94 (2), 353-370.

Herbert, I., \& Seal, W. (2009). The role of shared services. Management Services, Spring, 43- 46.

Herzberg, F., Bernard, M., \& Snyderman, B. (1956). The Motivation to Work. New York: Wiley.

Heskett, J., Jones, T.O., Loveman, G.W., Sasser, W.E., \& Schlesinger, L.A. (1994). Putting the service-profit chain to work. Harvard Business Review, MarchApril, 165-174.

Hession, P. (2008). Building a shared service. Retrieved on January 15, 2009, from http://www.netgov.ca/print.asp?pid=386

Hill, C. (2005). Casework job design and client outcomes in welfare-to-work offices. Journal of Public Administration Research and Theory, 16, 263-288.

Hogan, J., Hogan, R., \& Busch, C.A. (1984). How to measure service orientation. Journal of Applied Psychology, 69 (1), 167-73.

Homburg, C., Hoyer, W. D., \& Fassnacht, M. (2002). Service orientation of a retailer's business strategy: Dimensions, antecedents, and performance outcomes. Journal of Marketing, 66 (4), 86-101.

Humphrey, S.E., Nahrgang, J.D., \& Morgeson, F. P. (2007). Integrating motivational, social and contextual work design features: A meta-analytic summary and theoretical extension of the work design literature. Journal of Applied Psychology, 92 (5), 133-136. 
Hunter, J. E., \& Schmidt, F. L. (2004). Methods of meta- analysis: Correcting error and bias in research findings. Thousand Oaks, CA: Sage.

Hurley, A. E., Scandura, T. A., Schriesheim, C. A., Brannick, M. T., Seers, A., Vandenberg, R. J., \& Williams, L. J. (1997). Exploratory and confirmatory factor analysis: Guidelines, issues, and alternatives. Journal of Organizational Behavior, 18, 667-683.

Idaszak, J.R. \& Drasgow, F. (1987). A revision of the job diagnostic survey: Elimination of a measurement artifact. Journal of Applied Psychology, 72, 69-74.

Igbaria, M. \& Guimaraes, T. (1993). Antecedents and consequences of job satisfaction among information center employees. Journal of Management Information Systems, 9 (4), 145-174.

ITS Fact Sheets. (2009). Delivering Government of Canada IT Shared Services: Public Works and Government Services Canada. Retrieved on January 14, 2011 from http://www.tpsgc-pwgsc.gc.ca/apropos-about/fi-fs/its-sct-eng.html

Jackson, P.R., \& Mullarkey, S. (2000). Lean production teams and health in garment manufacture. Journal of Occupational Health Psychology, 5 (2), 231-245.

Janssen. M., \& Joha, A. (2006). Motives for establishing shared service centers in public administration. International Journal of Information Management, 26, $102-115$.

Janssen, M., Joha, A., \& Zuurmond, A. (2009). Simulation and animation for adopting shared services: Evaluating and comparing alternative arrangements. Government Information Quarterly, 26 (1), 15-24. 
Johns, G., Xie, J.L., \& Fang, Y. (1992). Mediating and moderation effects in job design. Journal of Management, 18, 657-676.

Kakabadse, A., \& Kakabadse, A.N. (2002). Trends in outsourcing: Contrasting USA and Europe. European Management Journal, 20 (2), 189-198.

Kaiser, H.F. (1958). The varimax criterion for analytic rotation in factor analysis. Psychometrika, 23, 187-201.

Karasek, R,A., Brisson, C., Kawakami, N., Houtman, I., Bongers, P. \& Amick, B. (1998). The job content questionnaire (JCQ): An instrument for internationally comparative assessments of psychosocial job characteristics. Journal of Occupational Health Psychology, 3, 322-355.

Karasek, R.A. \& Theorell, T. (1979). Job demands, job decision latitude, and mental strain: Implications for job design. Administrative Science Quarterly, 24, $285-308$.

Kelloway, E.K. (1998). Using LISREL for structural equation modeling: $A$ researcher's guide. Thousand Oaks, CA: SAGE.

Kern, T., \& Willcocks, L.P. (2001). The relationship advantage: Information technologies, management and sourcing. Oxford, UK: Oxford University Press

Kiggundu, M.N. (1981). Task interdependence and the theory of job design. Academy of Management Review, 6, 499-508.

Kiggundu, M.N. (1983). Task interdependence and job design: Test of a theory. Organizational Behaviour and Human Performance. 31, 145-172. 
Kirk, J., \& Miller, M.L. (1986). Reliability and validity in qualitative research. Beverly Hills, CA: SAGE

Kline, R.B.(2005). Principles and practice of structural equation modeling. New York: Guilford Press.

Kovessy, P. (2009). ICT industry pushes MPs to adopt IT shared services. Ottawa Business Journal, 14 (30), 3.

Kram, K.E., \& Isabella, L.A. (1985). Mentoring alternatives: The role of peer relationships in career development. Academy of Management Journal, 28, 110-132.

Lacity, M.C., \& Fox, J. (2008). Creating global shared services: Lessons from Reuters. MIS Quarterly Executive, 7 (1), 17-32.

Legare, T. L., \& Bechtel, R. L. (2001). The role of change management in establishing a shared services business model at air products and chemicals. Journal of Organizational Excellence, 20 (2), 33-48.

Levina, N., \& Vaast, E. (2005). The emergence of boundary spanning competence in practice: Implications for implementation and use of information systems. MIS Quarterly, 29 (2), 335-363.

Lim, V.M.G. (1996). Job insecurity and its outcomes: Moderating effects of work based and non-work based social support. Human Relations, 49 (2), 171.

Lincoln, Y.S., \& Guba, E. (1985). Naturalistic Inquiry. Beverly Hills, CA: SAGE

Lincoln, Y.S., Guba, E., \& Denzin, N.K. (1994). The fifth moment. In N.K Denzin and Y.S.Lincoln (Eds.), Handbook of qualitative research. Thousand Oaks, CA: SAGE. 
Lytle, R.S., Hom, P.W., \& Mokwa, M.P. (1998). SERV*OR: A managerial measure of organizational service orientation. Journal of Retailing, 74 (4), 455-489.

Lytle, R.S., \& Timmerman, J.E. (2006). Service orientation and performance: An organizational perspective. Journal of Services Marketing, 20 (2), 136-147.

Mabe, P.A., \& West, S.G. (1982). Validity of self-evaluation of ability: A review and meta-analysis. Journal of Applied Psychology, 67, 280-296.

Mak, B. \& Sockel, H. (1999). A Confirmatory factor analysis of IS employee motivation and retention. Information and Management, 38, 265-276.

McCloy, R.A., Campbell, J.E., \& Cudeck, R. (1994). A confirmatory test of a model of performance determinants. Journal of Applied Psychology, 79, 493-505.

McGregor, D. (1966). Leadership and motivation. Boston/Cambridge, MA: MIT Press.

McNulty, T. \& Ferlie, E. (2004). Process transformation: Limitations to radical organizational change within public service organizations. Organization Studies, 25 (8), 1389-1412 .

Metters, R., \& Vargas, V. (2000) Organizing work in service firms. Business Horizons, July/August, 23-32.

Miles, M.B., \& Huberman, A.M. (1994). Qualitative data analysis: A sourcebook of New method, Beverly Hills, CA:SAGE.

Morgeson, F., Dierdorff, E.C., \& Hmurovic, J.L. ( 2010). Work design in situ: Understanding the role of occupational and organizational context. Journal of Organizational Behaviour, 31, 350-360. 
Morgeson, F.P., \& Humphrey, S.E. (2006). The work design questionnaire (WDQ): Developing and validating a comprehensive measure for assessing job design and the nature of work. Journal of Applied Psychology, 91 (6), 1321-1339.

Morgeson, F.P., Johnson, M,D., Campion, M.A., Medsker, G.J., \& Mumford,T.V. (2006). Understanding reactions to job redesign: A quasi-experimental investigation of the moderating effects of organizational context on perceptions of performance behaviour. Personal Psychology, 59, 333-363.

Morrison, D., Cordery, J., Girardi, A., \& Payne, R. (2005). Job-design opportunities for skill utilization and intrinsic job satisfaction. European Journal of Work and Organizational Psychology, 14 (1), 59-79.

Morrison, D.L., Upton, M., \& Cordery, J. (1999). The role of supervisor behaviour in facilitating opportunities for skill development and utilization. Human Factors and Ergonomics in Manufacturing, 9 (1), 49-67.

Narayanan, S., Balasubramaniam, S., \& Swaminathan, J.M. (2009). A matter of balance: Specialization, task variety, and individual learning in a software maintenance environment. Journal of Management Science, 55 (11), 18611876.

Nevala-Puranen, N., Pakarinen, K. \& Louhevaara, V. (2003). Ergonomic intervention on neck, shoulder and arm symptoms of newspaper employees in work with visual display units. International Journal of Industrial Ergonomics, 31 (1), $1-10$.

Norusis, M. (2004). SPSS 12.0 guide to data analysis. Upper Saddle River, NJ: Prentice Hall. 
Ogilvie, J., (1986). The role of human resource management practices in predicting organizational commitment. Group \& Organization Management, 11 (4), $335-359$.

Ostroff, C. (1992). The relationship between satisfaction, attitudes and performance: An organizational level analysis. Journal of Applied Psychology, 77, 963-974. Parasuraman, A., Grewal, D.(2000). The impact of technology on the quality-valueloyalty chain: A research agenda. Journal of the Academy of Marketing Science, 28 (1), 168-174.

Parker, L.E., \& Price, R.H. (1994). Empowered managers and empowered workers: The effects of managerial support and managerial perceived control on workers' sense of control over decision making. Human Relations, 47, 91128.

Parker, S.K. (1998). Enhancing role breadth self-efficacy: The roles of job enrichment and other organizational interventions. Journal of Applied Psychology, 83 (6), 835-852.

Parker, S.K. (2003). Longitudinal effects of lean production on employee outcomes and the mediating role of work characteristics. Journal of Applied Psychology, $88(4), 620-634$.

Parker, S.K., Wall, T.D., \& Cordery, J.L. (2001). Future work design research and practice: Towards an elaborated model of work design. Journal of Occupational and Organizational Psychology, 74, 413-440.

Parkington, J,. \& Schneider, B. (1979) Some correlates of experienced job stress: A boundary role study. Academy of Management Journal, 22 (2), 270-281. 
Pond, S.B., \& Geyer, P.D. (1991). Differences in the relations between job satisfaction and perceived work alternatives among older and younger bluecollar workers. Journal of Vocational Behaviour, 39, 251-262.

Quinn, B.E., Cooke, R.S., \& Kris, A. (2000). Shared services: Mining for corporate gold. Financial Times, Prentice Hall.

Quinn, R.P., \& Shepard, L.G. (1974). The 1972-1973 quality of employment survey. Ann Arbor: University of Michigan, Institute for Social Research.

Redman, T., Snape, E., Wass, J., \& Hamilton, P. (2007). Evaluating the human resource shared services model: Evidence from the NHS. International Journal of Human Resources Management,18 (8), 1486-1506.

Reichers, A.E. (1986). Conflict and organizational commitments. Journal of Applied Psychology, 71, 508-514.

Reilly, P.A., \& Williams, T. (2003). How to get best value from HR: The shared services option.

Aldershot, England: Gower Publishing.

Repetti, R.L., \& Cosmas, K.A. (1991). The quality of the social environment at work and job satisfaction. Journal of Applied Social Psychology, 21, 840-854.

Ross, J.A. (1988). Controlling variables: A meta-analysis of training studies. Review of Educational Research, 58 (4), 405-437.

Ruge, F. (2007). Building blocks of shared services, Public CIO. Retrieved August 8, 2009, from http://www.govtech.com/pcio/150296 
SAP. (2004) Shared Services. White Paper. Retrieved August 8, 2009, from http://whitepapers.techrepublic.com.com/abstract.aspx?docid=382613\&promo $=100511$

Saura, I.G., Contri, G.B., Taulet, A.C., \& Velazquez, B.M. (2005). Relationship among customer orientation, service orientation and job satisfaction in financial services. International Journal of Service Industry Management, 16 (5), 23-50.

Schaubroeck, J., Cotton, J.L., \& Jennings, K.R. (1989). Antecedents and consequences of role stress: A covariance structure analysis. Journal of Organizational Behavior, 10 (1), 35-58.

Schermerhorn, L.L., Williams, L. \& Dickison, A. (Eds.). (1982). Project COMPAS (Consortium for operating and managing programs for the advancement of skills) East Peoria: Illinois Central College.

Schulz, V., Hochstein, A., Uebernickel, F., \& Brenner, W. (2009). Definition and classification of IT-shared-service-center. Proceedings of the Fifteenth Americas Conference on Information Systems, San Francisco, California.

Shah, B. (1998). Shared Service. Industrial Management, 40 (5), 4-8.

Sims, H.P., Szilagyi, A.D., \& Keller, R.T. (1976). The measurement of job characteristics. Academy of Management Journal, 19, 195-212.

Spector, P. E. (1986). Perceived control by employees: A meta-analysis of studies concerning autonomy and participation at work. Human Relations, 39, 10051016. 
Spinelli, M.A. \& Canavos, G.C. (2000). Investigating the relationship between employee satisfaction and guest satisfaction, Cornell Hotel \& Restaurant Administration Quarterly, 41 (6) 30-36.

Sprigg, C.A., and Jackson. P.R .(2006), Call centers as lean service environments: Job-related strain and the mediating role of work design. Occupational Health Psychology, 11(2), 197-212.

Statistics Canada (2004). National Survey on Information Technology Occupations, July 7th, 2004. Retrieved on February 18, 2011 from http://www.statcan.gc.ca/cgibin/imdb/p2SV.pl?Function=getSurvey\&SDDS=2939\&lang=en\&db=imdb\&a $\mathrm{dm}=8 \& \mathrm{dis}=2$

Steers, R.M . (1977). Antecedents and outcomes of organizational commitment. Administrative Science Quarterly, 22 (1), 46-56.

Stevens, J. (1992). Applied multivariate statistics for the social sciences. Hillsdale, NJ: Lawrence Erlbaum Associates.

Stone, D., Maxwell, S., \& Keating, M. (2001). Bridging research and policy. An International Workshop Funded by the UK Department for International Development, Radcliffe House, Warwick University.

Strikwerda, J. (2006) The shared service centre: Change, governance and strategy. Retrieved August 8, 2009, from ftp://www.pasaja.nl/Shared\%20Service\%20Centers.pdf

Tabachnick, B.G., \& Fidell, L.S. (2007). Using multivariate statistics (5th Edition). Boston: Pearson Education. 
Taylor, F.W. (1967). The principles of scientific management. New York: Norton.

Tech Republic. (2009). Siemens shared services serves 70,000 Siemens employees nationwide with new HR system. Retrieved August 8, 2009, from http://whitepapers. techrepublic.xom/abstract.aspx?.docid=382613 \& promos $=100511$.

Thomas, J.B., \& Trevino, L.K. 1993. Information processing in strategic alliance building: A multiple-case approach. Joumal of Management Studies, 30, 779 814.

Thompson, J. (1967). Organizations in action. New York: McGraw-Hill.

Torraco, R.T. (2005).Work design theory: A review and critique with implications for human resource development. Human Resource Development Quarterly, 16 (1), 85-106.

Trist, E.L. (1981). The evolution of socio-technical systems. In A.H. Van de Ven \& W.F Joyce (Eds.), Perspectives on organization design and behaviour. New York: Wiley.

Turner, R.J. (1981). Social support as a contingency in psychological well-being. Journal of Health \& Social Behaviour, 22, 357-67.

Tushman, M. \& Nadler, D.A. (1978). Information processing as an integrating concept in organizational design. The Academy of Management Review, 3 (3), $613-624$.

Ulbrich, F. (2006). Improving shared service implementation: Adopting lessons from the BPR movement. Business Process Management Journal, 12 (2), 191-205. 
Ulbrich, F. (2007). The adoption of IT-enabled management ideas: Insights from shared services in government agencies. (Doctoral dissertation, The Economic Research Institute, Stockholm School of Economics).

Ulrich, D. (1995). Shared services: From vogue to value. Human Resource Planning, $18,12-23$.

Walsh, P., McGregor-Lowndes, M., Newton, J.N. (1998). Shared services: Lessons from the public and private sectors for the nonprofit sector. Australian Journal of Public Administration, 67 (2), 200-212.

Welbourne, T.M., Johnson, D.E., \& Erez, A. (1998). The role-based performance scale: Validity analysis of theory. Academy of Management Journal, 41 (5), $540-555$.

Wexley, K.N., \& Klimoski, R. (1984) Performance appraisal: An update. In K.M. Rowland \& G.D. Ferris (Eds.), Research in personnel \& human resources management (Vol. 2, pp. 35-79). Greenwich, CT: JAI Press.

Whetten, D.A. (2001). What constitutes a theoretical contribution? Academy of Management Review, 14 (4), 490-495.

Whitfield, D. (2007). Shared services in Canada: A Report for the Public Service Association of South Australia. Retrieved on August 8, 2009, from http://www.cpsu.asn.au/webnews/Shared_Services_Can.pdf

Wong, C. \& Campion, M.A. (1991). Development and test of a task level model of motivational job design. Journal of Applied Psychology, 76 (6), 825-837. 
Woolley, C.M. (2009). Meeting the mixed methods challenge of integration in a sociological study of structure and agency. Journal of Mixed Methods Research, $l$ (3), 242-266.

Yoon, S., Choi, D., \& Park, J. (2007). Service orientation: Its impact on business performance in the medical service industry. The Service Industries Journal, $27(4), 317-388$. 
Appendix 1

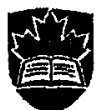

Carleton

Canada's Capital University

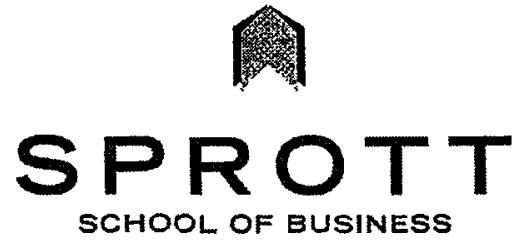

Dear Respondent

I am writing to ask for your help in a study about the nature of work in organizations that migrate to IT shared services organizations (IT-SSO). It is my understanding that you are currently employed in an IT-SSO work setting. We are contacting a random sample of employees in IT-SSO organizations to study how job characteristics influence job outcomes. The research also examines how the different services and types of work performed by IT-SSO employees affect the relationship between job characteristics and job outcomes.

At present there is no clear understanding as to what job characteristics lead to better job outcomes for individuals working in IT-SSOs. We are hoping that you will help us get a better picture of this by completing a short questionnaire, which will require 30-45 minutes of your time. Results from the questionnaire will help practitioners design jobs more efficiently and effectively for IT-SSO workers. Please be assured that your responses will be held in confidence by us. No one in your organization will see your questionnaire and only the summary results from the entire questionnaire will be presented in the final report. Please note that the questionnaire should be printed, completed and posted directly to the following address by Friday, July $9^{\text {th }}, 2010$.

Aareni Uruthirapathy

Sprott School of Business

710 Dunton Tower,

Carleton University,

1125 Colonel By Drive,

Ottawa, K1S 5B6.

If you have any questions or comments about this study, we would be happy to talk with you. Please email me at auruthir@connect.carleton.ca, or my supervisor Dr. Gerald Grant at gerald_grant@carleton.ca

Thank you very much for helping with this important study.

Sincerely,

Aareni Uruthirapathy

$\mathrm{PhD}$ Candidate

Sprott School of Business

Carleton University
Dr. Gerald Grant

Thesis Supervisor

Sprott School of Business

Carleton University, 


\section{Instructions:}

This job design questionnaire has five main parts:

a) General information - Information on you and your work

b) Motivation characteristics - Questions in this section examine what motivates you at work.

c) Social characteristics - Questions in this section examine the social characteristics of your work.

d) Service orientation characteristics - Questions in this section examine the service orientation characteristics of your work.

e) Job outcomes - Questions in this section seek your opinions on your job satisfaction, job performance and intention to quit.

This questionnaire consists of two primary types of questions:

a) Agree/Disagree statements and Excellent/Needs improvement statements: These 'questions' are statements about your job characteristics and job outcomes. For these statements please circle the response that best represents the extent to which you feel each statement describes your job outcomes.

b) Short answer questions: These are short answer questions about your work, personal information and your recommendations for improving the nature of your work. Please feel free to answer in your own words.

c) Please note that some questions may seem repetitive, but they are necessary to adequately assess your views.

\section{$\underline{\text { Part A }}$}

\section{Work Information}

a) Are you currently responsible for work directly related to an IT shared services organization? (Please Check)

$$
\square \text { Yes } \square \text { No }
$$

b) Please check the nature of work that you perform most often (more than $80 \%$ of the time) at this IT-SSO.

$\square$ Transactional work (e.g. Data center operations, Network services, Maintenance, Help Desk data support)

$\square$ Transformational work (e.g. Application development, Application architecture, Software/hardware installation, telecommunications strategy and training)

$\square$ Professional advisory and policy making (e.g. Enterprise- wide standards for software/hardware, Corporate purchasing policy, IT strategy, Infrastructure investment strategy) 
$\square$ Professional advisory and policy making (e.g. Enterprise- wide standards for software/hardware, Corporate purchasing policy, IT strategy, Infrastructure investment strategy)

c) Number of years working with this organization?

$\square 6$ months - 1year $\square 1.5-2$ years $\square$ 2.5-3 years $\square$ 3.5-4 years $\square$ 5years or more

d) Please check the job title that is closest to the one you hold

\begin{tabular}{|c|c|}
\hline$\square$ Computer and information systems manager & IInteractive media developer \\
\hline 口Computer and network operator & 口IT project manager \\
\hline ¿Computer programmer & घIT trainer \\
\hline $\begin{array}{l}\text { 口Computer and telecommunications hardware } \\
\text { engineer }\end{array}$ & 口Illustrator \\
\hline$\square$ Data analyst & $\begin{array}{l}\square \text { Network system and data } \\
\text { communication engineer }\end{array}$ \\
\hline 口Data administrator & $\square$ Systems security analyst \\
\hline 口E-commerce manager & $\square$ Systems testing technician \\
\hline $\begin{array}{l}\square \text { Electrical and electronics engineer (except } \\
\text { computer engineers) }\end{array}$ & $\square$ Systems auditor \\
\hline $\begin{array}{l}\text { 口Electrical and electronics engineering } \\
\text { technologist and technician }\end{array}$ & aSoftware engineer \\
\hline ¿Graphic designer & 口Technical writer \\
\hline aInformation system quality assurance analyst & aUser support technician \\
\hline $\begin{array}{l}\text { Information systems business analyst and } \\
\text { consultant }\end{array}$ & $\square$ Web designer and developer \\
\hline$\square$ Others & $\square$ Web technician \\
\hline
\end{tabular}

\section{Personal Information}
a) Age: $\square<29$ $60+$
30-35
$\square 36-40$
$\square 41-45$
口 46-50
$\square 51-55$
$\square 56-60$

b) Gender (please check) $\square$ Male $\square$ Female 


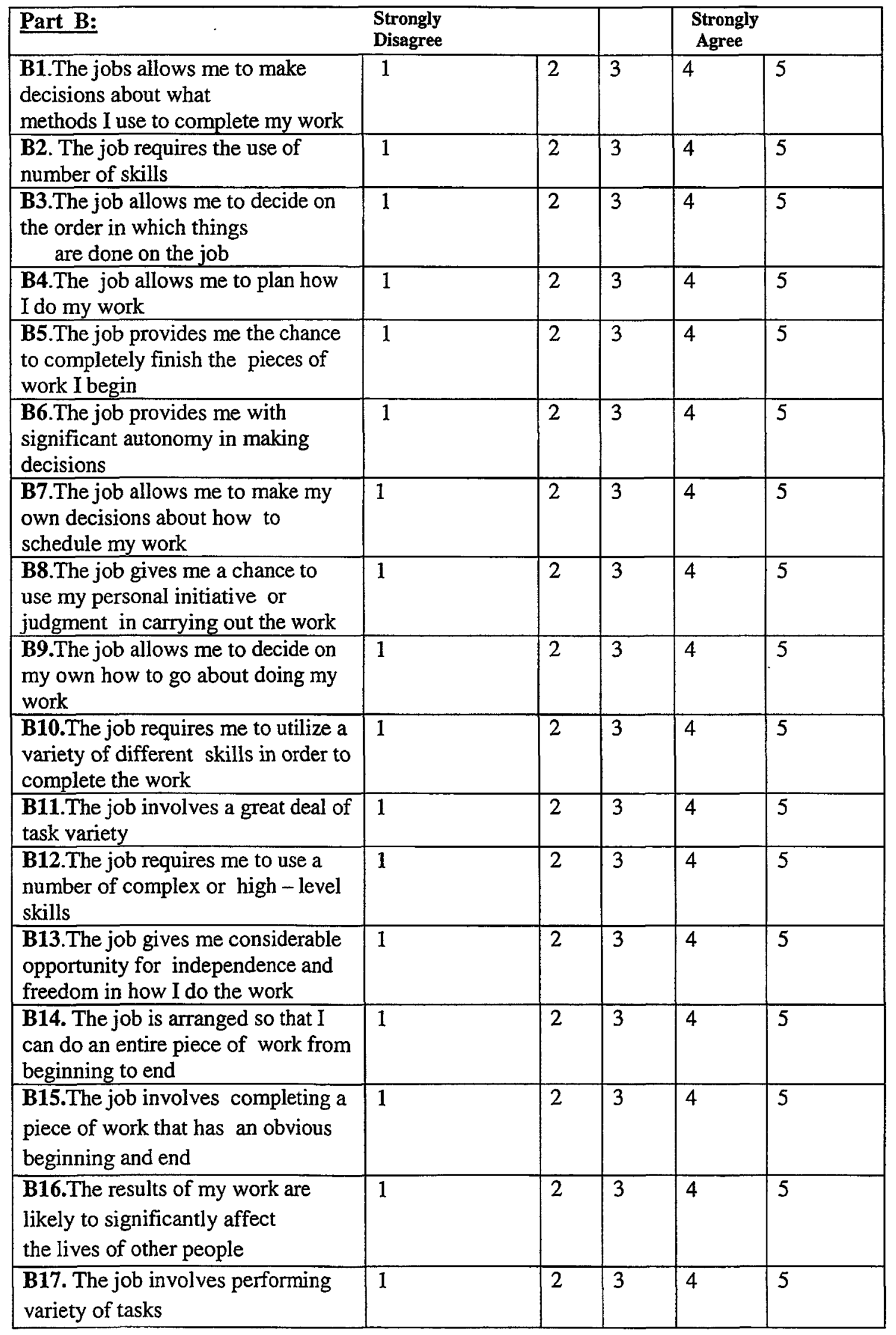




\begin{tabular}{|c|c|c|c|c|c|}
\hline $\begin{array}{l}\text { B18.The job requires the } \\
\text { performance of a wide range of } \\
\text { tasks }\end{array}$ & 1 & 2 & 3 & 4 & 5 \\
\hline $\begin{array}{l}\text { B19. The job itself is very } \\
\text { significant and important in the } \\
\text { broader scheme of things }\end{array}$ & 1 & 2 & 3 & 4 & 5 \\
\hline $\begin{array}{l}\text { B20.The job has a large impact on } \\
\text { people outside the organizations }\end{array}$ & 1 & 2 & 3 & 4 & 5 \\
\hline $\begin{array}{l}\text { B21. The work performed on the job } \\
\text { has a significant impact on people } \\
\text { outside the organization }\end{array}$ & 1 & 2 & 3 & 4 & 5 \\
\hline $\begin{array}{l}\text { B22. The job involves doing a } \\
\text { number of different things }\end{array}$ & 1 & 2 & 3 & 4 & 5 \\
\hline $\begin{array}{l}\text { B23. The job requires a variety of } \\
\text { skills }\end{array}$ & 1 & 2 & 3 & 4 & 5 \\
\hline $\begin{array}{l}\text { B24.The job itself provides } \\
\text { feedback on my performance }\end{array}$ & 1 & 2 & 3 & 4 & 5 \\
\hline $\begin{array}{l}\text { B25.The job allows me to complete } \\
\text { work I start }\end{array}$ & 1 & 2 & 3 & 4 & 5 \\
\hline $\begin{array}{l}\text { B26. The work activities themselves } \\
\text { provide direct and clear } \\
\text { information about the effectiveness } \\
\text { (e.g quality and quantity) of my } \\
\text { job performance }\end{array}$ & 1 & 2 & 3 & 4 & 5 \\
\hline $\begin{array}{l}\text { B27. The job allows me to make a } \\
\text { lot of decisions on my own }\end{array}$ & 1 & 2 & 3 & 4 & 5 \\
\hline $\begin{array}{l}\text { B28.The job itself provides me with } \\
\text { information about my performance }\end{array}$ & 1 & 2 & 3 & 4 & 5 \\
\hline & $\begin{array}{l}\text { To a very great } \\
\text { extent }\end{array}$ & & & & $\begin{array}{l}\text { Very little } \\
\text { extent }\end{array}$ \\
\hline $\begin{array}{l}\text { B29.I go over available information } \\
\text { until an excellent solution appears }\end{array}$ & 1 & 2 & 3 & 4 & 5 \\
\hline $\begin{array}{l}\text { B30.I keep gathering data until an } \\
\text { excellent solution emerges }\end{array}$ & 1 & 2 & 3 & 4 & 5 \\
\hline $\begin{array}{l}\text { B31.I have to wait until all } \\
\text { relevant information is examined } \\
\text { before deciding something }\end{array}$ & 1 & 2 & 3 & 4 & 5 \\
\hline $\begin{array}{l}\text { B32. The Information used in } \\
\text { making decisions means different } \\
\text { things to different people }\end{array}$ & & & & & \\
\hline $\begin{array}{l}\text { B33. The information provides more } \\
\text { than one satisfactory solution for } \\
\text { problems faced }\end{array}$ & 1 & 2 & 3 & \begin{tabular}{|l|}
4 \\
\end{tabular} & 5 \\
\hline
\end{tabular}




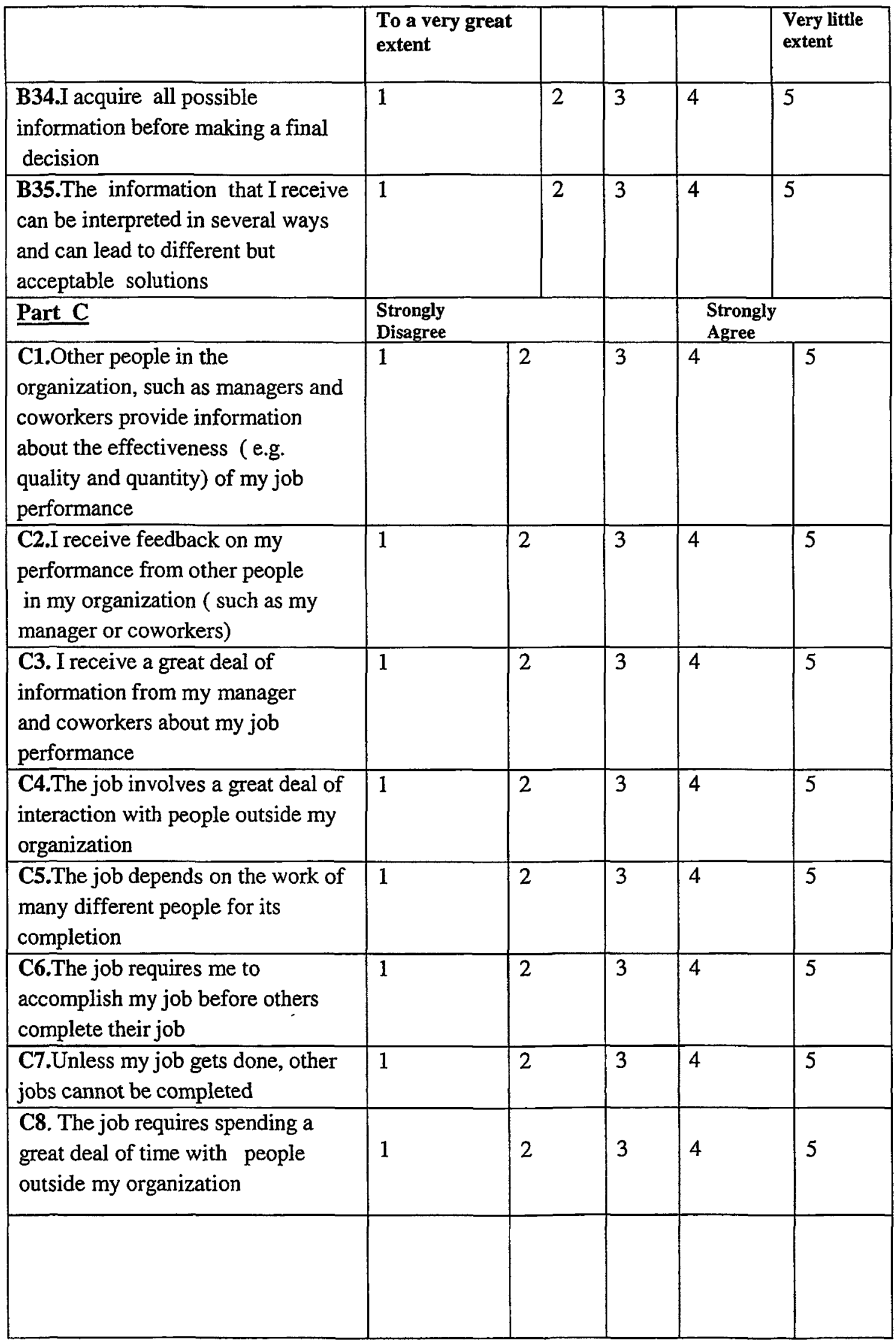




\begin{tabular}{|c|c|c|c|c|c|}
\hline Part C & $\begin{array}{l}\text { Strongly } \\
\text { Disagree }\end{array}$ & & & & $\begin{array}{l}\text { Strongly } \\
\text { Agree }\end{array}$ \\
\hline $\begin{array}{l}\text { C9. My job cannot be done unless } \\
\text { others do their work }\end{array}$ & 1 & 2 & 3 & 4 & 5 \\
\hline $\begin{array}{l}\text { C10. On the job, I frequently } \\
\text { communicate with people who do } \\
\text { not work for the same organization } \\
\text { as I do }\end{array}$ & 1 & 2 & 3 & 4 & 5 \\
\hline $\begin{array}{l}\text { C11.The job involves interaction } \\
\text { with people who are not } \\
\text { members of my organization }\end{array}$ & 1 & 2 & 3 & 4 & 5 \\
\hline $\begin{array}{l}\text { C12.The job activities are greatly } \\
\text { affected by the work of } \\
\text { other people }\end{array}$ & 1 & 2 & 3 & 4 & 5 \\
\hline $\begin{array}{l}\text { C13.Others jobs depend directly on } \\
\text { my job }\end{array}$ & 1 & 2 & 3 & 4 & 5 \\
\hline $\begin{array}{l}\text { C14. When things get tough at work, } \\
\text { I can always rely on my supervisor } \\
\text { to help me solve the problem }\end{array}$ & $\begin{array}{l}\text { Do not have } \\
\text { such a } \\
\text { person } \\
1\end{array}$ & $\begin{array}{l}\text { Not at } \\
\text { all } \\
2\end{array}$ & $\begin{array}{l}\text { A } \\
\text { little } \\
3\end{array}$ & \begin{tabular}{|l|} 
Somewhat \\
4
\end{tabular} & $\begin{array}{l}\text { Very } \\
\text { much } \\
5\end{array}$ \\
\hline $\begin{array}{l}\text { C15.It is easy for me to talk to my } \\
\text { colleagues when I need help }\end{array}$ & 1 & 2 & 3 & 4 & 5 \\
\hline $\begin{array}{l}\text { C16.My supervisor is always } \\
\text { willing to listen to my personal } \\
\text { problems }\end{array}$ & 1 & 2 & 3 & 4 & 5 \\
\hline $\begin{array}{l}\text { C17.My colleagues are always } \\
\text { willing to listen to my personal } \\
\text { problems }\end{array}$ & 1 & 2 & 3 & 4 & 5 \\
\hline $\begin{array}{l}\text { C18. When things get tough at work, } \\
\text { I can always rely on my colleagues } \\
\text { to help me solve the problem }\end{array}$ & 1 & 2 & 3 & 4 & 5 \\
\hline $\begin{array}{l}\text { C19.My colleagues will go out of } \\
\text { their way to support me in my work }\end{array}$ & 1 & 2 & 3 & 4 & 5 \\
\hline $\begin{array}{l}\text { C20.It is easy for me to talk to my } \\
\text { supervisor when I need help }\end{array}$ & 1 & 2 & 3 & 4 & 5 \\
\hline $\begin{array}{l}\text { C21.My supervisor will go out of } \\
\text { his/her way to support me in my } \\
\text { work }\end{array}$ & 1 & 2 & 3 & 4 & 5 \\
\hline
\end{tabular}




\begin{tabular}{|c|c|c|c|c|c|}
\hline Part D & $\begin{array}{l}\text { Strongly } \\
\text { Disagree }\end{array}$ & & & & \\
\hline $\begin{array}{l}\text { D1.We go out of our way to "head } \\
\text { off" or prevent customer problems } \\
\text { rather than reacting to problems } \\
\text { once they occur }\end{array}$ & 1 & 2 & 3 & 4 & 5 \\
\hline $\begin{array}{l}\text { D2. We have an excellent customer } \\
\text { complaint handling } \\
\text { system for service follow up }\end{array}$ & 1 & 2 & 3 & 4 & 5 \\
\hline $\begin{array}{l}\text { D3.We use high levels of } \\
\text { technology to support the efforts } \\
\text { of men and women on the front } \\
\text { line }\end{array}$ & 1 & 2 & 3 & 4 & 5 \\
\hline $\begin{array}{l}\text { D4.We go out of our way to prevent } \\
\text { customers problems }\end{array}$ & 1 & 2 & 3 & 4 & 5 \\
\hline $\begin{array}{l}\text { D5. We enhance our service } \\
\text { capabilities through the use of state } \\
\text { of the art technology }\end{array}$ & 1 & 2 & 3 & 4 & 5 \\
\hline $\begin{array}{l}\text { D6.We actively listen to our } \\
\text { customers }\end{array}$ & 1 & 2 & 3 & 4 & 5 \\
\hline $\begin{array}{l}\text { D7.Technology is used to build and } \\
\text { develop higher levels of service } \\
\text { quality }\end{array}$ & 1 & 2 & 3 & 4 & 5 \\
\hline $\begin{array}{l}\text { D8. Every efforts is made to explain } \\
\text { the results of customer research to } \\
\text { every employee in understandable } \\
\text { terms }\end{array}$ & 1 & 2 & 3 & 4 & 5 \\
\hline $\begin{array}{l}\text { D9. We provide follow-up service } \\
\text { calls to confirm that our services } \\
\text { are being provided properly }\end{array}$ & 1 & 2 & 3 & 4 & 5 \\
\hline $\begin{array}{l}\text { D10.We have a developed a chain } \\
\text { of objectives linking together every } \\
\text { branch in support of the corporate } \\
\text { vision }\end{array}$ & 1 & 2 & 3 & 4 & 5 \\
\hline $\begin{array}{l}\text { D11. We use internal standards to } \\
\text { pinpoint failures before we } \\
\text { receive customer complaints }\end{array}$ & 1 & 2 & 3 & 4 & 5 \\
\hline $\begin{array}{l}\text { D12.Service performance measures } \\
\text { are communicated openly with all } \\
\text { employees regardless of position or } \\
\text { function }\end{array}$ & 1 & 2 & 3 & 4 & 5 \\
\hline & & & & & \\
\hline
\end{tabular}




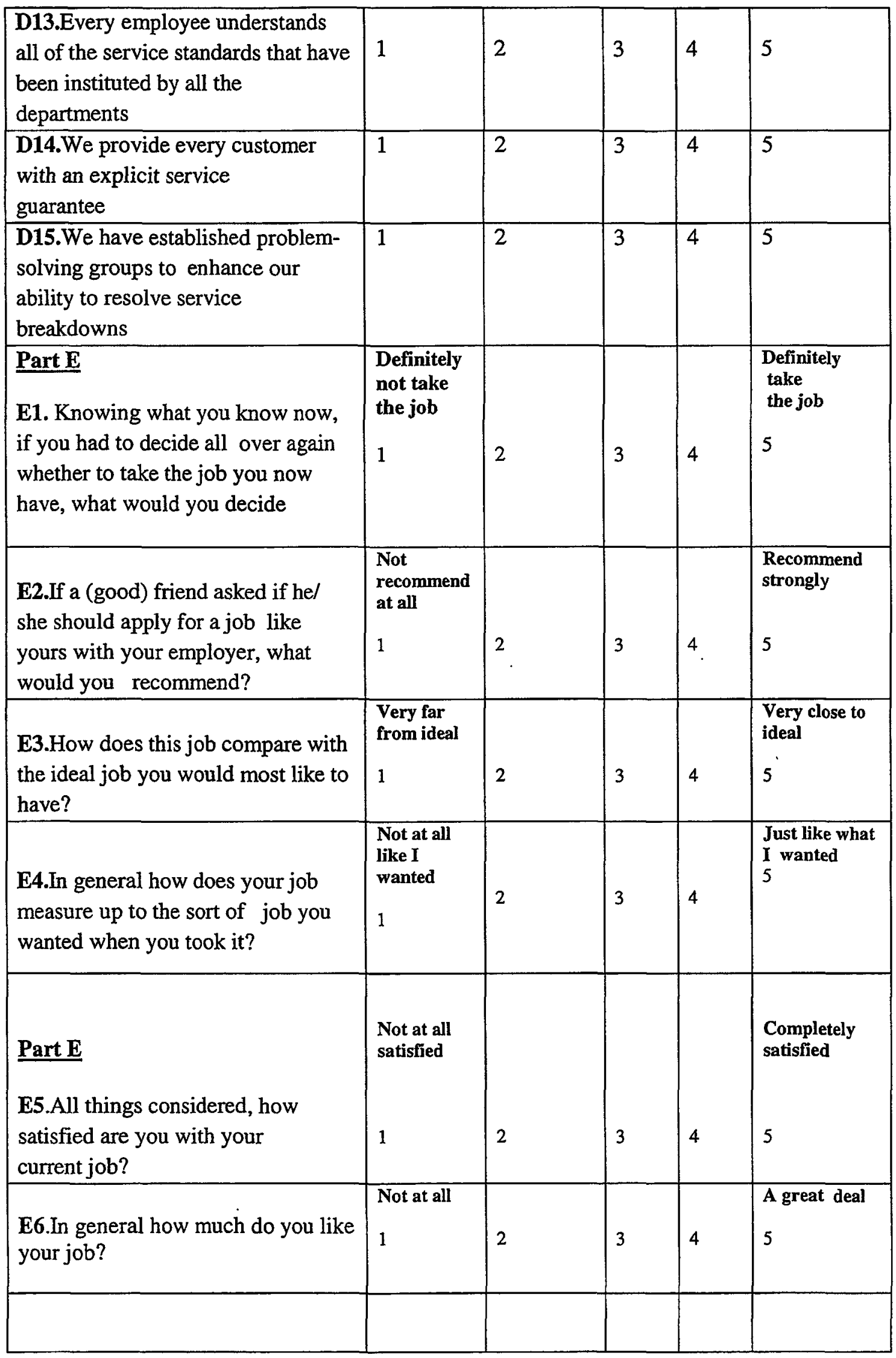




\begin{tabular}{|l|l|l|l|l|l|}
\hline & $\begin{array}{l}\text { Need } \\
\text { Improvement }\end{array}$ & $\begin{array}{l}\text { Need } \\
\text { Some } \\
\text { Improvement }\end{array}$ & $\begin{array}{l}\text { Satis- } \\
\text { factory }\end{array}$ & Good & Excellent \\
\hline $\begin{array}{l}\text { E7. Do you make the company a } \\
\text { good place to be? }\end{array}$ & 1 & 2 & 3 & 4 & 5 \\
\hline $\begin{array}{l}\text { E8. How are the career } \\
\text { opportunities in this IT_SSO? }\end{array}$ & & & & & \\
\hline $\begin{array}{l}\text { E9. Do you come up with new ideas } \\
\text { at work? }\end{array}$ & 1 & 2 & 3 & 4 & 5 \\
\hline $\begin{array}{l}\text { E10.In general how is your } \\
\text { customer service (internal and } \\
\text { external)? }\end{array}$ & 1 & 2 & 3 & 4 & 5 \\
\hline $\begin{array}{l}\text { E11.How are your personal career } \\
\text { goals? }\end{array}$ & 1 & 2 & 3 & 4 & 5 \\
\hline $\begin{array}{l}\text { E12.Do you seek information from } \\
\text { others in your group? }\end{array}$ & 1 & 2 & 3 & 4 & 5 \\
\hline $\begin{array}{l}\text { E13.How are you making progress } \\
\text { in your career? }\end{array}$ & 1 & 2 & 3 & 4 & 5 \\
\hline $\begin{array}{l}\text { E14.Do you make sure that your } \\
\text { group succeeds? }\end{array}$ & 1 & 2 & 3 & 4 & 5 \\
\hline E15.How accurate are you at work? & 1 & 2 & 3 & 4 & 5 \\
\hline $\begin{array}{l}\text { E16.Do you work to implement } \\
\text { new ideas at work? }\end{array}$ & & & 2 & & \\
\hline $\begin{array}{l}\text { E17.How much do you do to } \\
\text { promote the organization? }\end{array}$ & 1 & 2 & 3 & 4 & 5 \\
\hline $\begin{array}{l}\text { E18.Do you create better processes } \\
\text { and routines at work? }\end{array}$ & 1 & 2 & 3 & 4 & 5 \\
\hline $\begin{array}{l}\text { E19.Do you work for the overall } \\
\text { good of your organization? }\end{array}$ & 1 & 2 & 3 & 4 & 5 \\
\hline $\begin{array}{l}\text { E20.Do you do things that help } \\
\text { others when it's not part of your } \\
\text { work? }\end{array}$ & 1 & 2 & 3 & 4 & 5 \\
\hline $\begin{array}{l}\text { E21.How is your quantity of work } \\
\text { output? }\end{array}$ & 1 & 2 & 3 & 4 & 5 \\
\hline $\begin{array}{l}\text { E22.Do you respond to the needs of } \\
\text { others in your work? }\end{array}$ & 1 & 2 & 3 & 4 & 5 \\
\hline $\begin{array}{l}\text { E23.How is the development of } \\
\text { skills needed for your future career }\end{array}$ & 1 & 2 & 3 & 4 & 5 \\
\hline $\begin{array}{l}\text { E24.Do you work well as a part of a } \\
\text { team or work group? }\end{array}$ & 1 & 2 & 5 & 5 \\
\hline $\begin{array}{l}\text { E25.Do you find improved ways to } \\
\text { do things? }\end{array}$ & 1 & 2 & 5 & 5 \\
\hline $\begin{array}{l}\text { E26.How is your quality of work } \\
\text { output }\end{array}$ & 1 & 2 & 2 & 5 & 5 \\
\hline
\end{tabular}




\begin{tabular}{|l|l|l|l|l|l|}
\hline & $\begin{array}{l}\text { Strongly } \\
\text { Disagree }\end{array}$ & & & & $\begin{array}{l}\text { Strongly } \\
\text { Agree }\end{array}$ \\
\hline E27. I think about quitting & 1 & 2 & 3 & 4 & 5 \\
\hline $\begin{array}{l}\text { E28. I will probably look for a new } \\
\text { job in the next year }\end{array}$ & 1 & 2 & 3 & 4 & 5 \\
\hline
\end{tabular}

\section{Please go to the next page.}

Part F. In your opinion what job characteristics are very important for the nature of work at an IT shared services organization?

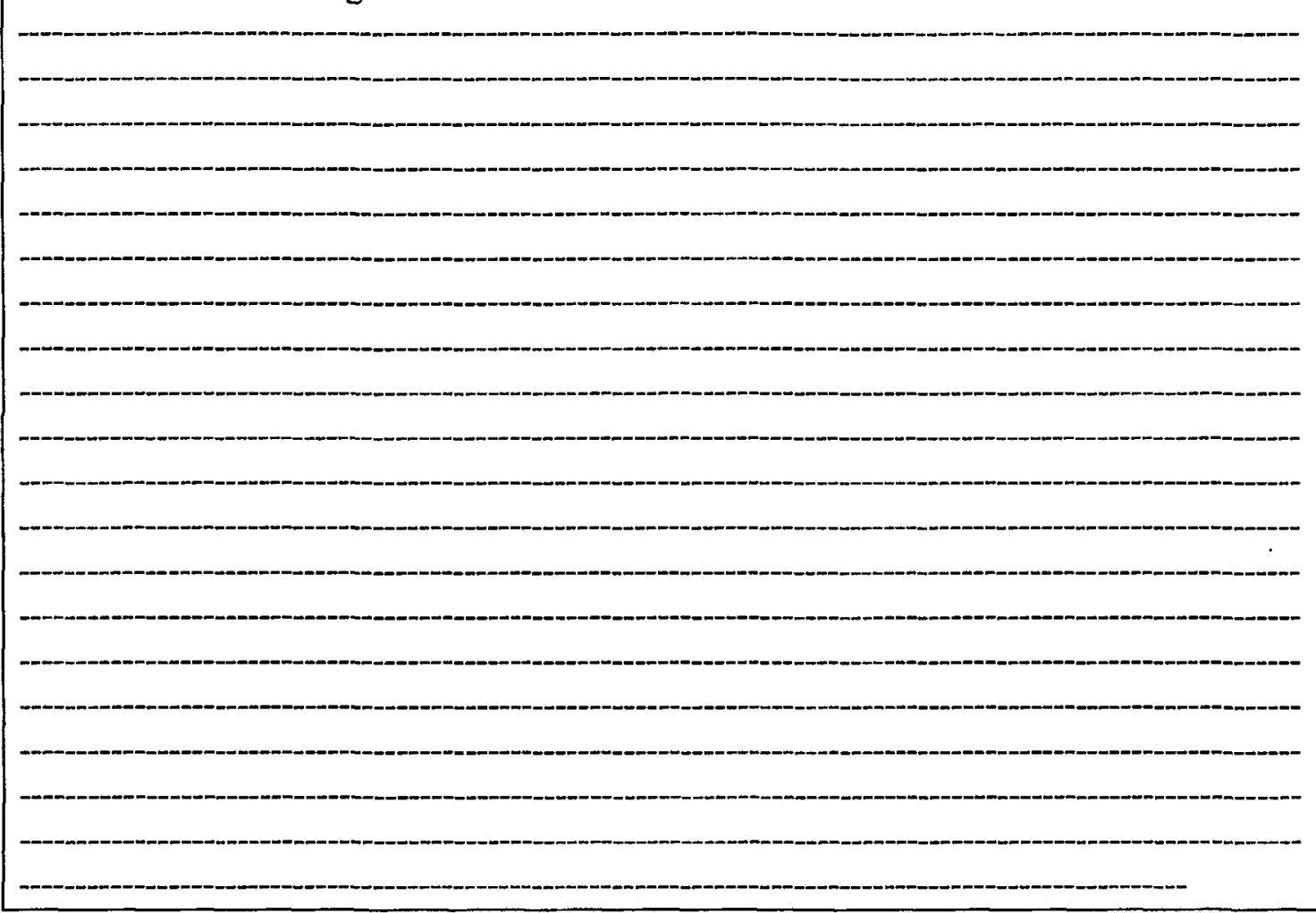




\section{End of Questionnaire}

Thank you for taking the time to complete this questionnaire. Your co-operation is much appreciated. If you would like to receive a copy of the questionnaire results, please provide your name and address below. CONFIDENTIALITY IS ASSURED.

Name:

Organization-

Address---1---

Email - 


\section{Appendix 2 - Introduction to the Interview and Interview Schedule}

Hello,

My name is Aareni Uruthirapathy and I am a Ph.D candidate from Eric Sprott School of Business working under the supervision of Dr. Gerald Grant. For my doctoral thesis I am researching what job characteristics enhance job outcomes for employees at an IT shared services work setting. We are studying the motivational, social and service characteristics and their effects on job outcomes such as job satisfaction, job performance and intensions to quit. I am conducting this interview to collect data to analyze these relationships between job characteristics and job outcomes.

The interview contains short questions and will last approximately 45- 60 minutes. The interview is divided into five sections. The first section contains general question about yourself and your work at the IT shared services organization. The second section is on the motivational characteristics of the research; the third section is on social characteristics while the fourth section is on service orientation characteristics. The last section contains questions on job outcomes such as job satisfaction, job performance and intensions to quit. At the end of the interview you will be asked to give specific recommendations that will help us propose more effective job designs for IT employees.

Please feel free to ask for clarification if you do not understand any of the questions that I am asking or if you have any questions about the interview process. You can stop me at any point during the interview and you may decide to pass on a question that you don't wish to answer. All responses will aggregated and individuals will not be named in the resulting report. Please be assured that your responses will be held in confidence by the researchers. No one in your organization will see your responses and only summary results from the entire study will be presented in the final report.

Comments and questions can be emailed to me at auruthir@ connect.carleton.ca or to my supervisor Dr. Gerald Grant at gerald_grant@carleton.ca. Thank you very much for taking the time to respond to my questions. Your responses are greatly appreciated.

The outcome of this research will allow us to understand which motivational, social and service orientation characteristics enhances job satisfaction, job performance and, which job characteristics relate to turn over intentions. Based on the research findings recommendations can be made to practitioners on designing or redesigning individual work for employees who work in an IT-SSO work setting.

Do you have any questions before I begin? 
Before we begin, I would like to have your permission to tape our conversation, I am not taping right now and will only start recording if you give me your permission. Once again let me assure you, you will not be identified by your name and the tapes will be destroyed after they are transcribed. You are not obligated to answer all the questions and if you want to terminate the interview at any point, just let me know.

(turn on the tape). Please confirm that I have your permission to tape our conversation.

\section{Part One}

\section{Work Information}

a) Are you currently responsible for work directly related to an IT shared services organization? (Please Check)

$$
\square \text { Yes } \square \text { No }
$$

b) Please check the nature of work that you most often (more than $80 \%$ of the time) perform at this organization as it moves to an IT_SSO?

$\square$ Transactional work (e.g. Data center operations, Network services, Maintenance, Help Desk Data Support)

$\square$ Transformational work (e.g. Application development, Application architecture, Software/hardware installation, telecommunications strategy and training)

$\square$ Professional advisory and Policy making (e.g. Enterprise wide standards for software/hardware, Corporate Purchasing policy, IT strategy, Infrastructure investment strategy)

b) Number of years working with this organization which is moving to an IT shared services organization (IT-SSO)?

$\square 6$ month-1year $\square 1.5-2$ years $\square 2.5-3$ years $\square$ 3.5-4 years $\square 5$-or more 
d) Please check the job title that is closest to the one you hold

\begin{tabular}{|c|c|}
\hline 口Computer and information system manager & DInteractive media developer \\
\hline 口Computer and network operator & 口IT project manager \\
\hline 口Computer programmer & 口IT trainer \\
\hline $\begin{array}{l}\text { aComputer and telecommunications hardware } \\
\text { engineer }\end{array}$ & alllustrator \\
\hline 口Data analyst & $\begin{array}{l}\text { 口Network system and data } \\
\text { communication } \\
\text { engineer }\end{array}$ \\
\hline 口Data administrator & 口Systems security analyst \\
\hline 口E-commerce manager & 口Systems testing technician \\
\hline $\begin{array}{l}\text { 口Electrical and Electronic engineer, (except } \\
\text { computer } \\
\text { engineers) }\end{array}$ & 口System auditor \\
\hline $\begin{array}{l}\text { 口Electrical and electronics engineering } \\
\text { technologists and } \\
\text { technician }\end{array}$ & $\square$ Software engineer \\
\hline 口Graphic designer & 口Technical writer \\
\hline 口Information system quality assurance analyst & 口Users support technician \\
\hline \multirow[t]{2}{*}{$\begin{array}{l}\text { DInformation systems business analysts and } \\
\text { consultant }\end{array}$} & $\square$ Web designers and developer \\
\hline & $\square$ Web technician \\
\hline
\end{tabular}

\section{Personal Information}

a) Age: $\square<29 \square 30-35 \quad \square 36-40 \quad \square 41-45 \quad \square 46-50 \quad \square 51-55 \square 56-60$
$\square 60+$

b) Gender (please check) $\square$ Male $\square$ Female 


\section{Part Two: Motivational characteristics}

1 The first question is about the level of autonomy in your job. Tell us how much autonomy you have in terms of scheduling your work, the methods you choose to accomplish tasks, and decision making in general.

2 How does your job require you to use a variety of skills? In general how many different type of skills do you use in your job?

3 Tell us the many different tasks which you carry out in your job?.

4 Do you think that your job itself is very significant and important in the broader scheme of things? Give us an example when you felt like this? Can you let us know how your job impacts people outside the organization?

5 How often can you identify your work in the whole scheme of things?

6 How much feedback do you receive from the job itself? Can you give us an example?

7 Tell us how much information you have to gather before you arrive at an excellent solution? Do you process a lot of information before you arrive at a decision? Give us an example how this happens in your jobs.

8 Can the information that you receive in your job be interpreted in several ways and can it lead to different but acceptable solutions? Could you illustrate this through an example?

\section{Part Three: Social Characteristics}

1 How do your work activities affect other people? Are there instances where you have to wait until others finish their work so that you can begin yours? Or, on the other hand, are there times when others must wait until you finish your work so that they can begin theirs?

2 Describe to us a few instances where others (peer, supervisor) have given you good feedback as to how you perform your jobs?

3 How does your supervisors and peers provided support at work. ? and what form of support do you receive?.

4 Does your job require spending a great deal of time with people outside your organization? Give us examples as to how this happens? 


\section{Part Four: Service Orientation Characteristics}

1 How does the technology used in this IT shared service organization allow you to build and develop higher levels of service quality?

2 Do you think that the your organizations goes out of its way to prevent customer problems rather than reacting to problems once they occur?. Could you elaborate it through an example.

3 Has the organization established problem-solving groups to enhance the ability to resolve service breakdowns? Could you illustrate it with an example.

4 What measures are taken by the organization to communicate service performance measures to employees regardless of position or function?

\section{$\underline{\text { Part Five: Job Outcomes }}$}

1 How does this job compare with your ideal job you would most like to have?

2 All things considered, how satisfied are you with your current jobs?

3 How would you rate the quality, quantity and accuracy of your work?

4 How do you feel about the progress you are making in your career within IT_SSO?

5 Do you come up with new ideas and then implement them at work?

6 Are you happy about the contribution you make in the group that you work in?

7 Tell us how your performance is related to the overall good of the company?

8 Do you ever think of quitting and looking out for another job?

\section{Recommendations}

1. In your opinion what job characteristics are very important for the nature of work at an IT shared servicing.

Thank you very much for your participation!! 


\section{Appendix Three}

Table one : Correlations between Motivational and Social Characteristics

\begin{tabular}{|c|c|c|c|c|c|c|}
\hline & $\begin{array}{l}\text { Initiated } \\
\text { interdepen } \\
\text {-dence }\end{array}$ & $\begin{array}{l}\text { Received } \\
\text { interdepen } \\
\text {-dence }\end{array}$ & $\begin{array}{c}\text { Feedback } \\
\text { others }\end{array}$ & $\begin{array}{l}\text { Social } \\
\text { Support } \\
\text { Friends }\end{array}$ & $\begin{array}{c}\text { Social } \\
\text { Support } \\
\text { Supervisor }\end{array}$ & $\begin{array}{c}\text { Outside } \\
\text { Interaction }\end{array}$ \\
\hline Autonomy & .195 & .067 & $.332^{\star \star}$ & $.436^{\star \star}$ & $.444^{\star * *}$ & .140 \\
\hline Skill variety & .144 & $.222^{*}$ & $.235^{\star}$ & .194 & .134 & $.216^{*}$ \\
\hline Task Variety & .134 & $.204^{\star}$ & $.276^{\star \star}$ & $.259^{\star \star}$ & .189 & $.239^{\star}$ \\
\hline $\begin{array}{l}\text { Task } \\
\text { significance }\end{array}$ & $.259^{\star \star}$ & $.269^{\star *}$ & .192 & .172 & .141 & $.464^{\star \star}$ \\
\hline Task Identity & .191 & -.060 & $.351^{\star \star}$ & $.319^{\star \star}$ & $.482^{\star \star}$ & .040 \\
\hline Feedback job & $.229^{* *}$ & .131 & $.438^{* \star}$ & $.366^{\star \star}$ & $.456^{\star \star}$ & $.241^{*}$ \\
\hline $\begin{array}{l}\text { Information } \\
\text { Amount }\end{array}$ & -.005 & .024 & -.147 & -.111 & .021 & .060 \\
\hline $\begin{array}{l}\text { Information } \\
\text { Equivocality }\end{array}$ & .067 & -.200 & .020 & -.185 & -.011 &. .074 \\
\hline
\end{tabular}

** Correlations is significant at the .01 level

* Correlations is significant at the .05 level

Table Two: Correlations between Motivational and Service Characteristics

\begin{tabular}{|l|r|r|r|r|}
\hline & $\begin{array}{c}\text { Service } \\
\text { Technology }\end{array}$ & $\begin{array}{c}\text { Service } \\
\text { Failures }\end{array}$ & $\begin{array}{c}\text { Service } \\
\text { Recovery }\end{array}$ & Service Standard \\
\hline Autonomy & $.358^{* *}$ & $.391^{* *}$ & $.368^{* *}$ & $.373^{\star *}$ \\
\hline Skill variety & $.329^{* *}$ & $.222^{*}$ & .169 & .094 \\
\hline Task Variety & $.328^{* *}$ & $.270^{* *}$ & .192 & .160 \\
\hline Task significance & $.234^{*}$ & $.302^{* *}$ & .176 & $.416^{* *}$ \\
\hline Task Identity & $.309^{* *}$ & $.478^{* *}$ & $.448^{* *}$ & $.385^{* *}$ \\
\hline Feedback job & $.279^{*}$ & $.582^{* *}$ & $.444^{* *}$ & -.048 \\
\hline Information Amount & -.119 & -.062 & $-.213^{*}$ & .031 \\
\hline $\begin{array}{l}\text { Information } \\
\text { Equivocality }\end{array}$ & .103 & .110 & .027 & \\
\hline
\end{tabular}

** Correlations is significant at the .01 level

* Correlations is significant at the .05 level 
Table Three: Correlations between Social and Service Characteristics

\begin{tabular}{|l|r|r|r|r|r|r|}
\hline & $\begin{array}{c}\text { Initiated } \\
\text { interdepen } \\
\text {-dence }\end{array}$ & $\begin{array}{c}\text { Received } \\
\text { interdepen- } \\
\text { dence }\end{array}$ & $\begin{array}{c}\text { Feedback } \\
\text { others }\end{array}$ & $\begin{array}{c}\text { Social } \\
\text { Support } \\
\text { Friends }\end{array}$ & $\begin{array}{c}\text { Social } \\
\text { Support } \\
\text { Supervisor }\end{array}$ & $\begin{array}{c}\text { Outside } \\
\text { Interaction }\end{array}$ \\
\hline $\begin{array}{l}\text { Service } \\
\text { Technology }\end{array}$ & -.001 & -.007 & $.355^{* \star}$ & .146 & .168 & -.037 \\
\hline $\begin{array}{l}\text { Service Failure } \\
\text { Prevention }\end{array}$ & .013 & .059 & $.473^{\star *}$ & $.341^{* *}$ & $.411^{* \star}$ & -.031 \\
\hline $\begin{array}{l}\text { Service Failure } \\
\text { Recovery }\end{array}$ & -.029 & -.070 & $.340^{* *}$ & $.306^{* *}$ & $.283^{* \star}$ & .061 \\
\hline $\begin{array}{l}\text { Service } \\
\text { Standard } \\
\text { Communication }\end{array}$ & .170 & -.062 & $.431^{* *}$ & .175 & $.317^{* *}$ & \\
\hline
\end{tabular}

** Correlations is significant at the .01 level

* Correlations is significant at the .05 level 


\section{Appendix Four}

\section{Descriptive Statistics - Motivational Characteristics}

\begin{tabular}{|l|l|l|l|l|l|l|l|l|}
\hline & Autonomy & $\begin{array}{l}\text { Skill } \\
\text { Variety }\end{array}$ & $\begin{array}{l}\text { Task } \\
\text { Variety }\end{array}$ & $\begin{array}{l}\text { Task } \\
\text { signific } \\
\text { ance }\end{array}$ & $\begin{array}{l}\text { Feedback } \\
\text { from job }\end{array}$ & $\begin{array}{l}\text { Information } \\
\text { Amount } \\
\text { Identity }\end{array}$ & $\begin{array}{l}\text { Information } \\
\text { Equivocality }\end{array}$ \\
\hline Mean & 3.87 & 4.23 & 4.13 & 3.39 & 3.53 & 3.59 & 2.63 & 2.82 \\
\hline SD & 0.66 & 0.62 & 0.71 & 1.01 & 0.89 & 0.77 & 0.89 & 0.92 \\
\hline
\end{tabular}

\section{Descriptive Statistics - Social Characteristics}

\begin{tabular}{|l|l|l|l|l|l|l|}
\hline & $\begin{array}{l}\text { Initated } \\
\text { Interdependence }\end{array}$ & $\begin{array}{l}\text { Received } \\
\text { Interdependence }\end{array}$ & $\begin{array}{l}\text { Feedback } \\
\text { From others }\end{array}$ & $\begin{array}{l}\text { Social } \\
\text { Support } \\
\text { Friends }\end{array}$ & $\begin{array}{l}\text { Social } \\
\text { Support } \\
\text { Supervisor }\end{array}$ & $\begin{array}{l}\text { Outside } \\
\text { Interaction }\end{array}$ \\
\hline Mean & 3.18 & 3.80 & 3.54 & 3.95 & 4.15 & 3.10 \\
\hline SD & 0.81 & 0.72 & 0.86 & 0.84 & 0.74 & 1.03 \\
\hline
\end{tabular}

Descriptive Statistics - Service Characteristics

\begin{tabular}{|l|l|l|l|l|}
\hline & $\begin{array}{l}\text { Service } \\
\text { Technology }\end{array}$ & $\begin{array}{l}\text { Service } \\
\text { Failure } \\
\text { Prevention }\end{array}$ & $\begin{array}{l}\text { Service } \\
\text { Failure } \\
\text { Recovery }\end{array}$ & $\begin{array}{l}\text { Service } \\
\text { Standard } \\
\text { Communication }\end{array}$ \\
\hline Mean & 3.17 & 3.53 & 3.12 & 2.81 \\
\hline SD & 0.95 & 0.87 & 0.93 & 0.78 \\
\hline
\end{tabular}

